Portland State University

PDXScholar

Summer 9-18-2015

\title{
Developmental Mechanisms that Support Genome Stability and Embryonic Survival in Stress-tolerant Embryos of the Annual Killifish Austrofundulus limnaeus
}

Josiah Tad Wagner

Portland State University

Follow this and additional works at: https://pdxscholar.library.pdx.edu/open_access_etds

Part of the Animal Sciences Commons, Biology Commons, and the Genetics and Genomics Commons Let us know how access to this document benefits you.

\section{Recommended Citation}

Wagner, Josiah Tad, "Developmental Mechanisms that Support Genome Stability and Embryonic Survival in Stress-tolerant Embryos of the Annual Killifish Austrofundulus limnaeus" (2015). Dissertations and Theses. Paper 2520.

https://doi.org/10.15760/etd.2517

This Dissertation is brought to you for free and open access. It has been accepted for inclusion in Dissertations and Theses by an authorized administrator of PDXScholar. Please contact us if we can make this document more accessible: pdxscholar@pdx.edu. 


\title{
Developmental Mechanisms that Support Genome Stability \\ and Embryonic Survival in Stress-tolerant Embryos of the Annual \\ Killifish Austrofundulus limnaeus
}

by

Josiah Tad Wagner

A dissertation submitted in partial fulfillment of the requirements for the degree of

\author{
Doctor of Philosophy \\ in \\ Biology
}

\begin{abstract}
Dissertation Committee:
Jason Podrabsky, Chair

Suzanne Estes

Justin Courcelle

Deborah Lutterschmidt

Gwen Shusterman
\end{abstract}

Portland State University

2015 
(C) 2015 Josiah Tad Wagner 
Abstract

In order to complete their life cycles, vertebrates require oxygen and water. However, environments are not always forgiving when it comes to constantly providing these basic needs for vertebrate life. The annual killifish Austrofundulus limnaeus is possibly the most well described extremophile vertebrate and its embryos have been shown to tolerate extremes in oxygen, salinity, and water availability. This phenotype is likely a result of the annual killifish life history, which includes periods of temporary habitat desiccation and oxygen deprivation, and requires the production of stress-tolerant embryos that depress metabolism in a state of suspended animation, known as diapause. Over the past several decades, the basic morphology and physiology of annual killifish development has become better characterized. However, there are still basic cellular processes that remain to be described in annual killifish such as A. limnaeus. Specifically, changes in DNA structure, expression, and copy number are known to have profound impacts on the phenotype and survival of an organism. Little is known as to how A. limnaeus maintains genome integrity during cell stress, nor how the A. limnaeus nuclear and mitochondrial genomes may have evolved under the unpredictable conditions in which A. limnaeus thrive. Early annual killifish embryonic development is also characterized by a complete dispersion and subsequent reaggregation of embryonic blastomeres prior to formation of the embryonic axis. This unusual period of 
early development may provide a functional adaptation that allows annual killifish embryos to survive these extreme conditions.

The overall goals of this project were to (1) characterize the ability of A. limnaeus to tolerate and repair DNA damage through enzymatic and developmental mechanisms, (2) to determine possible consequences of mitochondrial DNA sequence and copy number on the metabolism of $A$. limnaeus, and (3) to establish a draft genome of A. limnaeus for future comparative genome studies. The results of this project show that embryos of A. limnaeus have an impressive ability to survive and reverse high doses of DNA damage induced by ultraviolet-C (UV-C) radiation, especially when allowed to recover under photoreactivating light. Surprisingly, embryos that survived irradiation during blastomere dispersion phases were able to develop normally. Characterization of gene expression during embryonic development for genes important for axis formation and cellular differentiation suggests that $A$. limnaeus embryos may delay axis formation until several days after epiboly is complete, thus allowing time for cells that become damaged to be replaced by surrounding pluripotent cells. This outcome would represent first case of a developmental buffering stage in a vertebrate. A. limnaeus embryos are also unique in their mitochondrial response to anoxia. Whereas in other species the amount of mitochondrial DNA (mtDNA) copy number fluctuates following extremes in oxygen availability, A. limnaeus embryonic mtDNA remains stable. Additionally, characterization of the fully sequenced $A$. limnaeus mitochondrial genome 
reveals possible evolutionary adaptations that may have facilitated dormancy and anoxia tolerance when compared to other species within the Order Cyprinodontiformes. The final chapter of this project characterizes the draft genome of A. limnaeus and I provide evidence suggesting that epigenetic DNA methylation that may be involved in regulating diapause. 


\section{DEDICATION}

This dissertation is dedicated to Emma and Oliver whose development is the only thing more interesting than that of Austrofundulus. 


\section{ACKNOWLEDGEMENTS}

My completion of this dissertation required support from many people. I would like to thank my mentor and advisor Jason Podrabsky for his never-ending support and invaluable insight throughout my entire graduate experience. This document and the scientific publications derived from it would not exist without his expertise and belief in my ability to succeed. I thank my graduate committee: Suzanne Estes, Justin Courcelle, Deborah Lutterschmidt, and Gwen Shusterman for taking the time and effort to ensure my research, and myself as a scientist, could reach my potential. I thank Charmain Courcelle and Kim Brown for their advice and for allowing me to use their lab equipment. I am appreciative of the support of my colleagues, past and present: Kristin Culpepper, Claire Riggs, Amie Romney, Cody Woll, Ian Garrett, Florisela Chavez, Annie Lindgren and the rest of the Center for Life in Extreme Environments faculty, and the numerous fish-room student workers. I am grateful for the Ronald E. McNair scholars program and Forbes-Lea foundation for training and financial support in my research. I thank my parents Bouakeo and Tad for sparking my initial interest in science and for their support as I pursued biology. Finally, I thank my partner Jessica, her parents Edie and Subhuti, and our children Emma and Oliver for their love, support, and patience throughout my entire graduate career. 


\section{Table of Contents}

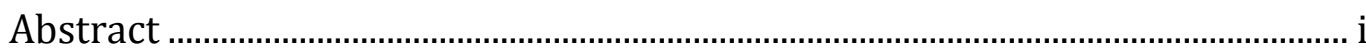

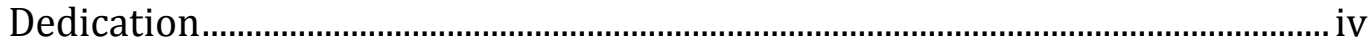

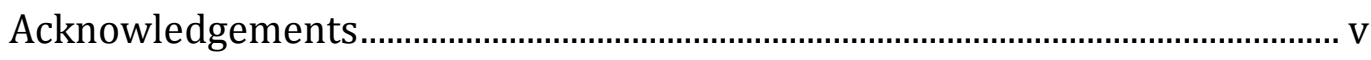

List of Tables.......................................................................................................

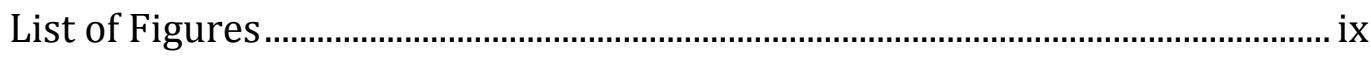

Chapter 1 Genome stability in an unstable environment ................................... 1

Chapter 2 Tolerance and repair of DNA damage...............................................10

Chapter 3 Gene expression patterns and developmental buffering ................68

Chapter 4 Mitochondrial DNA sequence and stability ....................................113

Chapter 5 Characterization of the Austrofundulus limnaeus genome............167

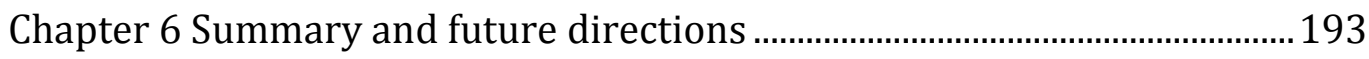

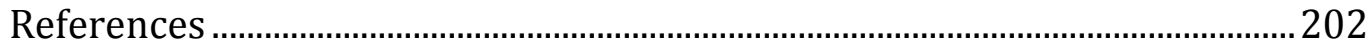


List of Tables

Table 2.1 Embryonic stages and doses of UV-C exposures 65

Table 2.2 Summary counts of UV-C irradiated embryos with CPD-positive nuclei 66

Table 2.3 Summary counts of UV-C irradiated embryos with TUNEL-positive nuclei. 67

Table 3.1 A. limnaeus stages selected for qPCR gene expression analysis ..104

Table 3.2 Degenerate primers used for PCR identification of A. limnaeus gene sequences. 105

Table 3.3 Isolated and cloned A. limnaeus gene fragments 107

Table 3.4 Blast results of cloned A. limnaeus gene fragments 110

Table 3.5 Quantitative PCR assay primers and probes

Table 3.6 Top blastx searches of A. limnaeus gene fragments to D. rerio.....112

Table 4.1 Illumina reads used for assembly and mapping of the A. limnaeus mitochondrial genome. 158

Table 4.2. Primer names and sequences used to verify regions of the $A$. limnaeus mitochondrial genome. 159

Table 4.3 Primers used to generate and sequence clones for assembly of the A. limnaeus mitochondrial genome. 160

Table 4.4 List of species with available mitochondrial sequences used for comparison to the A. limnaeus mitochondrial genome.

Table 4.5 Primers specific to A. limnaeus mitochondrial NADH dehydrogenase subunit 4 or nuclear insulin-like growth factor-1 used for measurement of relative mitochondrial DNA content. 162

Table 4.6 Positions of the identified A. limnaeus mitochondrial genes and elements 163 
Table 4.7 Top five most used codons in the A. limnaeus mitochondrial

zgenome

Table 4.8 Single nucleotide polymorphisms detected in the A. limnaeus mitochondriala genome using Geneious variant caller

Table 5.1 Selected A. limnaeus embryonic stages used for 5mC ELISA .........186

Table 5.2 Input Illumina reads and bases for de novo assembly of the $A$.

limnaeus genome

Table 5.3 Basic assembly statistics of the A. limnaeus genome 188

Table 5.4 Species comparison of total estimated genomic GC and repeat content

Table 5.5 Comparison of A. limnaeus repetitive elements identified by RepeatModeler to repeats identified in zebrafish

Table 5.6 CEGMA gene completion reports for the A. limnaeus, Atlantic Cod (G. morhua), and Stickleback (G. aculeatus) genome assemblies.

Table 5.7 Identified reading frames of genes of interest in the A. limnaeus genome. 


\section{List of Figures}

Figure 2.1 Plasmid standard used for CPD ELISA ................................................ 51

Figure 2.2 Representative images of stages selected for irradiation and subsequent effects on development..................................................................... 52

Figure 2.3 Survival and abnormal development in embryos exposed to UV-C irradiation 53

Figure 2.4 LD50 values for embryos exposed to UV-C irradiation and allowed to recover in constant dark or light.

Figure 2.5 Survival of $32 \mathrm{dpf}$ (DII) embryos UV-C irradiated and allowed to recover in the dark.

Figure 2.6 Proportion of embryos irradiated at 4 and $10 \mathrm{dpf}$ that were identified as escape embryos by $21 \mathrm{dpf}$.

Figure 2.7 Rates of somitogenesis in embryos UV-C irradiated at 4 or $10 \mathrm{dpf}$ and allowed to recover in constant light or dark

Figure 2.8 Representative photomicrographs of CPDs in whole-mount preparations of $4 \mathrm{dpf}$ UV-C irradiated embryos.

Figure 2.9 Representative photomicrographs of CPDs in whole-mount preparations of $10 \mathrm{dpf}$ UV-C irradiated embryos.

Figure 2.10 Representative photomicrographs of CPDs in whole-mount preparations of $32 \mathrm{dpf}$ UV-C irradiated embryos.

Figure 2.11 Representative photomicrographs and quantification of TUNEL staining in whole-mount $4 \mathrm{dpf}$ embryos after UV-C irradiation. 61

Figure 2.12 Representative photomicrographs of TUNEL staining in wholemount $10 \mathrm{dpf}$ and $32 \mathrm{dpf}$ embryos after UV-C irradiation.

Figure 2.13 Quantification of CPDs over time in irradiated DII embryos by ELISA 63

Figure 2.14 Comparison of $\mathrm{LD}_{50}$ values (UV-C, $254 \mathrm{~nm}$ ) between A. limnaeus embryos and embryos from other fish species. 64

Figure 3.1 Representative photographs of embryo stages used in Chapter 3 ... 
Figure 3.2 Expression of putative oct4, sox3, and sox2 transcripts during $A$. limnaeus development.

Figure 3.3 Gene expression patterns of oct4, sox3, and sox 2 during development in A. limnaeus and other teleost fishes 100

Figure 3.4 Expression of putative chordin, noggin-1, noggin-2, and follistatin transcripts during A. limnaeus development. 101

Figure 3.5 Gene expression patterns of chordin, noggin-1, noggin-2, and follistatin during development in A. limnaeus and zebrafish.

Figure 3.6 Model for delayed gastrulation and axis formation in A. limnaeus based on early BMP inactivation

Figure 4.1 Example of unmapped free ends following readmapping on an early A. limnaeus mtgenome assembly

Figure 4.2 Visualization of primer binding sites and PCR products generated used for gap closing of the initial A. limnaeus MitoBIM assembled mtgenome in this chapter 141

Figure 4.3 Coverage of Illumina reads across the assembled A. limnaeus mitochondrial genome

Figure 4.4 The complete annotated mtgenome of A. limnaeus 143

Figure 4.5 Pairwise alignment of mitochondrial Alim-D-loop 1 and Alim-Dloop 2 .

Figure 4.6 RepFind analysis of Alim-D-loop 1 and Alim-D-loop 2.

Figure 4.7 Consensus motifs of Conserved Sequence Block-1and Conserved Sequence Block-2.

Figure 4.8 Alignment of the $16 \mathrm{~S}$ rRNA to the pseudo-16S rRNA in the $A$. limnaeus mitochondrial genome.

Figure 4.9 Verification of A. limnaeus mitochondrial genome regions across individuals and tissue types using PCR.

Figure 4.10 Predicted folding structure of A. limnaeus origin of light-strand replication using the RNAstructure webserver 
Figure 4.11 Predicted secondary structures of identified mitochondrial tRNAs in A. limnaeus as generated from MITOS.

Figure 4.12 Alignment of tRNA-Ser from multiple species to identify $A$. limnaeus tRNA-Ser.

Figure 4.13 Possible secondary structure of A. limnaeus tRNA-Ser.

Figure 4.14 Species comparisons of coding gene, rRNA, and tRNA nucleotide compositions within the Superfamily Aplocheiloidei 153

Figure 4.15 Species comparisons of coding gene nucleotide compositions by position within the Superfamily Aplocheiloidei 154

Figure 4.16 Inferred phylogenetic tree of the order Cyprinodontiformes using MrBayes. 155

Figure 4.17 Changes in relative mtDNA copy number during normoxia or anoxia

Figure 4.18 Model of mtDNA, gDNA, and ETC complex activity content during post DII development 157

Figure 5.1 Size estimation of the A. limnaeus genome by flow cytometry...178 Figure 5.2 Size distribution of scaffolds in the current iteration of the $A$. limnaeus genome assembly

Figure 5.3 Top blastp alignments of the putative A. limnaeus genes identified by MAKER 180

Figure 5.4 Representative screen images of the A. limnaeus genome and annotations visualized in a graphical interface (J-Browse) 184

Figure 5.5 Comparison of global $5 \mathrm{mC}$ between A. limnaeus embryonic stages as measured by relative optical density at $405 \mathrm{~nm}$ following ELISA 185 


\section{CHAPTER 1:}

\section{Genome stability in an unstable environment}

The annual killifish Austrofundulus limnaeus is an emerging model for understanding the limits of vertebrate survival of extreme environmental

conditions. By exploring how organisms are able to survive and even thrive at life's limits, it may be possible to identify the critical molecular and physiological mechanisms that support the most basic biological processes. In this thesis, I explore physiological and developmental mechanisms for maintaining genome integrity and supporting normal development in the face of extreme environmental stress and DNA damage in developing and diapausing embryos of $A$. limnaeus. These studies suggested unique adaptations in A. limnaeus at the molecular level leading me to describe and explore for the first time the structure of the mitochondrial and nuclear genomes of A. limnaeus and lay the groundwork for future comparative genomics studies of "extremophile" vertebrates.

\section{Maintaining life's instruction manual}

Preserving DNA sequence integrity is a necessity shared by all living organisms. Because of its position at the first step of the Central Dogma of Molecular Biology, mutations in genomic DNA sequence can directly alter protein expression, structure, and function. It is therefore no surprise that 
molecular mechanisms for sensing DNA damage and effecting DNA repair exist in all domains of life (Eisen and Hanawalt, 1999; Friedberg et al., 2005). In cases where DNA repair mechanisms are insufficient to reverse cytotoxic DNA lesions, multicellular organisms utilize programmed cell death, also known as apoptosis, to remove dysfunctional cells and promote survival of the organism (Norbury and Zhivotovsky, 2004). For metazoans, failure of both of these systems often leads to cellular dysfunction, or cancer. Efficient DNA repair may be even more critical for developing metazoans because mutations that occur early in development have the potential to be inherited by all future daughter cells, including the germline (Behjati et al., 2014). Thus, development in highly variable, unpredictable, or stressful environments presents unique challenges with respect to maintaining the integrity of the genome in order to promote normal development and continuation of the species.

Repair of DNA requires energy from ATP hydrolysis, first in the ATP costs associated with expression of DNA repair proteins, and second from ATP costs associated with some of the repair enzymes (Sancar et al., 2004). Yet, many metazoans that thrive in highly stressful or variable environments cope by arresting development in diapause and entering into states of metabolic depression (Clegg, 1997; Clegg et al., 1996; Drinkwater and Clegg, 1991; Hahn and Denlinger, 2011; Hand and Podrabsky, 2000; Macrae, 2005; Podrabsky and Hand, 1999; Podrabsky and Hand, 2015). Thus, these 
organisms must deal with severe and often unpredictable environmental conditions while having an extremely limited ability to respond via changes in gene expression.

During diapause, DNA repair may be drastically reduced or eliminated altogether as illustrated by accumulation of DNA damage during metabolic arrest in the encysted embryos of the brine shrimp Artemia franciscana (McLennan, 2009). Additionally, apoptosis signaling may be suppressed in diapausing embryos even under conditions that are typically cytotoxic (Hand and Menze, 2008; Meller and Podrabsky, 2013). Considering the role that DNA mutation and suppression of apoptosis play in cancer and other diseases, understanding the molecular and gene expression mechanisms by which stress-tolerant embryos are able to accumulate, tolerate, and repair DNA damage at the organismal level is of great interest.

\section{A vertebrate model for extreme stress tolerance}

The annual killifish Austrofundulus limnaeus (Meyers) is an emerging model for vertebrate extreme stress tolerance. A. limnaeus (Order Cyprinodontiformes) is commonly found in ephemeral habitats of the Maracaibo basin of Venezuela (Hrbek et al., 2005; Podrabsky et al., 1998). Due to seasonal fluctuations in water and oxygen availability, diapausing embryos of A. limnaeus have developed extreme tolerance to abiotic stressors such as desiccation, anoxia, and high salinity during early 
embryogenesis (Machado and Podrabsky, 2007; Podrabsky et al., 2001;

Podrabsky et al., 2007). Diapause may occur at 3 distinct stages of development in annual killifish, termed diapause I, II, and III (Wourms 1972a; Wourms 1972b; Wourms 1972c).

Diapause I (DI) can occur early in development after completion of epiboly but prior to the formation of the embryonic axis. Contrasting with the typical pattern of convergence and extension of the amoeboid (deep) embryonic blastomeres that is observed in most other teleost embryos during epiboly, deep blastomeres of A. limnaeus dissociate and migrate away from each other across the yolk surface during epiboly (Lesseps et al., 1979a; Lesseps et al., 1979b). Essentially, this process appears to temporally disconnect epiboly from germ layer formation in annual killifish and these deep cells can remain randomly dispersed across the yolk surface for several days before reaggregating and forming a definitive embryonic axis (Wourms, 1972a; Wourms, 1972b). Although rare or perhaps absent in our lab stock of A. limnaeus, DI has been hypothesized to allow damaged embryonic cells to be "sloughed" off and replaced by surrounding pluripotent cells (Wourms, 1972b). It is noteworthy that African annual killifish may primarily arrest at DI (Genade et al., 2005). Diapause II (DII) occurs in the long-somite embryo approximately midway through development, just prior to the major phases of organogenesis, and appears to be the most stress-resistant diapause stage (Wourms, 1972a; Wourms 1972c; Podrabsky et al., 2001; Podrabsky et al., 
2007). Finally, embryos can arrest as a late pre-hatching embryo in diapause III (DIII) rather than immediately hatching (Wourms, 1972a).

From a physiological and metabolic perspective, diapausing embryos of A. limnaeus are clearly different than embryos that are actively developing. Entry into DII is associated with decreased protein synthesis and oxygen consumption by up to $93 \%$ and $90 \%$, respectively (Podrabsky and Hand, 1999; Podrabsky and Hand, 2000). In contrast to other described fish embryo species, most cells in developing A. limnaeus embryos are found in the $G_{1} / G_{0}$ phase of the cell cycle, and it is during this phase of the cell cycle that DII embryos arrest (Meller et al., 2012; Padilla and Roth, 2001; Schlueter et al., 2007). Additionally, DII embryos appear to tolerate extremes in salinity by exhibiting low rates of ion exchange and low water permeability which are lost during post-diapause II development (Machado and Podrabsky, 2007). Extreme tolerance of anoxia is supported during diapause II by reduced metabolism demand, accumulation of gamma-aminobutyric acid (GABA), and lactate as anaerobic end-products, and the ability of the cells to tolerate large decreases in cellular ATP without the induction of apoptosis (Podrabsky et al., 2007; Podrabsky et al., 2012b; Meller et al., 2013). While the majority of A. limnaeus embryos will enter into DII, a small proportion of "escape" embryos will bypass DII and instead develop directly to DIII or hatching (Podrabsky et al., 2010; Wourms, 1972b). Thus, diapause in A. limnaeus has a predictable and unique physiological and developmental 
phenotype that has been well characterized and provides an informed background for more mechanistic studies.

Because A. limnaeus embryos routinely enter into diapause even during ideal lab conditions, these embryos provide a useful model for understanding how DNA repair and tolerance strategies may have changed in response to the strong selection pressures associated with life in a temporary environment. Additionally, A. limnaeus embryos may have evolved unique physiological and developmental buffering strategies to deal with these stressors, and these strategies may involve the dispersed blastomere phase not found during typical vertebrate development. Analysis of gene expression and gene sequence can provide a comparative tool for determining how A. limnaeus has been able to succeed in its uncommon niche.

\section{The genomics of vertebrate stress tolerance}

Paradoxically, imperfect fidelity of DNA stability is essential for species survival and success. Mutation is the primary source of variation in a population, and the phenotypic variation resulting from these mutations is the basis of selection. Thus, a delicate balance must be established between maintaining the genome and allowing mutations to accumulate. In some microbial species, mutation rates increase during cellular stress through induction of error-prone polymerases increasing the probability that a 
phenotype with a higher chance of survival will occur (Metzgar and Wills, 2000). While this mechanism makes sense in terms of unicellular organisms, there is a great deal of debate surrounding evolvability in metazoans (Kirschner and Gerhart, 1998). Yet, few if any extremophile animals have been explored in any great detail with respect to maintenance of genome integrity and rates of evolution. Therefore, exploring these topics in a vertebrate lineage that has evolved under intense selection pressures with small effective population sizes may lend new insights into this debate.

While nuclear DNA sequence is certainly a primary factor in the evolution of a species, changes in mitochondrial genome (mtgenome) sequence and copy number can have profound effects on aerobic metabolism and responses to stressors such as anoxia. Rates of mitochondrial DNA substitutions are known to be significantly greater than those in the nuclear genome (Denver et al., 2000; Ballard and Whitlock, 2004; Neiman and Taylor, 2009), and yet the central importance of the proteins encoded in the mtgenome likely restrains the rate of evolution through purifying selection. The apparent increased mutation rate of mtgenomes is further complicated by the observation that mitochondria have competent DNA repair systems that recognize many potentially mutagenic DNA lesions (Alexeyev et al., 2013). The unique biology of $A$. limnaeus, including the small population sizes, unique and severe selection pressures, and long durations of exposure as embryos to DNA damaging stresses all have the potential to evolutionarily 
shape the nuclear and mitochondrial genomes of A. limnaeus in unique ways that have not yet been explored in other species.

\section{Organization of the remaining chapters}

Within the following four chapters, I determine the extent to which $A$. limnaeus embryos are able to tolerate and repair DNA damage over biological time (the lifespan of an organism), and how the life history A. limnaeus may have shaped their mitochondrial and nuclear genomes over evolutionary time (evolution of the species). The first two chapters (Chapters 2 and 3) have been previously published (Wagner and Podrabsky, 2015a; Wagner and Podrabsky, 2015b). In Chapter 2, entitled Tolerance and repair of DNA damage, I determine the ability of diapausing and actively developing embryos of A. limnaeus to tolerate and repair DNA damage induced with ultraviolet-C radiation. In the next chapter, Chapter 3, entitled Gene expression patterns and developmental buffering, I identify and measure expression of several genes important for axis formation in vertebrates to determine if A. limnaeus are able to postpone embryonic cell differentiation as a possible mechanism of surviving the extreme DNA damage described in Chapter 2. The following two chapters focus on the sequences of the $A$. limnaeus mitochondrial and nuclear genomes. In Chapter 4, entitled Mitochondrial DNA sequence and stability, I describe the complete mtgenome of A. limnaeus in a comparative context and determine possible impacts of 
anoxia on mitochondrial DNA copy number during embryonic development.

In Chapter 5, entitled Characterization of the Austrofundulus limnaeus genome

I describe the current iteration of the A. limnaeus nuclear genome and compare the assembly quality to other fish species. The A. limnaeus genome described in this chapter will be used as input for upcoming annotation of gene models. In the final chapter, Chapter 6, entitled Summary and future directions, I describe my overall conclusions of this dissertation, its significance to the understanding of DNA repair and evolution in diapausing and developing organisms, the unique strategies of organismal survival found during A. limnaeus embryonic development, and suggest future directions for research. 


\section{Chapter 2:}

\section{Tolerance and repair of DNA damage}

This chapter has been previously published:

Wagner, J. T. and Podrabsky, J. E. (2015). Extreme tolerance and

developmental buffering of UV-C induced DNA damage in embryos of the annual killifish Austrofundulus limnaeus. Journal of Experimental Zoology

323A, 10-30.

\section{Introduction}

The consequences of excessive ultraviolet (UV) radiation exposure during embryonic development have been described for a variety of aquatic vertebrates and invertebrates, and include abnormal development, delayed hatching, or death (Blaustein et al., 1997; Dong et al., 2007; Nahon et al., 2009; Wiegand et al., 2004). DNA damage induced by UV-A (315-400 nm), UV-B (280-315 $\mathrm{nm})$ and UV-C (100-280 $\mathrm{nm})$ radiation exposure has been well characterized and is known to be primarily cis-strand lesions in the form of cyclobutane pyrimidine dimers (CPDs) and 6-4 pyrimidine-pyrimidone photoproducts (6-4 PPs) (reviewed in Brash, 1997; Sinha and Häder, 2002). At the cellular level, failure to repair these lesions may lead to cell cycle arrest or cell death by apoptosis (Lesser et al., 2003; Pavey et al., 2001; Yabu et al., 2001). Many aquatic embryos have mechanisms of photorepair (PR) 
effectively reverses these DNA lesions. PR depends on the action of photolyases, enzymes known to bind pyrimidine dimers with high affinity and absorb visible light to catalyze the reversal of dimers (reviewed in Sancar, 1994). The capacity for PR has been described in several vertebrate embryo species, including fish and amphibians (Applegate and Ley, 1988; Dong et al., 2007; Hays et al., 1996; Hyodo-Taguchi, 1983; Park and Yi, 1989; Smith et al., 2002). In addition to PR, embryos may be able to repair UV radiation-induced DNA lesions in the absence of light (e.g. Applegate and Ley, 1988), likely by utilizing the nucleotide excision repair (NER) pathway. The NER pathway requires the excision of approximately 27 nucleotide residues around the lesion before replacing the missing nucleotides using a DNA polymerase (reviewed in Brash, 1997). Although 6-4 PPs may be more rapidly removed by NER when compared to CPDs, both types of lesions can induce cell death by apoptosis (Lima-Bessa et al., 2008; Batista et al., 2009). Both NER and PR efficiency can vary widely between species and tissue types (Mitchell et al., 2001), and NER may be lacking altogether in some aquatic embryos and adult tissues (Akimoto and Shiroya, 1987; Willett et al., 2001). Comparative studies in amphibian embryos suggest that there may be a degree of differential sensitivity to UV radiation between similar taxa, and this may partially be driven by life histories with different likelihoods of UV radiation exposure (Anzalone et al., 1998; Hays et al., 1996; Häkkinen et al., 2001; Langhelle et al., 1999). Taken together, these studies suggest that 
although aquatic embryos show a general sensitivity to UV radiation, there may be a wide range of UV radiation tolerance and capacity for DNA repair that is species-specific and dependent on life history.

The annual killifish Austrofundulus limnaeus is found in ephemeral ponds in the Maracaibo Basin of Venezuela (Hrbek et al., 2005; Podrabsky et al., 1998). Permanent populations of $A$. limnaeus are maintained by the production of drought-tolerant embryos that can enter a state of metabolic dormancy and developmental arrest, termed diapause. Diapause may occur at 3 distinct stages of development in annual killifish, termed diapause I, II, and III (Wourms, 1972a; Wourms, 1972c). Diapause I can occur early in development after completion of epiboly but prior to the formation of the embryonic axis, and is extremely rare or absent in our stock of A. limnaeus (Podrabsky and Wagner, pers. obs). Diapause II (DII) occurs in the longsomite embryo approximately midway through development, about 24 days post-fertilization (dpf) at $25^{\circ} \mathrm{C}$, and just prior to the major phases of organogenesis. Complete entry into DII is usually finished by $32 \mathrm{dpf}$ (Podrabsky and Hand, 1999). Diapause III occurs in the late pre-hatching embryo (Wourms, 1972a). While most embryos enter into diapause II, there is also an alternate developmental trajectory where embryos "escape" diapause and develop directly to diapause III (Podrabsky et al., 2010). In addition to diapause, annual killifish are unique among fishes because their normal embryonic development includes a period of complete 
blastomere dispersion and subsequent blastomere proliferation and reaggregation to form the embryonic axis (Wourms, 1972c). In our breeding population of A. limnaeus, I observe complete blastomere dispersal by $4 \mathrm{dpf}$ and subsequent blastomere reaggregation and axis formation by $10 \mathrm{dpf}$ when embryos are incubated at $25^{\circ} \mathrm{C}$. This contrasts to the early development of other characterized teleosts, such as zebrafish and Fundulus, in which the embryonic axis is formed concurrently with epiboly (Armstrong and Child, 1965; Kimmel et al., 1995).

Embryos of A. limnaeus develop extreme tolerance to abiotic stressors such as desiccation, anoxia, and high salinity during early embryogenesis (Machado and Podrabsky, 2007; Podrabsky et al., 2001; Podrabsky et al., 2007). This tolerance peaks about mid-way through development and is likely associated with entrance into diapause II, although non-diapausing embryos are also quite tolerant (Podrabsky et al., 2012b). Very little is known about the mechanisms that support extreme stress tolerance in this or any species, and even less is known about how genome integrity is protected in these organisms. Thus, the ability of A. limnaeus embryos to respond to DNA damage during active development or dormancy is of great interest.

In this study, I use UV-C radiation ( $254 \mathrm{~nm}$ ) to investigate the tolerance of A. limnaeus embryos to induced DNA damage. Although exposure to UV-C may cause damage to a variety of cellular structures such 
as lipid membranes and some membrane receptors (e.g. Murphy, 1983;

Rehemtulla et al., 1997), UV-C has classically been used to effectively induce DNA photoproducts while minimizing damage to other cellular components. The greater specificity of UV-C for DNA damage is due in large part to DNA's peak absorbance of light at $260 \mathrm{~nm}$ and efficient production of pyrimidine dimers after exposure to 254 - $260 \mathrm{~nm}$ light (Tsuboi, 1950; Setlow et al., 1963; Rosenstein and Mitchell, 1987; Matsunaga et al., 1991). Additionally, UV-C induces one of the most frequent DNA photoproducts, CPDs, which are also induced by light wavelengths (UV-A and UV-B) able to penetrate the ozone (Madronich et al., 1998; Mouret et al., 2006), and therefore the UV-C induced DNA damage is biologically relevant (Batista et al., 2009). Here, I compare the developmental effects of UV-induced DNA damage on the dispersed blastomere stage ( $4 \mathrm{dpf}$ ), embryonic axis formation stage (10 dpf), and during diapause II (32 dpf+) in A. limnaeus embryos. I focused on the most frequent DNA lesion induced by UV radiation, CPDs (Mitchell, 1988), and hypothesized that (1) A. limnaeus embryos are able to repair UV radiation induced DNA damage by PR and/or NER and (2) sensitivity to UV radiation in A. limnaeus embryos is developmental-stage dependent. 


\section{Materials and Methods}

\section{Husbandry of adults and maintenance of embryos}

Adult A. limnaeus and their embryos were cared for as previously described by Podrabsky (1999) and in accordance with approved Portland State University Institutional Animal Care and Use Committee (IACUC) protocols. Briefly, mating pairs were allowed access to spawning trays containing 1-2 $\mathrm{cm}$ of $500 \mu \mathrm{m}$ diameter glass beads (Thomas Scientific, Swedesboro, USA) for $2 \mathrm{hr}$. Embryos were separated from the glass beads by straining through a $1.5 \mathrm{~mm}$ mesh and were collected using a wide-mouthed plastic pipette. Unfertilized eggs were discarded. For the first 3 days of development, embryos were kept in embryo medium formulated to mimic the ionic composition of their native ponds $\left(10 \mathrm{mmol}^{-1} \mathrm{NaCl}, 2.14 \mathrm{mmol}^{-1}\right.$ $\left.\mathrm{MgCl}_{2}, 0.8 \mathrm{mmol} \mathrm{l}^{-1} \mathrm{CaCl}_{2}, 0.14 \mathrm{mmol}^{-1} \mathrm{KCl}, .0013 \mathrm{mmol}^{-1} \mathrm{MgSO}_{4}\right)$ containing $0.0001 \%$ methylene blue to suppress fungal growth (Podrabsky, 1999; Podrabsky et al., 1998). At 4 dpf, embryos were treated with two 5 min washes of a $0.001 \%$ solution of sodium hypochlorite in embryo medium and transferred to embryo medium containing $10 \mathrm{mg} \mathrm{l}^{-1}$ gentamicin sulfate. Due to the thick egg envelope without pores that is characteristic of annual killifish embryos, this dilute bleach treatment is not likely to penetrate to the embryonic tissues, and has been proven a safe and effective way to help control fungal and protozoal infestations in A. limnaeus embryos (Podrabsky, 1999). However, to avoid any small chance of possible confounding effects of 
the bleach treatment with UV-C irradiation, embryos irradiated at $4 \mathrm{dpf}$ were not bleached. Embryo medium was changed daily and embryos were incubated at $25^{\circ} \mathrm{C}$ in darkness until sorting.

\section{UV-C irradiation and treatment of embryos}

Prior to irradiation, embryos were visually sorted using a dissecting scope at 4,10 , or $32 \mathrm{dpf}$ for the appropriate developmental stage as previously described (Wourms, 1972a). Normal embryos chosen for the experiments were all in the dispersed cell phase at $4 \mathrm{dpf}$, while at $10 \mathrm{dpf}$ embryos were chosen that were in the process of forming the embryonic axis but had no more than 3 pairs of somites, and those at $32 \mathrm{dpf}$ were all in diapause II as defined by cessation of development with 38 pairs of somites and low or absent cardiac activity. All embryos were rinsed several times with embryo medium lacking gentamicin prior to UV-C irradiation. For survival experiments, embryos from 2-3 different spawning batches were irradiated in groups of 10 - 15 embryos $(n=3)$ for each developmental age (stage). Embryos were exposed to UV-C light (Sylvania 15-W germicidal lamp, $254 \mathrm{~nm}, 0.9 \mathrm{~J} \mathrm{~m}^{-2} \mathrm{sec}^{-2}$ incident dose) in plastic weigh dishes $(35 \times 47.6 \times 6.4 \mathrm{~mm})$ while covered with just enough embryo medium to completely cover the embryos by approximately $1 \mathrm{~mm}$. Percent transmittance of $254 \mathrm{~nm}$ light through the embryo medium was determined using a spectrophotometer (Shimadazu UV-1700) and quartz cuvette $(1 \mathrm{~cm}$ 
path length). When blanked on air, transmittance at $254 \mathrm{~nm}$ through the medium was $108 \%$. Lamp dosage rate at $254 \mathrm{~nm}$ was verified using the BlakRay J-225 UV intensity meter (UVP, Upland, CA) at the same distance that embryos were to be irradiated. Exposures ranged from 0 - $4680 \mathrm{~J} \mathrm{~m}^{-2}$ (Table 2.1). To ensure irradiation across as much of the embryo as possible and to limit shading effects on the experimental outcome, weigh dishes containing embryos were placed on a rotating platform at $60 \mathrm{rpm}$ during UV-C exposure. UV-C exposures were conducted in a room illuminated only with pure yellow light (F40/GO 40W Gold, General-Electric) to avoid uncontrolled activation of PR mechanisms (Sancar, 1994; Sancar, 2000). After irradiation, embryos were transferred to plastic Petri dishes $(60 \times 15 \mathrm{~mm})$ containing embryo medium supplemented with $10 \mathrm{mg} \mathrm{l}^{-1}$ gentamicin sulfate. Embryos were then allowed to recover from UV-C irradiation at $25^{\circ} \mathrm{C}$ either in constant darkness or constant illumination with full-spectrum lights (2 Ultra Sun 6000K, 1 Tropic Sun 5500K, and 1 Ocean Sun 10,000K; emission between approximately 300 - $700 \mathrm{~nm}$; Zoo Med Laboratories, San Luis Obispo, CA) for the duration of the study. Except during necessary observations using a microscope, dark-recovered embryo Petri dishes were incubated on a plastic tray, wrapped in aluminum foil, and covered in two layers of black plastic to block out light. The light-recovery incubator was adjusted to compensate for the heating effects of the full-spectrum lights such that embryo medium 
temperature was constantly $25^{\circ} \mathrm{C}$. Embryo medium was changed daily for all treatments starting at $24 \mathrm{~h}$ post-irradiation.

\section{Embryo survival and development}

Embryos were observed daily for survival and abnormal

development. Although embryos reaching diapause III (DIII) have completed embryonic development, they may not immediately hatch for extended periods of time (Wourms 1972a). For all stages examined, I considered embryos reaching DIII or hatching without visible abnormalities to have successfully completed embryonic development. For embryos irradiated at 4 and $10 \mathrm{dpf}$, developmental progression was determined by counting the addition of somite pairs between 10 and $24 \mathrm{dpf}$ using an inverted compound microscope (Leica DMIRB, Wetzlar, Germany). Embryos that follow the escape developmental trajectory have morphological characteristics that make counting somites in live embryos difficult after approximately 13-15 dpf. Therefore, for escape embryos, I counted somites up until an embryo had the morphological characteristics of an escaping embryo (Podrabsky et al., 2010). Somites from abnormal or dead embryos were not counted. Embryos were considered dead after loss of perivitelline space and a cloudy, opaque appearance throughout the embryo. Embryos were considered malformed if they had any of the following phenotypes: disproportionate or absent eye formation, blood clotting, truncation/curvature of the bodies, or 
deformed head structures. For embryos irradiated at $4 \mathrm{dpf}$, those that did not form an embryonic axis by $32 \mathrm{dpf}$ were considered abnormal. For all developmental stages tested, malformed embryos were recorded as being abnormal and removed with dead embryos. Proportions of embryos reaching DIII/hatching were calculated by dividing the total number of embryos reaching DIII/hatching over the total starting number of individuals in each replicate. Proportions of embryos that were abnormal were caclculated by dividing the total number of embryos recorded as being abnormal over the total starting number of individuals in each replicate.

Light recovery. Embryos irradiated at 4 and $10 \mathrm{dpf}$ were observed for 31 and 24 days, respectively. Embryos irradiated at $32 \mathrm{dpf}$ were observed for 31 days of recovery. All embryos that developed normally had completed embryonic development and either hatched or entered DIII by the time observations were complete.

Dark recovery. Embryos irradiated at 4 or $10 \mathrm{dpf}$ and arresting at DII were transferred into constant light conditions at $32 \mathrm{dpf}$ to break diapause (Podrabsky and Hand, 1999). Embryos irradiated while in DII at $32 \mathrm{dpf}$ were tracked for 3 weeks before any embryos that remained in DII were also transferred into constant light to break diapause. Embryos remained in the constant light for 31 days, and all 4, 10, and $32 \mathrm{dpf}$ control and UV-C irradiated embryos that did not break diapause and reach DIII or hatching by the end of the 31 days were considered abnormal. 
Fixation, storage, and pre-processing of embryos for whole mounts

For whole-mount visualization of apoptosis and CPDs, 4 and $10 \mathrm{dpf}$ embryos were exposed to 0 or $500 \mathrm{~J} \mathrm{~m}^{-2} \mathrm{UV}-\mathrm{C}$ radiation and sampled at 0,24 , and $48 \mathrm{~h}$ post-irradiation for both light and dark recovery treatments while DII embryos were exposed to 0,500 , or $4860 \mathrm{~J} \mathrm{~m}^{-2}$ of UV-C radiation and sampled at $0,48 \mathrm{hr}$, and $7 \mathrm{~d}$ post-irradiation for both recovery treatments. Sampled embryos were fixed in modified BT-fix (4\% paraformaldehyde, 0.12 mmol l-1 $\mathrm{CaCl}_{2}, 3.2 \%$ sucrose, $0.064 \mathrm{~mol} \mathrm{l}^{-1} \mathrm{Na}_{2} \mathrm{HPO}_{4}, 0.016 \mathrm{~mol} \mathrm{l}^{-1} \mathrm{NaH}_{2} \mathrm{PO}_{4}$, pH 7.4) overnight at $4^{\circ} \mathrm{C}$ (Westerfield, 1995) and shielded from light. The following day, embryos were transferred into Dulbecco's phosphate buffered saline (DPBS) with Triton-X 100 detergent (DPBSTX-100, 0.005\% Triton-X 100, $2.67 \mathrm{mmol} \mathrm{l}^{-1} \mathrm{KCl}, 1.47 \mathrm{mmol} \mathrm{l}^{-1} \mathrm{KH}_{2} \mathrm{PO}_{4}, 137.93 \mathrm{mmol} \mathrm{l}^{-1} \mathrm{NaCl}, 8.06$ mmol l-1 $\mathrm{Na}_{2} \mathrm{HPO}_{4}, \mathrm{pH} 7.4$ ), egg envelopes (chorions) were mechanically removed using sharp fine forceps, and the dechorionated embryos were incubated for 30 min at room temperature in DPBSTX-100 to increase embryo permeability. The slightly hypertonic solution of DPBSTX-100 increased embryonic perivitelline space and permitted easier chorion removal. Embryos damaged during dechorionation were discarded. Dechorionated embryos were returned to BT-fix overnight at $4^{\circ} \mathrm{C}$. The following day, embryos were dehydrated in 5 min sequential washes of 25 , 50, and 75\% methanol (MeOH) diluted in DPBSTX-100. Embryos were then 
transferred to $100 \% \mathrm{MeOH}$ for 5 min followed by two rinses with $100 \%$ $\mathrm{MeOH}$. Embryos were stored in $100 \% \mathrm{MeOH}$ at $-20^{\circ} \mathrm{C}$.

During whole mount processing, all washes and reactions were carried out in amber $1.7 \mathrm{ml}$ microcentrifuge tubes. Unless otherwise noted, steps were separated by 3 washes ( 5 min each) with DPBSTX-100 while gently rotating on an orbital shaker. Embryos previously stored at $-20^{\circ} \mathrm{C}$ in $\mathrm{MeOH}$ were rehydrated in 5 min sequential washes of $75,50,25$, and $0 \%$ MeOH diluted in DPBSTX-100. Embryos were then rinsed twice with DPBSTX-100 and incubated in $1 \mu \mathrm{g} \mathrm{ml}^{-1}$ Proteinase K in DPBSTX-100 (Thermo Scientific, \#E00491) at room temperature for 5 min. Embryos were refixed for 20 min at room temperature with BT-Fix, washed 3 times in DPBSTX-100 for 5 min per wash, and processed either to visualize cyclobutane pyrimidine dimers or for TUNEL assays.

Cyclobutane pyrimidine dimer whole-mount immunohistochemistry

Cyclobutane pyrimidine dimers (CPDs) were visualized in whole mounts using the OxiSelect Cellular UV-Induced DNA Damage Staining Kit for CPDs according to the manufacturer's instructions (Cell Bio Labs, \#STA-327). Washes were performed for 5 min per wash while gently rotating on an orbital shaker. Batches of 5-10 fixed and permeabilized embryos (see above) were incubated in $70 \%$ ethanol (EtOH) for $30 \mathrm{~min}$. The EtOH was removed and embryos were incubated in $50 \mu \mathrm{l}$ of denaturation solution A for $5 \mathrm{~min}$. 
Samples were then rinsed 3 times in DPBS prior to incubation in $50 \mu \mathrm{l}$ of denaturation solution B for 10 min. Embryos were then washed 3 times in DPBSTX-100 and incubated in blocking solution (10\% bovine serum albumin in DPBSTX-100) overnight at $4^{\circ} \mathrm{C}$. The following day, the blocking solution was removed and samples were incubated in anti-CPD primary antibody $(25$ $\mu \mathrm{l}$ total volume of a 1:100 dilution in blocking solution) overnight at $4^{\circ} \mathrm{C}$. On the final day, samples were washed 3 times in wash buffer provided by the kit. Excess wash was removed and samples were incubated in secondary antibody (FITC conjugate, $25 \mu \mathrm{l}$ total volume of a 1:100 dilution in blocking solution) for $1 \mathrm{hr}$ while rotating gently on an orbital shaker at room temperature. Samples were washed 3 times in kit provided wash buffer and refixed for 20 min at room temperature in BT-fix. Samples were then washed 3 times in DPBS, counterstained with $1 \mathrm{mg} \mathrm{ml}^{-1}$ Hoechst 33342 (Life Technologies, \#H3570) in DPBS for 5 sec at room temperature, rinsed twice in DPBS, and washed once for $5 \mathrm{~min}$ in DPBS. Excess DPBS was removed and samples were soaked in $50 \mu \mathrm{l}$ of SlowFade Gold antifade reagent (Life Technologies, \#S36936) for $45 \mathrm{~min}$ and were stored at $-80^{\circ} \mathrm{C}$ to preserve signal intensity until visualization.

\section{TUNEL whole-mount immunohistochemistry}

Apoptotic cells were visualized using the APO-BrdU TUNEL Assay Kit according to the manufacturer's instructions (Life Technologies, \#A23210). 


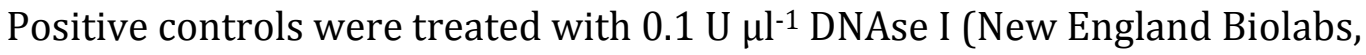
\#M0303S) in DNAse I buffer for $30 \mathrm{~min}$ at $37^{\circ} \mathrm{C}$ while rotating gently on an orbital shaker. Batches of 5-10 embryos previously fixed and permeabilized (see above) were transferred into a total volume of $25 \mu \mathrm{l}$ of DNA-labeling solution containing the enzyme terminal deoxynucleotidyl transferase (TdT) and bromodeoxyuridine $(\mathrm{BrdU})$ for $60 \mathrm{~min}$ at $37^{\circ} \mathrm{C}$ while rotating gently on an orbital shaker. At the end of incubation, samples were rinsed twice in kit provided rinse buffer and blocked overnight $10 \%$ bovine serum albumin in DPBSTX-100) at $4^{\circ} \mathrm{C}$. The anti-BrdU mouse monoclonal antibody (Alexa Fluor 488 conjugate) was diluted 1:100 in blocking solution and samples were incubated in $25 \mu \mathrm{l}$ of the antibody solution for $30 \mathrm{~min}$ at room temperature. Samples were washed 3 times in DPBSTX-100 and refixed for 20 min at room temperature in BT-fix. Samples were then washed 3 times in DPBS, counterstained with $1 \mathrm{mg} \mathrm{ml}^{-1}$ Hoechst 33342 in DPBS for $5 \mathrm{sec}$ at room temperature, rinsed twice in DPBS, and washed once in DPBS. Excess DPBS was removed and samples were soaked in $50 \mu \mathrm{l}$ of SlowFade Gold antifade reagent for $45 \mathrm{~min}$ before being stored at $-80^{\circ} \mathrm{C}$ until visualization.

\section{Visualization of whole-mount CPD staining and TUNEL assays}

Whole-mount samples were thawed at room temperature and transferred to a glass microscope slide using a plastic transfer pipette. To keep the embryos covered in SlowFade Gold reagent, extra reagent was 
added as necessary, and samples were surrounded by a thin piece of silicone that had a $2 \mathrm{~cm}$ diameter circular cutout. Embryos were viewed with excitation/emission filters of $470 / 525 \mathrm{~nm}$ for the antibody stains and $340 / 425 \mathrm{~nm}$ for the Hoechst nuclei counterstains on an inverted microscope (Leica DMIRB). Photographs were taken digitally using a Leica DFC450C camera and Leica Application Suite V4.3 software (Leica Microsystems, 2013). Scale bars were added using ImageJ (v1.47, NIH, 2013) software.

\section{Quantitative CPD ELISA}

DNA extraction: Diapause II embryos (32-42 dpf) were irradiated with 0 or $4680 \mathrm{~J} \mathrm{~m}^{-2}$ of UV-C and subsamples of 20 embryos were flash frozen in liquid nitrogen after 0,6 , and $48 \mathrm{hr}$ of recovery in light saturation or darkness. Embryos were stored at $-80^{\circ} \mathrm{C}$ in $1.7 \mathrm{ml}$ amber tubes until DNA was extracted using the DNeasy DNA purification kit (Qiagen \#69504). Embryos were homogenized on ice in their microcentrifuge tubes using a Teflon pestle in $200 \mu \mathrm{l}$ of kit provided lysis buffer ATL containing $2 \mathrm{mg} \mathrm{ml}^{-1}$ of Proteinase K (Thermo Scientific \# E00491) and were incubated at $55^{\circ} \mathrm{C}$ for 1 hr. Samples were then subjected to centrifugation for $5 \mathrm{~min}$ at $300 \mathrm{xg}$ at $4^{\circ} \mathrm{C}$ to pellet insoluble debris. The supernatant and $200 \mu \mathrm{l}$ of buffer AL were then transferred into a new microcentrifuge tube and incubated at $70^{\circ} \mathrm{C}$ for 10 min. The sample was then applied to the DNeasy silica columns according to manufacturer instructions. DNA was eluted in $200 \mu \mathrm{l}$ of TE buffer $(10 \mathrm{mmol}$ 
$\mathrm{l}^{-1}$ Tris-Cl, 1 mmol l-1 EDTA, pH 7.5) and DNA purity was assessed by the observation of $\mathrm{A}_{260} / \mathrm{A}_{280}$ ratios between 1.8-2.2. To assess DNA quality, 200 ng of embryo DNA was resolved by gel electrophoresis in 1\% agarose (45 min at $100 \mathrm{~V}$ ) in $0.5 \mathrm{X}$ TBE buffer ( $40 \mathrm{mmol} \mathrm{l}^{-1} \mathrm{Tris}^{-\mathrm{Cl}}, 45 \mathrm{mmol} \mathrm{l}^{-1}$ boric acid, $1 \mathrm{mmol} \mathrm{l}^{-1}$ EDTA). After ethidium bromide staining, acceptable DNA quality was determined by the observation of a single high-molecular weight band at $>20 \mathrm{~kb}$ in comparison to a DNA ladder (GeneRuler $1 \mathrm{~kb}$ Plus, Thermo Scientific, \#SM1332).

Generation of a CPD standard: To generate a plasmid DNA standard for CPDs, Escherichia coli bacteria (strain JM109, Promega \#P9751) transduced with the pGEM-T Easy plasmid (3015 kbp, or $6030 \mathrm{~kb}$, of DNA per plasmid; Promega \#A1360) were cultured overnight in lysogeny broth $\left(10 \mathrm{~g} \mathrm{l}^{-1}\right.$ Tryptone, $5 \mathrm{~g} \mathrm{l}^{-1}$ yeast extract, $172 \mathrm{mM} \mathrm{NaCl}$ ) at $37^{\circ} \mathrm{C}$ in a shaking incubator. Plasmids were purified using a QIAprep Spin Miniprep kit (Qiagen \#27104), eluted in two washes of $50 \mu \mathrm{l}$ TE buffer, and quantified by measuring absorbance at $260 \mathrm{~nm}\left(1 \mathrm{OD}_{260}=50 \mathrm{\mu g} \mathrm{ml}^{-2} \mathrm{dsDNA}\right)$. Plasmid DNA (50 $\mathrm{ng} \mu \mathrm{l}^{-}$ ${ }^{1}$ ) was then irradiated with UV-C at $0 \mathrm{~J} \mathrm{~m}^{-2}, 15 \mathrm{~J} \mathrm{~m}^{-2}, 30 \mathrm{~J} \mathrm{~m}^{-2}, 40 \mathrm{~J} \mathrm{~m}^{-2}, 100 \mathrm{~J} \mathrm{~m}^{-}$ 2, and $250 \mathrm{~J} \mathrm{~m}^{-2}$ in a small watch glass placed on an orbital shaker set to a speed that caused the solution to be gently mixed. T4 Endonuclease V (TEV) recognizes CPDs and cleaves the phosphodiester bond at the lesion site, creating a single stranded break (Yasuda and Sekiguchi, 1970). Therefore, supercoiled plasmids carrying CPDs are converted to a nicked, open circle 
conformation and the number of CPDs per plasmid can be determined based on the Poisson expression ( $\left.n=-\ln \mathrm{P}_{(0 \text { lesions })}\right)$, where $n$ represents the average number of CPDs per plasmid and $\mathrm{P}_{(0 \text { lesions })}$ is the fraction of plasmids with no CPDs (the zero class) (Courcelle et al., 2003). Irradiated plasmid DNA (250 ng) was digested for $1.5 \mathrm{~h}$ at $37^{\circ} \mathrm{C}$ with $2 \mathrm{U}$ of TEV enzyme (Trevigen \#4055100-EB) in TEV buffer (final reaction volume of $15 \mu \mathrm{l} ; 12.5 \mathrm{mmol} \mathrm{l}^{-1}$ sodium phosphate $\mathrm{pH}$ 6.8, $5.5 \mathrm{mmol} \mathrm{l}^{-1} \mathrm{EDTA}, 50 \mathrm{mmol} \mathrm{l}^{-1} \mathrm{NaCl}, 0.5 \mathrm{mmol} \mathrm{l}^{-1} \mathrm{DL}-$ Dithiothreitol, $0.01 \%$ Triton-X 100, $0.1 \mathrm{mg} \mathrm{ml}^{-1}$ bovine serum albumin). The reaction was stopped by the addition of an equal volume $(15 \mu \mathrm{l})$ of chloroform. Digested plasmid (200 ng) was resolved by gel electrophoresis in $1 \%$ agarose for $2 \mathrm{hr}$ at $100 \mathrm{~V}$ in $0.5 \mathrm{X}$ TBE buffer (Figure 2.1). The DNA nicking assay was performed in duplicate and the estimated number of CPDs per $6030 \mathrm{~kb}$ of irradiated plasmid DNA was averaged between the two assays. Using this method, I determined that $30 \mathrm{~J} \mathrm{~m}^{-2}$ of UV-C exposure was sufficient to cause an average of 0.805 CPDs per plasmid (or 1.33 CPDs per $10 \mathrm{~kb}$ plasmid DNA).

Quantitative ELISA: An indirect enzyme-linked immunosorbent assay (ELISA) was used to quantify CPDs in irradiated embryos using an antibody that recognizes CPDs in single-stranded DNA (Mori et al., 1991). Plasmid standard and embryonic DNA was quantified by fluorescence using the Quant-iT dsDNA Assay Kit (Invitrogen \#Q-33130) according to manufacturer instructions. Double-stranded DNA was denatured to single-stranded DNA 
by heating samples for $10 \mathrm{~min}$ at $99^{\circ} \mathrm{C}$ followed by rapid chilling on ice for 10 min. Samples were diluted to $0.5 \mathrm{ng} \mathrm{l}^{-1}$ using TE buffer. To facilitate binding of DNA to the polystyrene plates, the DNA was first mixed 1:1 (v:v) for 10 min (by vortexing) with Pierce Reacti-Bind DNA coating solution (Thermo Scientific \#17250) in a glass test tube. Samples were plated in triplicate using $100 \mu \mathrm{l}$ (25 ng of DNA) of sample per well in clear 96-well polystyrene flat-bottom plates (Greiner Bio-One \#655101). The plate was covered in aluminum foil and incubated at room temperature overnight while rotating gently on an orbital shaker.

The following day, wells were rinsed 5 times with $150 \mu \mathrm{l}$ of DPBST-20 washing buffer (DPBS pH 7.4, 0.05\% Tween-20). Excess washing buffer was decanted completely between each step. Wells were blocked with $100 \mu \mathrm{l}$ of $2 \%$ fetal bovine serum in DPBS for $30 \mathrm{~min}$ at $37^{\circ} \mathrm{C}$ while shaking at $200 \mathrm{rpm}$. The anti-CPD antibody (mouse monoclonal, clone TDM-2, Cosmo Bio USA \#CAC-NM-DND-001), previously resuspended in $100 \mu \mathrm{l}$ of deionized water, was diluted 1:1000 in blocking buffer and $100 \mu \mathrm{l}$ of the diluted antibody was added to each sample well. Wells were incubated with the primary antibody for $1 \mathrm{~h}$ at $37^{\circ} \mathrm{C}$ while shaking at $200 \mathrm{rpm}$. Wells were rinsed 5 times with 150 $\mu \mathrm{l}$ of DPBST-20 and $100 \mu \mathrm{l}$ of secondary antibody (Goat Anti-Mouse IgG alkaline phosphate conjugate, Abcam \#98635) diluted 1:1000 in block was added to each well. Plates were incubated for in the secondary antibody for 1 $\mathrm{h}$ at $37^{\circ} \mathrm{C}$ while shaking at $200 \mathrm{rpm}$. Wells were rinsed 5 times with $150 \mu \mathrm{l}$ of 
DPBST- 20 followed by the addition of $200 \mu \mathrm{l}$ of p-nitrophenyl phosphate (pNPP, Thermo Scientific Pierce \#37621). Sample absorbance at $405 \mathrm{~nm}$ was measured at 0 and 30 min after addition of pNPP. Background absorbance in the wells was corrected for by subtracting the $\mathrm{A}_{405}$ at $0 \mathrm{~min}$ from the $\mathrm{A}_{405}$ at 30 min. Technical replicates of the standard that deviated $\pm 20 \%$ from the triplicate mean were removed from analysis. Quantity of CPDs in embryonic DNA was determined by interpolation using a linear regression analysis of the plasmid DNA standards.

Statistics and data analysis

Data were analyzed using one-way or two-way Analysis of Variance (ANOVA) in Prism 5.0 software (GraphPad Software, Inc., 2009). Statistical significance was determined at a level of $\mathrm{p}<0.05$. Bonferroni or Dunnett post hoc tests were used when appropriate to compare individual means. For survival and abnormal development data, the statistics were applied to the arcsine transformation of the square root of the proportions (Zar, 1996). For somite development data, Prism 5.0 linear regression analysis tool was used to compare slopes and intercepts. The minimum dose of UV-C radiation necessary to cause $50 \%$ mortality (LD50) was calculated for each treatment group by using the Probit analysis feature in SPSS Statistics software version 21 (IBM, 2012). Significant differences between calculated LD50 values were 
determined by the observation of non-overlapping $95 \%$ confidence intervals (Hurtubise et al., 1998).

\section{Results}

Survival of UV-C irradiated embryos is stage and recovery dependent

Representative pictures of the stages selected for irradiation and common phenotypes after UV-C irradiation (dose of $500 \mathrm{~J} \mathrm{~m}^{-2}$ for $10 \mathrm{dpf}$ irradiated embryos, dose of $500 \mathrm{~m}^{-2}$ for the abnormal DII embryo, and a dose of $4680 \mathrm{~J} \mathrm{~m}^{-2}$ for the PDII embryos) are shown in Figure 2.2A-I. Many embryos UV-C irradiated at $10 \mathrm{dpf}$ (Figure 2.2B) had severe malformations such as a curved body axis, irregular somite morphology, truncated body, and/or enlarged heads (Figure 2.2D,E). Although a few embryos irradiated at $32 \mathrm{dpf}$ and subsequently recovered in the dark showed abnormal somite morphology (Figure 2.2F), severe malformations in embryos irradiated at this stage were not seen until after diapause was experimentally terminated (Figure $2.2 \mathrm{H}, \mathrm{I}$ ). When compared to control post-diapause II (PDII) embryos (Figure 2.2G), PDII embryos developing after UV-C irradiation at $32 \mathrm{dpf}$ had common malformations that included severely reduced or absent eyes, irregular vascularization patterning, truncated bodies, and/or enlarged heads (Figure 2.2H,I).

Survival of embryos irradiated at $4 \mathrm{dpf}$ was significantly affected by UV dose and recovery treatment (UV-C dose $\mathrm{p}<0.0001$; recovery treatment 
$\mathrm{p}<0.0001$; interaction $\mathrm{p}=0.3241$, Figure $2.3 \mathrm{~A}$ ). If $4 \mathrm{dpf}$ embryos that were treated with UV-C radiation are normalized to control embryos of the same recovery treatment, the survival differences are still statistically significant (UV-C dose $\mathrm{p}<0.023$; recovery treatment $\mathrm{p}<0.0001$; interaction $\mathrm{p}=0.36$ ). Embryos exposed at 10 (Figure 2.3B) and $32 \mathrm{dpf}$ (Figure 2.3C) were also significantly affected by UV dose and recovery treatment, and there was also a significant interaction between dosage and recovery for these treatments (for $10 \mathrm{dpf}$ embryos: UV-C dose $\mathrm{p}<0.0001$, recovery treatment $\mathrm{p}<0.0001$, and interaction $\mathrm{p}=0.0434$; for $32 \mathrm{dpf}$ embryos: UV-C dose $\mathrm{p}<0.0001$, recovery treatment $\mathrm{p}<0.0001$, interaction $\mathrm{p}<0.0001$ ). For embryos that recovered in the dark, Bonferroni post hoc tests indicate significant decreases in survival after $500 \mathrm{~J} \mathrm{~m}^{-2}$ of UV-C irradiation for embryos irradiated at 4 and $10 \mathrm{dpf}$, while embryos irradiated at $32 \mathrm{dpf}$ showed decreases in survival after $1000 \mathrm{~J} \mathrm{~m}^{-2}$ (Figure 2.3A-C, solid lines). For embryos that recovered in constant light, significant decreases in survival were observed after $500 \mathrm{~J} \mathrm{~m}^{-2}$, $2484 \mathrm{~J} \mathrm{~m}^{-2} 3240 \mathrm{~J} \mathrm{~m}^{-2}$ of UV-C irradiation for embryos irradiated at 4, 10, and $32 \mathrm{dpf}$, respectively (Figure 2.3A-C, dashed lines). Overall, I found embryos that were UV-C irradiated at $32 \mathrm{dpf}$ and subsequently allowed to recover in constant light had the highest survival rates of the 3 embryonic stages examined. Because I did not observe more than $50 \%$ mortality in this treatment, even at the maximum dose of $4860 \mathrm{~J} \mathrm{~m}^{-2} \mathrm{UV}-\mathrm{C}$ radiation, LD50 values could not be calculated. Incubation in light immediately after UV-C 
irradiation showed a significant increase in $\mathrm{LD}_{50}$ values (Figure 2.4) of embryos irradiated at $4\left(\mathrm{LD}_{50}\right.$ for dark $=369 \mathrm{~J} \mathrm{~m}^{-2}$, for light $\left.=746 \mathrm{~J} \mathrm{~m}^{-2}\right)$ and $10 \mathrm{dpf}\left(\mathrm{LD}_{50}\right.$ for dark $=496 \mathrm{~J} \mathrm{~m}^{-2}$, for light $\left.=1609 \mathrm{~J} \mathrm{~m}^{-2}\right)$. Among the embryos that recovered in the dark, those irradiated at $32 \mathrm{dpf}$ had a significantly higher LD50 (1307 J m${ }^{-2}$ ) compared to 4 and $10 \mathrm{dpf}$ embryos. Although 4 and $10 \mathrm{dpf}$ irradiated embryos allowed to recover in the dark did not have significantly different $\mathrm{LD}_{50}$ values, those allowed to recover in constant light at $10 \mathrm{dpf}$ had significantly higher LD50 values compared to the $4 \mathrm{dpf}$ embryos.

Recovery in light reduces malformation in 10 dpf UV-C irradiated embryos, but not 32 dpf irradiated embryos

Following UV-C irradiation at $10 \mathrm{dpf}$, there was a significant increase in embryo malformation for embryos that recovered in both dark (one-way ANOVA, $p=0.0028$ ) and light (one-way ANOVA, $p=0.0008$ ) treatments (Figure 2.3E). Recovery in light decreased malformation in $10 \mathrm{dpf}$ irradiated embryos when compared to embryos recovered in the dark (two-way ANOVA; interaction $\mathrm{p}=0.221$; recovery treatment $\mathrm{p}=0.0003$; UV-C dose $\mathrm{p}<$ 0.0001). Strikingly, UV-C irradiation did not result in malformation of embryos irradiated at $4 \mathrm{dpf}$ (Figure 2.3D) and recovered in the light (oneway ANOVA, $p=0.514$ ) or dark (one-way ANOVA, $p=0.151$ ). For embryos irradiated at $32 \mathrm{dpf}$, two-way ANOVA indicated no significant increase in abnormal embryos due to UV-C dose or recovery (Figure 2.3F; UV-C dose $\mathrm{p}=$ 
0.2994 , recovery $=0.2162$, interaction $=0.1506)$. However, Bonferroni posttests indicated significant increases in the mean proportion of abnormal embryos in treatments allowed to recover in constant light when compared to controls for some doses (Figure 2.3F; $\mathrm{p}<0.05$ for 1512, 3240, and $4680 \mathrm{~J}$ $\mathrm{m}^{-2}$ doses).

UV-induced mortality is delayed in DII embryos allowed to recover in the dark Most embryos (99.2\%) exposed to UV-C at $32 \mathrm{dpf}$ and allowed to recover in the dark remained in DII until diapause was experimentally terminated at week 3 (not shown). Embryos were considered to be in DII if they did not display evidence of pigmentation or red blood cells. There was no significant difference in survival between $32 \mathrm{dpf}$ UV-C irradiated embryos and controls (Figure 2.5) after 1 week (one-way ANOVA, $\mathrm{p}=0.5192$ ) or 2 weeks (one-way ANOVA, $p=0.4118$ ) of recovery. However, by week 3 there was a significant decrease in survival compared to controls (one-way ANOVA, $p=0.0016)$. Comparison of the 3 weeks indicated significant variation due to weeks of recovery and due to UV-C irradiation (two-way ANOVA, $p=0.0006$ for weeks of recovery, $\mathrm{p}=0.0001$ for UV-C dose, $\mathrm{p}=0.99$ for interaction).

Incubation in constant light induces early embryos to bypass diapause II 
Most 4 and $10 \mathrm{dpf}$ embryos that were incubated in constant darkness arrested development at diapause II. All of the embryos allowed to recover under conditions of constant light developed as "escape" embryos, defined as embryos that bypass DII and instead develop directly to DIII or hatching (Podrabsky et al., 2010). When compared to embryos that recovered in the dark, both control and UV-C treated $\left(250 \mathrm{~J} \mathrm{~m}^{-2}\right)$ embryos exposed to constant light had significantly more embryos escaping when incubated at $4 \mathrm{dpf}$ (oneway ANOVA, $\mathrm{p}<0.01$ ) or $10 \mathrm{dpf}$ (one-way ANOVA, $\mathrm{p}<0.01$ ). Control and UVC treated $\left(250 \mathrm{~J} \mathrm{~m}^{-2}\right)$ embryos incubated at 4 or $10 \mathrm{dpf}$ did not statistically differ in proportion bypassing DII between stages (Figure 2.6). Insufficient numbers of dark-recovered embryos survived after being irradiated with $500 \mathrm{~J} \mathrm{~m}^{-2}$ or higher at 4 and $10 \mathrm{dpf}$ to have meaningful escape embryo statistics for those doses, although the trend of $100 \%$ bypassing DII following UV-C radiation was observed for those doses (not shown).

Axis formation is delayed in 4 dpf UV-C irradiated embryos

Pairs of somites were added in a linear fashion during development for control and irradiated embryos exposed at $4 \mathrm{dpf}$ (Figure 2.7A,C; average $\mathrm{r}^{2}=0.96 \pm 0.039$, mean $\pm \mathrm{SD}$ ) and $10 \mathrm{dpf}$ (Figure 2.7B,D; average $\mathrm{r}^{2}=0.96 \pm$ 0.039 , mean $\pm \mathrm{SD}$ ). At doses of $1,000 \mathrm{~J} \mathrm{~m}^{-2}$ and above, insufficient numbers of $4 \mathrm{dpf}$ embryos survived (Figure 2.3A) to perform a meaningful regression analysis. When compared to controls, UV-C irradiated embryos had similar 
rates of somite addition (similar slopes of somites added per unit time) during early development (Figure 2.7A-D; 4 dpf dark $\mathrm{p}=0.12 ; 4 \mathrm{dpf}$ light $\mathrm{p}=$ $0.43 ; 10 \mathrm{dpf}$ dark $\mathrm{p}=0.89 ; 10 \mathrm{dpf}$ light $\mathrm{p}=0.84$ ). However, there was a significant delay in the onset of somitogenesis in embryos irradiated at $4 \mathrm{dpf}$ when compared to controls, as evidenced by a decrease in line elevations (yintercepts) for embryos recovering from UV-C treatment in both the light (Figure 2.7A, $\mathrm{p}<0.0001$ ) and dark (Figure 6C, $\mathrm{p}<0.0001$ ). This developmental delay was substantial. For example, embryos exposed at $4 \mathrm{dpf}$ to $250 \mathrm{~J} \mathrm{~m}^{-2}$ or $500 \mathrm{~J} \mathrm{~m}^{-2}$ of UV-C and recovered in darkness were delayed by about 3 days compared to control embryos, while light recovered embryos receiving the same UV doses were delayed by just over a day. In contrast to the $4 \mathrm{dpf}$ embryos, all $10 \mathrm{dpf}$ treatments had similar times for the onset of somitogenesis (Figure 2.7B,D).

Recovery in full spectrum light reduces CPD-positive nuclei in irradiated embryos

Whole-mount embryos that were processed without primary (antiCPD) or secondary antibody (fluorescent) did not show positive staining (not shown). Embryos irradiated at 4, 10, and $32 \mathrm{dpf}$ exhibited CPD-positive staining of both embryonic and enveloping cell-layer nuclei when sampled immediately after irradiation (Figures 2.8-2.10, far left). Embryos were considered to be CPD-positive if one or more nuclei showed fluorescent 
staining that could be distinguished from autoflouresence. Embryos irradiated at $4 \mathrm{dpf}$ maintained CPD-positive nuclei after 24 and $48 \mathrm{hr}$ of recovery in the dark, but there were no CPD-positive nuclei after 24 or $48 \mathrm{hr}$ of recovery in constant light (Figure 2.8). In contrast, $10 \mathrm{dpf}$ embryos exhibited noticeably weaker CPD-positive staining after recovery in the dark for 24 or $48 \mathrm{hr}$, and no CPD-positive nuclei after 24 or $48 \mathrm{hr}$ of recovery in constant light (Figure 2.9). Embryos irradiated at $32 \mathrm{dpf}$ (Figure 2.10) showed a similar pattern to embryos irradiated at $4 \mathrm{dpf}$, with CPD-positive nuclei remaining after $48 \mathrm{hr}$ and $7 \mathrm{~d}$ in darkness and no CPD-positive nuclei after recovery for $48 \mathrm{hr}$ or $7 \mathrm{~d}$ in light. Embryos irradiated at $32 \mathrm{dpf}$ with a dose of $500 \mathrm{~J} \mathrm{~m}^{-2}$ showed similar staining patterns to those irradiated with $4680 \mathrm{~J} \mathrm{~m}^{-2}$. Table 2.2 summarizes the results of the CPD staining experiments.

UV-C irradiation increases TUNEL positive nuclei in $10 \mathrm{dpf}$ embryos

Whole-mount embryos that were processed without TdT enzyme did not show TUNEL positive cells, while all embryos treated with DNAse I prior to enzyme showed TUNEL positive cells (not shown). Embryos irradiated at $4 \mathrm{dpf}$ exhibited positive TUNEL foci for both control and irradiated embryos (Figure 2.11A). I observed a high degree of background from the yolk at the Hoechst excitation wavelength after counterstaining embryos, and therefore show only bright-field and TUNEL images. To compare number of TUNEL- 
positive nuclei between controls and UV-C irradiated embryos I focused the microscope plane on the center edge of the embryos and counted fluorescent foci per embryo; these results were not significant (two-way ANOVA; UV-C dose $\mathrm{p}=0.5264$, recovery $\mathrm{p}=0.1545 ;$ interaction $=0.607 ;$ Figure $2.11 \mathrm{~B})$. Embryos irradiated at $10 \mathrm{dpf}$ showed TUNEL positive staining after $24 \mathrm{~h}$ and $48 \mathrm{~h}$ of recovery in the dark and after $24 \mathrm{hr}$ of recovery in constant light (Figure 2.12A). Embryos irradiated at $32 \mathrm{dpf}$ and allowed to recover in the dark had a small fraction with TUNEL positive nuclei, but there were no apparent TUNEL positive nuclei for those that recovered under constant light (Figure 2.12B). A high degree of background autofluorescence was observed at the Alexa Fluor 488/FITC wavelength in embryos that were PDII. A summary of embryos observed with TUNEL positive nuclei is shown in Table 2.3.

CPD lesion frequency remains unchanged if UV-C irradiated DII embryos are recovered in dark

I observed a linear increase in $\mathrm{A}_{405}$ of the plasmid DNA standards as UV-C dose increased $\left(r^{2}>0.99\right)$ after ELISA (Figure 2.1). Wells containing control DII DNA and wells that lacked primary or secondary antibody were indistinguishable from background (not shown). DII embryos experienced an average of 5.27 CPDs per $10 \mathrm{~kb}$ of DNA when sampled immediately after irradiation with $4680 \mathrm{~J} \mathrm{~m}^{-2}$ of UV-C (Figure 2.13). When compared to 
irradiated embryos without recovery, the number of CPDs did not change significantly after $6 \mathrm{hr}$ or $48 \mathrm{hr}$ of recovery in darkness (one-way ANOVA with Dunnett's Multiple Comparison Test, $\mathrm{P}>0.05$ ). However, there was a significant decrease in CPDs after $6 \mathrm{hr}$ (one-way ANOVA with Dunnett's Multiple Comparison Test, $\mathrm{P}<0.05$ ) or $48 \mathrm{hr}$ of light recovery (one-way ANOVA with Dunnett's Multiple Comparison Test, $\mathrm{P}<0.0001$ ). In comparison to irradiated embryos without recovery, an average of 53\% and 9\% of CPDs remained after $6 \mathrm{hr}$ and $48 \mathrm{hr}$ of light recovery, respectively. 


\section{Discussion}

To my knowledge, this is the first study examining DNA damage and repair in a diapausing vertebrate embryo. The strong impact of photoreactivation in decreasing mortality and abnormal development suggests that the primary cause of embryonic death or malformation is due to damaged DNA, and thus this is where I focus comparisons.

UV-C radiation exposure can cause mortality and abnormal development in $\mathrm{A}$. limnaeus embryos

Dose-dependent responses to UV radiation that result in embryonic mortality or malformation have been previously described in zebrafish, the fathead minnow Pimephales promelas, and the salamander Ambystoma macrodactylum (Applegate and Ley, 1988; Blaustein et al., 1997; Dong et al., 2007; Yabu et al., 2001). As expected, I observed significant decreases in $A$. limnaeus embryos surviving to DIII or hatching after UV-C radiation exposure for all stages examined (Figure 2.2A-C). These decreases in survival became more pronounced as UV-C radiation doses increased. Severe embryonic malformations following UV-C irradiation were most prominently observed in embryos at the axis-formation stage, $10 \mathrm{dpf}$, and subsequently allowed to recover in the dark (Figures 2.2D-E, 2.3E). The pronounced spinal curvature observed in many of these embryos had a similar phenotype to UV-B irradiated zebrafish (Danio rerio) embryos at the mid-gastrula stage (Dong et 
al., 2007). Dong et al. (2007) suggested that the kinked or curved spinal phenotype in irradiated embryos might be caused by differential lateral exposure on the embryo during irradiation, although I mixed the A. limnaeus embryos during UV-C radiation exposure to minimize this effect. There were increased instances of abnormal development after UV-C radiation exposure in $32 \mathrm{dpf}$ embryos, but these were not realized until after the termination of diapause (Figures 2.2F, 2.3F).

Embryos of A. limnaeus have a competent CPD photorepair system Previous work with UV-irradiated fish embryos from the medaka Oryzias latipes, the fathead minnow Pimephales promales, the self-fertilizing killifish Kryptolebias marmoratus, and D. rerio suggests that fish embryos may share a capacity for PR after UV-induced DNA damage (Applegate and Ley, 1988; Dong et al., 2007; Hyodo-Taguchi, 1983; Park and Yi, 1989). These studies showed significant increases in survival if embryos were allowed to recover in light following UV radiation exposure. The strong conservation of photolyase expression among diverse taxa suggests that PR is an ancient strategy (Essen and Klar, 2006) and CPD photolyases have been previously identified in O. latipes and Carassius auratus (goldfish) (Yasuhira and Yasui, 1992; Yasui et al., 1994). Unsurprisingly, I observed significant increases in survival for all 3 stages of A. limnaeus embryos if they were allowed to recover in full-spectrum light following UV-C irradiation (Figures 
2.3A-C, 2.4). Whole-mount staining of embryos for CPDs, which are the most common type of DNA lesion induced by UV radiation, suggests that CPDs are induced after UV-C irradiation and are reversed after recovery in fullspectrum light (Figures 2.8-2.10). This photoreversal of CPDs in UV irradiated embryos is likely due to expression of a CPD-specific photolyase, but because separate photolyases will recognize (6-4) photoproducts (Essen and Klar, 2006), it is currently unknown if A. limnaeus embryos express both types. Interestingly, embryos irradiated at $10 \mathrm{dpf}$ tended to have reduced CPD staining even when incubated in darkness for 24 and $48 \mathrm{hr}$ (Figure 2.8), suggesting a form of dark-repair (such as NER), reduction in CPD stain signal due to continued cell proliferation, or a reduction in CPD stain signal due to removal of damaged cells. Although some fish embryos have been shown to exhibit light-independent NER following UV radiation exposure (e.g. Applegate and Ley, 1988), A. limnaeus embryos irradiated at 4 and $32 \mathrm{dpf}$ maintain DNA lesions for several days after UV-C radiation exposure if recovered in darkness (Figures 2.8 and 2.10). Some other aquatic embryos, such as sea urchins, may not utilize NER as a main pathway to remove UV radiation induced DNA lesions (Lesser et al., 2003), and this may be the case with A. limnaeus. Park and Yi (1989) demonstrated that embryos of $K$. marmoratus exposed to UV-C radiation and incubated in darkness have significantly decreased survival if given caffeine during recovery to inhibit DNA damage signaling (Müller et al., 1996), thus suggesting the presence of a 
dark-repair system. Since then, however, caffeine has been shown to sensitize UV radiation treated mammalian cells to undergo apoptosis (Han et al., 2011), which may have resulted in the increased mortality observed in $K$. marmoratus. It would be difficult to accurately measure thymine dimer removal in embryos that may tolerate DNA damage by using polymerases able to bypass lesions during DNA replication (reviewed in Sale et al., 2012), as the ratio of undamaged DNA to damaged DNA would increase as the embryo developed without actually repairing the lesions. The extent that $A$. limnaeus may rely on these polymerases to tolerate DNA damage is unknown. Future work preventing embryonic cells from dividing or breaking dormancy would be ideal for determining the extent to which NER may be a factor for repairing DNA lesions in A. limnaeus.

It is interesting to note that the repair capacity of embryos irradiated during DII appears to be strongly dependent on a PR pathway (Figures 2.4C, 2.13). Similar to rates of thymine dimer removal in the sea urchin Hemicentrotus pulcherrimus (Akimoto and Shiroya, 1987), I was unable to detect significant changes in CPD frequency when DII embryos were recovered in darkness. Some frog and fish cells have also been demonstrated to show low $(<10 \%)$ levels of CPD removal even after $24 \mathrm{hr}$ of recovery in the dark (Regan et al., 1982). This contrasts with the dark-repair capacity of UV radiation irradiated (peak emission $313 \mathrm{~nm}$ ) P. promelas embryos, which are able to remove $>50 \%$ of CPDs in 9 hrs without photoreactivating light 
(Applegate and Ley, 1988). The role of lesion-bypassing polymerases in this reduction of CPDs in P. promelas is unknown. It should be noted that because the tissues of these different species were not irradiated to the same number of CPDs per kb of DNA, it is difficult to directly compare rates of repair between species.

Diapause II embryos of A. limnaeus possess an impressive tolerance of UV-induced DNA damage. Applegate and Ley (1988) reported that 52\% of $P$. promelas embryos irradiated between 12 and $24 \mathrm{dpf}$ (three-quarter epiboly to 18-20 somite pairs (Devlin et al., 1996)) survived an average UV-induced lesion load of 0.32 CPDs per $10 \mathrm{~kb}$ of DNA if recovered in light. In comparison, diapause II embryos of A. limnaeus sustained average lesion loads of 5.27 CPDs per $10 \mathrm{~kb}$ of DNA without reaching $50 \%$ mortality if recovered in light (Figures 2.3C, 2.13). These data suggest an estimated 16fold increase in CPD tolerance for A. limnaeus diapause II embryos compared to P. promelas embryos.

Because ATP turnover is low and ATP synthase activity is nearly undetectable during DII (Duerr and Podrabsky, 2010), a repair process requiring ATP, such as NER (Riedl et al., 2003; Ura et al., 2001) may be an unfavorable pathway during embryonic dormancy. Thus, a DNA-repair pathway requiring only photolyase and visible light to reverse UV radiation induced DNA lesions may be the preferential repair mechanism for DII $A$. limnaeus embryos. The robust increase in survival observed after UV-C 
irradiated $32 \mathrm{dpf}$ embryos were recovered in photoreactivating light (Figure 2.3C) suggests that either DII embryos constitutively express a CPDphotolyase or that expression of the enzyme is rapidly inducible. This is supported further by the removal of visible CPD-positive nuclei after $48 \mathrm{hr}$ of light in the DII embryos (Figure 2.10). If DII embryos indeed have an intracellular stock of photolyase, it may be possible for UV radiation exposed A. limnaeus embryos to repair most of the incurred DNA lesions if given enough light to activate repair without inducing the resumption of embryonic development caused by the extended photoperiod. However, photolyase activity levels during A. limnaeus development remain to be fully characterized.

Many embryos of A. limnaeus can withstand substantial amounts of UV-C radiation and still complete embryonic development

There have been limited studies using UV-C to induce DNA damage during vertebrate development at equivalent stages to the ones examined in this study. Compared to early embryos of K. marmoratus (Park and Yi, 1989), O. latipes (Hyodo-Taguchi, 1983), and D. rerio (Yabu et al., 2001), I found that A. limnaeus embryos irradiated at $4 \mathrm{dpf}$ tended to have higher $\mathrm{LD} 50$ values for both recovery treatments (Figure 2.14). Interestingly, the 1,000 cell stage of the zebrafish may be the most resistant embryonic stage to death and malformation due to UV radiation induced DNA damage (Dong et al., 2007). 
In contrast, I observed a trend for increased overall survival if $A$. limnaeus embryos were irradiated at later stages of development, especially for lightrecovered embryos (Figures 2.3A-C and 2.4). This trend agrees with previous studies suggesting $A$. limnaeus embryos in DII have the highest tolerances to environmental insults, such as desiccation and anoxia, when compared to earlier and later embryonic stages (Machado and Podrabsky, 2007; Podrabsky et al., 2001; Podrabsky et al., 2007). Mitchell and Hartman (1990) suggested that accessibility to damaged DNA by chromatin remodeling may be an important factor in DNA repair and may contribute to differential sensitivities to DNA damage during different stages of development. UV-induced DNA damage has been suggested to be more efficiently repaired in genomic regions associated with active transcription and thus relaxed chromatin (Thoma, 1999). Surprisingly, the most resistant stage I observed was dormant embryos with presumably low levels of gene expression, and thus likely a higher percentage of condensed chromatin compared to actively developing embryos. Analysis of chromatin structure during diapause would provide insight into its contribution to DNA damage tolerance. Additionally, how far the resistance to malformation and death may extend past DII remains to be determined. The most resistant stage and recovery treatment I observed (DII embryos irradiated at $32 \mathrm{dpf}$ and recovered in light) did not reach 50\% mortality (Figure 2.3C) even at doses 23-fold higher than the LD50 of the most resistant zebrafish embryonic stage 
to UV-C radiation. This suggests that $A$. limnaeus may have much higher resistance to negative effects of DNA damage than other vertebrate embryos, although further comparative studies sharing the same UV radiation wavelengths and doses would be necessary to determine how far the trend may hold.

Apoptosis may be utilized to remove damaged embryonic cells in embryos irradiated at $10 \mathrm{dpf}$, but not those irradiated at 4 or $32 \mathrm{dpf}$

Apoptosis is a pathway of programmed cellular death that can be induced by a diverse array of cellular stressors. Apoptotic responses following UV radiation exposure have been shown to occur in embryos of zebrafish and sea urchins (Lesser et al., 2003; Yabu et al., 2001) and adults of the nematode Caenorhabditis elegans (Stergiou et al., 2007), suggesting a conserved role of apoptosis in removing cells damaged by UV radiation. Yabu et al. (2001) found increases in TUNEL-positive nuclei after $200 \mathrm{~J} \mathrm{~m}^{-2}$ of UV-C radiation exposure of 1,000-cell stage (3 hours post-fertilization) zebrafish embryos, and I found a similar result for A. limnaeus embryos irradiated at $10 \mathrm{dpf}$ with $500 \mathrm{~J} \mathrm{~m}^{-2}$ of UV-C radiation (Figure 2.12A). Interestingly, I did not observe increased TUNEL-positive nuclei in embryos irradiated at $4 \mathrm{dpf}$ and most of the embryos irradiated at $32 \mathrm{dpf}$ (Figure 2.11; Table 2.3). Recent work with A. limnaeus embryos has suggested that levels of the phosphorylated active form of AKT (pAKT), a known apoptotic 
programmed cell death repressor (Hers et al., 2011), are highest at 4 and 32 dpf (Meller et al., 2012). The low amount of TUNEL-positive nuclei I observed in 4 and $32 \mathrm{dpf}$ embryos after UV-C irradiation, even at the highest dose for the $32 \mathrm{dpf}$ embryos, agrees with pervious work that suggests apoptosis may be suppressed at these stages (Meller and Podrabsky, 2014). Although our breeding stock do not routinely arrest at DI, the tendency to suppress apoptosis at this developmental stage may remain and could be a feature that is shared with DII embryos.

Limited apoptosis in A. limnaeus embryos after UV-C irradiation may be due to metabolic depression and cell cycle arrest

A possible explanation for the lack of TUNEL positive nuclei in $32 \mathrm{dpf}$ irradiated embryos is that UV-C radiation induced apoptosis may require sufficient blockage of RNA polymerases by DNA lesions during transcription. This is part of a process known as transcription-coupled repair, or TCR (Hanawalt and Spivak, 2008). In contrast to global genomic repair (GGR), which can target transcriptionally inactive sites, TCR appears to preferentially identify and remove DNA lesions in transcriptionally active regions after blockage by a stalled RNA polymerase. Both CPDs and 6-4 PPs are able to block transcription, and if adequate removal of these lesions by TCR fails, apoptosis may be triggered (Batista et al., 2009). Protein synthesis has been shown previously to be depressed by over $90 \%$ in DII embryos 
(Podrabsky and Hand, 2000), and correspondingly lowered transcription rates may delay or reduce the number of blocked RNA polymerases that could signal apoptosis, thus causing the delayed mortality I observed in darkrecovered embryos irradiated at $32 \mathrm{dpf}$ (Figure 2.5). However, protein synthesis has been shown to be high in $4 \mathrm{dpf}$ embryos and yet frequent apoptotic nuclei are not observed (Figure 2.11).

An alternate explanation for the lack of apoptosis in UV-C irradiated DII embryos centers around the hypothesis that UV-induced apoptosis is dependent on signaling pathways requiring active DNA synthesis (Batista et al., 2006). DNA content does not change in DII embryos and most isolated $A$. limnaeus cells from diapause II embryos contain a diploid genome (Podrabsky and Hand, '99; Meller et al., 2012). In addition, it appears that dispersed cell phase cells of Nothobranchius furzeri, a related annual killifish from Africa, are largely arrested in the $\mathrm{G}_{1}$ phase of the cell cycle (Dolfi et al., 2014). Thus, it appears that cells of both diapause II and 4 dpf embryos have withdrawn from active progression through the cell cycle. In contrast, embryos at $10 \mathrm{dpf}$ are likely actively proliferating. Thus, my data are consistent with apoptosis being induced only in cells that are actively dividing, and not in those that are arrested in G1.

The lack of CPD removal I observed in irradiated DII embryos after dark recovery (Figure 2.13) agrees with the possibility that DNA damage recognition and/or signaling may be depressed in diapausing embryos. 
Supporting this possibility further, C. elegans adult germ cells have been shown to require a functional NER pathway to recognize UV-C induced DNA damage and initiate apoptosis (Stergiou et al., 2011). Future characterization of transcription rates and NER activity levels during A. limnaeus embryonic development may provide insight into how DNA-damage recognition and apoptosis pathway activation may be atypical in vertebrates exhibiting diapause.

The dispersed blastomere embryonic stage may be a developmental stress buffer in A. limnaeus

An interesting outcome of this study is the significant developmental delay observed in embryos UV-C irradiated at 4 dpf (Figure 2.7). Surprisingly, the similar onset times for somitogenesis for $4 \mathrm{dpf}$ embryos irradiated with 250 or $500 \mathrm{~J} \mathrm{~m}^{-2}$ suggest that the degree of delay is recoverydependent but not dose dependent. Although the reason for this is unclear, it does suggest that, after an initial developmental arrest, DNA repair in dark or light is performed rapidly enough such that there is not a significant difference between doses. Though these embryos required several days longer to form their first somites, the majority of embryos that survived the initial UV-C irradiation developed normally (Figure 2.3). This contrasts to embryos irradiated after or during axis formation at $10 \mathrm{dpf}$ where many embryos developed abnormally if recovered in darkness (Figure 2.3). 
Wourms (1972b) and Epel et al. (1999) suggested that aquatic embryos incurring cellular damage during development might be able to "slough" off damaged cells through apoptotic or similar pathways if repair mechanisms were insufficient. The removed cells could then be replaced by surrounding cells through subsequent cellular divisions, provided those surrounding cells were pluripotent or multipotent. Although I did not observe a significant increase in apoptotic nuclei after UV-C radiation exposure at $4 \mathrm{dpf}$ (Figure 2.11), I cannot rule out that alternative cell death mechanisms are occurring. In addition, rate of somite addition was similar in UV-C exposed and control embryos once the delayed axis was established (Figure 2.7), suggesting that once the axis has formed the embryos are able to follow normal development. Zebrafish embryos UV-B irradiated after the onset of gastrulation have been shown to exhibit the most severe malformations at a significantly more frequent rate than those irradiated before gastrulation has commenced, suggesting that once cellular differentiation into germ layers has occurred, embryos become much more sensitive to exogenous cellular stressors (Dong et al., 2007). This supports the notion that the dispersed embryonic cells may benefit by remaining undifferentiated and disorganized at $4 \mathrm{dpf}$ until axis formation by $10 \mathrm{dpf}$. Because anecdotal evidence suggests that many annual killifish embryos remain in the dispersed blastomere state during extended periods of habitat desiccation (Genade et al., 2005), I speculate that the blastomere dispersion state serves to prevent abnormal 
development in annual killifish embryos by (1) delaying sensitive cellular configurations and differentiation states until the environment is favorable and (2) ensuring that cells lost to cellular stressors can be replaced by functionally equivalent surrounding cells. Additionally, the dispersed blastomere stage is a trait shared by both African and South American annual killifish (Wourms, 1972a), and because diapause has been predicted to have evolved independently in the African and South American killifishes lineages (Hrbek and Larson, 1999), this further supports the importance of the dispersed blastomere stage in maintaining normal embryonic development in an unpredictable environment. 

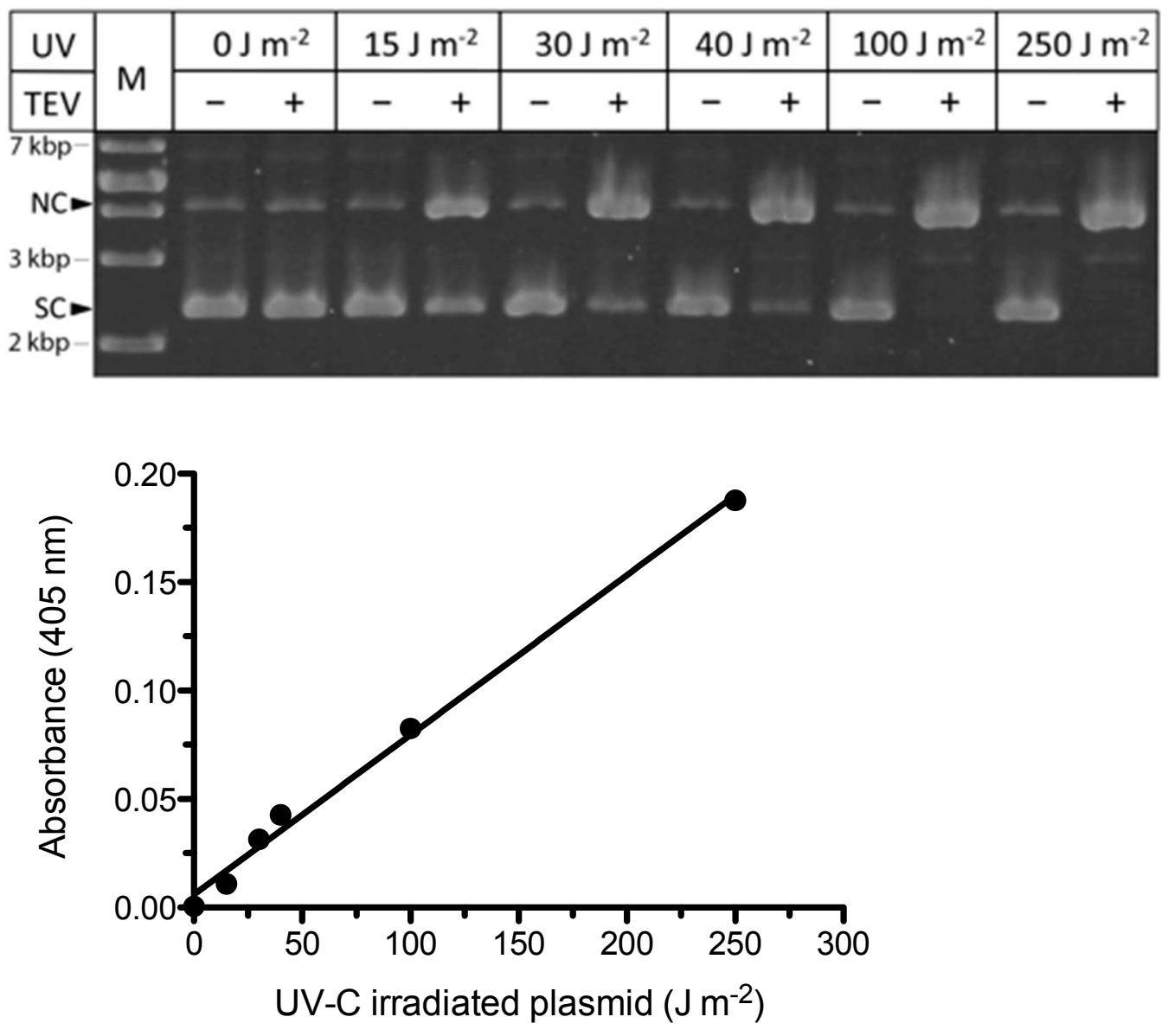

Figure 2.1. Top panel. Plasmid standard used for CPD ELISA. Following TEV digestion, the number of plasmids converted from supercoiled (SC) to nicked open circular (NC) form increased with UV-C dose. Plasmids were resolved using agarose-gel electrophoresis. The relaxed conformation of NC plasmids causes them to appear as a higher molecular weight band when compared to SC plasmids. M, ladder.

Bottom panel. Representative standard curve showing that absorbance at $405 \mathrm{~nm}$ increased linearly $\left(\mathrm{r}^{2}>0.99\right)$ with increasing UV-C dose following CPD ELISA. The same plasmid DNA assayed using TEV digestion in the top panel was used as the standard curve for the CPD ELISA. Symbols are means of 2-3 technical replicates. 


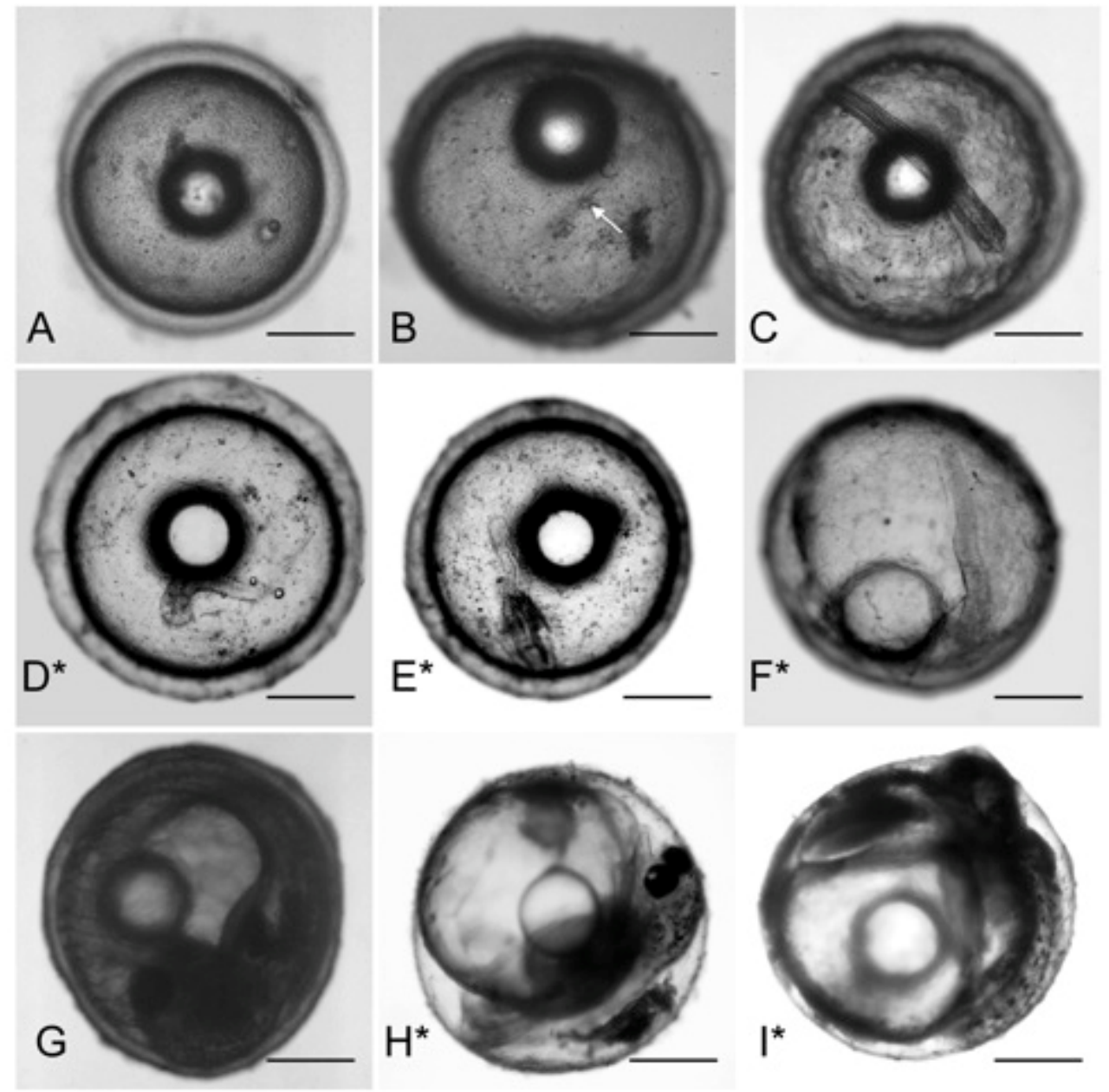

Figure 2.2. Representative images of stages selected for irradiation and subsequent effects on development. Embryos were irradiated at 4 (A), 10 (B), or $32 \mathrm{dpf}$ (C). Representative images of typical abnormal embryos after $500 \mathrm{~J} \mathrm{~m}^{-2} \mathrm{UV}-\mathrm{C}$ irradiation at $10 \mathrm{dpf}$ and dark recovery (D, E) and an abnormal DII embryo after similar treatment (F). A normally developing control post-diapause II embryo is shown in $\mathbf{G}$, and typical PDII embryos after exposure to $4680 \mathrm{~J} \mathrm{~m}^{-2} \mathrm{UV}-\mathrm{C}$ radiation at DII are shown in $\mathbf{H}$ and $\mathbf{I}$. Scale bars, $500 \mu \mathrm{M}$. Abnormal embryos are indicated with an asterisk $\left({ }^{*}\right)$. Arrow in panel $\mathbf{B}$ is pointing to the nascent embryonic axis. 

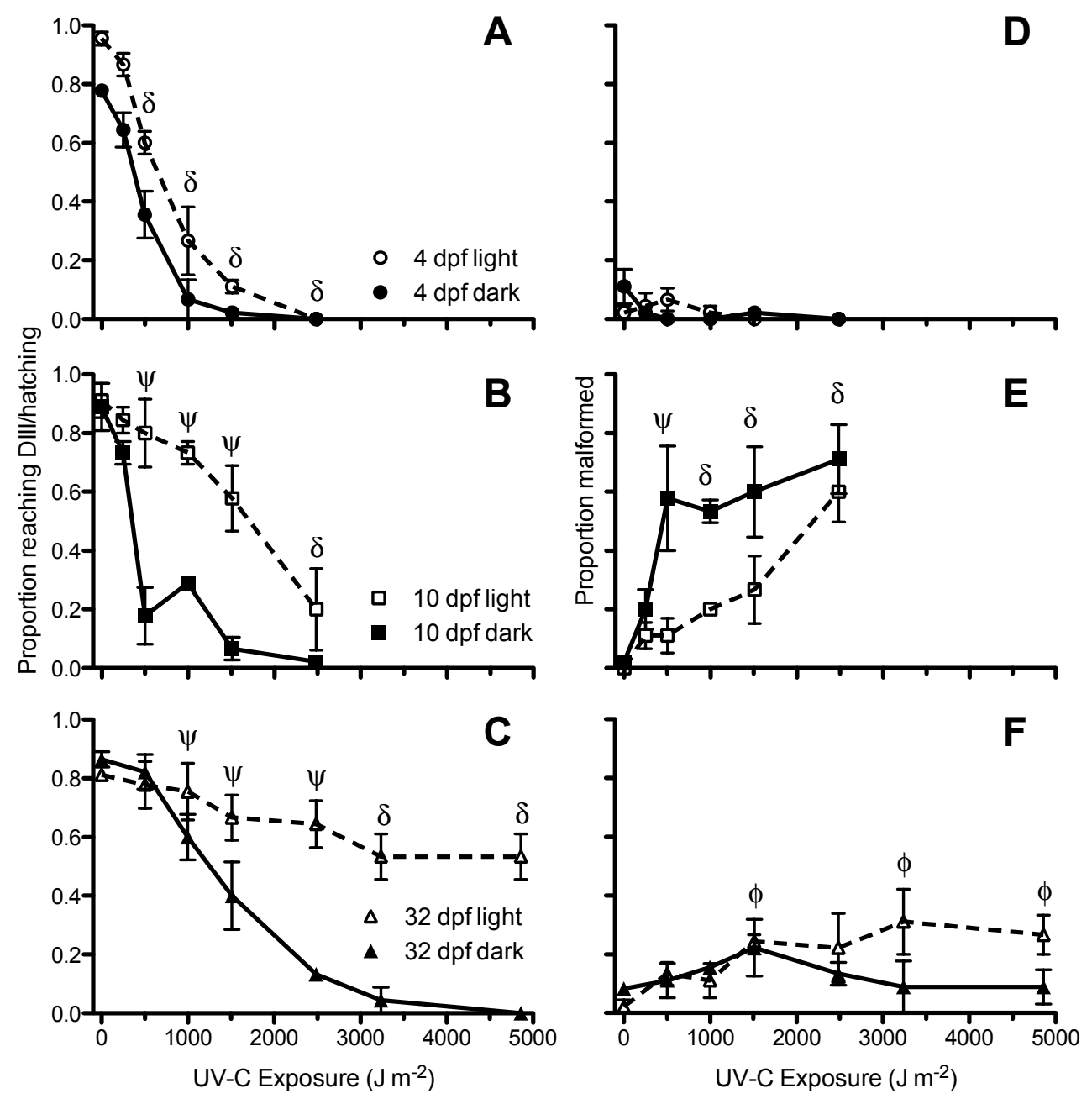

Figure 2.3. Survival and abnormal development in embryos exposed to UV-C irradiation. Doses of radiation exposure for each stage are described in Table 2.1. Graphs are of embryos UV-C irradiated at $4 \mathrm{dpf}(\mathbf{A}, \mathbf{D}), 10 \mathrm{dpf}(\mathbf{B}, \mathbf{E})$, or $32 \mathrm{dpf}(\mathbf{C}, \mathbf{F})$ and following recovery in the light or dark. Symbols represent means \pm SEM $(n=3)$. Significant changes in survival or abnormal development when comparing UV-C irradiated embryos to controls are indicated by symbols over corresponding doses (two-way ANOVA with Bonferroni post hoc comparisons, $\mathrm{p}<0.05$ ) $\delta$, significant for both light and dark recovery; $\psi$, significant for dark recovery only; $\phi$, significant for light recovery only. 


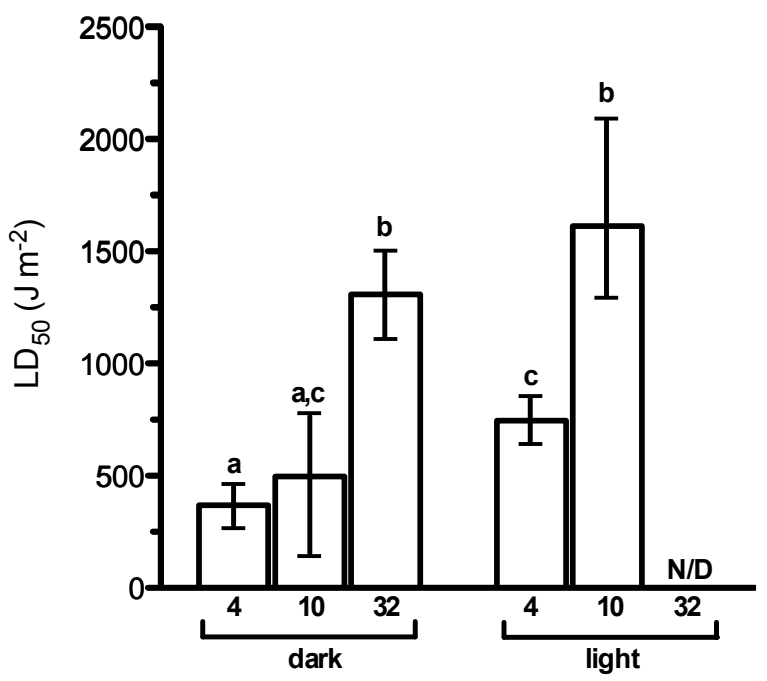

Figure 2.4. LD50 values for embryos exposed to UV-C irradiation and allowed to recover in constant dark or light. Embryo ages in dpf at time of irradiation are noted at the bottom of each bar. Values are from the same data set as Figure 2.3. Different letters above error bars denotes groups significantly different than each other. Bars represent means $\pm 95 \%$ C.I. $(n=3)$. N/D, not determined. 


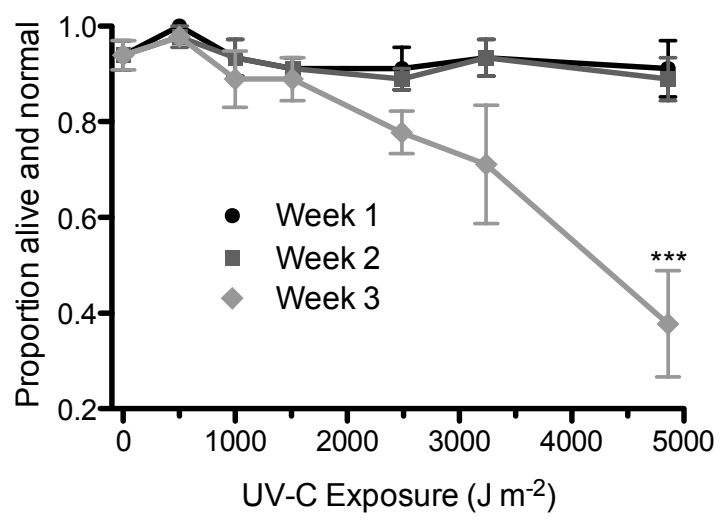

Figure 2.5. Survival of $32 \mathrm{dpf}$ (DII) embryos UV-C irradiated at 0, 250, 500, $1000,1512,2484,3240$, or $4680 \mathrm{~J} \mathrm{~m}^{-2}$ and allowed to recover in the dark. Death of UV-C irradiated DII embryos, as described in the main text, is delayed by several weeks post-irradiation. Symbols represent means \pm SEM $(\mathrm{n}=3)$. Statistically significant differences between control and UV-C treated embryos in week 3 are indicated with asterisks (one-way ANOVA with Bonferroni multiple comparison test; $\left.{ }^{* * *}, \mathrm{p}<0.001\right)$. 


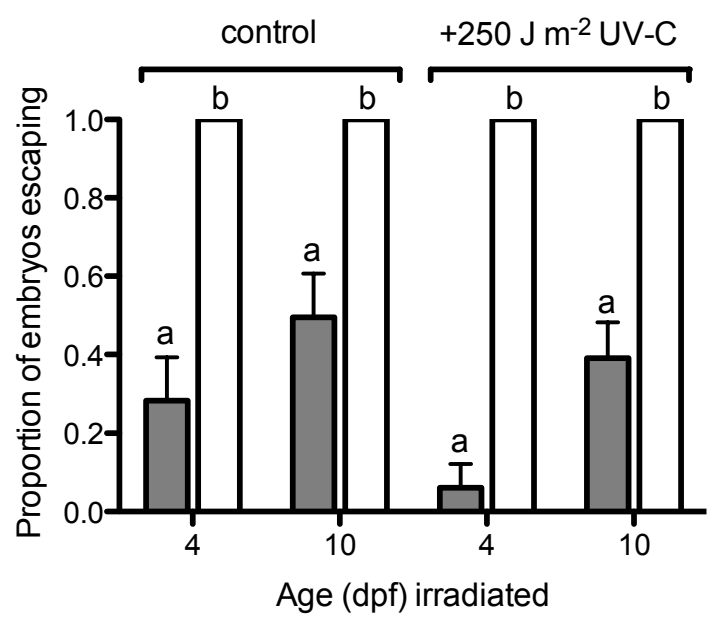

Figure 2.6. Proportion of embryos irradiated at 4 and $10 \mathrm{dpf}$ that were identified as escape embryos by $21 \mathrm{dpf}$. Dark bars represent embryos allowed to recover in the dark, while white bars represent those allowed to recover in the light. Escape embryos were distuinguished from embryos entering diapause II as described in the main text. Bars are means \pm SEM ( $n=$ 3). Bars with different letters are statistically different (two-way ANOVA, p < 0.05). 

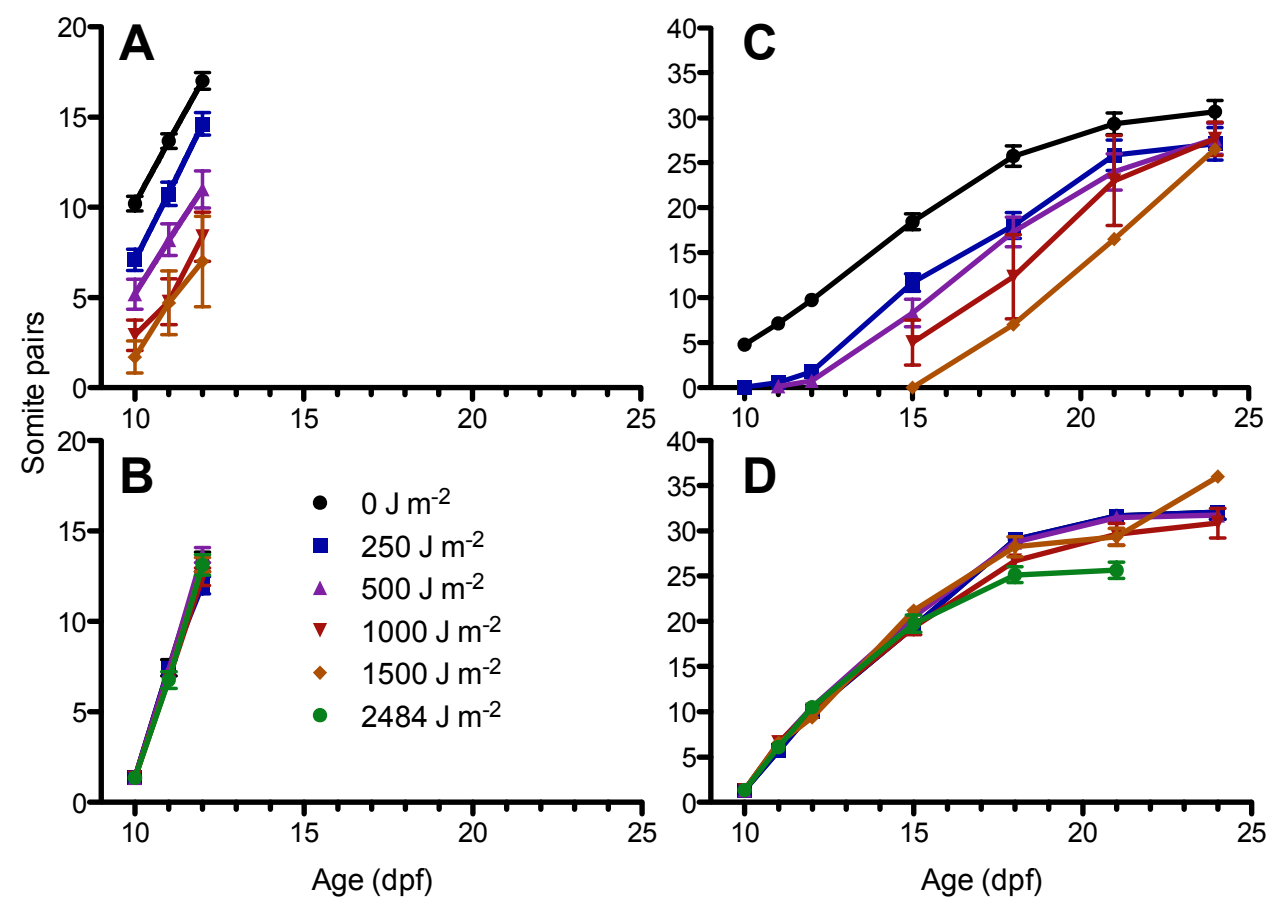

Figure 2.7. Rates of somitogenesis in embryos UV-C irradiated at 4 or $10 \mathrm{dpf}$ and allowed to recover in constant light $(\mathbf{A}, \mathbf{B})$ or dark (C, D). Somite pairs were counted using an inverted microscope. Abnormal or dead embryos were excluded from this data set. Development is significantly delayed in embryos exposed to UV-C at $4 \mathrm{dpf}$ (see text for statistical comparisons). Symbols represent means \pm SEM. 

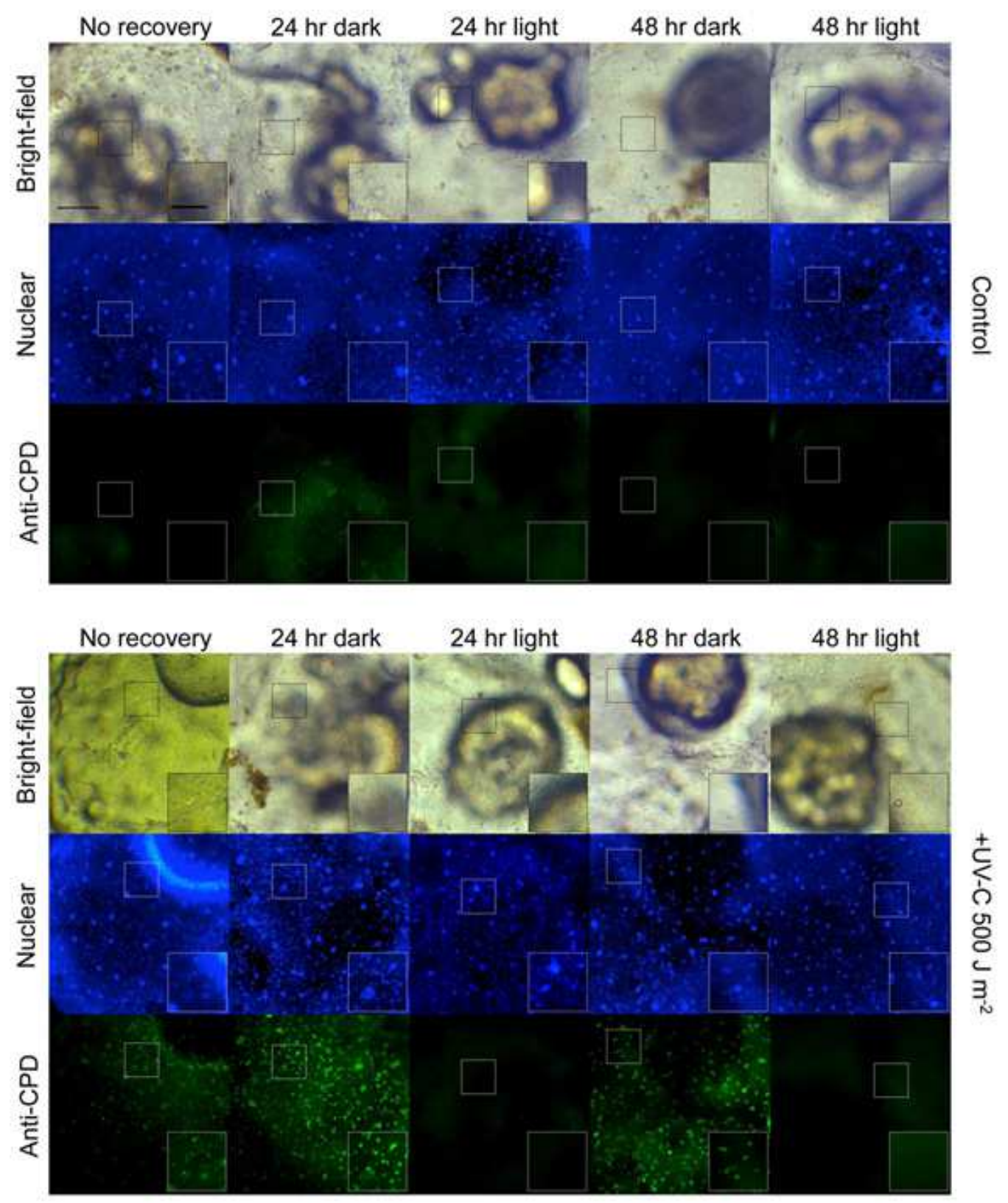

Figure 2.8. Representative photomicrographs of CPDs in whole-mount preparations of $4 \mathrm{dpf}$ UV-C irradiated embryos. Following UV-C irradiation, embryos were stained with an anti-CPD primary antibody and fluorescent secondary antibody after $0 \mathrm{hr}, 24 \mathrm{hr}$, or $48 \mathrm{hr}$ recovery in light or dark. Embryos UV-C irradiated at $4 \mathrm{dpf}$ with a dose of $500 \mathrm{~J} \mathrm{~m}^{-2}$ showed CPDpositive staining immediately after exposure, and after 24 or $48 \mathrm{hr}$ of recovery in the dark. All other treatments did not have CPD-positive staining. Scale bars are $200 \mu \mathrm{m}$ for larger pictures and $100 \mu \mathrm{m}$ for insets. 

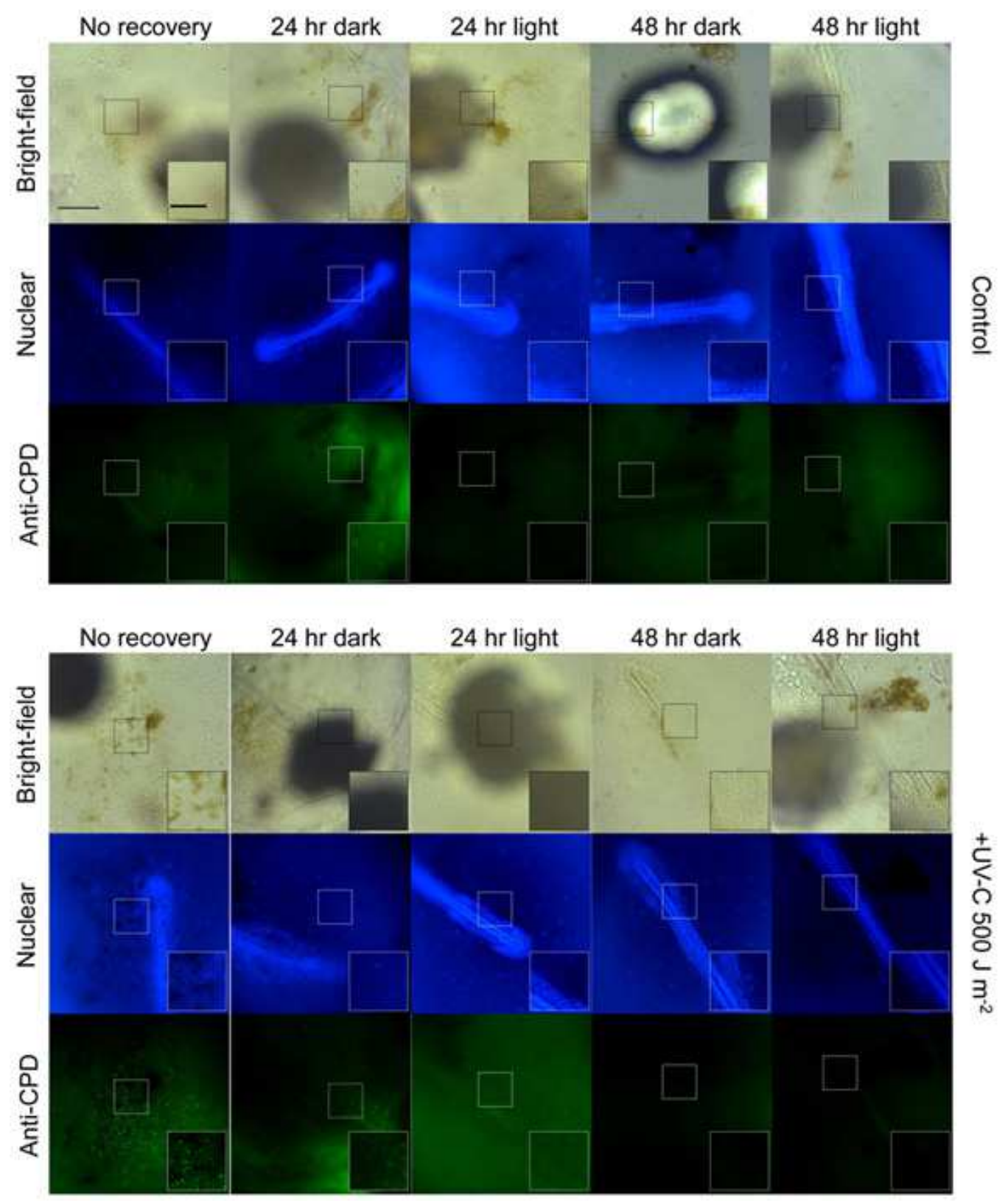

Figure 2.9. Representative photomicrographs of CPDs in whole-mount preparations of $10 \mathrm{dpf}$ UV-C irradiated embryos. Following UV-C irradiation, embryos were stained with an anti-CPD primary antibody and fluorescent secondary antibody after $0 \mathrm{hr}, 24 \mathrm{hr}$, or $48 \mathrm{hr}$ recovery in light or dark. Embryos UV-C irradiated at $10 \mathrm{dpf}$ with a dose of $500 \mathrm{~J} \mathrm{~m}^{-2}$ showed CPDpositive staining immediately after exposure, while only some of the embryos after 24 or $48 \mathrm{hr}$ of dark recovery showed CPD-positive staining. All other treatments did not have positive CPD staining. Scale bars are 200 $\mu \mathrm{m}$ for larger pictures and $100 \mu \mathrm{m}$ for insets. 

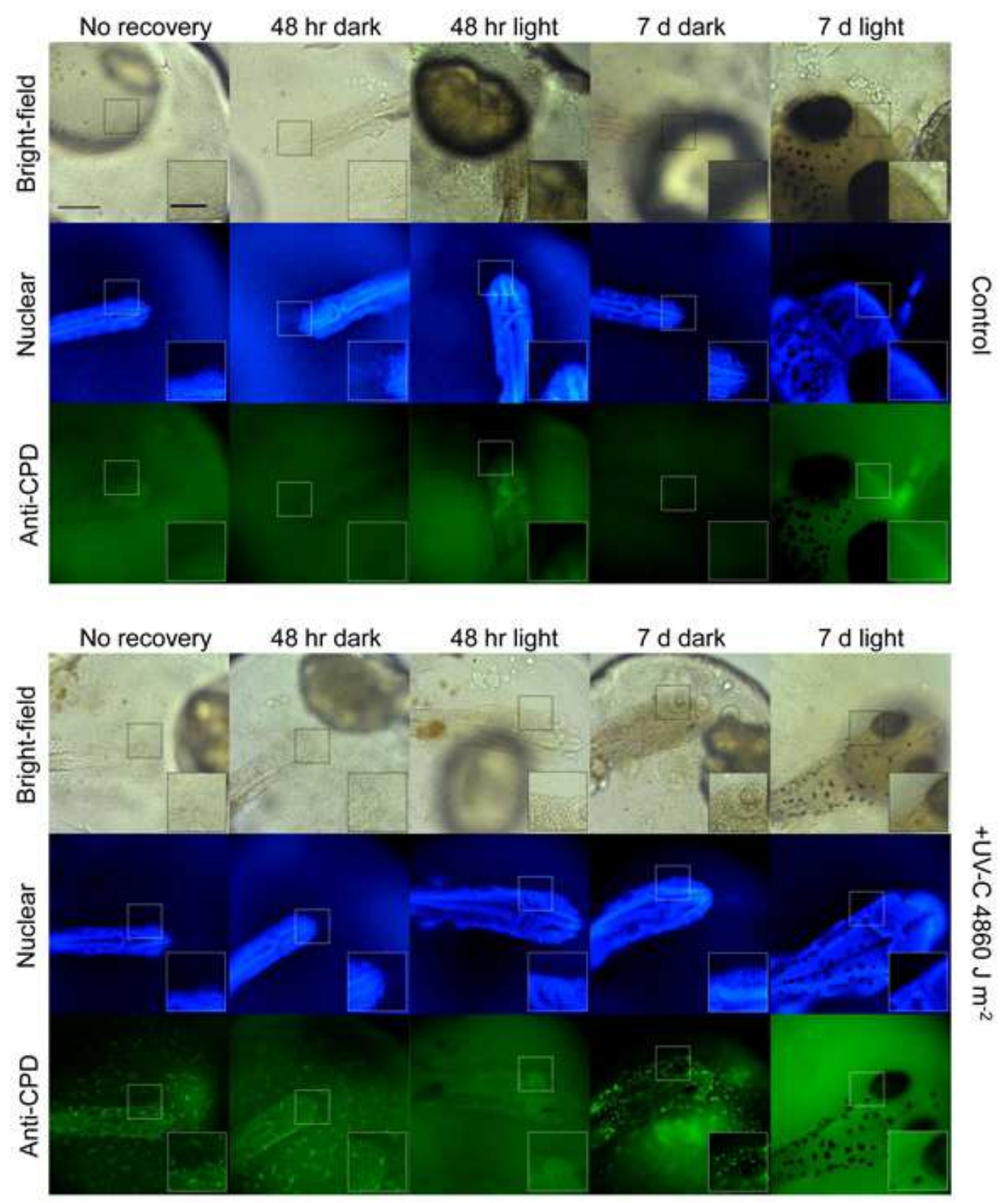

Figure 2.10. Representative photomicrographs of CPDs in whole-mount preparations of $32 \mathrm{dpf}$ UV-C irradiated embryos. Following UV-C irradiation, embryos were stained with an anti-CPD primary antibody and fluorescent secondary antibody after $0 \mathrm{hr}, 48 \mathrm{hr}$, or $7 \mathrm{~d}$ recovery in light or dark. Embryos irradiated at $32 \mathrm{dpf}$ showed CPD-positive staining immediately after exposure, as well as after $48 \mathrm{hr}$ and $7 \mathrm{~d}$ of recovery in the dark. All other treatments did not show CPD-positive stains. Scale bars are $200 \mu \mathrm{m}$ for larger pictures and $100 \mu \mathrm{m}$ for insets. 


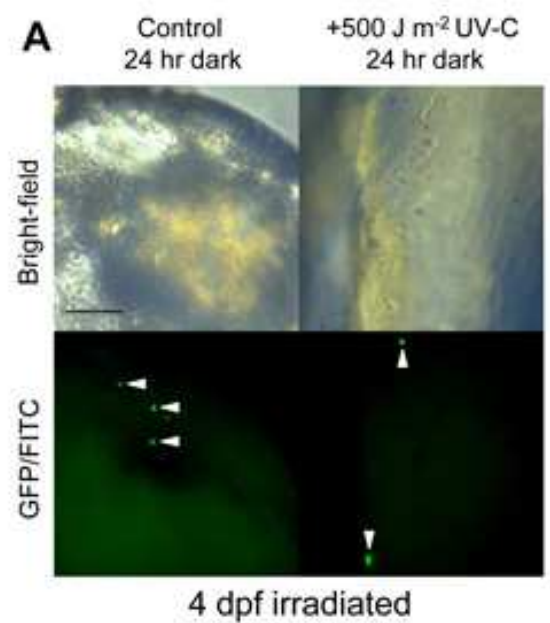

B

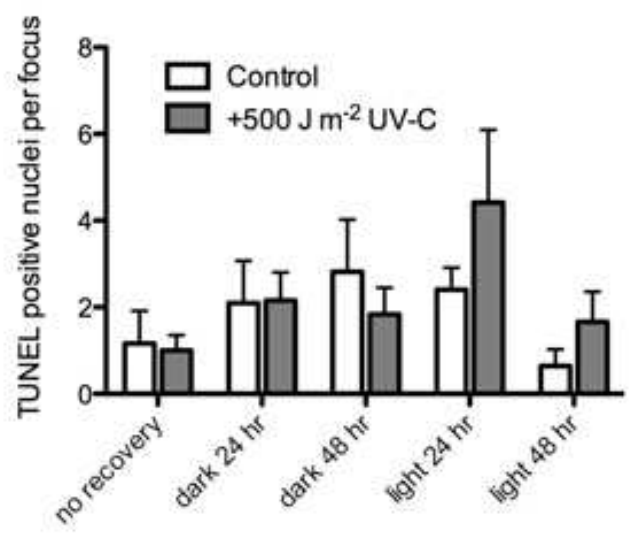

Figure 2.11. Representative photomicrographs and quantification of TUNEL staining in whole-mount $4 \mathrm{dpf}$ embryos after UV-C irradiation. Embryos were sampled after $0 \mathrm{hr}, 24 \mathrm{hr}$, or $48 \mathrm{hr}$ of recovery in light or dark following UV-C radiation exposure. Embryos were examined using an inverted fluorescent microscope for labeled nuclei that fluoresced using a GFP/FITC wavelength filter. (A) Average TUNEL positive nuclei per embryo in each treatment group (B). Representative positive staining nuclei are shown with white arrows (A). Scale bar is $100 \mu \mathrm{m}$. Bars represent means \pm SEM ( $\mathrm{n}=5$ 14 embryos per treatment group). 


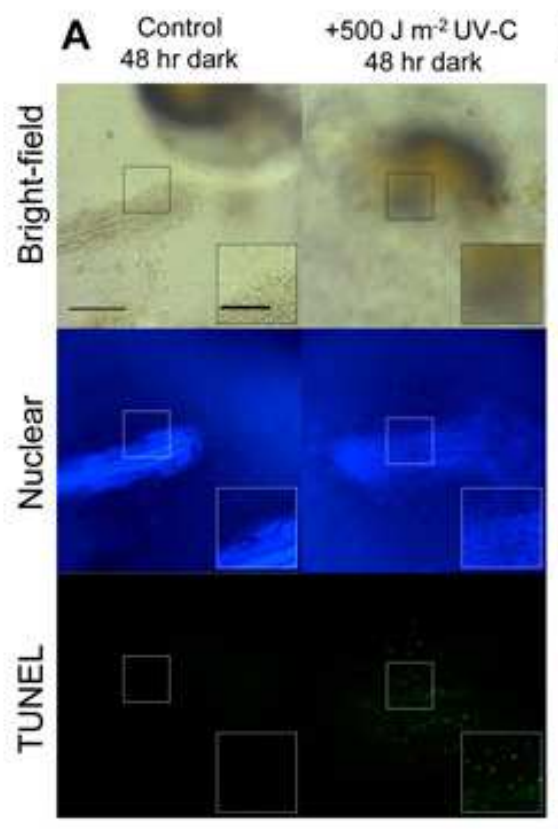

$10 \mathrm{dpf}$ irradiated

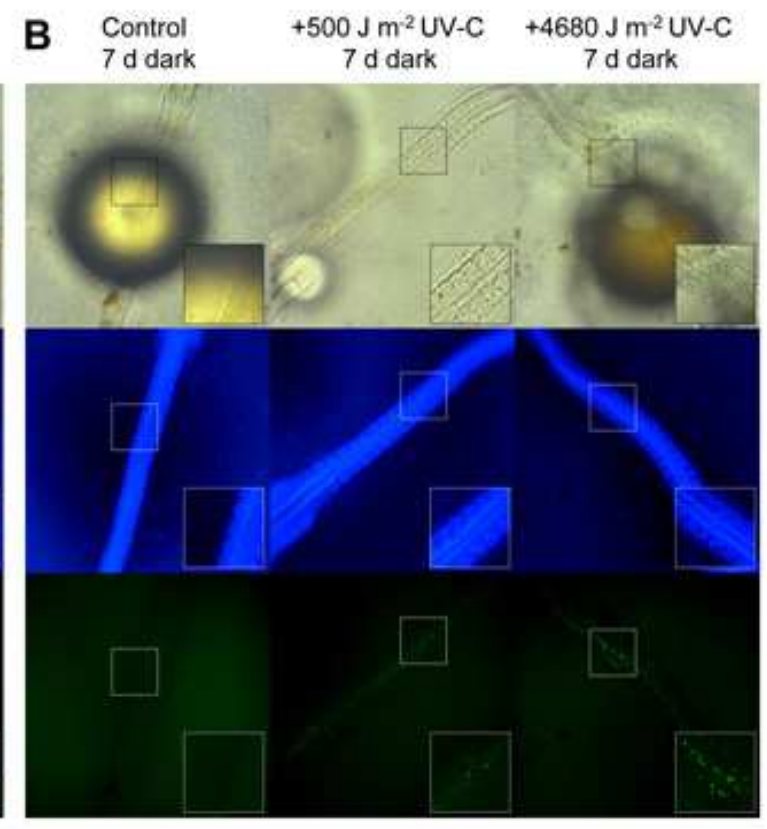

32 dpf irradiated

Figure 2.12. Representative photomicrographs of TUNEL staining in wholemount $10 \mathrm{dpf}(\mathbf{A})$ and $32 \mathrm{dpf}$ (B) embryos after UV-C irradiation. Some embryos irradiated at $10 \mathrm{dpf}$ exhibited positive TUNEL staining after $48 \mathrm{hr}$ of dark recovery (A, bottom right). Embryos were examined using an inverted fluorescent microscope for labeled nuclei that fluoresced using a GFP/FITC wavelength filter. Some embryos irradiated at $32 \mathrm{dpf}$ also stained positive for TUNEL after recovery in the dark (B, bottom center and bottom right), although most $32 \mathrm{dpf}$ irradiated embryos did not show positive TUNEL staining. The positive TUNEL staining nuclei appeared to be centered mostly within the body of the embryo for embryos irradiated at $32 \mathrm{dpf}$, while TUNEL positive nuclei were more dispersed for embryos irradiated at $10 \mathrm{dpf}$. 


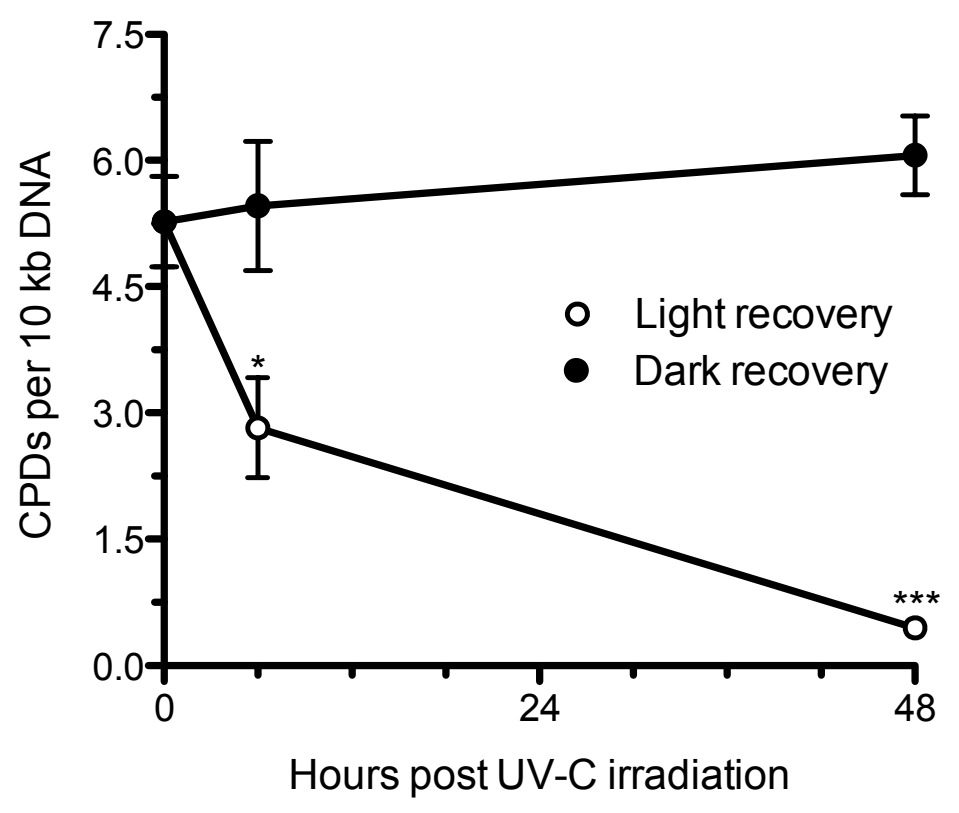

Figure 2.13. Quantification of CPDs over time in DII embryos irradiated with $4680 \mathrm{~J} \mathrm{~m}^{-2}$ of UV-C radiation as determined by CPD ELISA. Following UV-C radiation exposure, total DNA was extracted from embryos and this total DNA was used as input for the CPD ELISA. A standard curve was generated using a plasmid standard as described in Figure 2.1 to determine the average number of CPDs per $10 \mathrm{~kb}$. Embryos irradiated at DII did not show significant removal of CPDs after $6 \mathrm{hr}$ or $48 \mathrm{hr}$ of recovery in darkness. However, there was a significant decrease in CPDs after $6 \mathrm{hr}$ and $48 \mathrm{hr}$ of recovery in light. Statistically significant differences between embryos sampled immediately after UV-C irradiation and those allowed to recover in dark or light are indicated with asterisks (one-way ANOVA with Dunnett's multiple comparison test; ${ }^{*}, \mathrm{p}<0.01{ }^{* * *}, \mathrm{p}<0.001$ ). DNA from control DII embryos did not show a signal above wells that did not contain DNA. Bars represent means \pm SEM $(n=3)$. 


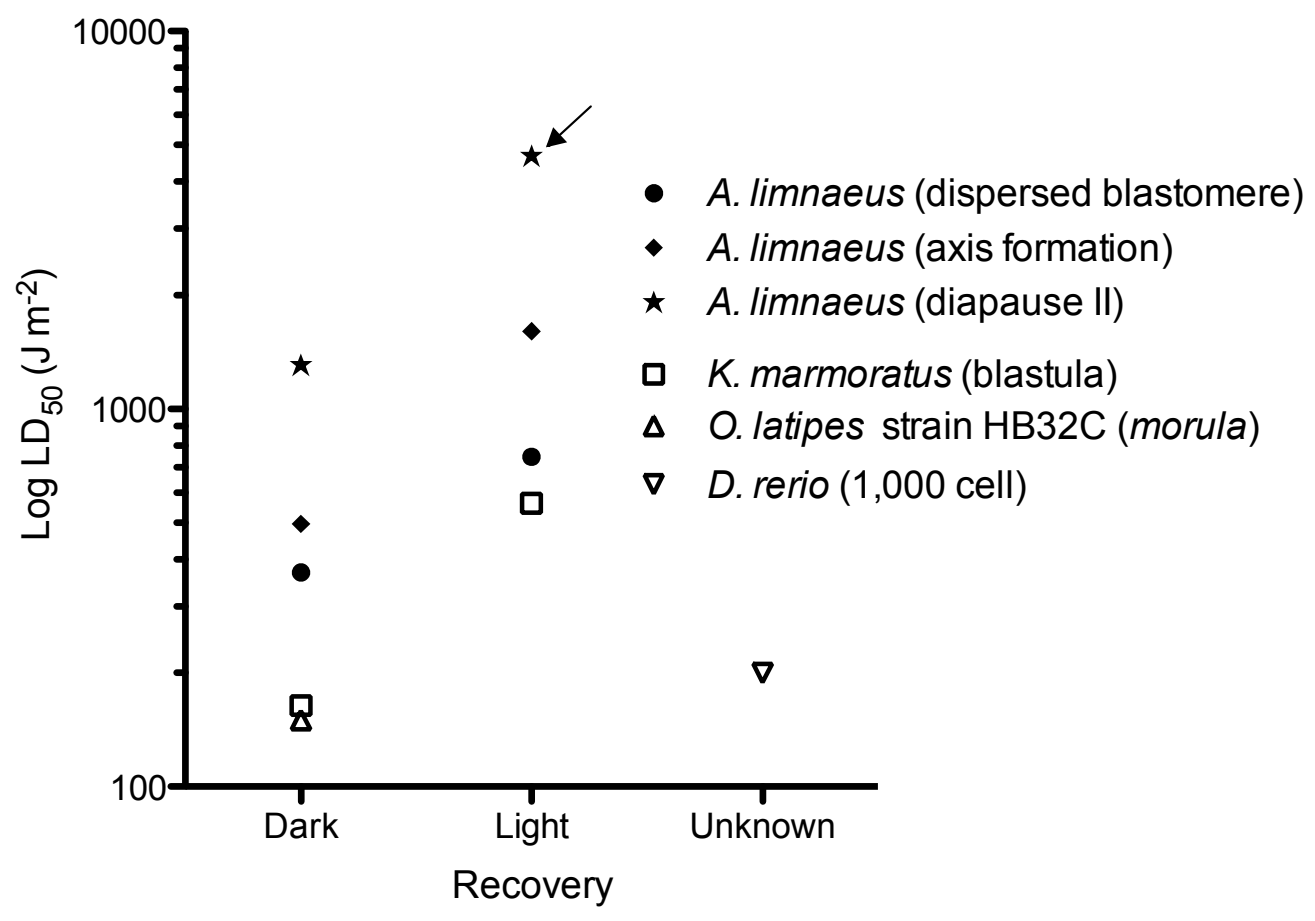

Figure 2.14. Comparison of LD50 values (UV-C, $254 \mathrm{~nm}$ ) between A. limnaeus embryos and embryos from other fish species. Developmental stages of embryos at time of irradiation are indicated in parenthesis. See text for references. Because A. limnaeus embryos irradiated at $32 \mathrm{dpf}$ and allowed to recover in the light (arrow) did not reach 50\% mortality at the maximum dose, the data presented here for comparison purposes is for $60 \%$ survival and thus is likely an under-estimate of the true LD50. 


\begin{tabular}{l|l}
\hline UV-C dose $^{\mathrm{a}}$ & Age of Exposed Embryos $^{\mathrm{b}}$ \\
\hline 0 & $4^{*}, 10^{*}, 32^{*}$ \\
250 & 4,10 \\
500 & $4^{*}, 10^{*}, 32^{*}$ \\
1000 & $4,10,32$ \\
1512 & $4,10,32$ \\
2484 & $4,10,32$ \\
3240 & 32 \\
4680 & 32 \\
\hline
\end{tabular}

Table 2.1. Embryonic stages and dosages of UV-C exposures. A. limnaeus embryos were staged and exposed to UV-C radiation (254 $\mathrm{nm}$ ) at specific doses. Embryos were observed for developmental defects, collected for whole-mount staining of CPDs, or collected for whole-mount TUNEL assays. a, UV-C dose in $\mathrm{J} \mathrm{m}^{-2}$

b, Age in days post-fertilization (dpf)

* = stages that were sampled for whole-mount staining for CPD dimers and TUNEL 


\begin{tabular}{l|ccc|ccc|c}
\hline Recovery & \multicolumn{3}{|c|}{ Control } & \multicolumn{3}{c|}{$500 \mathrm{~J} \mathrm{~m}^{-2}$} & $4860 \mathrm{~J} \mathrm{~m}^{-2}$ \\
& $\begin{array}{c}4 \\
\text { dpfa }\end{array}$ & $\begin{array}{c}10 \\
\mathrm{dpf}\end{array}$ & $\begin{array}{c}32 \\
\mathrm{dpf}\end{array}$ & $4 \mathrm{dpf}$ & $10 \mathrm{dpf}$ & $\begin{array}{c}32 \\
\mathrm{dpf}\end{array}$ & $32 \mathrm{dpf}$ \\
\hline $\begin{array}{l}\text { No } \\
\text { Recovery }\end{array}$ & $0 / 9^{\mathrm{b}}$ & $0 / 4$ & $0 / 5$ & $\mathbf{5 / 5}$ & $\mathbf{4 / 4}$ & $\mathbf{3 / 5}$ & $\mathbf{8 / 8}$ \\
\hline 24h dark & $0 / 5$ & $0 / 3$ & - & $\mathbf{5 / 5}$ & $\mathbf{3 / 5}$ & - & - \\
24h light & $0 / 5$ & $0 / 3$ & - & $0 / 5$ & $0 / 4$ & - & - \\
\hline 48h dark & $0 / 5$ & $0 / 3$ & $0 / 3$ & $\mathbf{5 / 5}$ & $\mathbf{1 / 3}$ & $\mathbf{2 / 3}$ & $\mathbf{4 / 4}$ \\
48h light & $0 / 5$ & $0 / 3$ & $0 / 5$ & $0 / 5$ & $0 / 5$ & $0 / 3$ & $0 / 5$ \\
\hline 7d dark & - & - & $0 / 8$ & - & - & $\mathbf{3 / 3}$ & $\mathbf{6 / 6}$ \\
7d light & - & - & $0 / 6$ & - & - & $0 / 6$ & $\mathbf{1 / 4}$ \\
\hline
\end{tabular}

Table 2.2. Summary counts of UV-C irradiated embryos with CPD-positive nuclei. DNA damage in embryos was visualized using whole-mount staining with an anti-CPD antibody.

a. dpf, days post-fertilization.

b. number of embryos with CPD-positive nuclei/total number of embryos observed. Groups with CPD positive stains are indicated in bold. 


\begin{tabular}{|c|c|c|c|c|c|c|c|}
\hline \multirow[t]{2}{*}{ Recovery } & \multicolumn{3}{|c|}{ Control } & \multicolumn{3}{|c|}{$500 \mathrm{~J} \mathrm{~m}^{-2}$} & \multirow{2}{*}{$\begin{array}{c}4860 \mathrm{~J} \mathrm{~m}^{-2} \\
32 \mathrm{dpf}\end{array}$} \\
\hline & $4 \mathrm{dpf}^{\mathrm{a}}$ & $\begin{array}{c}10 \\
\mathrm{dpf}\end{array}$ & $\begin{array}{c}32 \\
\mathrm{dpf}\end{array}$ & $4 \mathrm{dpf}$ & $\begin{array}{l}10 \\
\mathrm{dp}\end{array}$ & $\begin{array}{c}32 \\
\mathrm{dpf}\end{array}$ & \\
\hline $\begin{array}{l}\text { No } \\
\text { Recovery }\end{array}$ & $2 / 6^{b}$ & $0 / 4$ & $0 / 5$ & $6 / 13$ & $0 / 6$ & $0 / 7$ & $0 / 7$ \\
\hline $\begin{array}{l}\text { 24h dark } \\
24 \text { h light }\end{array}$ & $\begin{array}{c}7 / 10 \\
5 / 5\end{array}$ & $\begin{array}{l}0 / 4 \\
0 / 3\end{array}$ & - & $\begin{array}{l}9 / 13 \\
8 / 12 \\
\end{array}$ & $\begin{array}{l}3 / 4 \\
3 / 5\end{array}$ & - & - \\
\hline $\begin{array}{l}\text { 48h dark } \\
48 \text { h light }\end{array}$ & $\begin{array}{l}5 / 11 \\
1 / 11 \\
\end{array}$ & $\begin{array}{l}0 / 4 \\
0 / 6 \\
\end{array}$ & $\begin{array}{l}0 / 6 \\
0 / 6 \\
\end{array}$ & $\begin{array}{c}6 / 12 \\
5 / 9 \\
\end{array}$ & $\begin{array}{l}3 / 3 \\
0 / 8 \\
\end{array}$ & $\begin{array}{l}1 / 5 \\
0 / 5 \\
\end{array}$ & $\begin{array}{l}0 / 5 \\
0 / 7 \\
\end{array}$ \\
\hline $\begin{array}{l}\text { 7d dark } \\
7 \mathrm{~d} \text { light }\end{array}$ & - & - & $\begin{array}{l}0 / 5 \\
0 / 6\end{array}$ & - & - & $\begin{array}{l}0 / 6 \\
0 / 8\end{array}$ & $\begin{array}{l}2 / 6 \\
0 / 5\end{array}$ \\
\hline
\end{tabular}

Table 2.3. Summary counts of UV-C irradiated embryos with TUNELpositive nuclei. Positive TUNEL staining is indicative of apoptotic cells. a. dpf, days post-fertilization

b. number of embryos with TUNEL-positive nuclei/total number of embryos observed. Groups with TUNEL positive stains are indicated in bold. 


\section{CHAPTER 3:}

\section{Gene expression patterns and developmental stress buffering}

This chapter has been previously published:

Wagner, J. T. and Podrabsky, J. E. (2015). Gene expression patterns that support novel developmental stress buffering in embryos of the annual killifish Austrofundulus limnaeus. EvoDevo 6.

\section{Introduction}

The general course of early embryonic development is remarkably conserved between vertebrates, with developmental progression always following the same order: fertilization, cleavage, epiboly, gastrulation, axis formation, and organogenesis. Many of the morphogenic movements associated with these processes, such as gastrulation, are also conserved (Solnica-Krezel, 2005). Barring developmental abnormalities or environmental insult, these stages typically progress in a unidirectional manner and without interruption. However, this is not the case in annual killifish development, which is characterized by a temporal separation of the morphogenic movements of epiboly from formation of the embryonic axis, and is often discontinuous due to naturally occurring periods of arrested development (Wourms, 1972a; Wourms 1972b, Wourms 1972c). In this 
study I explore the temporal expression patterns of genes known to play key roles in the maintenance of pluripotency and the establishment of the vertebrate body plan during early development in embryos of the annual killifish Austrofundulus limnaeus.

\section{Austrofundulus limnaeus (Order Cyprinodontiformes, Family}

Rivulidae) is an annual killifish found in ephemeral ponds of the Maracaibo Basin in northern Venezuela (Hrbek et al., 2005; Podrabsky et al., 1998). Similar to other species of annual killifish, A. limnaeus maintains permanent populations by the production of drought- and anoxia-tolerant embryos (Podrabsky et al., 2001; Podrabsky et al., 2007; Podrabsky et al., 2012b) that are able to survive in the pond sediments after adult and juvenile fish are killed by habitat desiccation (Myers, 1952; Wourms, 1972a; Wourms, 1972c). Tolernce of the environmental stresses imposed by their ephemeral environment is supported by the ability of the embryos to enter into a state of metabolic and developmental dormancy, termed diapause, at up to three distinct developmental stages (Wourms, 1972a; Wourms 1972b; Wourms 1972c). Diapause I (DI) may occur in some species of annual killifish during the dispersed blastomere stage prior to formation of an embryonic axis (Genade et al., 2005), although I do not regularly observe arrest at DI in our lab population of A. limnaeus. Diapause II (DII) can occur midway through development in an embryo that has undergone neurulation and segmentation, but is just prior to initiation of the major phases of 
organogenesis (Podrabsky and Hand, 1999; Wourms, 1972c). Diapause III (DIII) can occur in the late pre-hatching embryo. Diapause II embryos display the highest resistance to abiotic stressors such as anoxia, salinity extremes, and desiccation when compared to other developmental stages (Machado and Podrabsky, 2007; Podrabsky et al., 2001; Podrabsky et al., 2007).

In addition to the interruption of development by diapause, both the African and South American clades of annual killifish lack formation of a germ-ring or shield structure during epiboly (Wourms, 1972a; Wourms, 1972b), which is atypical when compared to other described teleost fish species such as zebrafish (Danio rerio), the medaka (Oryzias latipes), and the mummichog (Fundulus heteroclitus) (Armstrong and Child, 1965; Iwamatsu, 2004; Kimmel et al., 1995) as well as other non-annual killifish in the family Rivulidae such as Kryptolebias marmoratus (Mourabit et al., 2011). Instead of the typical pattern of convergence and extension of the amoeboid (deep) embryonic blastomeres that is observed in most other teleost embryos during epiboly, deep blastomeres from annual killifish exhibit contact inhibition of cell movement and migrate away from each other across the yolk surface during epiboly where they remain dispersed across the yolk surface for several days ( Wourms, 1972b; Lesseps et al., 1979a; Lesseps et al., 1979b). These dispersed blastomeres later reaggregate, presumably through a delayed process of convergence and extension to form the definitive embryonic axis (Wourms, 1972b). Although this dispersion and 
subsequent reaggregation process $(\mathrm{D} / \mathrm{R})$ was described several decades ago by Wourms (Wourms, 1972b), the molecular mechanisms that control these movements remains unexplored and the environmental and ecological relevance of this process have only recently been investigated (Berois et al., 2012; Wagner and Podrabsky, 2015a).

Underlying the gross morphological changes associated with embryogenesis are expression of inter- and intracellular signaling factors that encode for cellular identity and differentiation (Tam and Loebel, 2007). As developmental time progresses, embryos generally decrease expression of pluripotency genes in favor of genes that promote differentiation. In mammals, one of the most important factors required to maintain pluripotency in vitro is the co-expression of transcription factors oct4 (also known as Pou5f1) and a member of the SOXB1 family, sox2 (Masui et al., 2007; Yu et al., 2007). The transcription factor sox3, also a part of the SOXB1 family, likely precedes expression of sox2 during embryonic development and may have both unique and redundant functions with sox2 depending on the species studied (Kamachi et al., 1998; Rogers et al., 2009; Wood and Episkopou, 1999). Homologous genes to mammalian oct4, sox2, and sox3 have been described in the zebrafish (Okuda et al., 2006; Reim and Brand, 2006; Takeda et al., 1994), and more recently in the medaka (Cui et al., 2011; Wang et al., 2011). Forming a complex with oct4, SOXB1 family transcription factors have a diverse array of targets during early fish development that are 
likely critical for normal developmental timing (Onichtchouk et al., 2010).

Whether annual killifish such as A. limnaeus express these pluripotencypromoting genes in a manner similar to other vertebrates is currently unknown. More importantly, the signaling mechanisms by which annual killifish embryos are able to transition from an undifferentiated blastula through a period of blastomere $\mathrm{D} / \mathrm{R}$ prior to the formation of the embryo proper remain unexplored.

One of the most important periods of cellular differentiation in embryogenesis occurs during the process of axis formation, which follows the induction of gastrulation and establishes the organismal body plan. Diffusible signaling factors secreted by the Spemann-Mangold Organizer (SMO), a structure first described in 1924 (Hamburger, 1988), have an important role in establishing asymmetry in early vertebrate embryos (De Robertis et al., 2000). In particular, correct dorsal-ventral (DV) patterning requires signaling gradients of bone morphogenic proteins (BMPs) and activin created by the expression of signaling antagonists by the SMO. The three major contributors to DV patterning through BMP inhibition are noggin, chordin, and follistatin. Chordin (Piccolo et al., 1996; Sasai et al., 1994) and noggin (Smith and Harland, 1992) are potent BMP antagonists, while follistatin (Hemmati-Brivanlou et al., 1994; Iemura et al., 1998) antagonizes both BMPs and activin. Since the initial characterization of noggin, several noggins have been described (Eroshkin et al., 2006; 
Fürthauer et al., 1999). The requirement of noggin and chordin expression by the SMO to dorsalize embryos appears to be conserved between amphibians and fish, although follistatin appears be excluded from fish organizers (Bauer et al., 1998; Dal-Pra et al., 2006; Schulte-Merker et al., 1997).

It is currently unknown how blastomere $\mathrm{D} / \mathrm{R}$ and the entrance into diapause II is regulated at the molecular level in A. limnaeus embryos. Additionally, the changes in expression of important developmental factors that are required to support the differences observed in early annual killifish development when compared to other teleosts are unclear. Although there are no morphological indications of embryonic patterning during epiboly in A. limnaeus, it has yet to be shown that cellular determination and differentiation does not occur during this period. Therefore, two major hypotheses for axis formation in annual killifish are: (1) cellular determination and differentiation occurs during epiboly, similar to other teleosts, and differentiated cells reaggregate later and segregate into germ layers to form an embryonic axis or (2), cellular differentiation and therefore embryonic patterning does not occur until after reaggregation. The dynamic spatiotemporal expression patterns and cross-species conservation of oct4, sox2, sox3, chordin, noggin, and follistatin make these genes ideal candidates for characterization of pluripotency and axis formation in annual killifish.

Recently, I have reported that the D/R phases of development may act to buffer developing embryos from what would otherwise be teratogenic 
environmental insults (Wagner and Podrabsky 2015a). The molecular mechanisms that support this unique buffering capacity remain to be resolved. If dispersed cells lack a unique cellular identity and location within the embryo, then cells lost or damaged during the D/R phase could presumably be replaced without negative consequences to the developmental program. This study describes for the first time the relative mRNA expression levels of genes critical for the maintenance of pluripotency and establishment of the embryonic axis across development in A. limnaeus, with the goal of comparing their patterns of expression to the highly conserved patterns noted in other vertebrates. The gene expression patterns reported here in A. limnaeus support a role for an extended period of pluripotency during the D/R phases of annual killifish development. This unique developmental pattern coupled with earlier reports of tolerance to cellular damage suggests that $\mathrm{D} / \mathrm{R}$ can act as a buffering mechanism that supports normal embryonic development in the face of what would otherwise be teratogenic levels of cell damage and/or cell death due to environmental stress (Wagner and Podrabsky 2015a).

\section{Methods}

Husbandry of adults and treatment of embryos

Adult and embryonic Austrofundulus limnaeus were cared for as previously described by Podrabsky (Podrabsky, 1999) and in accordance 
with approved Portland State University IACUC protocols. Mating pairs of fish were allowed access to spawning trays containing 1-2 cm of $500 \mu \mathrm{m}$ glass beads (Thomas Scientific, Swedesboro, USA) for $2 \mathrm{hr}$. Embryos were collected by sifting the glass beads through a $1.5 \mathrm{~mm}$ mesh and were transferred into embryo medium using a wide-mouthed plastic pipette. Fertilization was determined by the presence of a perivitelline space using a dissecting scope. Embryos were kept in embryo medium similar to the ionic composition of their native ponds $\left(10 \mathrm{mmol} 1^{-1} \mathrm{NaCl}, 2.14 \mathrm{mmol}^{1-1} \mathrm{MgCl}_{2}\right.$, $0.8 \mathrm{mmol} \mathrm{l}^{-1} \mathrm{CaCl}_{2}, 0.14 \mathrm{mmol}^{-1} \mathrm{KCl}, 0.0013 \mathrm{mmol}^{-1} \mathrm{MgSO}_{4}$ ) with $0.0001 \%$ methylene blue added for the first 3 days post-fertilization (dpf) to suppress fungal growth (Podrabsky, 1999; Podrabsky et al., 1998). At 4 dpf, embryos were treated with two 5 min washes of a $0.001 \%$ solution of sodium hypochlorite in embryo medium and transferred to embryo medium containing $10 \mathrm{mg} \mathrm{l}^{-1}$ gentamicin sulfate. Embryos sampled earlier than $4 \mathrm{dpf}$ were treated with the bleaching regimen immediately before being flashfrozen as described below. Embryos were observed and embryo medium changed daily. Embryos were incubated at $25^{\circ} \mathrm{C}$ in darkness.

Purification of total RNA from whole embryos and adult livers

Embryos: Embryos were observed using a dissecting microscope and sorted by stage as shown in Table 3.1 and Figure 3.1. Staged embryos were collected onto a nylon mesh screen $(100 \mu \mathrm{m}$ mesh $)$, blotted dry with 
Kimwipes, transferred into $2 \mathrm{ml}$ microcentrifuge tubes, and flash-frozen by submergence in liquid nitrogen. Embryos were stored at $-80^{\circ} \mathrm{C}$ until RNA extraction.

Adult livers: Adult A. limnaeus females were euthanized by immersion in ice water for several minutes followed by cervical transection. Livers were removed, transferred into $2 \mathrm{ml}$ microcentrifuge tubes, flash-frozen in liquid nitrogen, and stored at $-80^{\circ} \mathrm{C}$ until RNA extraction.

RNA extraction: Frozen embryos were immersed in TRIzol reagent (Invitrogen \#15596-026) at a ratio of $50 \mu \mathrm{l}$ TRIzol reagent per embryo. Frozen adult livers were immersed in TRIzol reagent at a ratio of $100 \mathrm{mg}$ liver per ml of TRIzol. Immediately after addition of TRIzol, embryos or livers were homogenized using an IKA Ultra-Turrax T8 (Wilmington, NC) at room temperature until lysis was complete. Homogenates were subjected to centrifugation at $10,000 \mathrm{xg}$ for $30 \mathrm{~min}$ at $4^{\circ} \mathrm{C}$ to remove cellular debris. Supernatants were transferred into new tubes and $0.2 \mathrm{ml}$ of chloroform per $\mathrm{ml}$ of TRIzol was added. Samples were gently mixed by vortexing and subjected to centrifugation for $20 \mathrm{~min}$ at $10,000 \times \mathrm{g}$ at $4^{\circ} \mathrm{C}$. The clear aqueous phase was removed carefully and transferred into a fresh tube. RNA was precipitated using a high salt method by addition of equal volumes (1.25 $\mathrm{ml}$ of each per ml of TRIzol used) of a solution containing $0.8 \mathrm{M}$ sodium citrate and 1.2 M NaCl and 100\% isopropanol. Samples were vortexed gently and incubated at $-20^{\circ} \mathrm{C}$ overnight to precipitate the RNA. The following day, 
samples were subjected to centrifugation at $10,000 \times \mathrm{g}$ for $30 \mathrm{~min}$ at $4^{\circ} \mathrm{C}$. Supernatants were decanted carefully so as to not disturb the RNA pellet. The RNA pellet was washed with $1 \mathrm{ml}$ of $60 \%$ ethanol (EtOH) followed by centrifugation at $10,000 \mathrm{x} g$ for $30 \mathrm{~min}$ at $4^{\circ} \mathrm{C}$. Supernatants were decanted and the wash step repeated. After the final wash, EtOH was removed and the pellet was centrifuged at $10,000 \mathrm{x} g$ for $1 \mathrm{~min}$ at $4^{\circ} \mathrm{C}$ to collect residual EtOH. The residual EtOH was removed and remaining EtOH was allowed to evaporate for 10 - 15 min. RNA pellets were resuspended in $25-55 \mu \mathrm{l}$ of 1 $\mathrm{mM}$ sodium citrate (pH 6.4). Incubation of samples for $4-5 \mathrm{~min}$ at $55^{\circ} \mathrm{C}$ facilitated RNA pellet resuspension. Sample concentrations and $A_{260} / A_{280}$ ratios were determined using the Infinite M200 Pro plate reader equipped with a NanoQuant plate (Tecan, San Jose, CA) using $2 \mu \mathrm{l}$ of sample and default software settings (i-control software, Tecan). RNA integrity was determined by agarose gel electrophoresis of $0.5 \mu \mathrm{g}$ of total RNA and observing distinct banding for $18 \mathrm{~S}$ and $28 \mathrm{~S}$ rRNA subunits. Average $\mathrm{A}_{260} / \mathrm{A}_{280}$ ratios of 1.7-2.2 were routinely obtained with the exception of DII embryos, which had low ratios (mean $1.3 \pm 0.12 \mathrm{SD}$ ) but retained $18 \mathrm{~S}$ and $28 \mathrm{~S}$ rRNA banding after gel electrophoresis that was comparable to other stages. Samples were stored at $-80^{\circ} \mathrm{C}$ or used immediately as template for reverse transcription reactions.

Identification and PCR amplification of A. limnaeus RNA transcripts of interest 
Austrofundulus limnaeus sequences for genes of interest were amplified from total RNA by polymerase chain reaction (PCR). Total RNA was reverse transcribed using the RevertAid first strand cDNA synthesis kit (Fermentas \#K1621). Prior to addition of enzymes, RNA was mixed with primer, heated to $65^{\circ} \mathrm{C}$ for $5 \mathrm{~min}$, and chilled rapidly on ice. Reverse transcription (RT) reactions (20 $\mu$ l total volume) contained RNA (250-500 ng), $5 \mu \mathrm{M}$ anchored oligonucleotide dT primer (sequence: 5' TTT TTT TTT TTT TTT TTT TTV N 3'), 1 mM dNTP mix, 20 U RiboLock RNAse inhibitor, $200 \mathrm{U}$ of RevertAid M-MuLV reverse transcriptase, in 1X RevertAid reaction buffer (50 mM Tris-HCl pH 8.3, 50 mM KCl, 4 mM MgCl, 10 mM DTT). Reactions were incubated at $42^{\circ} \mathrm{C}$ for 60 min and were terminated by incubation at $70^{\circ} \mathrm{C}$ for $5 \mathrm{~min}$. The single-stranded cDNA was used immediately for PCR or was stored at $-20^{\circ} \mathrm{C}$.

Prior to PCR amplification, remaining RNA from the RT reaction was degraded by incubation at $65^{\circ} \mathrm{C}$ for $15 \mathrm{~min}$ in $200 \mathrm{mM} \mathrm{NaOH}$ and $100 \mathrm{mM}$ EDTA. Following RNA degradation, $\mathrm{pH}$ was neutralized by addition of $1 \mathrm{M}$ Tris $(\mathrm{pH}=7.5)$ to a final concentration of $20 \mathrm{mM}$. The ssDNA samples were purified using the QIAquick PCR purification kit (Qiagen \#28104) according to the manufacturer's instructions and were eluted in $30 \mu \mathrm{l}$ of nuclease-free $\mathrm{dH}_{2} \mathrm{O}$. RNA transcript sequences for genes of interest from other vertebrates (Table 3.2) were identified using NCBI GenBank database searches. Degenerate or specific primers were used depending on sequence 
conservation between species and were created using PrimaClade online software (Gadberry et al., 2005). The PCR parameters were adjusted according to specific primer pairs, and often one or more parameter had to be adjusted in order to cleanly amplify a particular gene of interest. In general, 1 - $5 \mu \mathrm{l}$ of purified cDNA, $5-10$ pmol of both forward and reverse gene-specific primer (Integrated DNA Technologies), $0.125 \mathrm{U}$ Taq polymerase (New England BioLabs \#M0267L), and $2.5 \mu \mathrm{l}$ 10X ThermoPol buffer (New England BioLabs \# M0267L) were used per $25 \mu$ l reaction. Reactions were cycled for 37-46 cycles with varying melting, annealing, and extension temperatures (Table 3.2).

Cloning and sequencing of genes

Creation of plasmids with cDNA fragments and growth of transformed bacterial cell cultures were performed based on the methods of Sambrook et al. (Sambrook et al., 1989). DNA templates generated during PCR were analyzed by gel electrophoresis through a $1.5 \%$ agarose gel in $0.5 \mathrm{X}$ TBE for $30-45$ min at 100 V. Fragment sizes were estimated by comparison to a GeneRuler 1kb Plus DNA ladder (Thermo Scientific \#SM1332). DNA fragments that were in the range of expected PCR product size were excised with a razor and purified using the QIAquick MinElute gel extraction kit (Qiagen \#28606) according to manufacturer's instructions. DNA was eluted in $10 \mu \mathrm{l}$ of nuclease-free water and stored at $-20^{\circ} \mathrm{C}$ or used immediately for 
cloning. Purified PCR products were cloned into the pGEM-T Easy Vector System (Promega \#A1360). For each $10 \mu$ cloning reaction, $50 \mathrm{ng}$ of pGEM-T Easy Vector was mixed with $3 \mu$ of purified PCR product and 3 Weiss units of T4 DNA ligase in $1 \mathrm{X}$ rapid ligation buffer. Samples were mixed and incubated overnight at $4^{\circ} \mathrm{C}$. The next day, $2 \mu \mathrm{l}$ of each ligation reaction was added to 20 - $30 \mu \mathrm{l}$ of competent Escherichia coli cells (Strain JM109, Promega \#L2001,

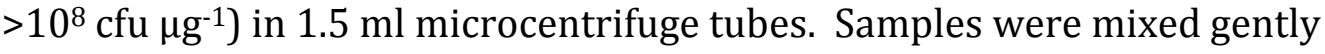
and incubated on ice for $20 \mathrm{~min}$. Cells were transformed by heat shock for 50 sec in a $42^{\circ} \mathrm{C}$ water bath and were immediately returned to ice for $2 \mathrm{~min}$. SOC medium (2\% Bacto-tryptone, 0.5\% yeast extract, $10 \mathrm{mM} \mathrm{NaCl}, 0.5 \mathrm{mM}$ $\mathrm{KCl}, 10 \mathrm{mM} \mathrm{MgCl}_{2}, 10 \mathrm{mM}, \mathrm{MgSO}_{4}, 20 \mathrm{mM}$ glucose) was added to each tube of cells (19 $\mu \mathrm{l}$ SOC medium per $1 \mu \mathrm{l}$ of cells) and cells were transferred to sterile $15 \mathrm{ml}$ polypropylene round-bottom culture tubes. Cells were incubated for $1.5 \mathrm{hr}$ at $37^{\circ} \mathrm{C}$ while shaking (150 rpm). Following incubation, $40-60 \mu \mathrm{l}$ of the SOC cultures were plated onto agar screening plates (1.5\% Bacto-agar, 1\% Bacto-tryptone, $42.8 \mathrm{mM} \mathrm{NaCl}, 33.5 \mathrm{mM} \mathrm{KCl}, 1 \mathrm{mM} \mathrm{CaCl} 20.02 \mathrm{mg} \mathrm{ml}^{-1} \mathrm{X}-$ Gal, $0.014 \mathrm{mg} \mathrm{ml}^{-1} \mathrm{IPTG}, 0.1 \mathrm{mg} \mathrm{ml}^{-1}$ ampicillin sodium salt). Plates were incubated overnight at $37^{\circ} \mathrm{C}$. White colonies were selected using a sterile toothpick and used to inoculate $1 \mathrm{ml}$ of lysogeny broth (1\% Bacto-tryptone,

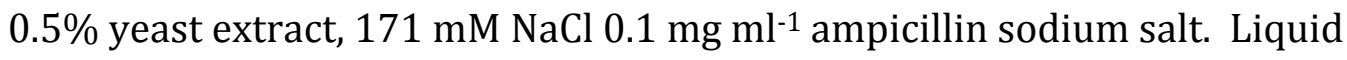
cultures were incubated overnight at $37^{\circ} \mathrm{C}$ while shaking $(200 \mathrm{rpm})$. The following day, cultures were subjected to centrifugation at 7,000 $\mathrm{x} g$ for 3 
min at room temperature to pellet cells. Plasmids were purified from the cell pellet using the QIAprep Spin Miniprep Kit (Qiagen, \#27104) according to manufacturer's instructions and were eluted in $30 \mu \mathrm{l}$ of nuclease-free water. Plasmid quantity was determined by measuring sample absorbance at 260 $\mathrm{nm}$ and quality was determined by the observation of $\mathrm{A}_{260} / \mathrm{A}_{280}$ ratios between 1.8-2.0. Purified plasmids were diluted with nuclease-free water and $500 \mathrm{ng}$ of plasmid template was mixed with $6.4 \mathrm{pmol}$ of pUC/M13 reverse primer (sequence 5'-TCA CAC AGG AAA CAG CTA TGA C-3') in final volumes of $20 \mu \mathrm{l}$. Plasmids were submitted for Sanger sequencing at the Oregon Health and Science University DNA Services Core (Portland, OR) using an Applied Biosystems 3730xl capillary sequencer. Sequenced plasmids were visualized using FinchTV software (Geospiza, v. 1.4, 2013) and vector sequences were removed to reveal cloned A. limnaeus sequences. Sequence identity was inferred using NCBI blastx (non-redundant protein database) or blastn (nucleotide database) searches for the 7 genes of interest (Tables 3.3 and 3.4). Partial mRNA sequences for sox3 and noggin-2 were identified during clone screening using primers for sox2 and noggin-1, respectively. Sequences for $\beta$-actin and 18S rRNA were also cloned while screening for other genes.

Reverse transcription of total RNA for quantitative PCR 
Treatment of RNA and cDNA prior to quantitative PCR (qPCR) was based on previously described methods (Schmittgen and Livak, 2008). RNA samples were treated with DNAse enzyme to degrade possible genomic DNA contaminants. DNAse reactions consisted of $5.5 \mu \mathrm{g}$ of total RNA for each sample, 2 U of RNAse-free DNAse I (New England Bio Labs \#M0303S), 40 U of RiboLock RNase inhibitor (Thermo Scientific \#EO0381), and $2 \mathrm{mM} \mathrm{MgCl}$, in a final volume of $16.5 \mu \mathrm{l}$. Samples were incubated at $37^{\circ} \mathrm{C}$ for $10 \mathrm{~min}$ followed by incubation at $90^{\circ} \mathrm{C}$ for $5 \mathrm{~min}$. DNAse-treated total RNA ( $5 \mu \mathrm{g}$ ) was reverse transcribed into single-stranded cDNA using $1 \mu \mathrm{l}$ of iScript advanced reverse transcriptase in $1 \mathrm{X}$ iScript advanced reaction mix (Bio-Rad $\# 170-8842$ ) in a final volume of $20 \mu \mathrm{l}$. The iScript advanced buffer contains both oligo(dT) and random primers. Samples were incubated at $42^{\circ} \mathrm{C}$ for 30 min followed by reaction termination at $85^{\circ} \mathrm{C}$ for $5 \mathrm{~min}$. Samples were diluted 1:4 in nuclease-free water and stored at $-20^{\circ} \mathrm{C}$ until use in qPCR.

qPCR primer-probe design and reaction conditions

Primer and probe sequences to be used for qPCR were created using the PrimerQuest tool and purchased from Integrated DNA Technologies (Table 3.5) (IDT). For probe chemistry I used PrimeTime ZEN DoubleQuenched Probes. Probes were 5' labeled with fluorescein (FAM), internally labeled with a ZEN quencher, and 3' labeled with an IBFQ quencher (IDT). Probes are hydrolyzed by the 5' to 3' exonuclease activity of the DNA 
polymerase, freeing the quenchers from the FAM dye. The difference in estimated melting temperature $\left(\mathrm{T}_{\mathrm{m}}\right)$ between forward and reverse primers was designed to be no more than $5^{\circ} \mathrm{C}$. Probes were selected to have melting temperatures approximately $5^{\circ} \mathrm{C}$ greater than the forward and reverse primers. Observation of a single amplicon of the appropriate estimated size on a $1 \%$ agarose gel following PCR amplification from single-stranded cDNA was used to verify primer specificity. The DNA sequence of each amplicon from each gene/primer set was verified by cloning and DNA sequencing as described above. Synthetic DNA standards identical to the amplicons generated by the qPCR primers were purchased from IDT (Table 3.3). qPCR reactions were set up in triplicate using SsoFast Probes Supermix (Bio-Rad, \#172-5230) and consisted of $1 \mu \mathrm{l}$ of diluted cDNA, $10 \mu \mathrm{l}$ of 2X SsoFast Probes Supermix, $500 \mathrm{nM}$ of forward and reverse primers and $250 \mathrm{nM}$ of probe in final volumes of $20 \mu \mathrm{l}$. All reactions used this 1:2 ratio of primers:probe except for the oct4 assay which used a 1:1 ratio. Assays were set up in clear 96-well semi-skirted PCR plates (Hard-Shell High-Profile PCR plates, Bio-Rad, \#HSS-9601) with optical flat caps (Bio-Rad, \#TCS-0803). All qPCR reactions were carried out in a Stratagene Mx3005P thermocycler (Agilent Technologies, Santa Clara, CA). Standard curves were generated using 1 x 10$3,1 \times 10^{-4}, 1 \times 10^{-5}$, and $1 \times 10^{-6}$ copies of synthetic standard. Reactions were initially heated at ${ }^{9} 5^{\circ} \mathrm{C}$ for $30 \mathrm{sec}$ to activate the DNA polymerase and subsequently thermocycled for 40 cycles by denaturation at $95^{\circ} \mathrm{C}$ for $30 \mathrm{sec}$ 
and annealing/elongation at $60^{\circ} \mathrm{C}$ for $30 \mathrm{sec}$. Fluorescence readings (excitation $492 \mathrm{~nm}$, emission $516 \mathrm{~nm}$ ) were taken at the end of each elongation step. Quantification cycle $\left(\mathrm{C}_{\mathrm{q}}\right)$ thresholds were set automatically in Stratagene MxPro software (ver. 4.10, 2007) using adaptive baseline, moving average, and amplification-based threshold settings. Although rarely necessary, thresholds were manually adjusted to improve standard curve best-fit regressions.

\section{Statistics}

Fold changes for the genes were calculated relative to one of the SNK (10 dpf) samples using the efficiency corrected $d_{d C_{q}}$ method (Pfaffl, 2001). To correct for between-plate variation, I used the efficiency of the standards run on each plate for the fold-change calculations. As suggested by Bustin and Nolan (2004), $C_{q}$ values within 5 cycles of the no template control or the 40th cycle were dropped from analysis to reduce the possibility of false positives. Prior to statistical analysis, relative expression values were normalized relative to $\beta$-actin or $18 \mathrm{~S}$ rRNA expression and $\log _{2}$ transformed. Differences in relative expression between developmental stages were calculated using one-way ANOVAs followed by Tukey's multiple comparison test. Statistical significance was determined at $\mathrm{P}<0.05$.

\section{Results and Discussion}

Identification of A. limnaeus transcripts 
Partial mRNA sequences for A. limnaeus oct4, chordin, sox2, sox3, noggin-1, noggin-2, and follistatin were identified using the blastx sequence alignment tool against sequences in NCBI nucleotide databases for all vertebrates or against only D. rerio (Tables 3.4 and 3.6). Putative conserved domains were also identified by sequence similarity using blastx. The oct 4 transcript fragment (278 bp) isolated from A. limnaeus included a POUsuperfamily domain from nucleotide residues $1-75\left(\mathrm{E}=1.52 \times 10^{-3}\right)$ and a DNA binding domain from nucleotide residues $136-276\left(\mathrm{E}=1.13 \times 10^{-4}\right)$. The $A$. limnaeus sox 2 transcript fragment (287 bp) included a SOX transcription factor domain from nucleotide residues $35-286\left(\mathrm{E}=1.94 \times 10^{-8}\right)$. The transcript fragment for A. limnaeus sox3 (295 bp) included a SOX transcription factor domain from nucleotide residues 53-124 (E=3.02 x 10-3) and a SOX-TCF HMG-box, class I domain from nucleotide residues 191-295 $\left(\mathrm{E}=1.52 \times 10^{-6}\right)$. The isolated A. limnaeus chordin transcript fragment (773 bp) included a CHRD (chordin) superfamily domain from nucleotide residues 1-294 $\left(E=8.57 \times 10^{-9}\right)$ and a von Willebrand factor type $C$ domain from nucleotide residues 403-537 ( $\left.\mathrm{E}=1.91 \times 10^{-5}\right)$. The identified A. limnaeus noggin-1 fragment included a Noggin superfamily domain from nucleotide residues 1-483 ( $\left.E=1.71 \times 10^{-66}\right)$ while the noggin-2 fragment included a Noggin superfamily domain from nucleotide residues 1-243 (E=1.72 x 10-35). The A. limnaeus follistatin transcript fragment included a Follistatin-like SPARC (secreted protein, acidic, and rich in cysteines) domain from 
nucleotide residues 71-286 $\left(\mathrm{E}=2.31 \times 10^{-9}\right)$ and between 521-661 $(\mathrm{E}=1.20 \mathrm{e}-$ 09). The follistatin transcript also included a Kazal type serine protease inhibitor domain from nucleotide residues $176-280\left(\mathrm{E}=3.19 \times 10^{-7}\right)$ and 362$505\left(1.2 \times 10^{-9}\right)$. Nucleotide residues from 41-598 were identified as being a part of the high cysteine membrane protein group $4\left(\mathrm{E}=7.82 \times 10^{-3}\right)$. For all genes tested, I observed dynamic expression profiles across development. Additionally, I observed high $\mathrm{r}^{2}$ values for the synthetic standards following qPCR ( $>0.99)$. I did not observe substantial differences in expression after normalization to either $\beta$-actin or 18S rRNA (not shown), and therefore I present data and focus my discussions on data normalized to expression of $\beta$ actin mRNA. Expression of oct4, sox3, sox2, chordin, noggin-1, noggin-2, and follistatin was not observed in adult liver samples, and therefore I focus my discussion on embryonic patterns of expression.

Expression of pluripotency and neural differentiation regulators in A. limnaeus oct4. The transcription factor oct 4 is widely conserved between vertebrates and is often associated with its ability to maintain pluripotency during development. Homologs to mammalian Oct4/Pou5f1 have been described in a wide range of species, including Xenopus, zebrafish, medaka, the goldfish Carassius auratus, and the chicken (Morrison and Brickman, 2006; Takeda et al., 1994; Wang et al., 2011). Although the zebrafish oct4 gene was initially known as pou2, the similarity to mammalian Oct4/Pou5f1 
suggests that they are indeed orthologs, and thus the zebrafish pou2 is considered to be equivalent to oct4 in other vertebrates (Burgess et al., 2002; Onichtchouk et al., 2010). Teleost expression of oct 4 mRNA begins very early during embryonic development (Marandel et al., 2013; Sánchezembryonic development at they are indeed orthologs, and thus t, suggesting maternal packaging, and similarly I found highest expression of oct4 mRNA before the completion of epiboly in A. limnaeus embryos (Figure 3.2A). Expression of $A$. limnaeus oct4 mRNA decreased over developmental time until becoming undetectable after DII. This pattern of oct4 transcript expression (Figure 3.3) is similar to that found in zebrafish by Takeda et al. (1994), in medaka by Wang et al. (2011), and in goldfish by Marandel et al. (2013), suggesting a conserved role for oct4 in early development for A. limnaeus. Interestingly, whereas medaka oct4 may have similar functions to mammalian Oct4 in maintaining pluripotency, zebrafish oct4 may not be necessary for this purpose (Morrison and Brickman, 2006; Sánchez - Sánchez et al., 2010). Localization of oct4 transcripts and protein in A. limnaeus embryos during development will be necessary to determine if the spatial expression of the transcription factor is similar to other described taxa.

sox2 and sox3. Similar to oct 4 transcripts, I detected a high abundance of sox3 transcripts beginning in early A. limnaeus development (Figure 3.2B), which suggests it is maternally inherited. sox 3 transcript abundance was high during early cleavage, but expression generally decreased as development 
progressed (Figure 3.1B). In zebrafish, sox3 mRNA expression is detected starting at the 32-cell stage (Figure 3.3; the earliest stage sampled), suggesting maternal inheritance, and is detectable until $48 \mathrm{hpf}$ (early hatching) (Okuda et al., 2006; Zimmerman et al., 1996). I also observed sox3 expression for the entire duration of A. limnaeus embryonic development, but in contrast to zebrafish, I observed the highest expression of sox3 just following fertilization with a significant decrease in expression during early development leading to lowest expression at the SNK stage (10 dpf). $A$. limnaeus sox2 transcripts were not detectable prior to reaching the SNK stage and had highest expression between DII and mid-organogenesis (3/4overgrowth or $9 \mathrm{dpd}$ ) (Figure 3.2C). In zebrafish, sox2 expression is not observed until 30\% epiboly, and is associated with initiation of gastrulation (Okuda et al., 2006). Similarly, sox2 expression is not observed prior to epiboly in goldfish, with the first transcripts being detected at 75\% epiboly (Marandel et al., 2013). Expression of sox2 in Xenopus has been suggested to be activated by sox3, and thus it is not surprising I observed sox3 expression prior to sox2 (Rogers et al., 2009). In contrast to zebrafish and A. limnaeus, medaka sox 2 expression appears to be more transient, although the strongest expression of sox 2 is between the early neurula ( $1 \mathrm{dpf})$ and $16-19$ somites $(2$ dpf) stages (Cui et al., 2011). The Japanese flounder Paralichthys olivaceus also differs slightly from both zebrafish and medaka in that low expression of sox2 mRNA is first observed in the high blastula and peak expression occurs 
in the early to mid-gastrula (Gao et al., 2014). Although the expression patterns of sox2 appear to differ across development in these teleosts, they share the pattern of increased expression near the beginning of gastrulation (Figure 3.3).

SOXB1 genes, including sox2 and sox3, work with oct4 to regulate neural fate and differentiation (Archer et al., 2011; Dee et al., 2008; Okuda et al., 2010). Expression of oct4 early in development, and simultaneous expression of sox2 and sox3 genes at the SNK stage (presumably the time for neural induction) in A. limnaeus suggests that the function of these genes in regulating pluripotency and neurulation are conserved with other vertebrates. Interference with oct 4 or sox3 function produces gastrulation defects in Xenopus and zebrafish (Burgess et al., 2002; Zhang et al., 2004), and thus the expression of oct 4 and sox 3 in A. limnaeus embryos prior to axis formation also suggests a possible conserved role in gastrulation. In contrast to the strong upregulation of sox3 at 30\% epiboly in zebrafish (Okuda et al., 2006), sox3 is downregulated after $50 \%$ epiboly in A. limnaeus. The developmental consequences of this reversal in sox 3 expression during $A$. limnaeus development are unknown. Future studies that establish the molecular targets and localization of oct4, sox3 and sox 2 in A. limnaeus will be important in determining if the roles of these transcription factors are indeed similar to other vertebrates. 
Expression of DV-patterning genes during A. limnaeus embryonic development

Chordin, noggin, and follistatin are potent BMP antagonists that are commonly associated with their role in DV patterning. Gradients of BMP across the developing embryo are established by secretion of these BMP antagonists by the Spemann-Mangold organizer, a structure that forms during gastrulation and whose function in inducing dorsal structures appears to be conserved between vertebrates (De Robertis et al., 2000). chordin. Only one chordin gene has been identified in zebrafish and medaka and its expression is required for correct dorsal structure formation (Dal-Pra et al., 2006; Miller-Bertoglio et al., 1997; Schulte-Merker et al., 1997; Takashima et al., 2007). Expression of chordin is first observed in the late blastoderm of both medaka and zebrafish, just prior to epiboly, and transcripts appear to be expressed until around the end of somitogenesis for both species. I detected chordin expression throughout $A$. limnaeus embryonic development (Figure 3.4A) with peak expression just after fertilization followed by a sharp drop after the completion of epiboly ( $4 \mathrm{dpf}$ ). This pattern suggests maternal packaging of the chordin transcript, which appears to be a unique expression pattern, compared to other fishes (Figure 3.5) and other vertebrates in general, and may indicate a role for chordin expression in the unique dispersion and reaggregation phases of development observed in annual killifish. 
noggin-1 and noggin-2. At least three noggin genes have been described in zebrafish, with expression of noggin-1 starting at the late blastula stage and noggin-2 appearing at the end of gastrulation (Fürthauer et al., 1999). High expression of noggin-1 was observed just after fertilization in A. limnaeus (early cleavage), after which expression became undetectable until the SNK stage at $10 \mathrm{dpf}$ (Figure 3.4B). The constitutive expression of zebrafish noggin-1, beginning shortly before gastrulation and continuing for the duration of embryonic development (Figure 3.5), contrasts with this expression profile of A. limnaeus noggin-1 (Bauer et al., 1998; Fürthauer et al., 1999). Expression of noggin-2 was first detected at the SNK stage in $A$. limnaeus in association with the formation of the embryonic axis, similar to zebrafish where noggin-2 is first detected in the axial mesoderm at the end of gastrulation (Fürthauer et al., 1999). Expression of noggin-2 continued to increase during development reaching peak levels in mid to late organogenesis (3/4 overgrowth) and DIII embryos (Figure 3.4C). After the SNK stage, expression of both noggin-1 and noggin-2 was observed for the remainder of the embryonic stages, suggesting roles in DV patterning and neural development similar to other teleosts during these periods of development (Bauer et al., 1998; Fürthauer et al., 1999; Lamb et al., 1993). follistatin. While localization studies in zebrafish have determined that chordin and noggin are likely secreted as part of the organizer, follistatin appears to be absent in this structure (Bauer et al., 1998; Dal-Pra et al., 
2006). A. limnaeus follistatin expression is first measurable at $50 \%$ epiboly and increases dramatically between the late reaggregation and SNK stages of development ( 8 - $10 \mathrm{dpf}$ ) after which it is expressed constitutively until the end of embryonic development (Figure 3.4D). This timing of follistatin expression in A. limnaeus is similar to zebrafish (Figure 3.5) in that high expression of transcripts is not seen until the embryonic axis is visible, suggesting a role outside of the early gastrulation processes (Bauer et al., 1998).

Expression of chordin, noggin-1, and noggin-2 at the first appearance of a visible embryonic axis, suggests that these factors may play a role in DV patterning in A. limnaeus that is similar to other described vertebrates, such as zebrafish (Figure 3.5). However, contrasting to zebrafish embryos, the surprising observation of maternally packaged chordin and noggin-1 during early cleavage suggests that these genes may have a unique function during early development in A. limnaeus. Transcript localization and protein expression studies for these genes will be necessary to determine where these genes are expressed during development and may clarify their roles in A. limnaeus morphogenesis.

The dispersed blastomere stage may prolong an undifferentiated state that can buffer environmental stress 
In zebrafish, previously reported transcript data shows that simultaneous expression of chordin, noggin-1, noggin-2, follistatin, and sox2 is only observed after commencement of germ layer formation. Similarly, I do not observe simultaneous expression of these five genes until after formation of the solid neural keel when there is a visible embryonic axis (Figures 3.3 and 3.5). Cross-species comparisons of sox2 transcripts also reveal that sox2 expression is generally strongest following gastrulation (Figure 3.3), similar to my observation of highest sox2 expression following axis formation (Figure 3.2). Taken together, expression profiles of the genes tested in this study suggest that gastrulation and axis formation in A. limnaeus is not completed until late in the reaggregation process or perhaps shortly after (between 8-10 dpf).

Wourms (1972b) suggested that the dispersed cells might be "developmentally equivalent" and therefore able to replace cells that are damaged or destroyed after environmental insult. Recently, I have shown that A. limnaeus embryos irradiated with ultraviolet-C (254 nm) during the dispersed blastomere phases ( $4 \mathrm{dpf}$ ) suffer a delay in development, but are able to develop normally at doses that cause a high degree of abnormal development in SNK stage embryos (Wagner and Podrabsky 2015a). Taken together with the gene expression profiles in this report, these data support the hypothesis that the dispersed cell phase in annual killifish can serve to buffer development against environmental insults through the prolonged 
maintenance of pluripotency and the delay of sensitive developmental processes (e.g. gastrulation and axis formation) until the environment is favorable for normal development. The fact that many species of annual killifish can either substantially prolong D/R or enter diapause at this stage in response to environmental stress (Genade et al., 2005; Wourms, 1972b; Wourms, 1972a) suggests a mechanism for embryos to survive prolonged bouts of what would otherwise be lethal or teratogenic environmental stress. To my knowledge, this is the first evidence supporting this type of mechanism for dealing with environmental stress during development.

\section{Early expression of BMP antagonists may prevent gastrulation}

The most unexpected results of this study were the observed expression of both chordin and noggin-1 transcripts beginning just after fertilization (3 hpf). This is earlier expression than any other vertebrate studied, certainly prior to the formation of the SMO, and strongly suggests maternal inheritance (Figure 3.4A,B). Although chordin is expressed early during development in other taxa, the expression appears to begin after the midblastula transition and therefore is likely transcribed from the zygotic genome (Chapman et al., 2002; Ishibashi et al., 2008; Takashima et al., 2007; Schier and Talbot, 2005). However, chordin expression declined during cleavage and epiboly, reaching lowest expression levels at 50\% epiboly. Similarly, noggin-1 expression was high just after fertilization but was not 
detectable again until after $\mathrm{D} / \mathrm{R}$ at $10 \mathrm{dpf}$. This maternal provisioning and early expression of chordin and noggin-1 suggests a novel role for these transcripts during early development in A. limnaeus compared to other vertebrates. Work by von der Hardt et al. (von der Hardt et al., 2007) suggests that gradients of BMP2 and BMP4, two targets of chordin and noggin (Larraín et al., 2000; Zimmerman et al., 1996; Piccolo et al., 1996), appear to be essential for guiding cellular direction during cell migrations associated with zebrafish gastrulation. Importantly, BMP2 transcripts have been identified as early as the late blastula stage in zebrafish where the transcripts are expressed uniformly throughout the blastoderm (Nikaido et al., 1997). The BMP2 transcripts localize to the presumptive ventral side just prior to the onset of epiboly, suggesting an early role in polarizing the blastoderm in preparation for zebrafish gastrulation. Prior to the formation of an embryonic axis, A. limnaeus embryos share several similarities to zebrafish embryos with disrupted BMP2 signaling, including lack of convergence movements and random migration of motile cells (Wourms, 1972b; von der Hardt et al., 2007). The importance of BMP signaling during gastrulation is further demonstrated by the observation that BMP4 is essential for mouse germ layer formation (Winnier et al., 1995). We hypothesize that early expression of chordin and noggin-1 in A. limnaeus functions to disrupt BMP gradients that would otherwise guide embryonic cells through gastrulation movements, thus leading to dissociation of 
blastomeres during epiboly. Following reaggregation, a BMP gradient established by ventral BMP signaling and BMP inhibition by dorsal BMP antagonists (increased expression of chordin and noggin-2) would promote DV patterning (Figure 3.6). The possibility that BMP disruption could be a major factor in delaying gastrulation movements in A. limnaeus is supported by the observation that BMP-guided gastrulation movements are independent of the role of BMPs in DV patterning, thus allowing disruption of early BMP activity without affecting later DV patterning (von der Hardt et al., 2007). While currently untested, this is an attractive hypothesis that could help to explain the differences associated with early development in annual killifishes. Comparative studies of chordin and noggin-1 expression and BMP2 and BMP4 expression in annual and non-annual members of the Rivulidae would be especially powerful in addressing the validity of this hypothesis.

Gene expression during diapause II and implications for the annual killifish life history

In all lineages of annual killifish, the processes of $\mathrm{D} / \mathrm{R}$ and the ability to arrest development in diapause always co-occur despite the lack of a necessary connection between the two processes. This has led us to hypothesize that the molecular mechanisms that support the two processes may be somehow linked. I observed mRNA expression of oct4, sox3, sox2, 
chordin, follistatin, noggin-1, and noggin-2 in DII embryos. Perhaps most interesting is the high and prolonged expression of chordin for the entire duration of embryonic development in A. limnaeus which is in contrast to the pattern observed in zebrafish (Figure 3.5). While the genes investigated in this study are of central importance to normal vertebrate development, it is not clear why their expression would be maintained during diapause II. Previous work suggests low rates of protein turnover during diapause II, but the reduction is not complete and some transcripts are very likely translated during dormancy (Podrabsky and Hand, 2000). Presently, it is unclear if these seven mRNAs in DII embryos are (1) actively translated and have a role in maintaining diapause, (2) stabilized in order to support rapid resumption of development once diapause is terminated, or are (3) leftover from pre-DII development. Further studies of the action of these genes before, during, and after diapause II, especially the prolonged expression of chordin, might lead to interesting discoveries on the molecular regulation and evolution of this complex developmental pattern. 


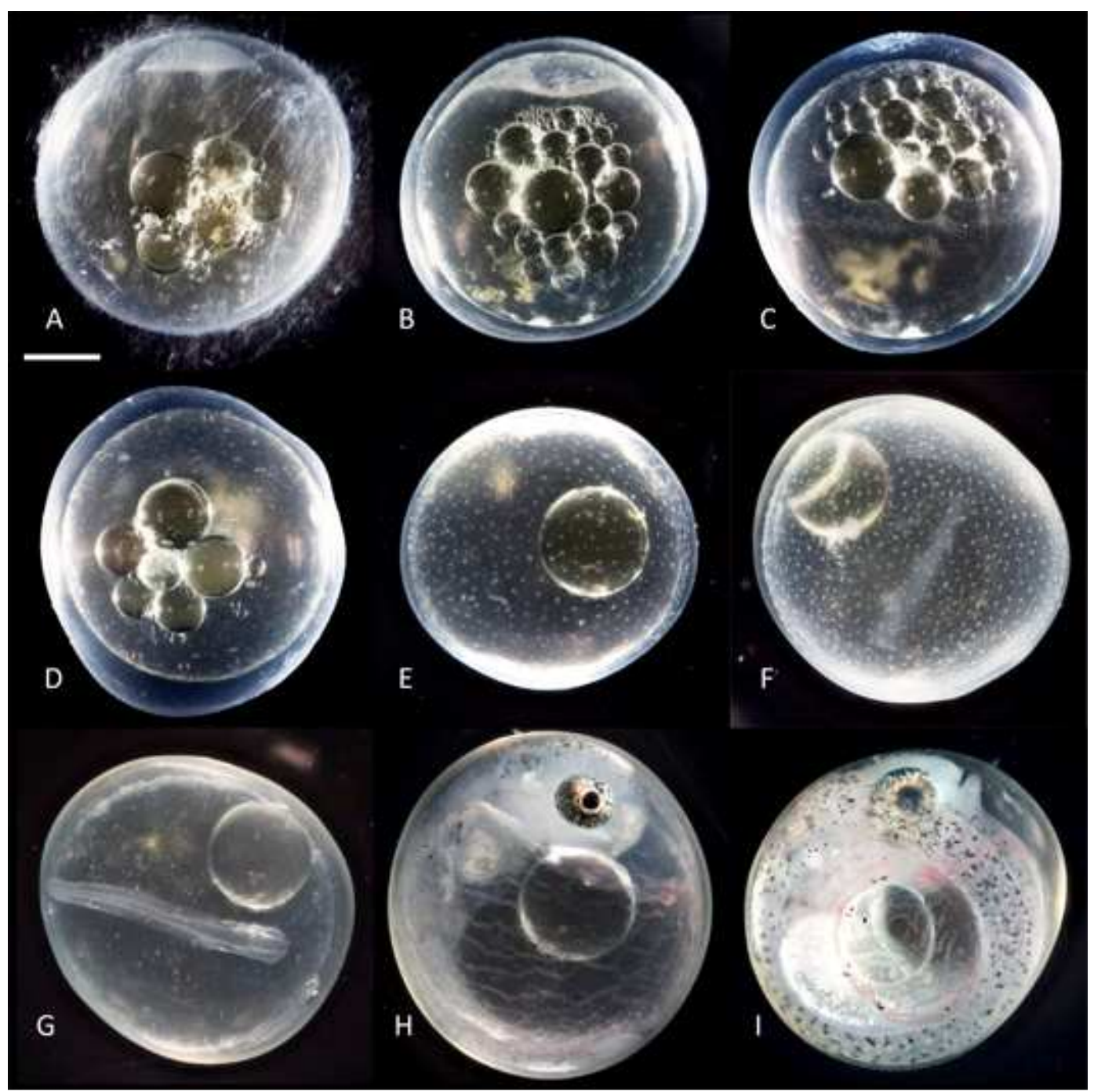

Figure 3.1. Representative photographs of embryo stages used in Chapter 3. (A) Early cleavage, (B) Early hollow blastula, (C) 50\% epiboly, (D)Dispersed blastomere phases, (E) Reaggregation phases, (F) Solid neural keel, (G) Diapause II, (H) Three-quarter overgrowth, (I) Diapause III. Scale bar is $0.5 \mathrm{~mm}$. Photos are from Riggs and Podrabsky, unpublished. 

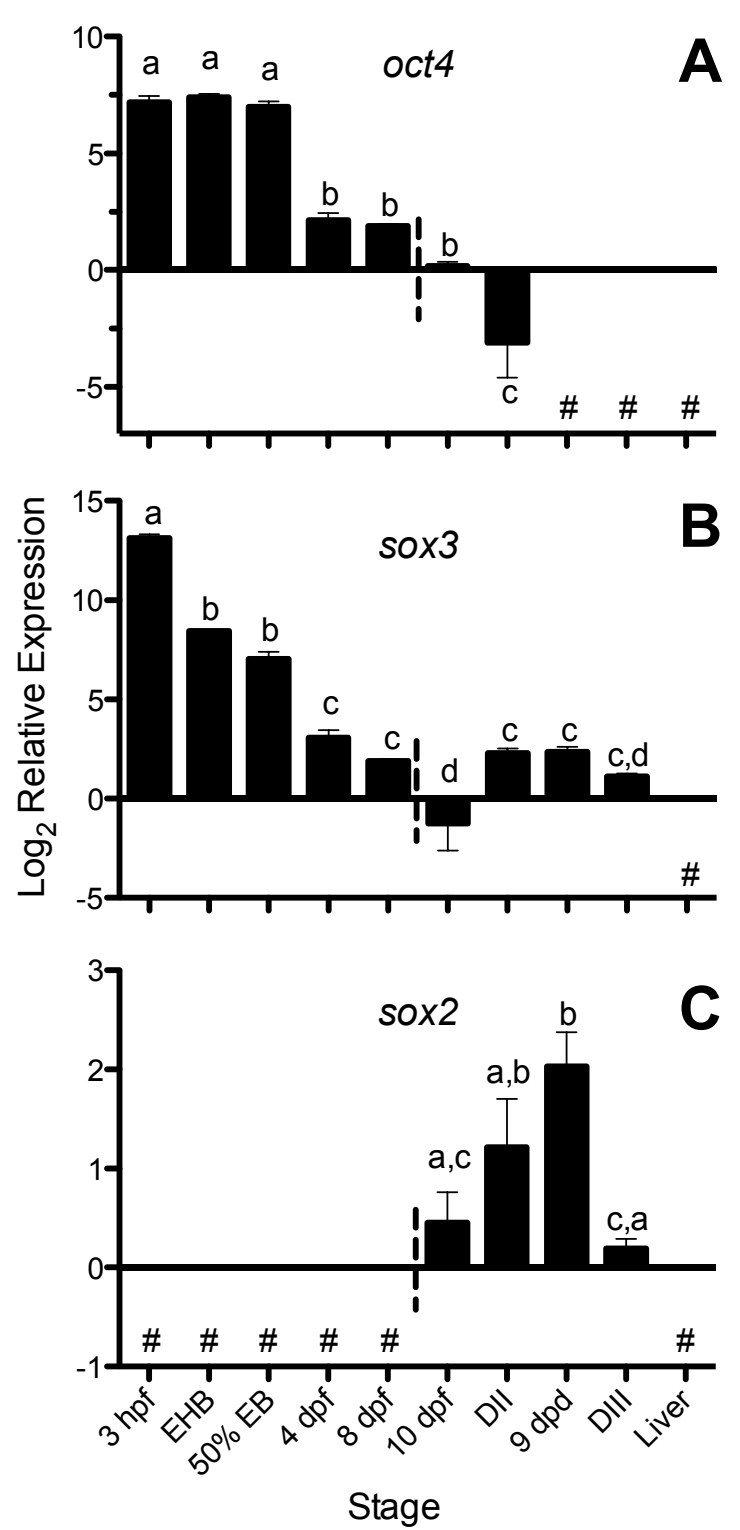

Figure 3.2. Expression of putative oct4 (A), sox3 (B), and sox2 (C) transcripts during A. limnaeus development. Developmental stages to the left of the horizontal dashed line do not have a visible embryonic axis. Bars with different letters are statistically different $(\mathrm{P}<0.05$, one-way ANOVA with Tukey's post-test). Values are means \pm SEM $(n=3-4)$. Stages with undetected expression are noted with \#. 


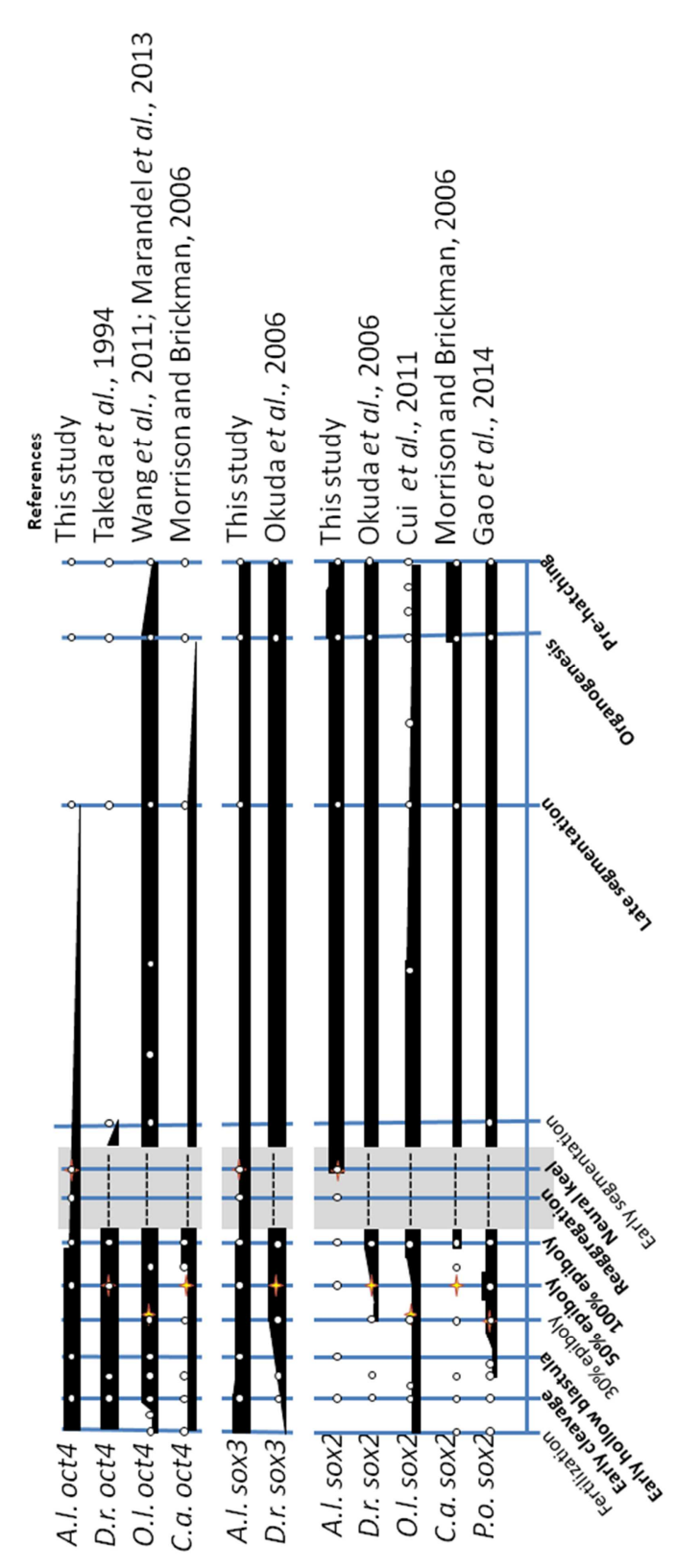

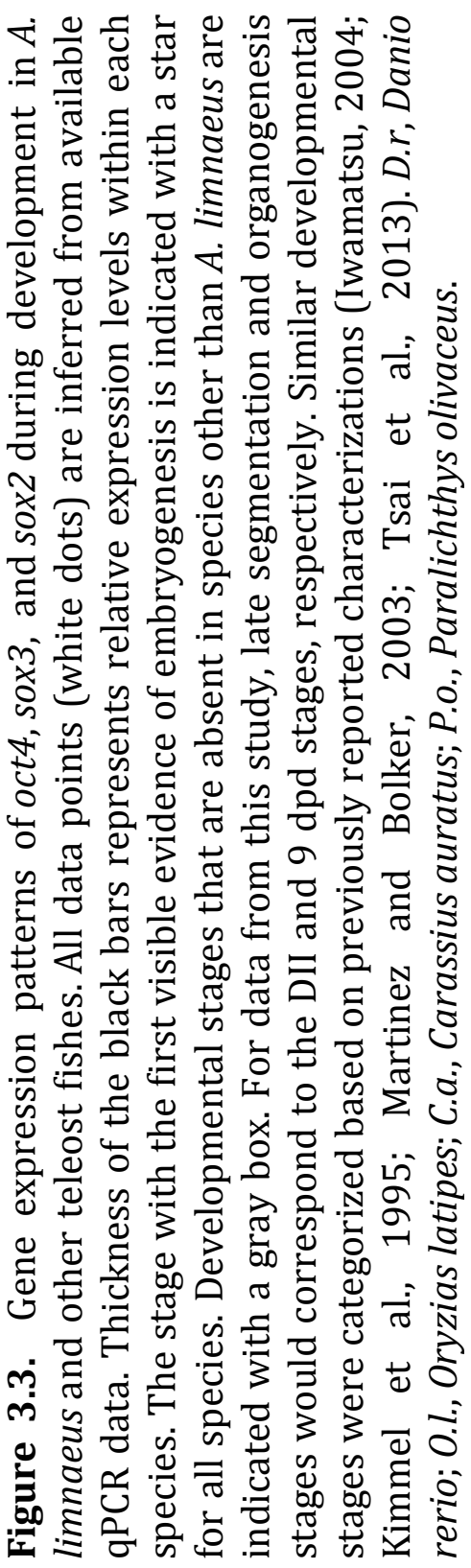




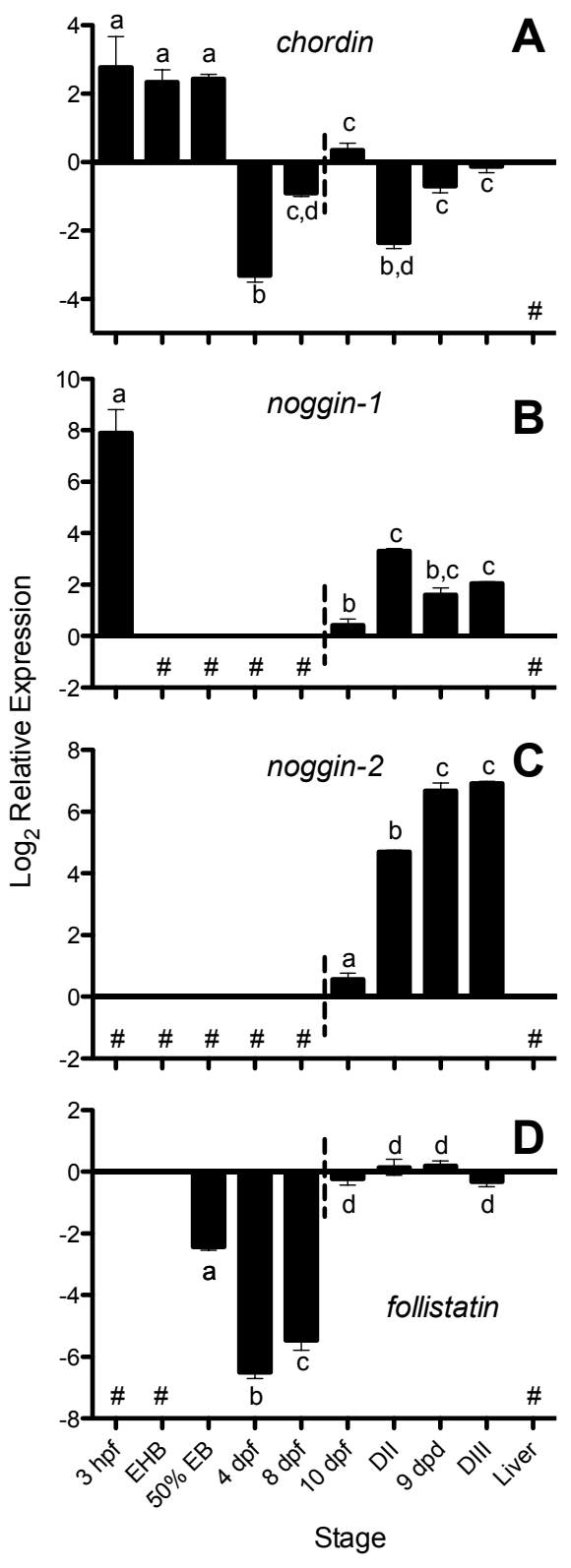

Figure 3.4. Expression of putative chordin (A), noggin-1 (B), noggin-2 (C), and follistatin (D) transcripts during A. limnaeus development.

Developmental stages to the left of the horizontal dashed line do not have a visible embryonic axis. Bars with different letters are statistically different ( $P$ $<0.05$, one-way ANOVA with Tukey's post-test). Values are means \pm SEM $(n=3-4)$. Stages with undetected expression are noted with \#. 


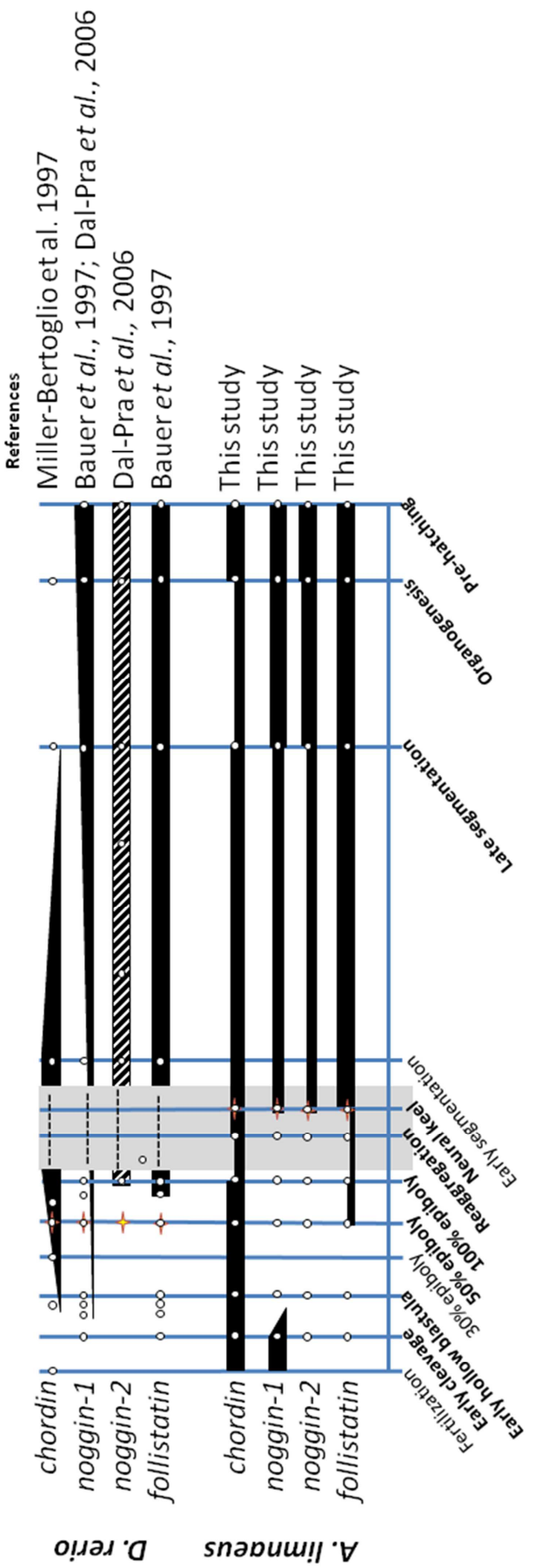

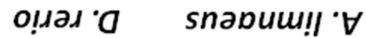

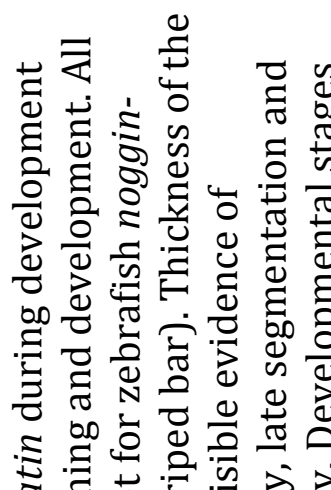

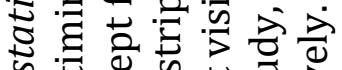

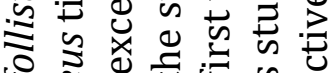

ᄂ \& 0

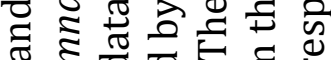

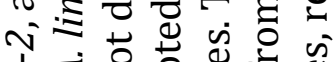

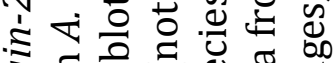

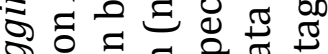

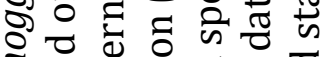

$\therefore 山$ 过

100 요의

डิ

จ $\pi$ के

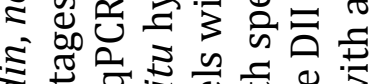

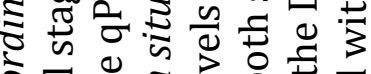

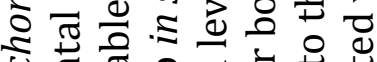

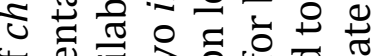

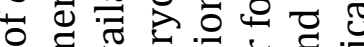

ह

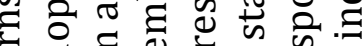

ब

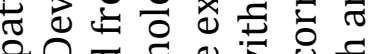

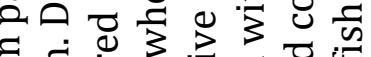

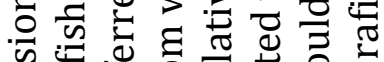
के

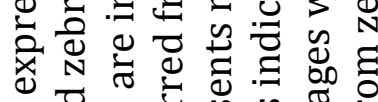

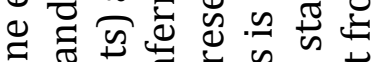
बै $4 \leqslant 0$ के के

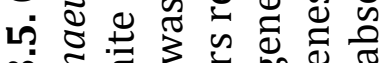

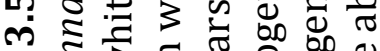
¿

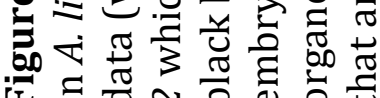




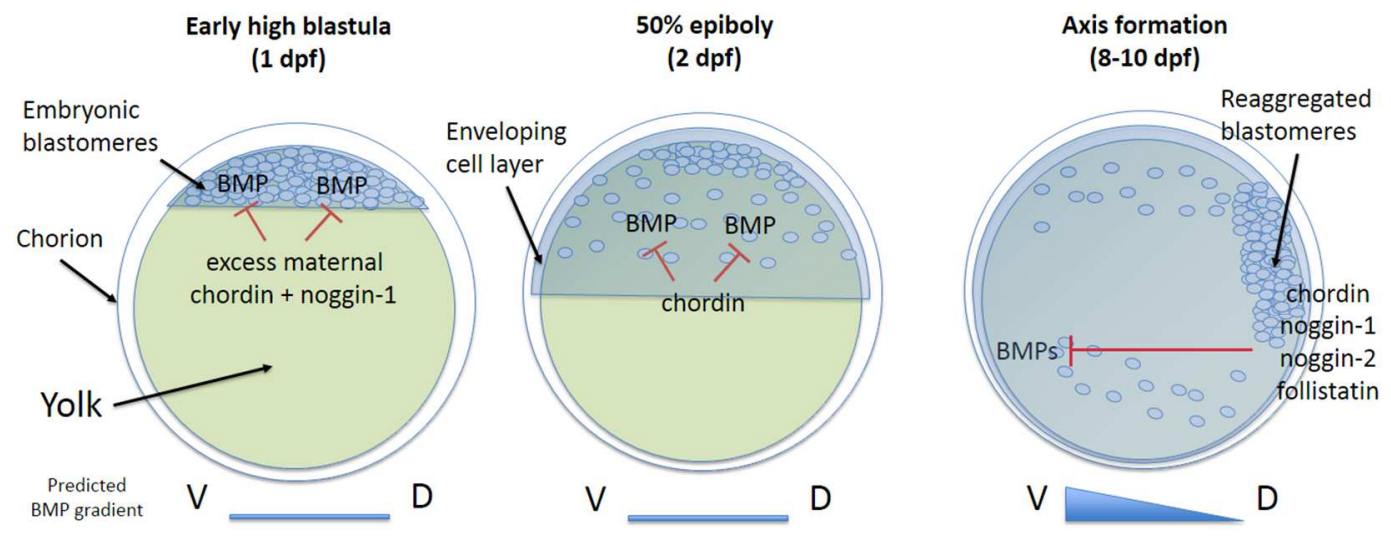

Figure 3.6. Model for delayed gastrulation and axis formation in A. limnaeus based on early BMP inactivation. Early expression of BMP antagonists chordin and noggin prevent directed cellular migration necessary for gastrulation because BMP gradient cannot be established (A). Continued expression of chordin prevents gastrulation from occurring during epiboly (B). No embryonic shield forms and the ameboid blastomeres continue to move randomly across the yolk surface. Following reaggregation, the SMO is established and secretes BMP antagonists to establish DV patterning, similar to other vertebrates (C). Neurulation proceeds. 
Table 3.1. A. limnaeus stages selected for qPCR gene expression analysis. Embryos were staged as described in this table before being sampled for RNA extraction. The number of pooled individuals per biological replicate $(N)$ are indicated.

\begin{tabular}{|c|c|c|c|c|c|}
\hline Stage & Age & WS & Description & $\begin{array}{c}\text { Pooled } \\
\text { individuals }\end{array}$ & $N$ \\
\hline $1-4$ cell & $3 \mathrm{hpf}$ & $3-5$ & 1-4 blastomeres & 100 & 3 \\
\hline $\begin{array}{l}\text { Early hollow } \\
\text { blastula }\end{array}$ & $1 \mathrm{dpf}$ & 12 & $\begin{array}{l}\text { Presence of a segmentation cavity } \\
\text { containing blastomeres and covered by } \\
\text { enveloping layer cells }\end{array}$ & 100 & 4 \\
\hline $50 \%$ epiboly & $2 \mathrm{dpf}$ & 17 & $\begin{array}{l}\text { Half of the yolk surface covered by } \\
\text { periblast and enveloping layer. In } \\
\text { between the two layers are embryonic } \\
\text { blastomeres that have become } \\
\text { ameboid and migrated away from the } \\
\text { central blastula. }\end{array}$ & 100 & 4 \\
\hline $\begin{array}{l}\text { Dispersed } \\
\text { blastomere }\end{array}$ & $4 \mathrm{dpf}$ & $\begin{array}{l}20- \\
21\end{array}$ & $\begin{array}{l}\text { Yolk surface completely covered by } \\
\text { periblast, enveloping layer, and } \\
\text { randomly distributed embryonic } \\
\text { blastomeres. }\end{array}$ & 100 & 4 \\
\hline $\begin{array}{l}\text { Reaggregation } \\
\text { phases }\end{array}$ & $8 \mathrm{dpf}$ & $\begin{array}{l}22- \\
26\end{array}$ & $\begin{array}{l}\text { Embryonic blastomeres remain } \\
\text { distributed across yolk, but a } \\
\text { subpopulation are beginning to migrate } \\
\text { towards a small area of the yolk where } \\
\text { the future embryo will form. No } \\
\text { discernable embryonic axis present. }\end{array}$ & 100 & 4 \\
\hline $\begin{array}{l}\text { Solid neural } \\
\text { keel }\end{array}$ & $\begin{array}{l}10 \\
\mathrm{dpf}\end{array}$ & 28 & $\begin{array}{l}\text { Presence of a solid neural keel, head } \\
\text { fold, and Kupffer's vesicle. No somites } \\
\text { present. }\end{array}$ & 50 & 4 \\
\hline Diapause II & $\begin{array}{l}32 \\
\mathrm{dpf}\end{array}$ & 33 & $\begin{array}{l}\text { Presence of optic cups and associated } \\
\text { lenses, otic vesicles, functional heart, } \\
\text { and } 38-40 \text { pairs of somites. Heart rate } \\
\text { of } 0-10 \mathrm{bpm} \text {. }\end{array}$ & 100 & 3 \\
\hline $\begin{array}{l}\text { Three-quarter } \\
\text { overgrowth }\end{array}$ & $\begin{array}{l}9 \\
d p d\end{array}$ & 39 & $\begin{array}{l}\text { Embryo occupies about three-fourths } \\
\text { of the perimeter of the yolk. Eyes are } \\
\text { heavily pigmented with gold colored } \\
\text { material. Presence of incompletely } \\
\text { developed gut, liver, and swimbladder. }\end{array}$ & 40 & 4 \\
\hline Diapause III & $\begin{array}{l}24 \\
\mathrm{dpd}\end{array}$ & 43 & $\begin{array}{l}\text { Fully formed larva that has completed } \\
\text { embryonic development, but has not } \\
\text { yet hatched. }\end{array}$ & 40 & 4 \\
\hline Adult liver & Adult & $\mathrm{N} / \mathrm{A}$ & Whole liver from an adult female. & 1 & 3 \\
\hline
\end{tabular}


Table 3.2: Degenerate primers used for PCR identification of A. limnaeus gene sequences. Primers are listed in 5'-3' orientation and specific PCR conditions temperature are listed.

\begin{tabular}{|c|c|c|c|c|}
\hline Gene & $\begin{array}{l}\text { F } \\
\text { primer }\end{array}$ & R primer & $\begin{array}{l}\text { Species used with accession } \\
\text { IDs }\end{array}$ & PCR cycling \\
\hline oct4 & $\begin{array}{l}\text { GAGGCT } \\
\text { CTSCAR } \\
\text { CTKAGY } \\
\text { TTC }\end{array}$ & $\begin{array}{l}\text { RGATGT } \\
\text { RGTVCG } \\
\text { WGTDTG } \\
\text { GTT }\end{array}$ & $\begin{array}{l}\text { Danio rerio } \\
\text { [GenBank:NM_131112.1], } \\
\text { Homo sapiens } \\
\text { [GenBank:NM_002701.4], } \\
\text { Labeo rohita } \\
\text { [GenBank:GU443948.1],Pagrus } \\
\text { major [GenBank:AB378582.1] }\end{array}$ & $\begin{array}{l}\text { Initial: } 30 \mathrm{sec}, \\
94^{\circ} \mathrm{C} \\
37 \text { cycles: } 30 \mathrm{sec} \text {, } \\
50^{\circ} \mathrm{C}>30 \mathrm{sec} \text {, } \\
72^{\circ} \mathrm{C} \\
\text { End: } 7 \mathrm{~min}, 72^{\circ} \mathrm{C}\end{array}$ \\
\hline sox2 & $\begin{array}{l}\text { CAAGAC } \\
\text { CCTCAT } \\
\text { GAAGAA } \\
\text { GGAC }\end{array}$ & $\begin{array}{l}\text { TBCAGT } \\
\text { ACAACTC } \\
\text { CATGACY } \\
\text { A }\end{array}$ & $\begin{array}{l}\text { F primer: Oreochromis niloticus } \\
\text { [ GenBank:EF431920.1], } \\
\text { Takifugu rubripes } \\
\text { [GenBank:AY277952.1], } \\
\text { Epinephelus coioides } \\
\text { [GenBank:FJ432695.1] } \\
\text { R primer: Danio rerio } \\
\text { [GenBank:NM_213118.1], } \\
\text { Oryzias latipes } \\
\text { [GenBank:FJ895588.1],Salmo } \\
\text { salar } \\
\text { [GenBank:NM_001141718.1] }\end{array}$ & $\begin{array}{l}\text { Initial: } 30 \mathrm{sec} \text {, } \\
95^{\circ} \mathrm{C} \\
5 \mathrm{cycles}: 20 \mathrm{sec}, \\
95^{\circ} \mathrm{C}>20 \mathrm{sec} \\
63^{\circ} \mathrm{C}>1.5 \mathrm{~min}, \\
68^{\circ} \mathrm{C} \\
5 \mathrm{cycles}: 20 \mathrm{sec}, \\
95^{\circ} \mathrm{C}>20 \mathrm{sec} \\
58^{\circ} \mathrm{C}>1.5 \mathrm{~min}, \\
68^{\circ} \mathrm{C} \\
35^{\mathrm{cycles}:} 20 \mathrm{sec} \\
95^{\circ} \mathrm{C}>20 \mathrm{sec} \\
53^{\circ} \mathrm{C}>1.5 \mathrm{~min}, \\
68^{\circ} \mathrm{C} \\
\text { End: } 7 \mathrm{~min}, 72^{\circ} \mathrm{C}\end{array}$ \\
\hline sox3 & $\begin{array}{l}\text { AACCCM } \\
\text { AAAATG } \\
\text { CACAAY } \\
\text { TC }\end{array}$ & $\begin{array}{l}\text { ATGAAC } \\
\text { GGCTGG } \\
\text { ACMAAY }\end{array}$ & $\begin{array}{l}\text { Danio rerio } \\
\text { [GenBank:NM_213118.1], } \\
\text { Oryzias latipes } \\
\text { [GenBank:FJ895588.1], Salmo } \\
\text { salar } \\
\text { [GenBank:NM_001141718.1] }\end{array}$ & $\begin{array}{l}\text { Initial: } 30 \mathrm{sec}, \\
95^{\circ} \mathrm{C} \\
5 \mathrm{cycles}: 20 \mathrm{sec}, \\
95^{\circ} \mathrm{C}>20 \mathrm{sec}, \\
65^{\circ} \mathrm{C}>1.5 \mathrm{~min}, \\
68^{\circ} \mathrm{C} \\
5 \mathrm{cycles}: 20 \mathrm{sec}, \\
95^{\circ} \mathrm{C}>20 \mathrm{sec} \\
60^{\circ} \mathrm{C}>1.5 \mathrm{~min}, \\
68^{\circ} \mathrm{C} \\
36^{\mathrm{ccycles}:} 20 \mathrm{sec}, \\
95^{\circ} \mathrm{C}>20 \mathrm{sec}, \\
55^{\circ} \mathrm{C}>1.5 \mathrm{~min}, \\
68^{\circ} \mathrm{C}\end{array}$ \\
\hline
\end{tabular}


Table 3.2 continued.

\begin{tabular}{|c|c|c|c|c|}
\hline chordin & $\begin{array}{l}\text { AGCRGG } \\
\text { TCAYGC } \\
\text { MTGGGT }\end{array}$ & $\begin{array}{l}\text { CACTGY } \\
\text { GAGAA } \\
\text { GGTGA } \\
\text { CST }\end{array}$ & $\begin{array}{l}\text { Danio rerio } \\
\text { [GenBank:NM_130973.1], } \\
\text { Xenopus laevis } \\
\text { [GenBank:NM_001088309.1] }\end{array}$ & $\begin{array}{l}\text { Initial: } 30 \mathrm{sec} \text {, } \\
95^{\circ} \mathrm{C} \\
5 \mathrm{cycles}: 20 \mathrm{sec}, \\
95^{\circ} \mathrm{C}>20 \mathrm{sec}, \\
65^{\circ} \mathrm{C}>1.5 \mathrm{~min}, \\
68^{\circ} \mathrm{C} \\
5 \mathrm{cycles}: 20 \mathrm{sec}, \\
95^{\circ} \mathrm{C}>20 \mathrm{sec} \text {, } \\
60^{\circ} \mathrm{C}>1.5 \mathrm{~min}, \\
68^{\circ} \mathrm{C} \\
30^{\circ} \mathrm{cycles}: 20 \mathrm{sec}, \\
95^{\circ} \mathrm{C}>20 \mathrm{sec}, \\
55^{\circ} \mathrm{C}>1.5 \mathrm{~min}, \\
68^{\circ} \mathrm{C}\end{array}$ \\
\hline noggin-1 & $\begin{array}{l}\text { ANCTNA } \\
\text { ACGAGA } \\
\text { CCGAGC } \\
\mathrm{T}\end{array}$ & $\begin{array}{l}\text { TCACA } \\
\text { GASTGC } \\
\text { AAATG } \\
\text { CTCM }\end{array}$ & $\begin{array}{l}\text { Danio rerio } \\
\text { [GenBank:AF159147.1], Fugu } \\
\text { ribripes [GenBank:AF095337.1] }\end{array}$ & $\begin{array}{l}\text { Initial } 30 \mathrm{sec}, 95^{\circ} \mathrm{C} \\
5 \mathrm{cycles}: 20 \mathrm{sec}, \\
95^{\circ} \mathrm{C}>20 \mathrm{sec}, \\
65^{\circ} \mathrm{C}>1.5 \mathrm{~min}, \\
68^{\circ} \mathrm{C} \\
5 \mathrm{cycles}: 20 \mathrm{sec}, \\
95^{\circ} \mathrm{C}>20 \mathrm{sec}, \\
60^{\circ} \mathrm{C}>1.5 \mathrm{~min}, \\
68^{\circ} \mathrm{C} \\
36 \mathrm{cycles}: 20 \mathrm{sec}, \\
95^{\circ} \mathrm{C}>20 \mathrm{sec}, \\
55^{\circ} \mathrm{C}>1.5 \mathrm{~min}, \\
68^{\circ} \mathrm{C} \\
\text { End: } 7 \mathrm{~min}, 72^{\circ} \mathrm{C}\end{array}$ \\
\hline noggin-2 & $\begin{array}{l}\text { CTGTGG } \\
\text { NCCTAC } \\
\text { TCNTTC } \\
\text { TGC }\end{array}$ & $\begin{array}{l}\text { TCACA } \\
\text { GASTGC } \\
\text { AAATG } \\
\text { CTCM }\end{array}$ & $\begin{array}{l}\text { Danio rerio } \\
\text { [GenBank:AF159147.1], Fugu } \\
\text { ribripes [GenBank:AF095337.1] }\end{array}$ & Same as noggin-1 \\
\hline follistatin & $\begin{array}{l}\text { CTCATG } \\
\text { GAACAT } \\
\text { CAAAAA } \\
\text { GTTCAA }\end{array}$ & $\begin{array}{l}\text { CGACA } \\
\text { ACACCA } \\
\text { CATATC } \\
\text { CCA }\end{array}$ & $\begin{array}{l}\text { Oreochromis mossambicus } \\
\text { [GenBank:DQ343148.1], } \\
\text { Micropterus salmoides } \\
\text { [GenBank:EF128004.1], } \\
\text { Larimichthys crocea } \\
\text { [GenBank:JF499691.1], Takifugu } \\
\text { rubripes } \\
\text { [GenBank:NM_001037858.1], } \\
\text { Sparus aurata } \\
\text { [GenBank:AY544167.1] }\end{array}$ & $\begin{array}{l}\text { Initial: } 30 \mathrm{sec}, \\
95^{\circ} \mathrm{C} \\
5 \mathrm{cycles}: 20 \mathrm{sec}, \\
95^{\circ} \mathrm{C}>20 \mathrm{sec} \\
65^{\circ} \mathrm{C}>1.5 \mathrm{~min}, \\
68^{\circ} \mathrm{C} \\
5 \mathrm{cycles}: 20 \mathrm{sec}, \\
95^{\circ} \mathrm{C}>20 \mathrm{sec} \\
60^{\circ} \mathrm{C}>1.5 \mathrm{~min}, \\
68^{\circ} \mathrm{C} \\
30^{\circ} \mathrm{cycles}: 20 \mathrm{sec}, \\
95^{\circ} \mathrm{C}>20 \mathrm{sec} \\
55^{\circ} \mathrm{C}>1.5 \mathrm{~min}, \\
68^{\circ} \mathrm{C} \\
\text { End: } 7 \mathrm{~min}, 68^{\circ} \mathrm{C}\end{array}$ \\
\hline
\end{tabular}


Table 3.3. Isolated and cloned A. limnaeus gene fragments. Gene fragments were generated using PCR with primers listed in Table 3.2, cloned into the pGEM-T vector, and sequenced. The amplicon generated in qPCR assays is indicated in bold.

\begin{tabular}{|c|c|c|c|}
\hline $\begin{array}{l}\text { Putative } A \text {. } \\
\text { limnaeus } \\
\text { gene }\end{array}$ & $\begin{array}{l}\text { Stage(s) } \\
\text { used }\end{array}$ & Cloned fragment sequence (sense mRNA) & $\begin{array}{l}\text { Size } \\
\text { (bp) }\end{array}$ \\
\hline oct 4 & $3 \mathrm{dpf}$ & $\begin{array}{l}\text { GAGGCTCTGCAGCTGAGCTTCAAGAACATGTGCAAGCTGA } \\
\text { AGCCCCTTCTGCAGAGATGGCTGGTCGAGGCAGAGACCTC } \\
\text { GGAAAATCCTCAAGATATGTACAAGGTTGAGCGAGTTT } \\
\text { TTGTCGACACCAGAAAAAGGAAGAGGAGGACCAGCCTG } \\
\text { GAGGGAGCGGTGCGCTCCGCCCTGGAGTCCTTCTACATC } \\
\text { AAGTGTCCCAAACCGAACACTCAGGAAATCACACAAATC } \\
\text { GCAGACGAGTTGGGCCTGGAAAGAGATGTGGTGCGTGTTT } \\
\text { GGTT }\end{array}$ & 278 \\
\hline sox2 & $\begin{array}{l}4 \mathrm{dpd}- \\
8 \mathrm{dpd}\end{array}$ & $\begin{array}{l}\text { TAGTCATGGAGTTGTACTGGAGCGCGCTCATGTCGTAGCG } \\
\text { GTGCATGGGCTGCATCTGGCCCGCGCCGTGCGCGTTCAGGC } \\
\text { CCGGGTGCTGGTAGCTCAGCTGCTCCTGCATCATCCCGT } \\
\text { AGCCGCCGTTGGTCCAGCCGTTCATGTGCGCCGCGTAGC } \\
\text { TGTCCATCCTCTGGTTCACCCCGCCGCCCAGCCCGGCCCC } \\
\text { GACCCCGACCCCGGTGCCCATCCCGTTGCCCCCGGGCGCCA } \\
\text { GCAGCCCCCCCGGCAGGGTGTACTTGTCCTTCTTCATGAGG } \\
\text { GTCTTG }\end{array}$ & 287 \\
\hline sox3 & $\begin{array}{l}4 \mathrm{dpd}- \\
8 \mathrm{dpd}\end{array}$ & $\begin{array}{l}\text { AACCCCAAAATGCACAACTCTGAAATCAGCAAGCGGCTCG } \\
\text { GCGCCGACTGGGAAACTTCTGACGGACGCGGAGAAGAG } \\
\text { GCCGTTCATCGACGAGGCCAAGCGGCTGCGCGCGATGCA } \\
\text { CATGAAAGAGCACCCGGATTATAAATACCGGCCCCGCAG } \\
\text { GAAGACCAAGACCCTGCTCAAGAAAGACAAGTATTCTTT } \\
\text { GCCCGGGGGTCTGTTGGCGCCAGGATCCAACGCCGTCAACA } \\
\text { ACTCGGTGTCGGTGGGGCAGCGCATGGACGGTTACGCGCA } \\
\text { CATGAACGGCTGGACCAAC }\end{array}$ & 295 \\
\hline chordin & $10 \mathrm{dpf}$ & $\begin{array}{l}\text { GCGTGGGTGTCAGTGGACAAACAGTGCCACCTGCACTATG } \\
\text { AAATAGTAGTCGCGGGTCTGAGTAAGAAGGAGGACGTCAC } \\
\text { TGTGAATGCCCACCTACATGGACTGGCTGAGATCGGGGAG } \\
\text { CTGGACAACAGCAGCACCACACACAAGAGGCTGCTGACGG } \\
\text { GCTTCTATGGCTCCCAGGCTCAGGGGATTTTAAAGGACCT } \\
\text { TAGTCTTGAATTACTGCAACACCTGGACCAGGGAACGGCC } \\
\text { TTCATCCAAGTCAGCACCAAGCTGAATCCCCAAGGAGAAA } \\
\text { TACGAGGACGGGTCCATGTTCCAAACAGCTGCGAGTCTGG } \\
\text { AGCCGGAGCCGAGGTGGAGGAGGCCGAGTTGGTGACACG } \\
\text { TTGCTGACAGATCCCGAGGAACTAAAGAAAGACCCCAACA } \\
\text { CTTGTTTTTTTGAGAACCAGCACCACGCTCATGGTTCCCGC } \\
\text { TGGACGCCTAACTATGACAAGTGTTTCACCTGCAGCTGCC } \\
\text { AGAAGAGGACAGTAATCTGTGATCCTGTCATCTGTCCCG } \\
\text { TGTTGACCTGCTCCAGAACCATTCAGCCTGAGGACAAG } \\
\text { TGCTGTCCCATCTGTGATGAAAAGCGAGAGCCCAAAGA } \\
\text { CATGAAAGCTGGAGAGAAGGTGGAAGAACATCCTGAAGG } \\
\text { GTGTTACTCTGAAGGAGATCAGAAAATGCATGCTCCAGGA } \\
\text { ATATCATGGCATCCGTTTGTTCCTCCATTTGGCTACATTAA } \\
\text { ATGTGCTGTCTGCACCTGCAAGGGGTCTTCAGGGGAGGTC } \\
\text { CACTGCGAGAAGGTGAC }\end{array}$ & 773 \\
\hline
\end{tabular}


Table 3.3 continued.

\begin{tabular}{|c|c|c|c|}
\hline noggin-1 & $\begin{array}{l}8 \mathrm{dpd}- \\
9 \mathrm{dpd}\end{array}$ & $\begin{array}{l}\text { CTGAACGAGACCGAGCTGAGGAGCATCCTGGGGGAGTTTG } \\
\text { ACCTGCGCTTTTTGTCCGCGTCCGTCCCCGCGGAGGACAGG } \\
\text { TTCCCGGGGAACGACGAGCTGGACGCGTCCGACAGCCTGA } \\
\text { GGGCGGGCGGCGGGATGATGCCCAAAGAGATCCGCGCCGT } \\
\text { GGACTTCGACGTCCAGGTGGGCAAGAAACAGAAACCCAG } \\
\text { CAAGAAGCTGAAGCGGCGGCTGCAGCAGTGGCTGTGGG } \\
\text { CCTACACCTCCTACCCGGTTCTGTACAGCTGGACCGACCT } \\
\text { GGGGATCCGCTTCTGGCCGCGCCACGTGCGCGCGGCCAGCT } \\
\text { GTCTGAGCAAGAGGTCGTGCTCCGTCCCGGAAGGGATGGT } \\
\text { CTGCAAACCCGCGAACTCGACCCACCTGACGCTGCTGAGGT } \\
\text { GGAGGTGCGTGCAGAGGAAGGCGGGGCTGAAGTGCGCGTG } \\
\text { GATCCCGATCCAGTACCCGCTCATCACAGACTGCAAATGCT } \\
\text { CC }\end{array}$ & 483 \\
\hline noggin-2 & $\begin{array}{l}8 \mathrm{dpd}- \\
9 \mathrm{dpd}\end{array}$ & $\begin{array}{l}\text { CTGTGGACCTACTCTTTCTGCCCTGTGGTGTACACCTGGAA } \\
\text { GGACCTGGGCGTGAGGTTCTGGCCGCGCTACATCAAGGAG } \\
\text { GGCAACTGTTTCTCCGAGCGCTCGTGCTCCTTCCCGGAGGG } \\
\text { GATGTCCTGCAAGCCCGTCAAGTCGGTCACCAAGATCTT } \\
\text { CCTGCGGTGGTACTGCCAGGGCTTTCTAAGACAGAAAT } \\
\text { ACTGTACGTGGATACAGGTGCAATACCCGGTCATCACAG } \\
\text { ACTGCAA }\end{array}$ & 245 \\
\hline follistatin & $\begin{array}{l}8 \mathrm{dpd}- \\
9 \mathrm{dpd}\end{array}$ & $\begin{array}{l}\text { CACCCTCTTTAGGTGGATGATCTTCAATGGGGGCGCGCCT } \\
\text { AATTGCATACCTTGCAAAGGTGGAGAAAGCTGCGAAAAC } \\
\text { GTGGACTGTGGGCCCGGGAAGACGTGCAAGATCAACCG } \\
\text { CAAGGGGAAGCCGCGCTGCGTGTGCGCGCCCGACTGCTC } \\
\text { CAACATCACCTGGAAGGGACCCGTCTGCGGCACAGACGG } \\
\text { CAAGACCTACAAAAACGAGCGCGCGCTCCTGAGGGCGAAA } \\
\text { TGCAAAACCAACCCGGACCTGGACGTGCAGTACCAGGGCA } \\
\text { AATGCAAGAAAACGTGCCGTCAGGTCTTGTGCCCCGGGAC } \\
\text { CTCCAACTGCGTTGTGGACCAGACGAACAACGCGTACTGC } \\
\text { GTGACGTGTAATCGGATTTGCCCCCCGCGACCTCGCCTGA } \\
\text { TCTGTACCTGTGTGGAAACGACGGGATCACATATCCGAGC } \\
\text { GCGTGCCACCTGAGAAAGGCGACCTGTCTGCTCGGCAGGTC } \\
\text { CATCGGGGTGGCGTACGACGGAAAATGCATCAAGGCCAAG } \\
\text { TCGTGTCAGGCCATCACGTGCAGCGCAGGAAAGAAGTGTC } \\
\text { TGTGGGACGATCGGACGGGCCGGGGCCGCTGCTCGGTCTGC } \\
\text { GTGGACCCCTGTCCACAGAGCCGGCCGAACGAGGCGGTGT } \\
\text { GTGCCAGCGACAACACCACATATCCCA }\end{array}$ & 665 \\
\hline$\beta$-actin & $3 \mathrm{dpf}$ & $\begin{array}{l}\text { CTGGAACGATGAAGGAAACTTAATGTTTTGGCTATGTT } \\
\text { TAATAAAAACACCCGGTTCATCTGGGGACTTAAAAATG } \\
\text { TACCTTTTTGTCATTCCAAATGTTTGTTAACTGCATTG } \\
\text { TTCAGACATGATTCCAGATGTTAACTGCATTGTTCAGAC } \\
\text { ACGTATTTGCCTCTGTGAAGGCTGCCCAGTGGTTGGCGCA } \\
\text { TACTTTAACATGGTTGTAGTATCGCTTGTATGTAAATTTG } \\
\text { TCTGGGGTTTTTTTAACTTTCAGCCTTAAAGAAAAACTTG } \\
\text { GTCCTGTTTAA }\end{array}$ & 284 \\
\hline
\end{tabular}


Table 3.3 continued.

\begin{tabular}{|l|l|l|l|}
\hline 18s rRNA & $3 \mathrm{dpf}$ & GAGGCTCTGCAGCTGAGCTTCCGGCCGGGGCCCGAAGCGTT & 427 \\
& & TACTTTGAAAAAATTAGAGTGTTCAAAGCAGGCCCGGTCG & \\
& & CCTGAATACCGCAGCCAGGAATAATGGAATAGGACTCCGG & \\
& & TTCTATTTTGTGGGTTTCCCTGAACTGGGGCCATGAT & \\
& TAAGAGGGACGGCCGGGGGCATTCGTATTGTGCCGCTA & \\
& GAGGTGAAATTCTTGGACCGGCGCAAGACGGACGAAAGC & \\
& GAAAGCATTTGCCAAGAATGTTTCATTAATCAAGAACGA & \\
& AAGTCGGAGGTTCGAAGACGATCAGATACCGTCGTAGTTC & \\
& CGACCATAAACGATGCCGACTAGCGATCCGGCGGCGTTAT & \\
& TCCCATGACCCGCCGGGCAGCGTCCGGGAAACCAAAGTCTT & \\
& TGGGTTCCGGGGCGAGTATGGTTCTGCAAC & \\
\hline
\end{tabular}


Table 3.4. Blast results of cloned A. limnaeus gene fragments. PCR fragments generated using primers and conditions listed in Table 3.3 were cloned, sequenced, and identities were inferred with blastn or blastx matches.

\begin{tabular}{|c|c|c|c|c|c|c|}
\hline $\begin{array}{l}\text { Putative } A . \\
\text { limnaeus } \\
\text { gene }\end{array}$ & $\begin{array}{l}\text { Top blast } \\
\text { hit }\end{array}$ & Algorithm & Identity & E value & $\begin{array}{l}\text { Query } \\
\text { Coverage }\end{array}$ & $\begin{array}{l}\text { GenBank } \\
\text { Accession }\end{array}$ \\
\hline oct 4 & $\begin{array}{l}\text { PREDICTED: } \\
\text { POU domain, } \\
\text { class 5, } \\
\text { transcription } \\
\text { factor 1-like } \\
\text { [Stegastes } \\
\text { partitus] }\end{array}$ & blastx & $92 \%$ & $9 e-53$ & $99 \%$ & $\begin{array}{l}\text { XP_00830 } \\
2560.1\end{array}$ \\
\hline sox2 & $\begin{array}{l}\text { PREDICTED: } \\
\text { transcription } \\
\text { factor SOX-2 } \\
\text { [Cynoglossus } \\
\text { semilaevis] }\end{array}$ & blastx & $95 \%$ & $2 \mathrm{e}-30$ & $99 \%$ & $\begin{array}{l}\text { XP_00833 } \\
6454.1\end{array}$ \\
\hline sox3 & $\begin{array}{l}\text { PREDICTED: } \\
\text { transcription } \\
\text { factor Sox-3- } \\
\text { like } \\
\text { [Xiphophorus } \\
\text { maculatus] }\end{array}$ & blastx & $100 \%$ & $1 \mathrm{e}-32$ & $100 \%$ & $\begin{array}{l}\text { XP_00579 } \\
9559.1\end{array}$ \\
\hline chordin & $\begin{array}{l}\text { PREDICTED: } \\
\text { chordin-like } \\
\text { [Poecilia } \\
\text { formosa] }\end{array}$ & blastx & $88 \%$ & $7 e-148$ & $99 \%$ & $\begin{array}{l}\text { XP_00756 } \\
2667.1\end{array}$ \\
\hline noggin-1 & $\begin{array}{l}\text { PREDICTED: } \\
\text { noggin-like } \\
\text { [Maylandia } \\
\text { zebra] }\end{array}$ & blastx & $78 \%$ & $2 \mathrm{e}-75$ & $100 \%$ & $\begin{array}{l}\text { XP_00455 } \\
6443.1\end{array}$ \\
\hline noggin-2 & $\begin{array}{l}\text { noggin2 } \\
\text { [Trachinotus } \\
\text { blochii] }\end{array}$ & blastx & $91 \%$ & $2 \mathrm{e}-49$ & $99 \%$ & $\begin{array}{l}\text { ACX71862 } \\
.1\end{array}$ \\
\hline follistatin & $\begin{array}{l}\text { PREDICTED: } \\
\text { follistatin-A- } \\
\text { like isoform } \\
\mathrm{X} 2 \\
\text { [Oreochromis } \\
\text { niloticus] }\end{array}$ & blastx & $84 \%$ & $3 e-132$ & $99 \%$ & $\begin{array}{l}\text { XP_00547 } \\
3610.1\end{array}$ \\
\hline$\beta$-actin & $\begin{array}{l}\text { Scatophagus } \\
\text { argus beta- } \\
\text { actin mRNA }\end{array}$ & blastn & $87 \%$ & $7 e-82$ & $98 \%$ & KF649214 \\
\hline 18S rRNA & $\begin{array}{l}\text { Nothobranch } \\
\text { ius furzeri } \\
\text { 18S rRNA }\end{array}$ & blastn & $97 \%$ & 0.0 & $97 \%$ & $\begin{array}{l}\text { N603833. } \\
1\end{array}$ \\
\hline
\end{tabular}


Table 3.5. Quantitative PCR assay primers and probes. Primer and probes were specific for the A. limnaeus genes identified in this chapter.

\begin{tabular}{|c|c|c|c|c|}
\hline $\begin{array}{l}\text { Putative } A . \\
\text { limnaeus } \\
\text { gene }\end{array}$ & F primer & R primer & Probe & $\begin{array}{l}\text { Amplico } \\
\text { n size } \\
\text { (bp) }\end{array}$ \\
\hline oct 4 & $\begin{array}{l}\text { AGATATGTACA } \\
\text { AGGTTGAGCGA } \\
\text { G }\end{array}$ & $\begin{array}{l}\text { TGTGATTTCC } \\
\text { TGAGTGTTCG } \\
\text { G }\end{array}$ & $\begin{array}{l}\text { /6- } \\
\text { FAM/TTGATGTAG/ZEN/A } \\
\text { AGGACTCCAGGGCG/IBFQ/ }\end{array}$ & 136 \\
\hline sox2 & $\begin{array}{l}\text { TAGCTCAGCTG } \\
\text { CTCCTGCATCA } \\
\text { T }\end{array}$ & $\begin{array}{l}\text { TGAACCAGAG } \\
\text { GATGGACAGC } \\
\text { TAC }\end{array}$ & $\begin{array}{l}\text { l6- } \\
\text { FAM/CGTTGGTCC/ZEN/A } \\
\text { GCCGTTCATGTG/IBFQ/ }\end{array}$ & 85 \\
\hline sox3 & $\begin{array}{l}\text { GACTGGGAAAC } \\
\text { TTCTGACGG }\end{array}$ & $\begin{array}{l}\text { TTTCTTGAGC } \\
\text { AGGGTCTTGG }\end{array}$ & $\begin{array}{l}\text { l6- } \\
\text { FAM/TGCACATGA/ZEN/A } \\
\text { AGAGCACCCGGAT/IBFQ/ }\end{array}$ & 136 \\
\hline chordin & $\begin{array}{l}\text { TTCATGTCTTT } \\
\text { GGGCTCTCG }\end{array}$ & $\begin{array}{l}\text { TGTCATCTGT } \\
\text { CCCGTGTTG }\end{array}$ & $\begin{array}{l}\text { /6- } \\
\text { FAM/TTGTCCTCA/ZEN/G } \\
\text { GCTGAATGGTTCTGG/IBF } \\
\text { Q/ }\end{array}$ & 96 \\
\hline noggin-1 & $\begin{array}{l}\text { TGTACAGAACC } \\
\text { GGGTAGGAG }\end{array}$ & $\begin{array}{l}\text { CAAGAAACAG } \\
\text { AAACCCAGCA } \\
\text { AG }\end{array}$ & $\begin{array}{l}\text { l6- } \\
\text { FAM/AGCAGTGGC/ZEN/T } \\
\text { GTGGGCCTA/IBFQ/ }\end{array}$ & 83 \\
\hline noggin-2 & $\begin{array}{l}\text { GTCAAGTCGGT } \\
\text { CACCAAGATC }\end{array}$ & $\begin{array}{l}\text { ATTGCACCTG } \\
\text { TATCCACGTA } \\
\text { C }\end{array}$ & $\begin{array}{l}\text { /6- } \\
\text { FAM/CTGTCTTAG/ZEN/A } \\
\text { AAGCCCTGGCAGTACC/IBF } \\
\text { Q/ }\end{array}$ & 85 \\
\hline follistatin & $\begin{array}{l}\text { GAGAAAGCTGC } \\
\text { GAAAACGTG }\end{array}$ & $\begin{array}{l}\text { TTTGTAGGTC } \\
\text { TTGCCGTCTG }\end{array}$ & $\begin{array}{l}\text { /6- } \\
\text { FAM/CTTCCCCTT/ZEN/GC } \\
\text { GGTTGATCTTGC/IBFQ/ }\end{array}$ & 146 \\
\hline$\beta$-actin & $\begin{array}{l}\text { TGGAACGATGA } \\
\text { AGGAAACTTAA } \\
\text { TG }\end{array}$ & $\begin{array}{l}\text { GGAATCATGT } \\
\text { CTGAACAATG } \\
\text { CAG }\end{array}$ & $\begin{array}{l}\text { /6- } \\
\text { FAM/TCCCCAGAT/ZEN/G } \\
\text { AACCGGGTGTTTT/IBFQ/ }\end{array}$ & 129 \\
\hline 18S rRNA & $\begin{array}{l}\text { ACTCCGGTTCT } \\
\text { ATTTTGTGGGT }\end{array}$ & $\begin{array}{l}\text { TCCAAGAATT } \\
\text { TCACCTCTAG } \\
\text { CG }\end{array}$ & $\begin{array}{l}\text { /6- } \\
\text { FAM/CCGTCCCTC/ZEN/TT } \\
\text { AATCATGGCCCC/IBFQ/ }\end{array}$ & 100 \\
\hline
\end{tabular}




\begin{tabular}{|l|l|c|c|c|l|}
\hline $\begin{array}{l}\text { Putative } \boldsymbol{A} . \\
\text { limnaeus } \\
\text { gene }\end{array}$ & $\begin{array}{l}\text { Danio rerio top } \\
\text { blastx hit }\end{array}$ & Identity & $\begin{array}{l}\text { E } \\
\text { value }\end{array}$ & $\begin{array}{l}\text { Query } \\
\text { Coverage }\end{array}$ & $\begin{array}{l}\text { GenBank } \\
\text { Accession }\end{array}$ \\
\hline oct4 & OCT4/POU5f1 & $88 \%$ & $7 \mathrm{e}-52$ & $99 \%$ & Q90270.1 \\
\hline sox2 & SOX2 & $91 \%$ & $2 \mathrm{e}-26$ & $91 \%$ & NP_998283.1 \\
\hline sox3 & SOX3 & $95 \%$ & $2 \mathrm{e}-29$ & $100 \%$ & NP_001001811.2 \\
\hline chordin & Chordin & $70 \%$ & $\begin{array}{c}1 \mathrm{e}- \\
122\end{array}$ & $99 \%$ & AAI62594.1 \\
\hline noggin-1 & Noggin-1 & $68 \%$ & $4 \mathrm{e}-63$ & $100 \%$ & NP_571058.2 \\
\hline noggin-2 & $\begin{array}{l}\text { Noggin-2 } \\
\text { precursor }\end{array}$ & $86 \%$ & $3 \mathrm{e}-47$ & $99 \%$ & NP_571067.1 \\
\hline follistatin & Follistatin & $81 \%$ & $\begin{array}{c}7 \mathrm{e}- \\
126\end{array}$ & $99 \%$ & AAH78241.1 \\
\hline
\end{tabular}

Table 3.6. Top blastx searches of $A$. limnaeus gene fragments to $D$. rerio. The blastx algorithm infers sequence similarity by first translating mRNA into an amino acid sequence. 


\section{CHAPTER 4:}

\section{Mitochondrial DNA sequence and stability}

\section{Introduction}

The majority of vertebrates are notoriously sensitive to oxygen

deprivation. Taking place exclusively within intracellular organelle known as mitochondria, oxidative phosphorylation (OXPHOS) is the primary mechanism by which ATP is produced in vertebrates and requires a steady supply of oxygen as the terminal electron receptor (Scheffler, 2011). In mammals, insufficient oxygen quickly leads to disruption of cellular homeostasis and cell death (Nilsson and Lutz, 2004). Even under normal physiological conditions, mitochondria are by no means a static organelle, and are constantly degraded and replenished (Youle and Van Der Bliek, 2012). Mitochondria are hypothesized to be descendant from an endosymbiotic relationship between an alpha-proteobacteria and an early eukaryotic host (Lang et al., 1999). As such, mitochondria contain their own, albeit diminished, genomes (mtgenomes) that code for several proteins, rRNAs, and tRNAs, and many studies agree that mtgenomes can evolve several times faster than nuclear genomes (Jacobs et al., 2000; Youle and Van Der Bliek, 2012) due in part to increased rates of mutation in the mtgenome (Denver et al. 2000). The process of OXPHOS is inherently complicated, requiring coordination between nuclear and mitochondrial proteins. 
Changes in mtDNA sequence and copy number can have profound effects on mitochondrial protein function and expression. These changes can often have effects on mitochondrial physiology and subsequently affect the ability of an organism to cope with oxygen stress (Bratic and Larsson, 2013; Kowald and Kirkwood, 2014).

Although the majority of vertebrates have a similar sensitivity to anoxia after considering differences in body temperature, several aquatic vertebrates have developed unique strategies to cope with bouts of anoxia (Podrabsky et al., 2012b). Specifically, embryos of A. limnaeus are highly tolerant to anoxia and have two orders of magnitude greater tolerance than any other vertebrate examined (Podrabsky et al., 2007; Podrabsky et al., 2012b). The most anoxia tolerant embryonic stage of A. limnaeus occurs approximately midway through development during diapause (DII); this tolerance is retained for the first 4-6 days of resumed development and is then subsequently lost by the time embryos enter diapause III (Podrabsky et al., 2007). The mechanisms by which A. limnaeus embryos are able to tolerate anoxia are not completely known. However, previous work has suggested that during diapause, a combination of reduced ATP consumption through depressed protein synthesis, extremely low levels of OXPHOS activity, and depressed heart rate likely all contribute to the anoxia tolerant phenotype (Duerr and Podrabsky, 2010; Podrabsky and Hand, 1999; Podrabsky and Hand, 2000). In addition, A. limnaeus embryos are able to 
avoid apoptosis following anoxia treatment, which is highly atypical of a vertebrate response to anoxia (Meller and Podrabsky, 2013). However, little is known about the regulation of A. limnaeus embryonic mitochondria during anoxia, specifically whether or not mitochondrial genomes are stabilized as opposed to being degraded. Previous work has suggested that in anoxia- and hypoxia-sensitive mammalian models, exposure of cells to low oxygen conditions can result in mitochondrial autophagy (mitophagy) or mitochondrial biogenesis following reoxygenation (Youle and Van Der Bliek, 2012; Zhang et al., 2008). As a part of these previous studies, measurement of mitochondrial:genomic DNA ratios were used to give an indication of mitochondrial degredation and biogenesis during normal and stressful physiological conditions. Considering the extensive role of mitochondria in regulating and carrying out OXPHOS and apoptosis signaling, characterization of the A. limnaeus mitochondrial genome sequence, dynamics of mtDNA copy number during embryonic development, and the response of mtDNA to anoxia are of great interest. On a broader level, the physiological consequences of shifts in mtDNA/gDNA ratios during vertebrate embryonic development is poorly understood and warrant further investigation.

Because all vertebrates contain mitochondria, the use of mitochondrial DNA (mtDNA) for phylogenetic inference has been a common practice for several decades. Although more recently the validity of such 
inferences that rely only on a single molecule with very important physiological roles has come into question (Ballard and Whitlock, 2004), phylogenetic inference based on mtDNA is still commonly used for species for which nuclear genome evidence is sparse. Use of all coding and tRNA sequences of mtgenomes has been shown to improve bootstrap support in teleost molecular phylogenies, and thus may provide improved phylogenetic inferences (Miya and Nishada, 2000). Because only a small fraction of the $A$. limnaeus mtgenome has previously been sequenced and used for phylogenetic inference (Murphy et al., 1999), increasing the number of phylogenetically informative positions with a complete mtgenome may improve the placement of A. limnaeus within the Order Cyprinodontiformes.

To further advance A. limnaeus as a comparative model for vertebrate extreme stress tolerance, I describe the complete mtgenome sequence of $A$. limnaeus and compare it to other closely related species. I also measure relative mtDNA content during post-diapause development following anoxia and recovery from anoxia in both anoxia-tolerant ( 4 days post-diapause II, dpd) and anoxia-sensitive (12 and $22 \mathrm{dpd}$ ) embryos. Potential implications for understanding the role of mitochondria in anoxia tolerance of A. limnaeus are then discussed.

\section{Materials and Methods}

\section{Total genomic DNA extraction of adult and embryonic tissues}


DNA extraction of adult tissues: The tissue used for Illumina sequencing was derived from a single male A. limnaeus (hatch date: $12 / 17 / 13$, euthanize date: $3 / 11 / 14,3.7 \mathrm{~g}$ wet mass). The fish was euthanized by immersion in an ice bath for approximately five minutes followed by cervical transection. Liver, white muscle (skin and scales removed), and brain tissue were removed and transferred to DNA extraction buffer (10 mM Tris, $100 \mathrm{mM}$ EDTA, 0.5\% SDS, $200 \mu \mathrm{g} \mathrm{ml}^{-1}$ Proteinase K (Thermo Scientific \#E00491), pH 8.0) at a ratio of $1 \mathrm{mg}$ tissue per $10 \mu \mathrm{l}$ buffer. Tissues were gently homogenized using a Teflon pestle in $1.5 \mathrm{ml}$ microcentrifuge tubes and incubated for $3 \mathrm{~h}$ at $50^{\circ} \mathrm{C}$ with agitation every 2030 min. DNA was extracted by mixing (briefly vortexing) the homogenates with 1 vol phenol (equilibrated with $10 \mathrm{mM}$ Tris-HCl pH 8.0, 1 mM EDTA) followed by centrifugation at $5,000 \mathrm{x} g$ for $10 \mathrm{~min}$ at $4^{\circ} \mathrm{C}$. The aqueous phases were collected using a wide-bore pipette and extracted again as above with phenol. Following the second phenol extraction, the aqueous phase containing the DNA was extracted a third time by gentle mixing with 1 volume of chloroform:phenol (1:1) followed by centrifugation at 5,000 $\mathrm{x} g$ for 10 min at $4^{\circ} \mathrm{C}$. The aqueous phase was collected and the DNA precipitated by the addition of $\mathrm{NaCl}$ (final concentration of $200 \mu \mathrm{M}$ ) and 2 volumes of $100 \%$ EtOH followed by mixing by tube inversion. DNA was pelleted by centrifugation at $16,000 \mathrm{x} g$ for $10 \mathrm{~min}$ at $4^{\circ} \mathrm{C}$. The DNA pellet was washed twice with $1 \mathrm{ml}$ 70\% EtOH. After each wash the DNA was pelleted by 
centrifugation at $16,000 \mathrm{xg}$ for $5 \mathrm{~min}$ at $4^{\circ} \mathrm{C}$. The air-dried $(5-10 \mathrm{~min}$ at room temperature) DNA pellet was resuspended in $500 \mu \mathrm{l}$ of RNAse buffer (10 mM Tris, 5 mM EDTA) with $100 \mu \mathrm{g} \mathrm{ml}^{-1}$ DNAse-free RNAse A (Thermo Scientific \#EN0531) by incubation at $37^{\circ} \mathrm{C}$ for $45 \mathrm{~min}$ with occasional tube inversion. The samples were extracted twice more as described above with chloroform:phenol (1:1) followed by precipitated using 0.1 vol of 3 M sodium acetate, $\mathrm{pH} 5.2$, and 2 vol of $100 \%$ EtOH. DNA was pelleted by centrifugation at $16,000 \mathrm{xg}$ for $10 \mathrm{~min}$ at $4^{\circ} \mathrm{C}$ and the pellet was washed twice with $1 \mathrm{ml}$ $70 \%$ EtOH as described above. The DNA pellets were dried briefly at room temperature and resuspended in $100 \mu \mathrm{l}$ of buffer EB (10 mM Tris-Cl pH 8.5, Qiagen \#19086) at $37^{\circ} \mathrm{C}$ with occasional agitation until pellets dissolved completely.

DNA quantification and quality assessment: Total genomic DNA concentrations and $\mathrm{A}_{260} / \mathrm{A}_{280}$ ratios were determined using the Infinite M200 Pro plate reader equipped with a NanoQuant plate (Tecan, San Jose, CA, USA) using $2 \mu \mathrm{L}$ of sample and default software settings (i-control software, Tecan). DNA integrity was determined by $1 \%$ agarose gel electrophoresis of $1 \mu \mathrm{g}$ of total DNA and observation of high-molecular weight DNA above 20 $\mathrm{kb}$.

\section{Sequencing and read quality control}


Illumina Sequencing: DNA sequencing libraries were prepared and sequenced at the University of Oregon High Throughput DNA sequencing and Genomics facility. Purified DNA was sonicated to an average size of $170 \mathrm{bp}$ and was prepared for sequencing using the Nextera library prep kit (Illumina). Fragment libraries were sequenced on the Illumina Hi-Seq 2000 platform with 101 bp paired-end reads.

Sanger sequencing: Polymerase chain reaction (PCR) was used to amplify specific regions of the mitochondrial genome. PCR products were generated using total DNA from adult liver as the DNA template. The primers used in this chapter are listed in Table 4.2. PCR reactions (50 $\mu$ l total volume) consisted of $50 \mathrm{ng}$ total DNA, $10 \mathrm{pmol}$ of forward and reverse primers (Integrated DNA Technologies, Table 4.2), 0.25 U Taq polymerase (New England BioLabs \#M0267L), in 1X ThermoPol buffer (New England BioLabs \# M0267L). The reactions were heated for an initial $5 \mathrm{~min}$ at $95^{\circ} \mathrm{C}$ followed by 40 cycles of: $20 \mathrm{sec}$ at $95^{\circ} \mathrm{C}, 20 \mathrm{sec}$ at $60^{\circ} \mathrm{C}$, and $5 \mathrm{~min}$ at $68^{\circ} \mathrm{C}$. A single final elongation step of $10 \mathrm{~min}$ at $68^{\circ} \mathrm{C}$ followed the initial 40 cycles. PCR products were resolved on $1 \%$ agarose, excised, cloned into the pGEM-T vector, and transformed into E. coli JM109 high-efficiency cells (Promega) as described in Chapter 2. Plasmids were purified using the Qiagen Miniprep kit and Sanger sequenced at Oregon Health and Science University using the primers indicated in Table 4.3. 
Read quality control: Adapters were removed from Illumina reads using Trimmomatic (Bolger et al., 2014) and the included Illumina adapter list. Error-correction was performed using the Allpaths error correction module (Gnerre et al., 2011). Sanger reads were trimmed of vector contamination using the UniVec tool in the Geneious 6.1.8 suite (New Zealand) and bases with a greater than $5 \%$ chance of error were trimmed (Kearse et al., 2012).

\section{Assembly and annotation of the A. limnaeus mitochondrial genome}

The A. limnaeus mitochondrial genome was assembled using mitochondrial baiting and iterative mapping (MitoBIM) software on the default settings (Hahn et al., 2013). Input sequence consisted of a 100 million read subset of the total DNA Illumina reads (Table 4.1). A short DNA sequence of A. limnaeus cytochrome oxidase I (NCBI accession AF002589.1) was used to seed the initial baiting of mitochondrial reads. Sanger contigs from sequenced clones were assembled de novo using Geneious. Reads were mapped using the Geneious algorithm post-assembly to verify assembly quality. SNPs were called using the Geneious Variant Caller with a minimum frequency of $25 \%$.

The resulting A. limnaeus mitochondrial genome was annotated using the MitoAnnotator pipeline (Iwasaki et al., 2013). Geneious software was used to visualize alignments and annotations. Conserved sequence blocks 
(CSBs) were identified from consensus sequences derived from previously identified sequences (Broughton et al., 2001; Lee et al., 2001). The MITOS webserver was used to fold tRNAs into predicted cloverleaf structures (Bernt et al., 2013). Repetitive motif identification and clustering were obtained using RepFind (Betley et al., 2002).

\section{Mitochondrial genome investigations}

Phylogenetic analysis: Complete mitochondrial genomes from other Cyprinodontid species were retrieved from the MitoFish database for comparative analysis (Iwasaki et al., 2013) and included Aplocheilus panchax (Acanthopterygii; Atherinomorpha; Cyprinodontiformes; Aplochelidae), Cyprinodon rubrofluviatillis (Acanthopterygii; Atherinomorpha;

Cyprinodontiformes; Cyprinodontidae), Fundulus spp. (Acanthopterygii; Atherinomorpha; Cyprinodontiformes; Fundulidae), Gambusia affinis (Acanthopterygii; Atherinomorpha; Cyprinodontiformes; Poeciliidae), Jordanella floridae (Acanthopterygii; Atherinomorpha; Cyprinodontiformes; Cyprinodontidae), Kryptolebias marmoratus (Acanthopterygii; Atherinomorpha; Cyprinodontiformes; Rivulidae), Nothobranchius furzeri (Acanthopterygii; Atherinomorpha; Cyprinodontiformes; Nothobranchiidae), Xenotoca eiseni (Acanthopterygii; Atherinomorpha; Cyprinodontiformes; Goodeidae), and Xiphophorus spp. (Acanthopterygii; Atherinomorpha; Cyprinodontiformes; Poeciliidae). Oryzias latipes (Acanthopterygii; 
Atherinomorpha; Beloniformes, Adrianichthyidae) was used as an outgroup (Table 4.4). Mitochondrial genes in comparator species were identified using the MitoAnnotator pipeline as done with A. limnaeus. Individual coding genes and tRNAs were aligned using the MUSCLE alignment tool as part of the Geneious suite (Edgar, 2004; Kearse et al., 2012). Alignments were concatenated and poorly aligned regions were trimmed (total trimmed was $4 \%$ of initial alignment) following visual inspection using Geneious. Third codon positions were removed from alignments to avoid saturation bias (Kumazawa and Nishida, 1993). The final alignment contained 7,713 nucleotide positions and phylogenetic relationships were inferred using MrBayes 3.1.2 (Ronquist and Huelsenbeck, 2003). MrBayes was run using this alignment on the public CIPRES server (Miller et al., 2010) with the following settings: Nst $=6$, Rrates $=$ Invgamma, Ngen $=10,000,000$, sampling every 1,000 gen, nchains $=8$, nruns $=2$, burnin $=0.25$, outgroup $=$ O. latipes, as previously used by Whitehead (2009).

Codon usage. Codon usage tables and nucleotide position composition ratios of coding genes were obtained using CAIcal (Puigbò et al., 2008). RNA and DNA secondary structure predictions. tRNA-Ser2 secondary structures were predicted using LocARNA with default settings (Smith et al., 2010; Will et al., 2012). LocARNA uses RNA alignments to predict a possible secondary structure. DNA secondary structures were predicted using the 
RNAstructure webserver with settings for DNA folding (Reuter and Mathews, 2010).

\section{qPCR analysis of normoxic and anoxia-treated A. limnaeus embryos}

Anoxia treatment: Embryos were exposed to anoxia as previously described (Podrabsky et al., 2012a). A. limnaeus embryos were staged at DII, 4 dpd (early organogenesis), $12 \mathrm{dpd}$ (full overgrowth), and $22 \mathrm{dpd}$ (prehatching) (Wourms, 1972a). Prior to anoxia treatment, embryos were collected in petri dishes (100 x $15 \mathrm{~mm}$ plastic dishes) and excess embryo medium was removed using a pipette. Embryos were transferred into a Bactron III anaerobic chamber and rinsed three times with embryo medium that was previously purged for 30 min with $\mathrm{N}_{2}$ gas. Anoxic conditions were maintained through the use of an anaerobic gas mixture $\left(5 \% \mathrm{H}_{2}, 5 \% \mathrm{CO}_{2}\right.$, balance $\mathrm{N}_{2}$ ) and a palladium catalyst (Sheldon Manufacturing, Cornelius, OR) for the duration of anoxia exposure. Embryos at stages $4 \mathrm{dpd}, 12 \mathrm{dpd}$, and 22 dpd were sampled at $0 \mathrm{~h}$ normoxia $(\mathrm{t}=0), 24 \mathrm{~h}$ anoxia, and $24 \mathrm{~h}$ recovery (9 embryos per replicate). Embryos were staged as previously described by Wourms (1972a). Unexposed normoxic embryos at $24 \mathrm{~h}$ and $48 \mathrm{~h}$ were also sampled for comparison. DII embryos were sampled only at normoxia. Embryos were incubated at $25^{\circ} \mathrm{C}$ for the duration of the experiment in all treatments. Control and normoxic-recovery embryos were collected onto a nylon mesh screen (100 $\mu \mathrm{m}$ mesh) and blotted dry using Kimwipes before 
being transferred into $1.5 \mathrm{ml}$ microcentrifuge tubes and immediately flashfrozen in liquid N2. Embryos sampled during anoxia were blotted dry, transferred into tubes, and sealed within the anoxic chamber prior to freezing. Frozen embryos were stored at $-80^{\circ} \mathrm{C}$ until DNA extraction. Total genomic DNA extraction of embryos. Embryonic DNA was extracted using the DNeasy Blood and Tissue Kit (Qiagen \#69581). Embryos were homogenized on ice in their microcentrifuge tubes using a Teflon pestle in $400 \mu \mathrm{l}$ of kit provided lysis buffer ATL containing $2 \mathrm{mg} \mathrm{ml}^{-1}$ of Proteinase $\mathrm{K}$ (Thermo Scientific \# E00491) and were incubated at $56^{\circ} \mathrm{C}$ for $1 \mathrm{hr}$. Samples were then centrifuged for $5 \mathrm{~min}$ at $300 \mathrm{xg}$ at $4^{\circ} \mathrm{C}$ to pellet insoluble debris. The supernatant and $400 \mu \mathrm{l}$ of buffer AL were then transferred into a new microcentrifuge tube and incubated at $56^{\circ} \mathrm{C}$ for $10 \mathrm{~min}$. The sample was then mixed with $400 \mu \mathrm{l}$ of $100 \% \mathrm{EtOH}$ and was applied to the DNeasy silica columns and washed according to manufacturer instructions. DNA was eluted in $100 \mu \mathrm{l}$ of buffer AE. Quality and quantity of DNA was assessed as described above for the adult tissues. $m t D N A$ and gDNA qPCR assay. Primers for qPCR were designed using default settings in the IDT PrimerQuest tool (IDT) with the mitochondrial gene NADH dehydrogenase 4 (ND4) or nuclear insulin-like growth factor-1 receptor (IGFR1) genes as inputs (Table 4.5). The DNA sequence of each amplicon from each gene/primer set was verified by cloning and DNA sequencing as described in Chapter 1. Purified plasmids with verified PCR 
inserts for either ND4 or IGFR1 were used as standards. qPCR reactions (20 $\mu$ l total volume) were set up in triplicate using SsoAdvanced Universal SYBR Green Supermix (Bio-Rad, \#172-5270) and consisted of $25 \mathrm{ng}$ total DNA, 10 $\mu \mathrm{l}$ of $2 \mathrm{X}$ SsoFast Probes Supermix, $500 \mathrm{nM}$ of forward and reverse primers. Assays were set up in clear 96-well semi-skirted PCR plates (Hard-Shell High-Profile PCR plates, Bio-Rad, \#HSS-9601) with optical flat caps (Bio-Rad, \#TCS-0803). All qPCR reactions were carried out in the Stratagene Mx3005P thermocycler (Agilent Technologies, Santa Clara, CA). Standard curves were generated using a serial 1:10 dilution of amplicon-specific plasmid copies (1 ng $-1 \mathrm{e}^{-7} \mathrm{ng}$ for ND4 and $1 \mathrm{e}^{-1}-1 \mathrm{e}^{-7}$ for IGFR1). Reactions were initially heated at $95^{\circ} \mathrm{C}$ for 5 min to activate the DNA polymerase and subsequently thermocycled for 35 cycles by denaturation at $95^{\circ} \mathrm{C}$ for $30 \mathrm{sec}$ and annealing/elongation at $60^{\circ} \mathrm{C}$ for $30 \mathrm{sec}$. Fluorescence readings (excitation $492 \mathrm{~nm}$, emission $516 \mathrm{~nm}$ ) were taken at the end of each elongation step. Quantification cycle $\left(\mathrm{C}_{q}\right)$ thresholds were set automatically in Stratagene MxPro software (ver. 4.10, 2007) using adaptive baseline, moving average, and amplification-based threshold settings. Although rarely necessary, thresholds were manually adjusted to improve standard curve best-fit regressions. Assays were validated by visualizing qPCR end products via gel electrophoresis in addition to observation of a single melting dissociation curve. 


\section{Results}

\section{Sequence analysis of the A. limnaeus mitochondrial genome}

The initial assembly of the A. limnaeus mtgenome using only MITObim and Illumina reads incorrectly assembled the D-loop region, as discovered by post-assembly readmapping and identification of breakpoints characteristic of misassembly (Figure 4.1). Usage of cloned PCR products identified the correct sequence order (Figure 4.2) and was confirmed by mapping of Illumina reads with a final average coverage of 8,863X (Figure 4.3).

The complete $A$. limnaeus mitochondrial genome contains 21,039 bases, 37.3\% GC, and is circular. MitoAnnotator identified two rRNAs, 21 tRNAs, 13 protein-coding genes, and two D-loops (D-loop 1 and D-loop 2) separated by a partial 16S rRNA and duplicated tRNA-Leu sequences (Figure 4.4). The protein-coding genes included NADH-ubiquinone oxidoreductase subunits $1,2,3,4,5$, and 6 (ND1, ND2, ND3, ND4, ND5, and ND6), cytochrome $c$ oxidase subunits 1,2 , and 3 (C01, CO2, C03), cytochrome $b$ (Cytb), and $\mathrm{F}_{1} \mathrm{~F}_{0}-\mathrm{ATP}$ synthase subunits (ATPase-6 and ATPase-8). The A. limnaeus mtgenome is maximally $68.9 \%$ similar to $K$ marmoratus, when D-loops are omitted. Sequence alignment of the two A. limnaeus D-loops (Alim-Dloop 1 and Alim-Dloop 2) identified a 1,497 bp region with 100\% pairwise identity (Figure 4.5). The remaining D-loop sequence contains a high amount of AT repeats, the most frequent of which is the motif "TAA", and a significant proportion of repeats clustered in the unshared portion of D-loop sequences 
(Figure 4.6). After alignment of D-loops from several species, two putative CSBs were identified in A. limnaeus (CSB-1 and CSB-2), and these CSBs were discovered in both D-loop 1 and D-loop 2 (Figure 4.7). Occurring between Dloop 1 and D-loop 2 is a region with partial homology to the $16 \mathrm{~S}$ rRNA, including a $178 \mathrm{bp}$ (95.2\% identity) and $431 \mathrm{bp}$ (88.5\% identity) region, collectively referred to as pseudo-16S (Figure 4.8). The region between Cytb-12S, in addition to the occurrence of both the $16 \mathrm{~S}$ and pseudo-16S, were confirmed in multiple A. limnaeus adult individuals (Figure 4.9). The putative origin of light-strand replication $\left(\mathrm{O}_{\mathrm{L}}\right)$ is a $36 \mathrm{bp}$ region found between tRNAAsn and tRNA-Cys and is predicted to fold into a hairpin structure (Figure 4.10) (Seutin et al., 1994).

Although most tRNAs were identified and folded into predicted structures (Figure 4.11), neither MitoAnnotator nor MITOS annotation pipelines were able to automatically identify tRNA-Ser (anticodon TGA) in $A$. limnaeus. The A. limnaeus tRNA-Ser was identified by MUSCLE alignment of tRNA-Ser from N. furzeri, O. niloticus, F. heteroclitus, and K. marmoratus to the assembled A. limnaeus mtgenome and extracting the overlapping sequence (Figure 4.12). The putative A. limnaeus tRNA-Ser has the potential to fold into a cloverleaf structure, as predicted using LocARNA (Figure 4.13). Identically to the mtgenomes of other species within the Order Cyprinodontiformes, most identified genes were determined to be encoded on the $\mathrm{H}$ strand, aside from the ND6 gene and eight tRNAs which are encoded 
on the L strand (Table 4.6). The lengths of the coding genes are comparable to other species, except for ND1, which appears to be truncated by 27 nucleotides at the 5' end of the gene when compared to K. marmoratus. The A. limnaeus ND1 gene also differs from other species by having a "GTG" start codon, as opposed to "ATG" found in K. marmoratus, A. panchax, and N. furzeri. The overall gene nucleotide composition of the A. limnaeus mtgenome is similar to other Cyprinodontiformes examined (Figures 4.14 and 4.15). Also similar to the other Cyprinodontiformes, the A. limnaeus coding genes that are transcribed on the $\mathrm{H}$ strand are depleted of guanine at the second and third codon positions. This bias against guanine at the second and third codon positions is not as apparent in ND6, which is transcribed on the $\mathrm{L}$ strand, although A. limnaeus and K. marmoratus have lower guanine at these positions when compared to A. panchax and N. furzeri. The top five most frequent codons for A. limnaeus, A. panchax, N. furzeri, and K. marmoratus are listed in Table 4.7. These four species share four of the top five most frequently used codons in their respective mtgenomes. Five SNPs were identified, with four occurring in the $16 \mathrm{~S}$ rRNA and one predicted to cause a synonymous amino acid change in ND4L (Table 4.8).

\section{Phylogenetic analysis}

Bayesian phylogenetic analysis using mtgenomes revealed a single clade for A. panchax, A. limnaeus, K. marmoratus, and N. furzeri. Aside from 
the outgroup O. latipes, all other species (C. rubrofluviatillis, the Fundulus spp., G. affinis, J. floridae, X. eiseni, and the Xiphophorus spp.) formed a single separate clade (Figure 4.14). As indicated by differences in branch lengths, the number of substitutions per site of annual killifish species A. limnaeus and $N$. furzeri are approximately doubled when compared to non-annuals $K$. marmoratus and A. panchax.

\section{Mitochondrial genome copy number dynamics}

Relative mtDNA copy number did not change significantly in $4 \mathrm{dpd}, 12$ dpd, and 22 dpd embryos in response to exposure to anoxia or during normoxic recovery (Figure 4.15). However, relative copy number decreases during early post-diapause II development under normoxic conditions and, by 12 and $13 \mathrm{dpd}$, relative mtDNA content decreased by approximately $40 \%$ (One-way ANOVA with Dunnett's Multiple Comparison Test, p < 0.05). At other normoxic stages, the difference in relative mtDNA is not significant.

\section{Discussion}

\section{A. limnaeus mtgenome features}

The sequencing and assembly of the complete A. limnaeus mtgenome represents the fourth mtgenome available for the Superfamily Aplocheiloidei, the first South American annual killifish species sequenced, and only the second annual killifish sequenced (Figure 4.4). Many features thought to be 
conserved among vertebrate mitochondria have been identified, including all 13 expected coding genes, 22 tRNAs, 2 rRNAs, the origin of light-strand replication, D-loop, CSB-1, and CSB-2 (Table 4.6, Figures 4.5 and 4.7) . Aside from tRNA-Cys, the identified A. limnaeus tRNAs folded into the expected four-armed cloverleaf structures (Figure 4.11) (Jühling et al., 2009). Although the A. limnaeus tRNA-Cys is predicted to be missing the D-arm of the cloverleaf structure, loss of the D-arm in tRNAs has been previously described in other animals and there is no evidence that loss of this structure inhibits tRNA function (Seutin et al., 1994; Watanabe et al., 2014). Nucleotide composition and synteny of the A. limnaeus mtgenome is generally well shared with other members of the Order Cyprinodontiformes. Previously reported mitochondrial-sequencing biases using Illumina chemistry, especially in repetitive AT-rich regions, likely explain the variation in sequencing coverage observed in the A. limnaeus genome (Ekblom et al., 2014; Harismendy et al., 2009; Vancampenhout et al., 2014). Overall, these results suggest that this current iteration of the A. limnaeus mtgenome is highly complete and will serve as a valuable reference for future studies that require the A. limnaeus mtgenome sequence.

Although the overall gene lengths are similar between species examined, the A. limnaeus ND1 gene appears to have a 27 nucleotide-pair (9 amino acid) truncation at the 5' end of the gene when aligned to $K$. marmoratus, $N$. furzeri, and A. panchax. Currently, there is no evidence of 
heteroplasmy of the ND1 gene in our laboratory stock A. limnaeus. In the nematode Caenorhabditis briggsae, a naturally occurring partial deletion of $785 \mathrm{bp}$ of ND5 has been shown to persist in heteroplasmic individuals, and may even be preferentially inherited over the wildtype allele (Clark et al., 2012). This deletion is associated with elevated levels of ROS and reduced fitness in C. briggsae (Estes et al., 2011). Flanking direct repeats, thought to facilitate the deletion of ND5 in C. briggsae, were not observed in the $A$. limnaeus genome around ND1. As an essential component of Complex I in the mitochondrial ETC, ND1 is a protein typically consisting of 8 transmembrane $\alpha$-helices (Hirst, 2013). ND1 forms the binding site for the matrix arm of complex I and is thought to participate in forming a channel for ubiquinone to move out of the membrane and into the protein complex (Hirst, 2013). While the functional consequence of this apparent deletion is unknown, even this small deletion of 9 amino acids, which corresponds to half of a typical 20 amino acid length for a transmembrane helix, could have significant consequences for function of the intact protein. It is curious that this deletion occurs in mitochondria from the most anoxia tolerant vertebrate. This deletion could potentially lead to increased efficiency of the electron transfer process and thus reduce ROS production by preventing electron escape as they pass through Complex I. Or conversely, it could decrease efficiency of Complex I and lead to the rather slow rates of metabolism associated with A. limnaeus development and entrance into 
diapause (Podrabsky and Hand, 2015). It should be noted that N. furzeri does not appear to have the ND1 deletion, but neither does it share the extreme anoxia tolerance of $A$. limnaeus embryos (Polačik and Podrabsky, unpublished). Thus, this deletion (if functionally important) is more likely to be associated with tolerance of anoxia rather than the ability to enter diapause. Confirmation of this deletion in other populations of A. limnaeus and exploration of the functional consequences of this deletion in ND1 may be a fruitful area for future studies.

Another region in A. limnaeus that is divergent when compared to other species was the D-loop region. It has been known for several decades that this region can be highly variable in sequence and length between species. Although the mechanisms of this variation are unclear, it is possibly the result of relaxed selection (Lee et al., 1995). All fish species within the Order Cyprinodontiformes, with the exception of three out of the four Superfamily Aplocheiloidei species, have a D-loop located between tRNA-Phe and tRNA-Pro, suggesting this location as the ancestral genotype. However, divergent D-loop architecture is certainly the case within the Superfamily Aplocheiloidei. Out of the four killifish species with complete mitochondrial sequences available, three (K. marmoratus, N. furzeri, and A. limnaeus) have some degree of D-loop duplication. Out of these three species, A. limnaeus is the only one that appears to have lost the ancestral D-loop between tRNAPhe and tRNA-Pro. While the D-loop duplication of K. marmoratus produced 
two nearly identical regions, the D-loop duplications of A. limnaeus and $N$. furzeri appear to be more complex, containing both duplicated regions as well as unique regions. Without evidence for heteroplasmy in A. limnaeus, it is difficult to infer the sequence of events that occurred to generate the modified D-loop sequences observed in these data. One possibility includes 4 sequential steps: (1) duplication of the ancestral D-loop from tRNA-Phe tRNA-Pro into the region between tRNA-Leu2 and ND1 to form Alim-D-loop 1, (2) deletion of most of the ancestral tRNA-Phe - tRNA-Pro D-loop, (3) duplication of Alim-D-loop 1 to form Alim-D-loop 2, which also includes a partial duplication of the nearby $16 \mathrm{~S}$ rRNA thus producing the pseudo-16S sequence between Alim-D-loop 1 and Alim-D-loop 2, possibly through illegitimate recombination (Hoarau et al., 2002; Mjelle et al., 2008; Raboin et al., 2010; Rokas et al., 2003), and (4) expansion of repetitive AT elements in Alim-D-loop 1 and Alim-D-loop 2, possibly by polymerase slippage at the repetitive AT clusters (Levinson and Gutman, 1987).

The physiological implications of having repositioned and/or duplicated D-loops are unclear. In snakes, duplicated D-loop regions are not uncommon, and there is evidence that both regions are able to function in replication and transcription processes (Jiang et al., 2007). Similar to the Dloop duplication found in K. marmoratus (Lee et al., 2001), the snake duplicated D-loop regions flank both the $12 \mathrm{~S}$ and $16 \mathrm{~S}$ rRNAs, and Jiang et al. (2006) proposed that having dual regulatory regions might allow for 
differential regulation of mitochondrial rRNA and mRNA. However, this hypothesis has yet to be tested. In typical mammalian mitochondria, different transcriptional binding sites allow for differential transcription of rRNA and mRNAs, with one polycistronic molecule transcribing almost the entire $\mathrm{H}$-strand, and the other stopping after transcribing through the $12 \mathrm{~S}$ and 16S rRNAs (Fernández-Silva et al., 2003). It is thought that the incomplete polycistronic RNA containing the $16 \mathrm{~S}$ and $12 \mathrm{~S}$ rRNA is transcribed $\sim 20$ times more frequently than the polycistronic RNA covering nearly the entire $\mathrm{H}$ strand, suggesting that rRNA abundance is an important factor in mitochondrial function (Fernández-Silva et al., 2003). Interestingly, $\mathrm{H}$-strand transcription starting from the repositioned D-loop in A. limnaeus would cause the rRNAs to be transcribed near the end of the polycistronic molecule. This implies that either a new transcriptional start site has evolved upstream of the rRNAs, or that all of the $\mathrm{H}$-strand protein coding and tRNA genes would be transcribed along with rRNAs after every round of transcription. Coordinated expression of the entire H-strand may be advantageous to A. limnaeus by allowing for rapid and simultaneous expression, or depression, of tRNA, rRNA, and mRNA. The presence of CSB-2, thought to be important in mitochondrial RNA transcription stabilization (Fernández-Silva et al., 2003; Pham et al., 2006; Xu and Clayton, 1995), in both D-loops suggests that H-strand RNA polymerase binding sites may also be duplicated, perhaps allowing for increased transcription rates of the $\mathrm{H}$ - 
strand. A mechanism to rapidly resupply mitochondrial RNAs, as embryos transition from metabolic dormancy into active development may be advantageous. Determining the extent to which the duplicated D-loop is present in other species of annual killifish, and rates of mitochondrial transcription between species with one or two D-loops, and identifying transcriptional start sites will be essential for testing this hypothesis.

Increased rate of evolution in annual killifish mtgenome

In agreement with previously described phylogenies, Bayesian phylogenetic analysis of the Order Cyprinodontiformes revealed two major clades that included the Superfamily Aplocheiloidei and Superfamily Cyprinodontoidei (Figure 4.16) (Setiamarga et al., 2008; Whitehead, 2009). Within the Superfamily Aplocheiloidei, the Family Rivulidae is represented by sister taxa A. limnaeus and K. marmoratus, while species N. furzeri (Family Nothobranchidae) and A. panchax (Family Aplochelidae) are placed into separate clades (Hrbek and Larson 1999).

Based on the observation of the increased rate of substitution in annual killifish genomes compared to non-annuals, and the unconventional D-loop structures found in the Superfamily Aplocheiloidei, it is tempting to associate development in a hostile environment to increased rates of mutation. However, a recent study in nematodes suggests that increased rates of cell stress, such as ROS, do not increase the rate of heritable 
mutations due to base substitutions (Joyner-Matos et al., 2011). Similar studies have not yet been performed in vertebrates. Annual killifish likely face small, isolated populations and seasonal death of all reproductively viable adults. Therefore, it is difficult to determine how much of the mitochondrial genome architecture in the annual killifish is due to bona fide natural selection, and how much is actually due to stochastic drift events (Ballard and Whitlock, 2004; Hanski and Gilpin, 1997). Future analysis in multiple killifish species of both mitochondrial and nuclear derived genes important to aerobic metabolism will be essential for determining how annual killifish mitochondria have evolved to tolerate extreme environmental stress.

\section{Mtgenome copy number paradox}

Although regulation of mtDNA copy number is clearly important during development and aging, whether or not it correlates with mitochondrial OXPHOS activity appears to be tissue and species specific (Carling et al., 2011; Montier et al., 2009; Youle and Van Der Bliek, 2012). Nonetheless, measurement of mtDNA copy number may provide insight into changes in mitochondria as organisms develop and encounter stressful conditions. In zebrafish embryos, the mtDNA/gDNA ratio does not change significantly from $6 \mathrm{hpf}$ (shield stage) until the end of embryonic development, while the overall rate of aerobic metabolism increases linearly 
over this same period (Artuso et al., 2012; Stackley et al., 2011).

Interestingly, A. limnaeus mtDNA/gDNA ratios are the lowest in $12 \mathrm{dpd}$ embryos, when OXPHOS activity has been measured to be at its peak (Duerr and Podrabsky, 2010). This suggests that mtDNA abundance may not be directly linked to OXPHOS activity during normoxic development in $A$. limnaeus (Figure 4.18). These data also suggest that mtDNA primary template is "stockpiled" at relatively high abundance per cell during dormant stages (DII and DIII). Because the stability of transcribed mitochondrial RNA may be on the order of hours or days (Gelfand and Attardi, 1981; Piechota et al., 2006), it may be more advantageous to maintain high copies of longerlived mtDNA instead of RNA. In principle, high abundance of primary mtDNA copies could allow rapid expression of mitochondrial genes upon termination of diapause, although this has only been demonstrated in mammalian tissue (Bai et al., 2000). Because mtDNA synthesis does not necessarily need to be coupled with gDNA synthesis (Alcolea et al., 2006), it is possible that depletion of mtDNA copies in actively developing (12 dpd) embryos occurs because excessive mtDNA from diapause II is carried over, thus obviating the need for additional mtDNA synthesis (Figure 4.18). Determining if the trend in mtDNA copy number during development is conserved during annual and non-annual killifish development in multiple species would begin to test these hypotheses. 
Changes in cellular mtDNA content are also associated with treatment of anoxia and reoxygenation. Specifically, anoxia-sensitive mammalian cells substantially reduce mitochondrial volume and mtDNA copy number when exposed to a hypoxic environment, a result likely achieved through mitophagy (Youle and Van Der Bliek, 2012; Zhang et al., 2008). Reoxygenation after ischemia is typically accompanied by biogenesis of mitochondria, with a nearly four-fold increase in mtDNA content after $24 \mathrm{~h}$ of reoxygenation. It is likely that ROS associated with reperfusion initiates this response (Lee and Wei, 2005; Li et al., 2012; Yin et al., 2008). Whether this biogenesis following reoxgenation is adaptive is uncertain, although it has been suggested to counteract mitochondrial dysfunction by the production of new mitochondria (Chen et al., 2011; Rasbach and Schnellmann, 2007). Nonetheless, these studies suggest that mammalian mitochondria respond dynamically to low oxygen and ischemia/reoxygenation conditions. This response is clearly not shared by dormant or developing embryos of $A$. limnaeus, as demonstrated by unchanged relative mtDNA content following anoxia and reoxygenation (Figure 4.17). It should be noted that active development of 12 dpd embryos is absolutely dependent on aerobic respiration (Podrabsky and Hand, 1999). Further, these embryos are comprised of several tissues that are typically oxygen-sensitive, such as a brain and heart, and yet there is no significant change in total mtDNA content in response to anoxia or recovery from anoxia. These data suggest that 
anoxia-tolerant organisms such as $A$. limnaeus may not utilize mitophagy during periods of anoxia and do not experience mitochondrial biogenesis following reoxygenation. Although ROS levels have not yet been measured in A. limnaeus embryos following anoxia treatment, it is possible that mitochondrial biogenesis does not occur following reoxygenation because ROS levels are not increased sufficiently. This is supported by evidence from studies in adult tissues from another anoxia-tolerant vertebrate, the turtle, where ROS levels are not elevated following $2 \mathrm{~d}$ anoxia and $1 \mathrm{~d}$ reoxygenation (Lutz et al., 2003). Additionally, there is no evidence for lipid peroxidation during anoxia or recovery in the turtle, further supporting the hypothesis that ROS is effectively controlled in anoxia-tolerant species (Lutz and Milton, 2004; Willmore and Storey, 1997). Future studies that determine if A. limnaeus mitochondrial volume and capacity for respiration correlate with mtDNA content and remain unchanged during anoxia/reoxygenation will be helpful in determining the extent to which mitochondria are stabilized during periods of depleted oxygen. Additionally, it would be worthwhile to measure ROS levels following anoxia/reoxygenation to determine if ROS may play a role in mitochondrial function during anoxia, or if there is an alternative mechanism that is preventing mitochondrial biogenesis in A. limnaeus. 


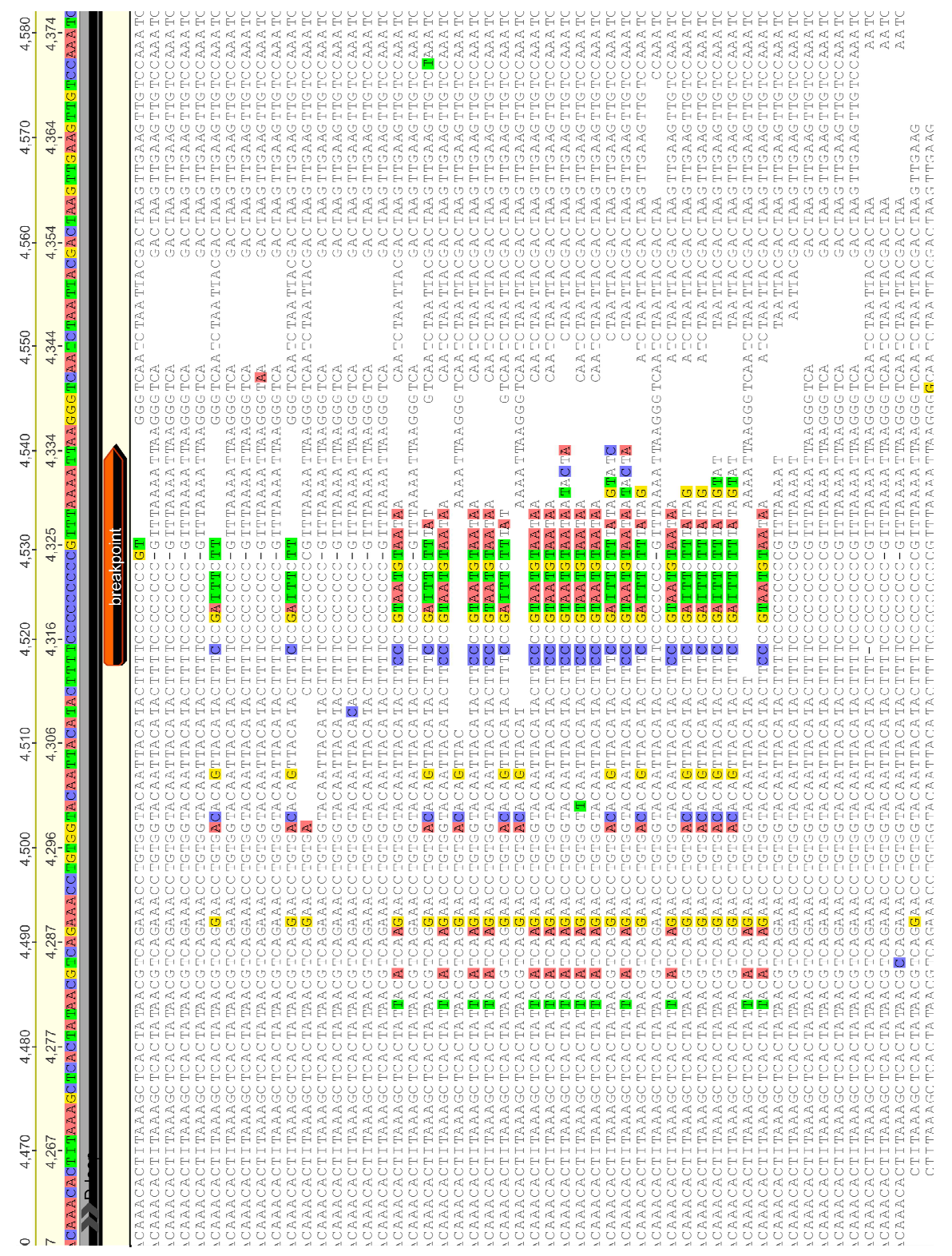

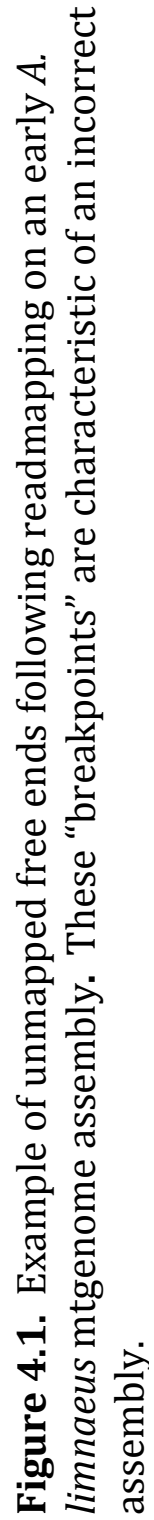




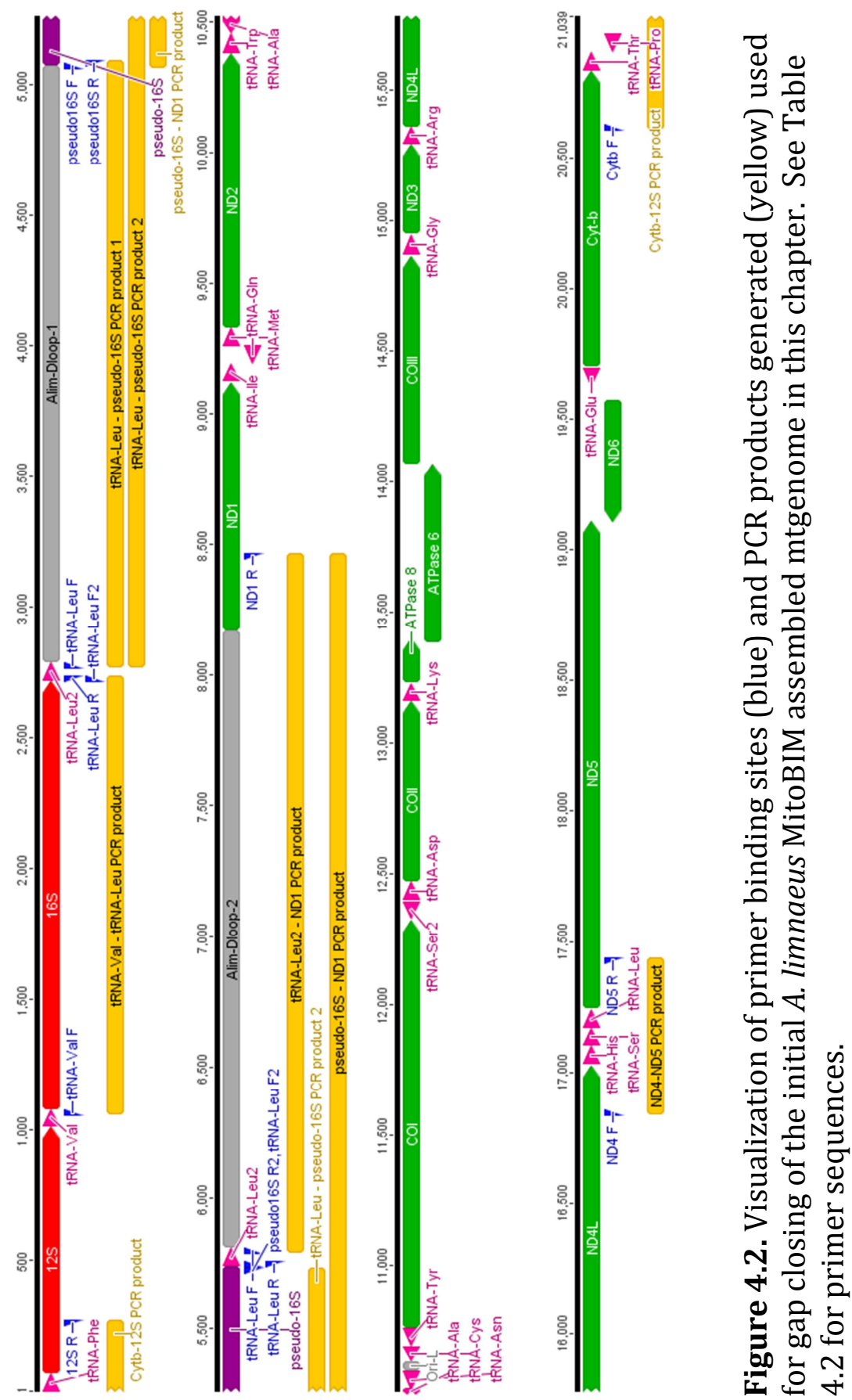




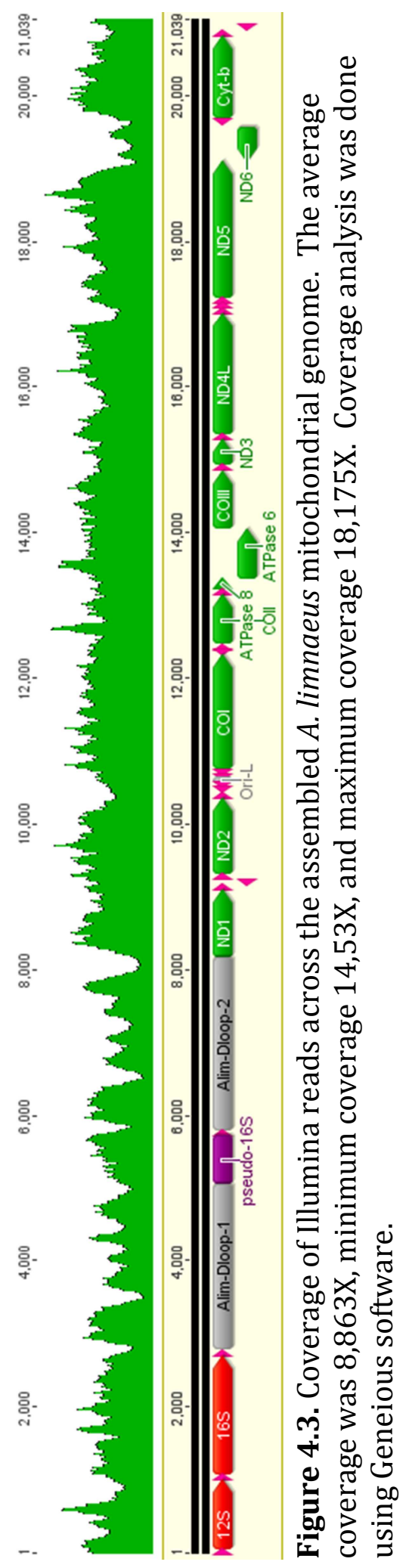




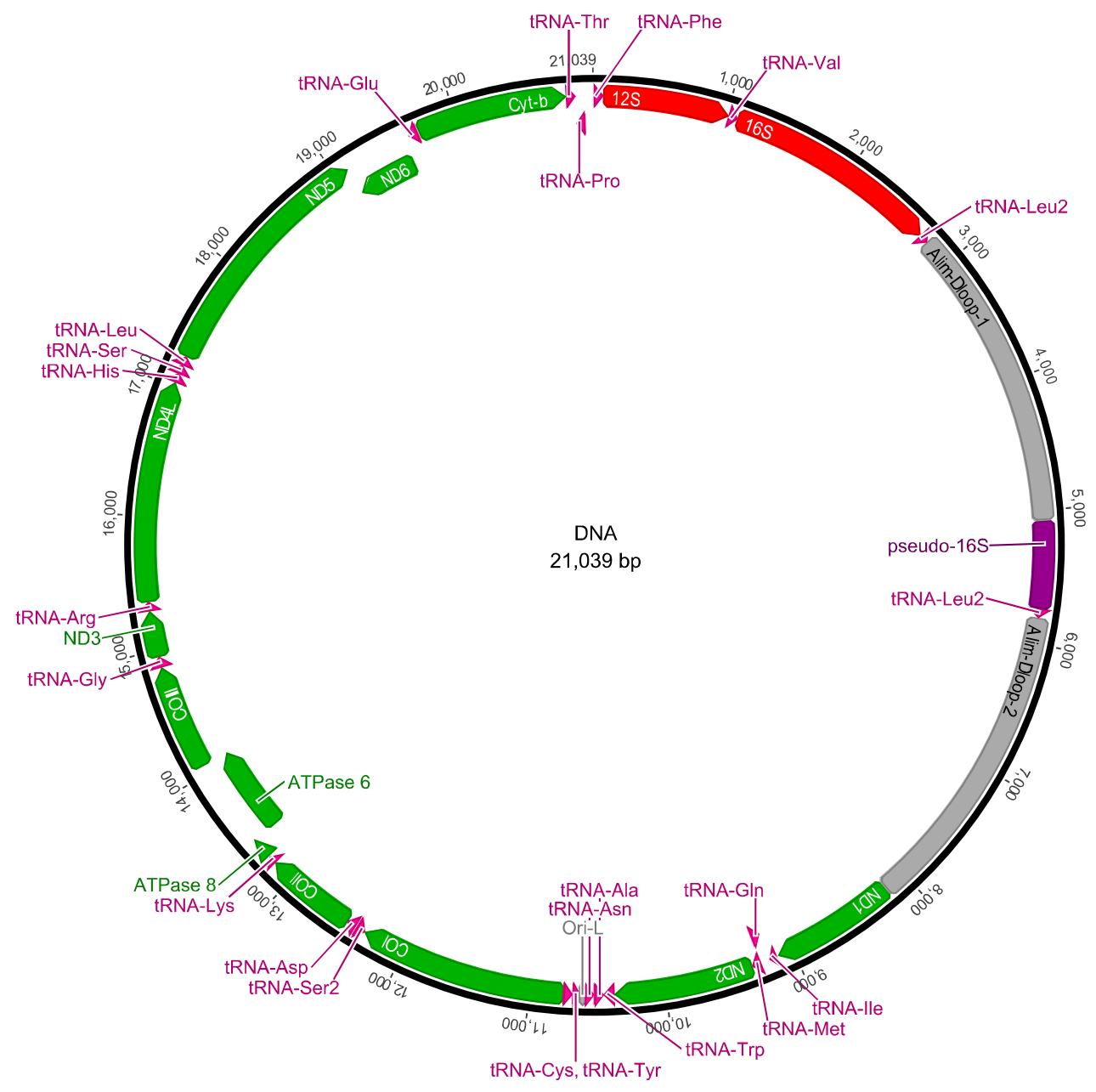

Figure 4.4. The complete annotated mtgenome of $A$. limnaeus. Genes are noted in green, tRNAs in pink, D-loops and the origin of light strand replication (abbreviated Ori-L) are in grey, rRNA in red, and the pseudo-16S rRNA in purple. 


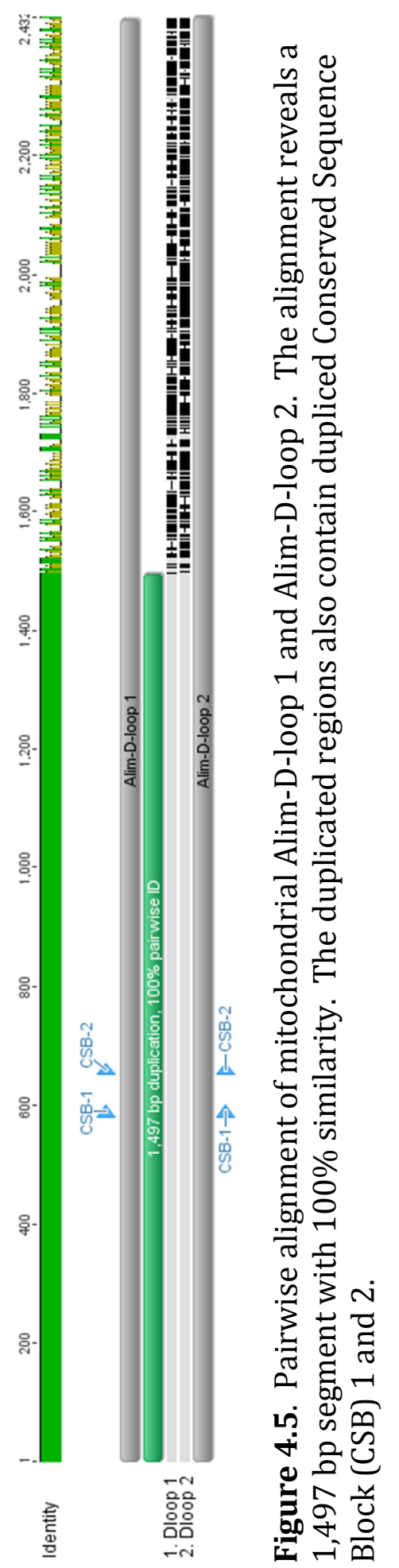


Alim-D-loop 1

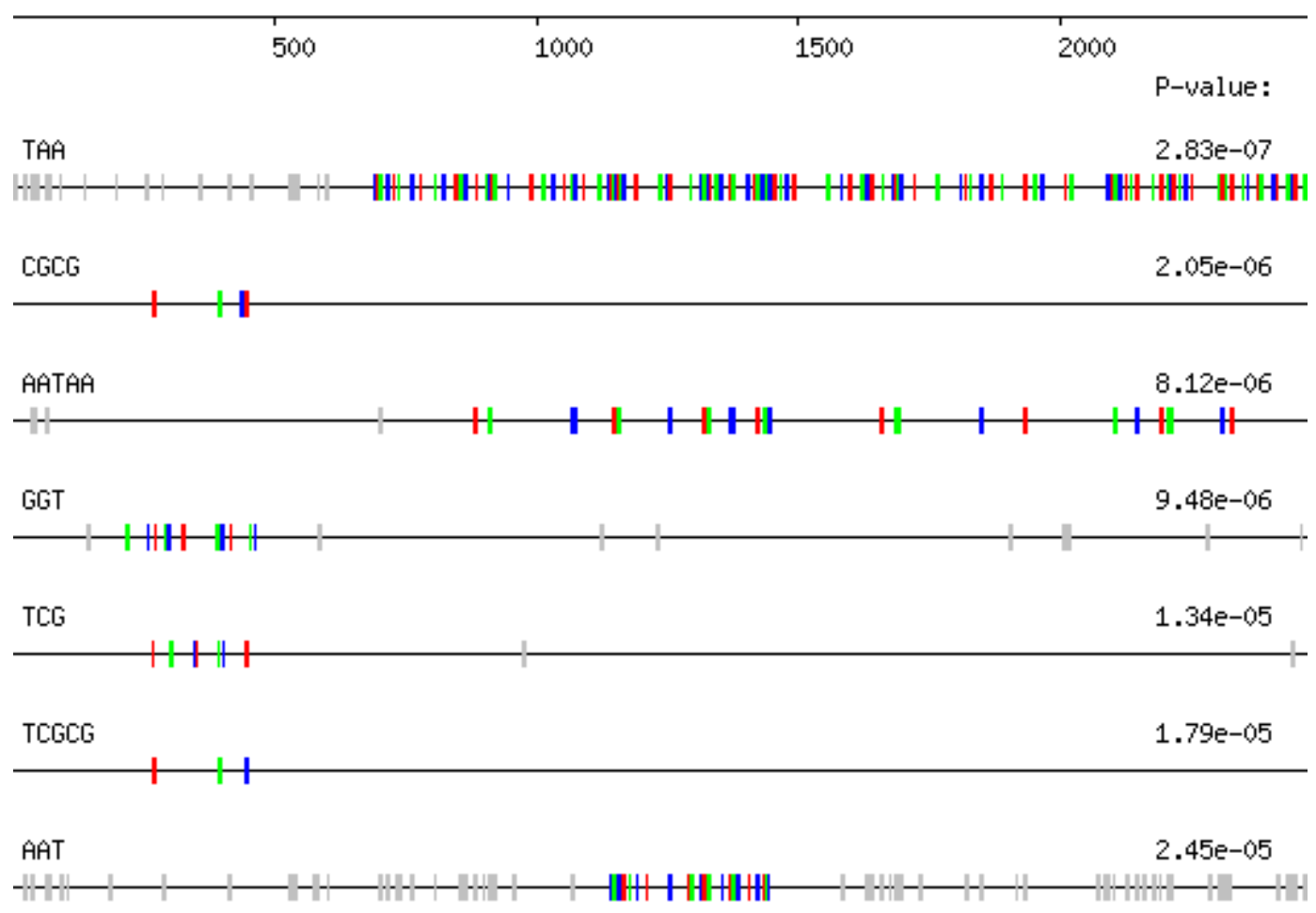

Alim-D-loop 2

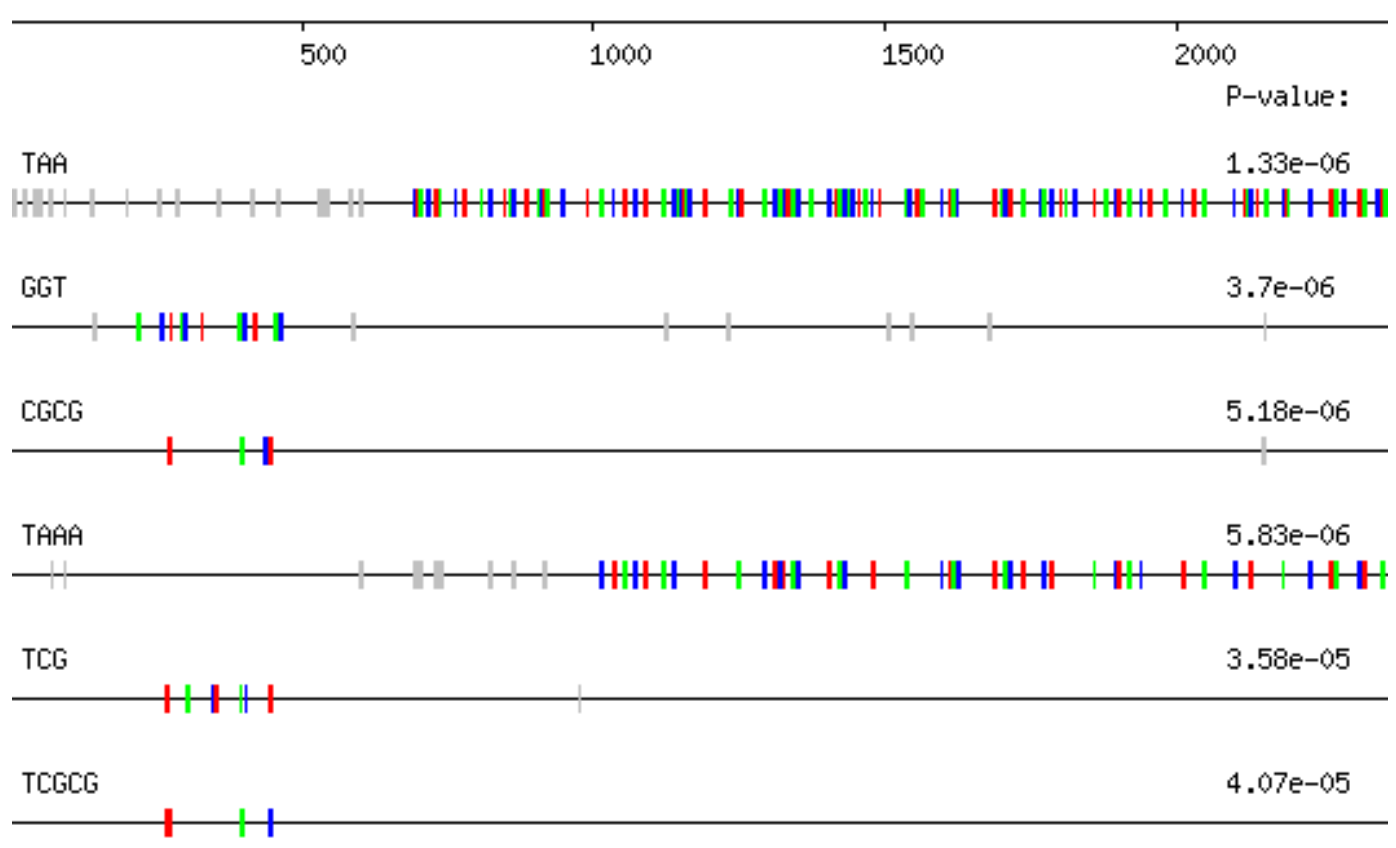

Figure 4.6. RepFind analysis of Alim-D-loop 1 (top panel) and Alim-D-loop 2 (bottom panel) repetitive motifs. The RepFind P-value indicates the probability of finding the cluster of the specific type of repeats by chance alone (Betley et al., 2002). 
Consensus

1. A. limnaeus

2. A. panchax

3. K. marmoratus

4. F. heteroclitus

5. X. maculatus

Consensus

1. A. limnaeus

2. A. panchax

3. F. heteroclitus

4. K. marmoratus

5. X. maculatus

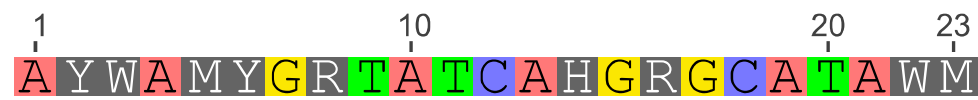

. C T.A T.G... T.A... A A

.TA.C . A ... T.A....AA

.TA.CT.A.... . G... TC

.TA.CT.A....A.A....AA

$. \mathrm{TA} . \mathrm{CT} . \mathrm{A} \ldots . . \mathrm{A} . \mathrm{A} \ldots \mathrm{AA}$

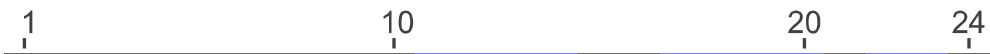

Figure 4.7. Consensus motifs of Conserved Sequence Block-1 (CSB-1, top) and Conserved Sequence Block-2 (CSB-2, bottom). The consensus sequences were used to find homologous sequences in the D-loops of the A. limnaeus mtgenome. 


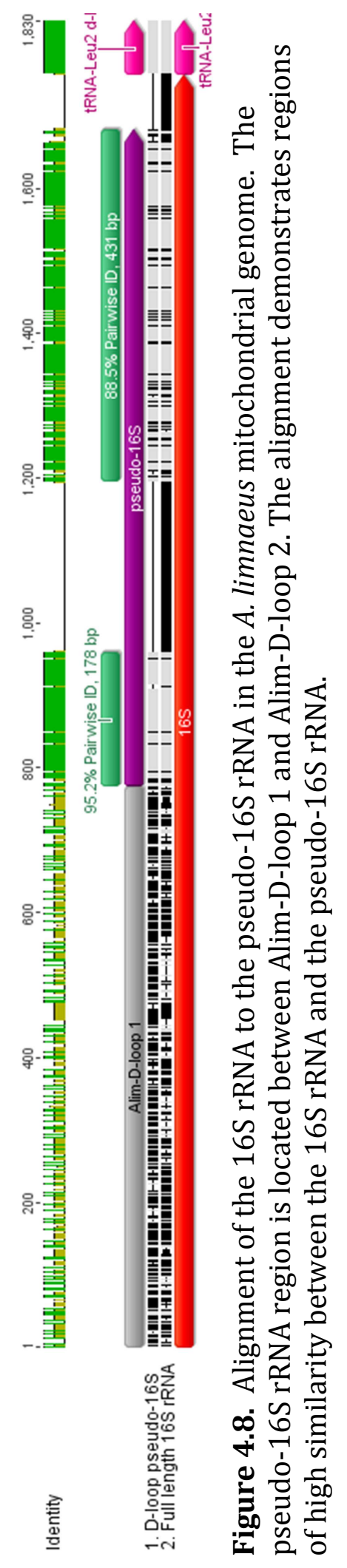




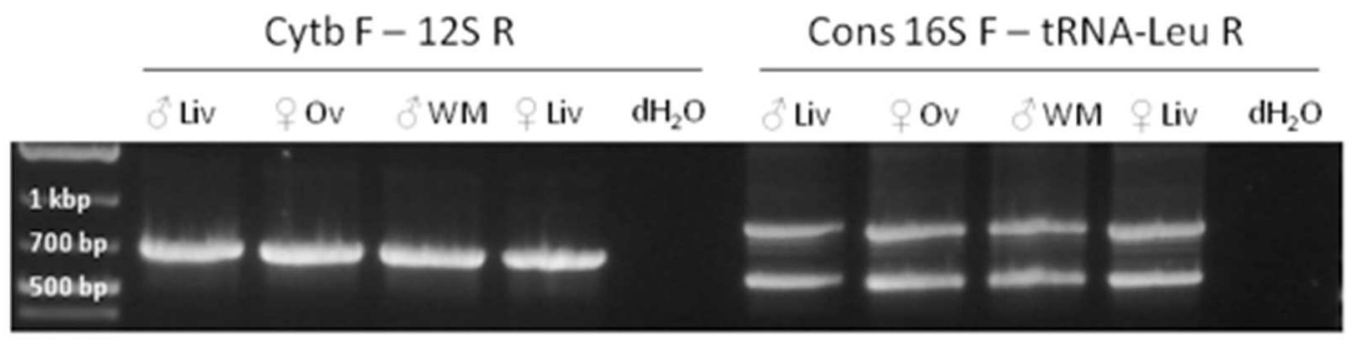

Figure 4.9. Verification of $A$. limnaeus mtgenome regions across individuals and tissue types using PCR. The Cytb F-12S R primer set amplifies the region that usually contains the D-loop in other species, thus confirming the loss of the ancestral D-loop in multiple A. limnaeus individuals and tissue types. The Cons $16 \mathrm{~S}$ - F - tRNA-Leu R primer set amplifies regions using primers that are conserved between the 16S rRNA and pseudo-16S, demonstrating the truncated length associated with the pseudo-16S. Abbreviations: Liv, liver; Ov, ovary; WM, white muscle. 

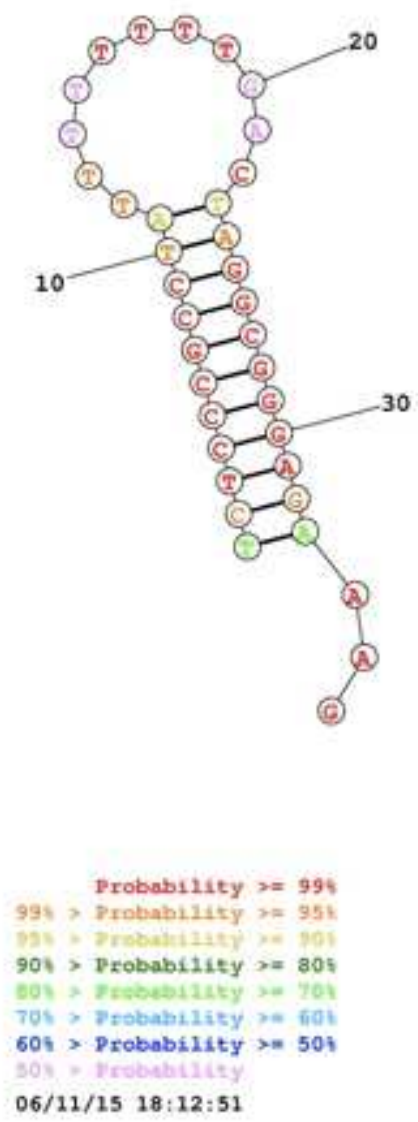

Figure 4.10. Predicted folding structure of A. limnaeus origin of light-strand replication $\left(\mathrm{O}_{\mathrm{L}}\right)$ using the RNAstructure webserver. The sequence is located between tRNA-Asn and tRNA-Cys and has a high probability of folding into a stem-loop structure. 

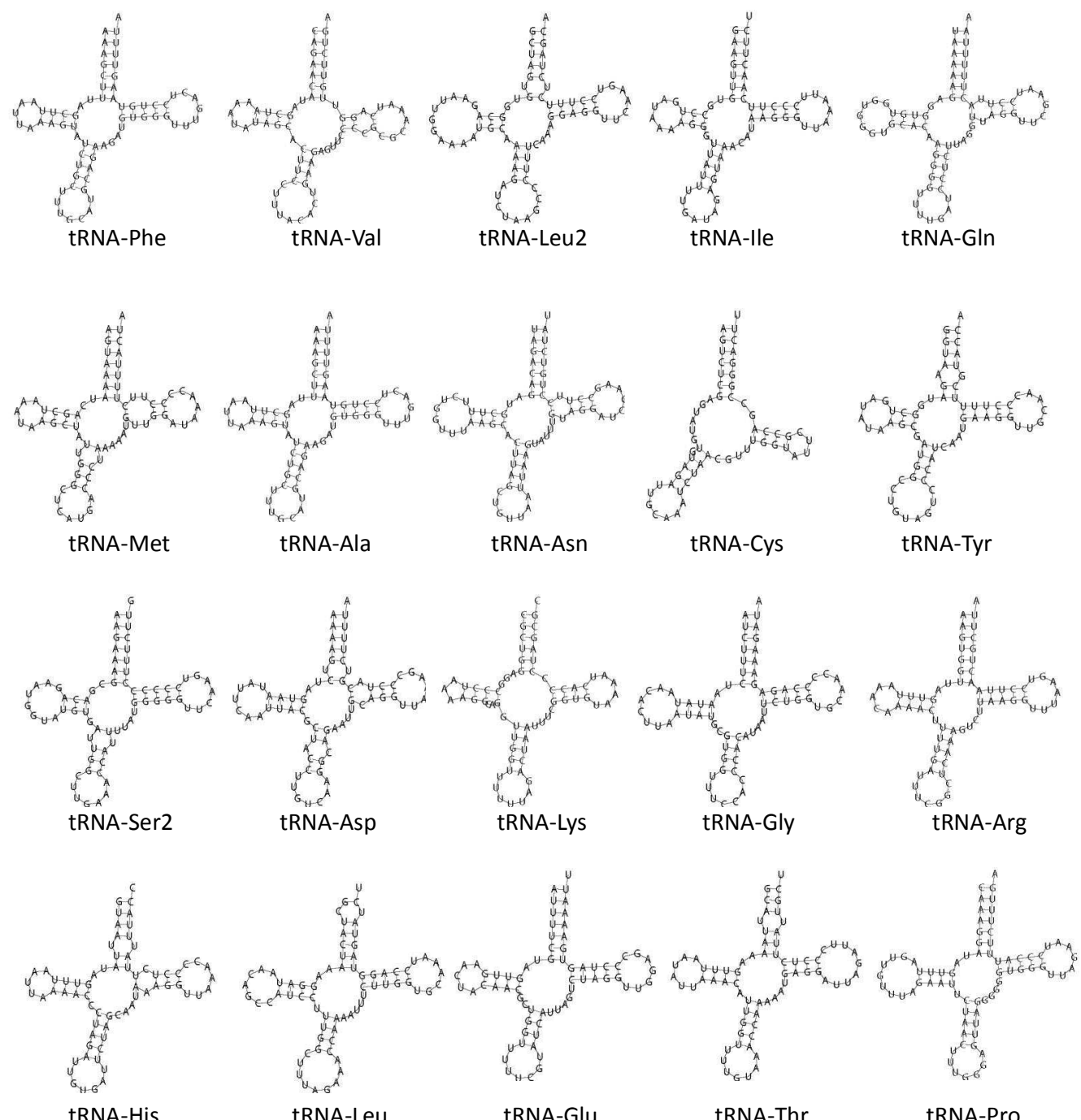

tRNA-His

tRNA-Leu

tRNA-Glu

tRNA-Thr

tRNA-Pro

Figure 4.11. Predicted secondary structures of identified mitochondrial tRNAs in A. limnaeus as generated from MITOS. These tRNAs were also identified by MitoAnnotator. 


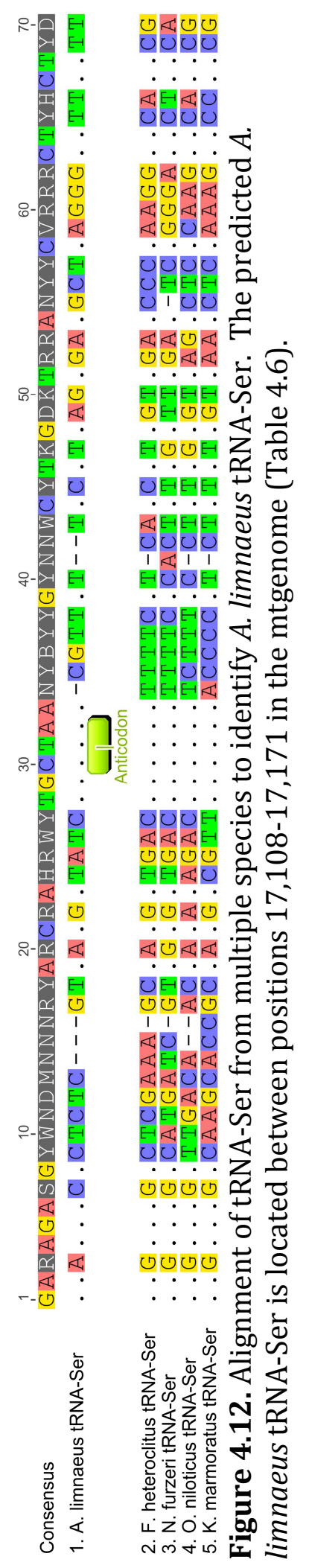




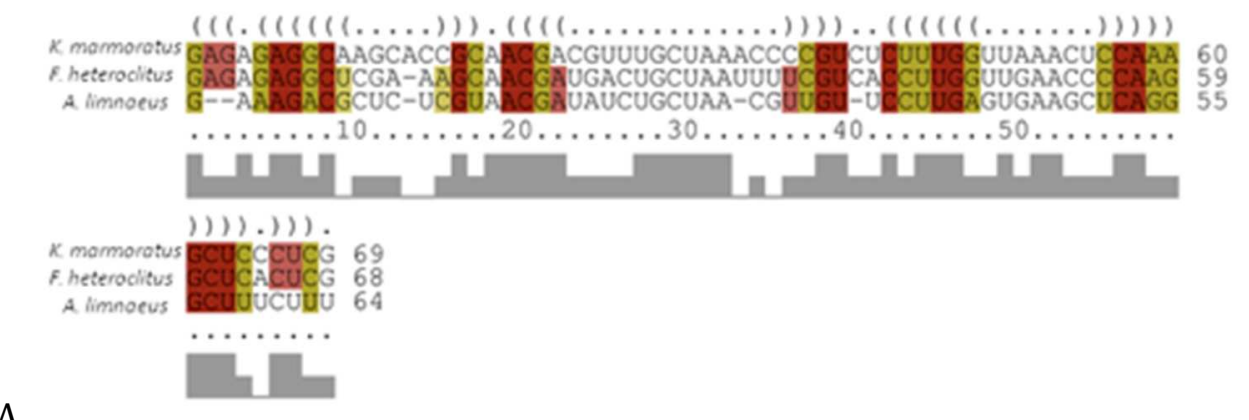

A.
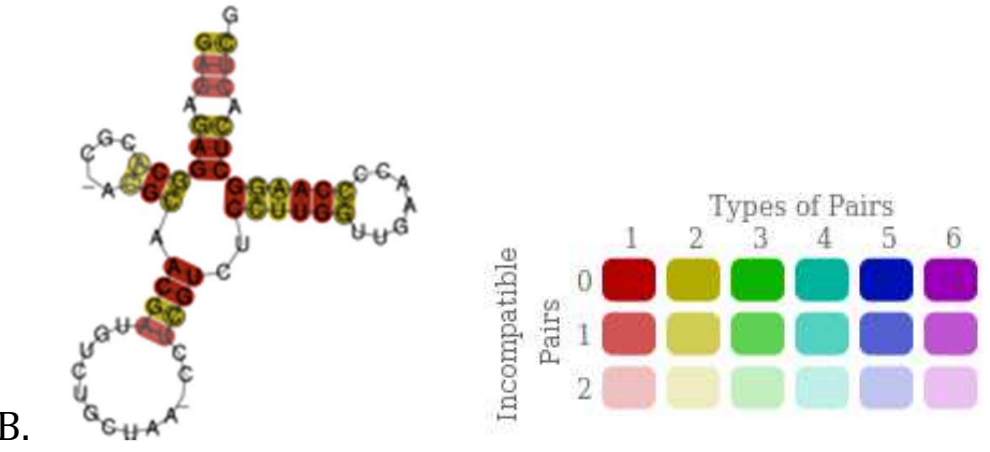

Figure 4.13. Possible secondary structure of $A$. limnaeus tRNA-Ser. (A) Alignment of the putative tRNA-Ser of $A$. limnaeus to $K$. marmoratus and $F$. heteroclitus. Alignments showing in white are predicted to form loop structures. (B) Predicted secondary structure of the tRNA-Ser using the alignment from $\mathbf{A}$. As colors fade, a greater number of incompatible pairs are predicted from the alignment. The most strongly conserved basepairs are red and unfaded. 
Coding gene nucleotide composition (excl. ND6)

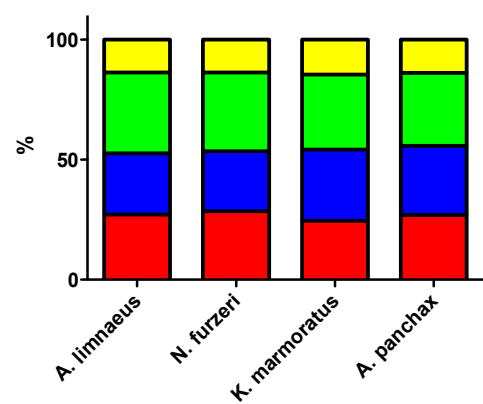

rRNA nucleotide composition

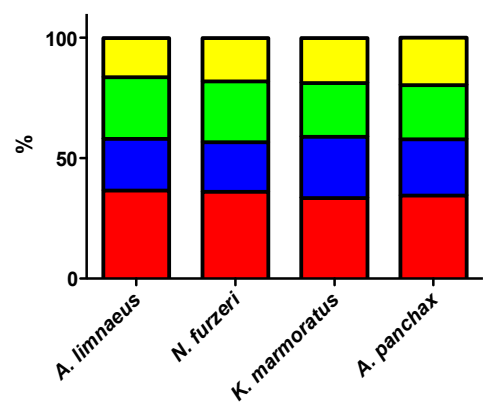

Nucleotide compostition of ND6

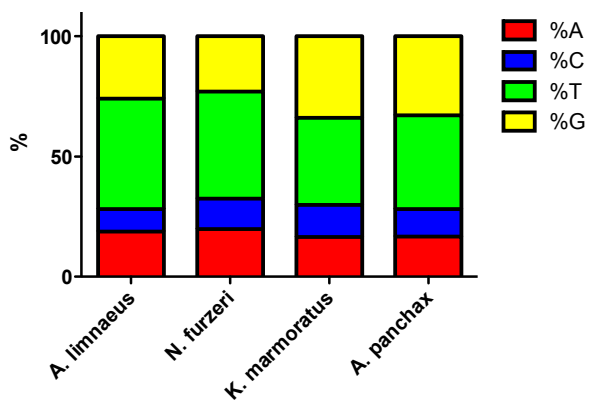

tRNA nucleotide compositon

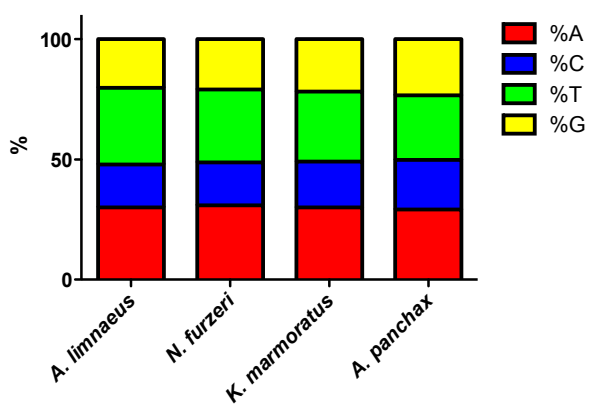

Figure 4.14. Species comparisons of coding gene, rRNA, and tRNA nucleotide compositions within the Superfamily Aplocheiloidei. A. limnaeus and $N$. furzeri are annual killifish, while K. marmoratus and $A$. panchax are not. 
Coding gene nucleotide composition pos1 (excl. ND6)

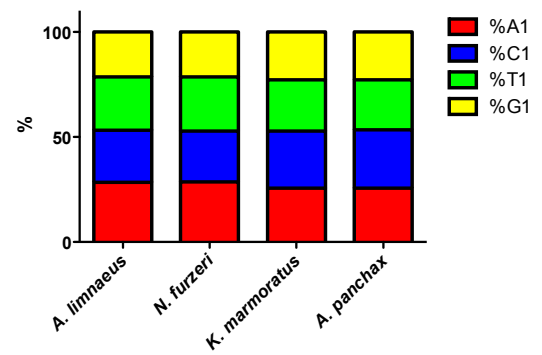

Coding gene nucleotide composition pos2 (excl. ND6)

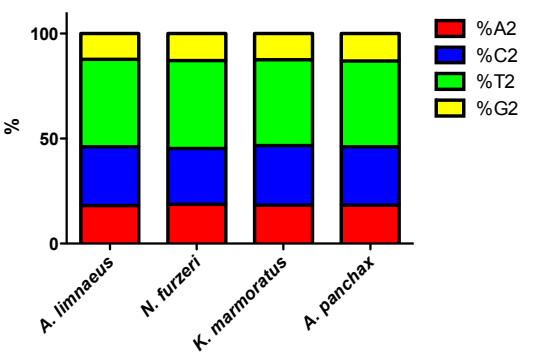

Coding gene nucleotide composition pos3 (excl. ND6)
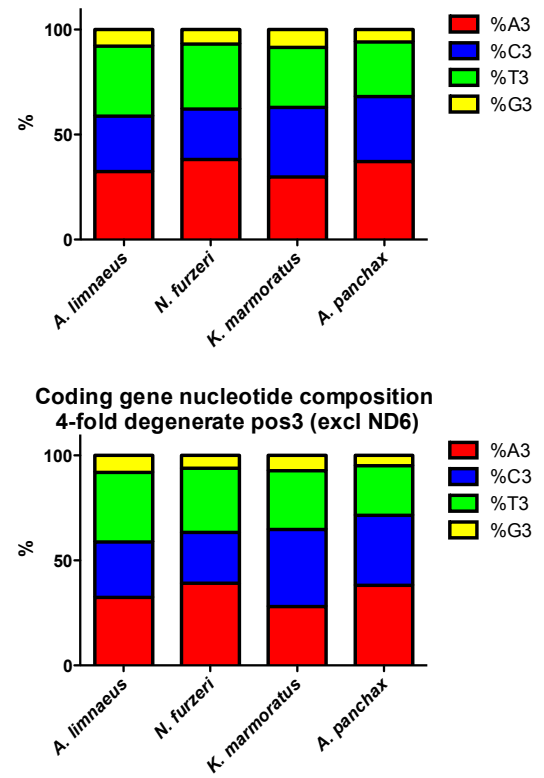

Nucleotide composition pos1 (ND6)

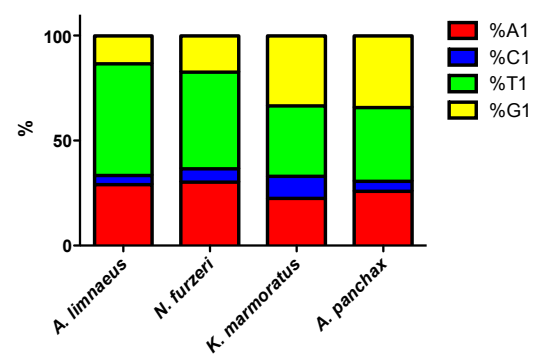

Nucleotide composition pos2 (ND6)

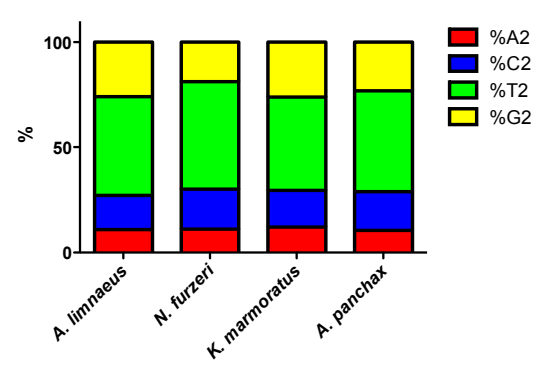

Nucleotide composition pos3 (ND6)
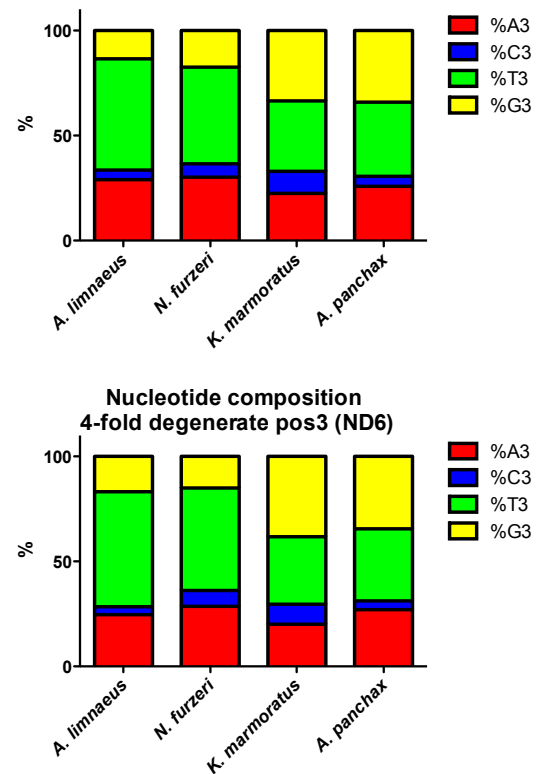

Figure 4.15. Species comparisons of coding gene nucleotide compositions by position within the Superfamily Aplocheiloidei. A. limnaeus and N. furzeri are annual killifish, while K. marmoratus and A. panchax are not. 


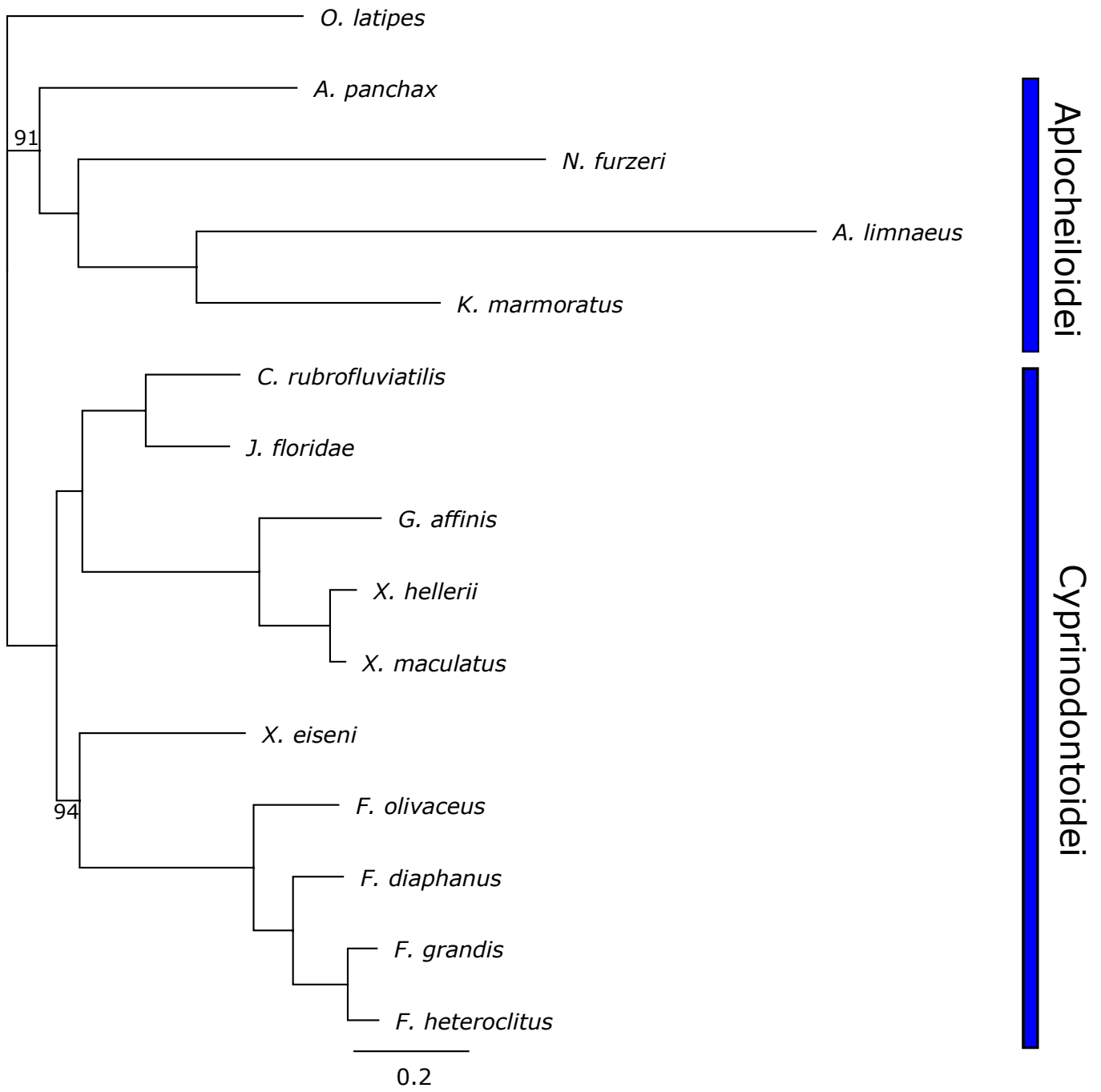

Figure 4.16. Inferred phylogenetic tree of the order Cyprinodontiformes using MrBayes. Posterior probability values are indicated only if less than 100. Scale bar, average number of nucleotide substitutions per site. 


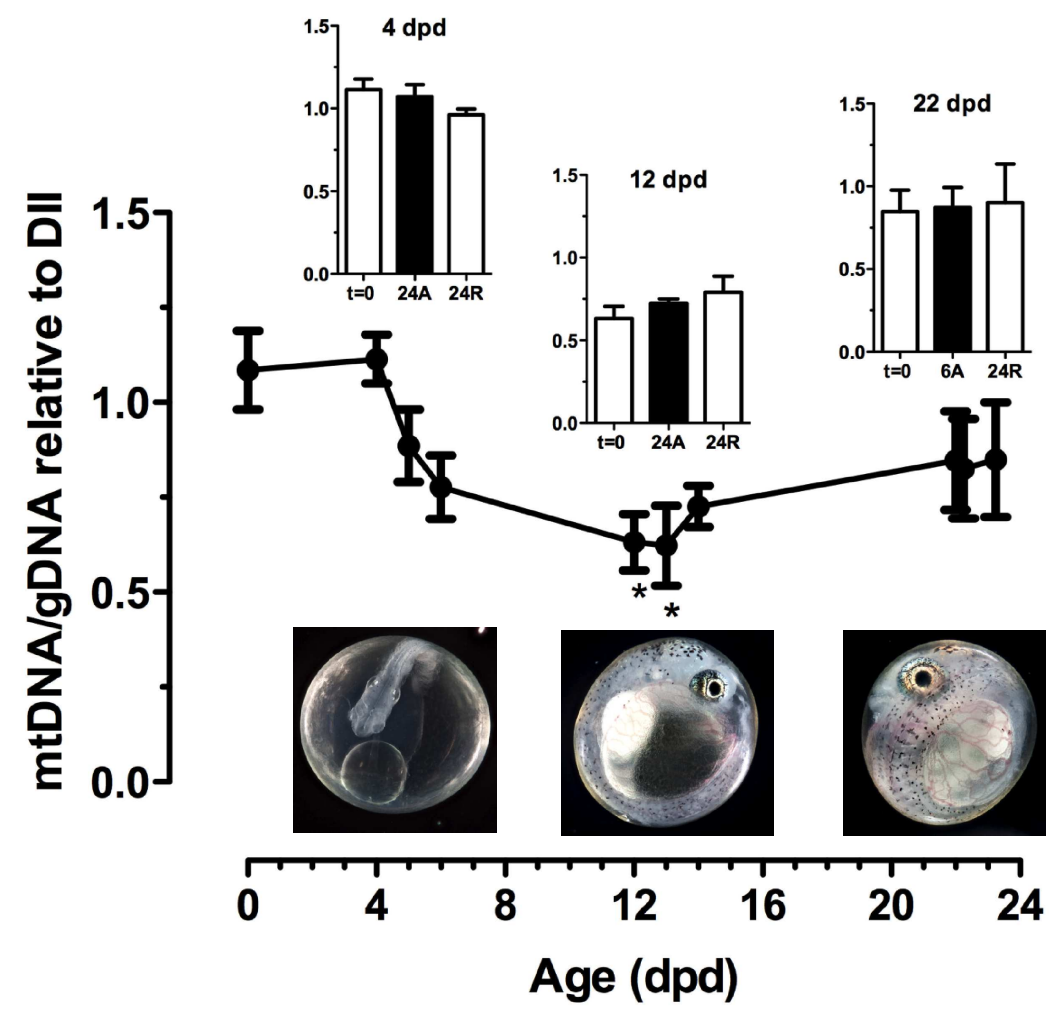

Figure 4.17. Changes in relative mtDNA copy number during normoxia (white bars and line graph) or anoxia (black bars). Anoxia treatment bar graphs are labeled by $24 \mathrm{~h}$ or $6 \mathrm{~h}$ anoxia $(24 \mathrm{~A}$ or $6 \mathrm{~A}$ ) and $24 \mathrm{~h}$ recovery (24R). Data were log2 transformed prior to analysis. There was a significant difference in relative mtDNA content between normoxic 12 and $13 \mathrm{dpd}$ embryos and DII ( $0 \mathrm{dpd}$ ) controls, indicated with asterisks (One-way ANOVA with Dunnett's Multiple Comparison Test, $\mathrm{p}<0.05$ ). Symbols represent means \pm SEM $(n=4)$. 


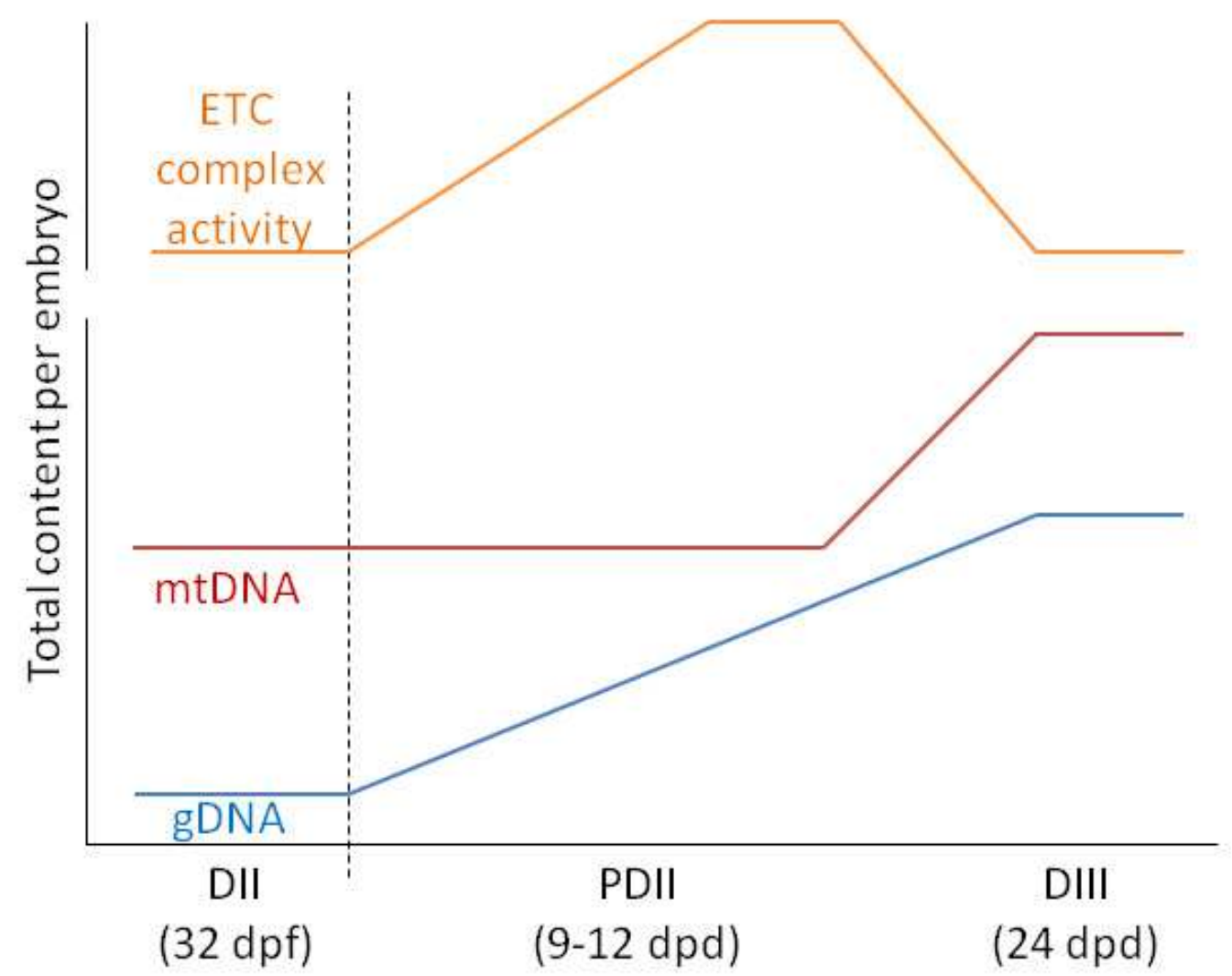

Figure 4.18. Model of mtDNA, gDNA, and ETC complex activity content during post DII development. The starting points of the three graphs are arbitrary. Although the ratios of mtDNA to gDNA have been measured, their relation to ETC complex activity has not. Therefore, the ETC graph is independent of the mtDNA and gDNA graphs. Following termination of DII (dashed line), gDNA increases until embryos enter DIII. However, mtDNA content does not increase for most of PDII development until near DIII. ETC complex activity peaks during PDII development but returns to DII levels as embryos enter into DIII. The ETC complex activity data was taken from Duerr and Podrabsky (2010). 


\begin{tabular}{|l|l|l|l|l|l|}
\hline & $\begin{array}{l}\text { total } \\
\text { bases }\end{array}$ & $\begin{array}{l}\text { Average } \\
\text { post-trim } \\
\text { read length }\end{array}$ & $\begin{array}{l}\text { total } \\
\text { reads }\end{array}$ & $\begin{array}{l}\text { insert } \\
\text { size }\end{array}$ & $\begin{array}{l}\text { insert size } \\
\text { SD }\end{array}$ \\
\hline $\begin{array}{l}\text { Forward } \\
\text { pair }\end{array}$ & $9.42 \mathrm{~GB}$ & $94.25 \mathrm{bp}$ & $\begin{array}{l}100 \\
\text { million }\end{array}$ & $170 \mathrm{bp}$ & $20 \mathrm{bp}$ \\
\hline $\begin{array}{l}\text { Reverse } \\
\text { pair }\end{array}$ & $9.43 \mathrm{~GB}$ & $94.25 \mathrm{bp}$ & $\begin{array}{l}100 \\
\text { million }\end{array}$ & $170 \mathrm{bp}$ & $20 \mathrm{bp}$ \\
\hline
\end{tabular}

Table 4.1. Illumina reads used for assembly and mapping of the A. limnaeus mitochondrial genome. Reads were trimmed using Trimmomatic prior to sequence assembly using MitoBIM. SD, standard deviation. 


\begin{tabular}{|l|l|}
\hline Primer name & Sequence (5' to 3') \\
\hline 12S R & GGTCGATCTTACGTTCATTGCT \\
\hline cons16S F1 & GGAGCAATCCAGGTCAGTTT \\
\hline Cytb F & CCCTTCCTCCACACCTCTAA \\
\hline Dloop R & GTTATGTTGGGACTTGGCTTTG \\
\hline Dloop R2 & TTTCACAGGAGTAAGGGCTTT \\
\hline Dloop R3 & ACACTATAAATCTACCAACACCTCT \\
\hline ND1 R & CCTAGGTCTAAATCTGCTAAGGG \\
\hline pseudo16S F & TGTGGTACAATTACATACTTC \\
\hline pseudo16S R & ACATTACGGGGAAGTATGTAATT \\
\hline pseudo16S R2 & CAGATGCTCTTCTTTGGTTCTTTC \\
\hline pseudo16S R3 & GAAGTATGTAATTGTACCACA \\
\hline pUC/M13 F & CGCCAGGGTTTTCCCAGTCACGAC \\
\hline pUC/M13 R & TCACACAGGAAACAGCTATGAC \\
\hline tRNA-Leu F & GGTTCAAGTCCTTTCTCTAGCA \\
\hline tRNA-Leu F2 & GCTAGTGTGGCAGAATTGGA \\
\hline tRNA-Leu R & TCCAATTCTGCCACACTAGC \\
\hline tRNA-Val F & GCGCAAATCAGGTTGTTCTG \\
\hline
\end{tabular}

Table 4.2. Primer names and sequences used to verify regions of the $A$. limnaeus mtgenome. These primers were used to generate PCR fragments for cloning into the pGEM-T vector, for sequencing the vectors, or both. 


\begin{tabular}{|r|l|l|l|}
\hline Clone \# & F primer & R primer & Sequencing primers used \\
\hline 1 & tRNA-Leu F & ND1 R & pUC/M13 F, pUC/M13 R, Dloop R, Dloop R2 \\
\hline 2 & tRNA-Leu F & pseudo16S & pUC/M13 F, pUC/M13 R, Dloop R3, \\
R2 & pseudo16S R3 \\
\hline 3 & $\begin{array}{l}\text { pseudo16S } \\
\text { F }\end{array}$ & ND1 R & $\begin{array}{l}\text { pUC/M13 F, pUC/M13 R, Dloop R, tRNA-Leu } \\
\text { FRNA-Val F }\end{array}$ \\
\hline tRNA-Leu R & pUC/M13 F, pUC/M13 R \\
\hline
\end{tabular}

Table 4.3. Primers used to generate and sequence clones for assembly of the A. limnaeus mtgenome. PCR fragments were generated using the listed primer pairs for each clone and were inserted into the pGEM-T vector. Clones were sequenced using the listed primers. 


\begin{tabular}{|l|l|l|}
\hline Species & Annual & Reference \\
\hline Aplocheilus panchax & No & (Setiamarga et al., 2008) \\
\hline $\begin{array}{l}\text { Cyprinodon } \\
\text { rubrofluviatilis }\end{array}$ & No & NCBI accession NC_009125 \\
\hline Fundulus diaphanus & No & (Whitehead, 2009) \\
\hline Fundulus grandis & No & (Whitehead, 2009) \\
\hline Fundulus heteroclitus & No & (Whitehead, 2009) \\
\hline Fundulus olivaceus & No & (Whitehead, 2009) \\
\hline Gambusia affinis & No & (Miya et al., 2003) \\
\hline Jordanella floridae & No & (Setiamarga et al., 2008) \\
\hline $\begin{array}{l}\text { Kryptolebias } \\
\text { marmoratus }\end{array}$ & No & (Lee et al., 2001) \\
\hline $\begin{array}{l}\text { Nothobranchius } \\
\text { furzeri }\end{array}$ & Yes & (Hartmann et al., 2011) \\
\hline Oreochromis niloticus & No & $\begin{array}{l}\text { Yang et al., unpublished, NCBI } \\
\text { Accession NC_013663 }\end{array}$ \\
\hline Oryzias latipes & No & (Miya et al., 2003) \\
\hline Xenotoca eiseni & No & (Setiamarga et al., 2008) \\
\hline Xiphophorus hellerii & No & (Setiamarga et al., 2008) \\
\hline $\begin{array}{l}\text { Xiphophorus } \\
\text { maculatus }\end{array}$ & No & (Setiamarga et al., 2008) \\
\hline
\end{tabular}

Table 4.4. List of species with available mitochondrial sequences used for comparison to the A. limnaeus mitochondrial genome. Genes were identified in mitochondrial sequences with MitoAnnotator. 


\begin{tabular}{|l|l|}
\hline Gene & Primer sequence (5' to 3') \\
\hline ND4 F & CTTATTACTGGGCTCGGAACAT \\
\hline ND4 R & GAGGAGCGTTGGGTAAATAGAG \\
\hline IGFR1 F & CCTGTACAACCTGAGGAACATC \\
\hline IGFR1 R & CTCGGCATCCATAATCAGAGAC \\
\hline
\end{tabular}

Table 4.5. Primers specific to mitochondrial NADH dehydrogenase subunit 4 (ND4) or nuclear insulin-like growth factor-1 receptor (IGFR1) used for measurement of relative mtDNA content. 
Table 4.6. Positions of the identified A. limnaeus mitochondrial genes and elements. The 3' column indicates the distance in bases until the start of the next gene.

\begin{tabular}{|c|c|c|c|c|c|c|c|}
\hline Gene/element & Strand & \begin{tabular}{|l} 
Start \\
position
\end{tabular} & $\begin{array}{l}\text { Stop } \\
\text { position }\end{array}$ & Size & $\begin{array}{l}\text { Start } \\
\text { codon }\end{array}$ & $\begin{array}{l}\text { Stop } \\
\text { codon }\end{array}$ & $3^{\prime}$ \\
\hline tRNA-Phe (GAA) & $\mathrm{H}$ & 1 & 69 & 69 & - & - & 0 \\
\hline 12S rRNA & $\mathrm{H}$ & 70 & 1015 & 946 & - & - & 0 \\
\hline tRNA-Val (TAC) & $\mathrm{H}$ & 1016 & 1084 & 69 & - & - & 0 \\
\hline 16S rRNA & $\mathrm{H}$ & 1085 & 2718 & 1634 & - & - & 0 \\
\hline tRNA-Leu2 (TAA) & $\mathrm{H}$ & 2719 & 2791 & 73 & - & - & 0 \\
\hline D-loop 1 & - & 2792 & 5075 & 2284 & - & - & 0 \\
\hline pseudo16S & $\mathrm{H}$ & 5076 & 5739 & 664 & - & - & 0 \\
\hline tRNA-Leu2 (TAA) & $\mathrm{H}$ & 5740 & 5812 & 73 & - & - & 0 \\
\hline D-loop 2 & - & 5813 & 8175 & 2363 & - & - & 0 \\
\hline ND1 & $\mathrm{H}$ & 8176 & 9123 & 948 & GTG & TAA & 0 \\
\hline tRNA-Ile (GAT) & $\mathrm{H}$ & 9126 & 9193 & 68 & - & - & 2 \\
\hline tRNA-Gln (TTG) & $\mathrm{L}$ & 9193 & 9263 & 71 & - & - & -1 \\
\hline tRNA-Met (CAT) & $\mathrm{H}$ & 9263 & 9332 & 70 & - & - & -1 \\
\hline ND2 & $\mathrm{H}$ & 9333 & 10383 & 1051 & ATT & T- & 0 \\
\hline tRNA-Trp (TCA) & $\mathrm{H}$ & 10384 & 10457 & 74 & - & - & 0 \\
\hline tRNA-Ala (TGC) & $\mathrm{L}$ & 10458 & 10526 & 69 & - & - & 0 \\
\hline tRNA-Asn (GTT) & $\mathrm{L}$ & 10528 & 10600 & 73 & - & - & 1 \\
\hline $\mathrm{O}_{\mathrm{L}}$ & - & 10601 & 10636 & 36 & - & - & 0 \\
\hline tRNA-Cys (GCA) & $\mathrm{L}$ & 10637 & 10693 & 57 & - & - & 0 \\
\hline tRNA-Tyr (GTA) & $\mathrm{L}$ & 10696 & 10763 & 68 & - & - & 2 \\
\hline COI & $\mathrm{H}$ & 10765 & 12327 & 1563 & ACG & TAA & 1 \\
\hline tRNA-Ser2 (TGA) & $\mathrm{L}$ & 12330 & 12399 & 70 & - & - & 2 \\
\hline tRNA-Asp (GTC) & $\mathrm{H}$ & 12402 & 12472 & 71 & - & - & 2 \\
\hline COII & $\mathrm{H}$ & 12475 & 13165 & 691 & GTG & T- & 2 \\
\hline tRNA-Lys (TTT) & $\mathrm{H}$ & 13166 & 13231 & 66 & - & - & 0 \\
\hline ATPase-6 & $\mathrm{H}$ & 13234 & 13401 & 168 & ACG & TAA & 2 \\
\hline ATPase-8 & $\mathrm{H}$ & 13386 & 14073 & 688 & ATG & TAA & -16 \\
\hline COIII & $\mathrm{H}$ & 14074 & 14868 & 795 & ATG & TAA & 0 \\
\hline tRNA-Gly (TCC) & $\mathrm{H}$ & 14875 & 14946 & 72 & - & - & 6 \\
\hline ND3 & $\mathrm{H}$ & 14953 & 15295 & 343 & ATA & T- & 6 \\
\hline tRNA-Arg (TCG) & $\mathrm{H}$ & 15296 & 15364 & 69 & - & - & 0 \\
\hline ND4L & $\mathrm{H}$ & 15365 & 17031 & 1667 & GTG & TAA & 0 \\
\hline tRNA-His (GTG) & $\mathrm{H}$ & 17037 & 17105 & 69 & - & - & 5 \\
\hline tRNA-Ser (TAG) & $\mathrm{H}$ & 17108 & 17171 & 64 & - & - & 2 \\
\hline tRNA-Leu (TAG) & $\mathrm{H}$ & 17175 & 17246 & 72 & - & - & 3 \\
\hline ND5 & $\mathrm{H}$ & 17249 & 19111 & 1863 & ATA & TAA & 2 \\
\hline
\end{tabular}


Table 4.6 continued.

\begin{tabular}{|l|l|r|r|r|l|l|r|}
\hline & L & 19108 & 19575 & 468 & GTG & TAA & -4 \\
\hline tRNA-Glu (TTC) & L & 19630 & 19698 & 69 & - & - & 54 \\
\hline Cyt-b & H & 19703 & 20838 & 1136 & ATG & TA- & 4 \\
\hline tRNA-Thr (TGT) & H & 20839 & 20908 & 70 & - & - & 0 \\
\hline tRNA-Pro (TGG) & L & 20908 & 20980 & 73 & - & - & -1 \\
\hline
\end{tabular}




\begin{tabular}{|c|c|c|c|c|c|}
\hline \multicolumn{6}{|l|}{ A. limnaeus } \\
\hline Codon & ATT & TTA & TTT & CTA & ATA \\
\hline Amino Acid & Ile & Leu & Phe & Leu & Met \\
\hline Total codon occurrence & 201 & 190 & 183 & 162 & 162 \\
\hline \multicolumn{6}{|l|}{ A. panchax } \\
\hline Codon & ATT & CTA & CTT & TTA & TTT \\
\hline Amino Acid & Ile & Leu & Leu & Leu & Phe \\
\hline Total codon occurrence & 187 & 178 & 156 & 150 & 138 \\
\hline \multicolumn{6}{|l|}{ N. furzeri } \\
\hline Codon & TTA & ATT & TTT & ATA & CTA \\
\hline Amino Acid & Leu & Ile & Phe & Met & Leu \\
\hline Total codon occurrence & 208 & 185 & 163 & 158 & 157 \\
\hline \multicolumn{6}{|l|}{ K. marmoratus } \\
\hline Codon & ATT & TTT & CTT & TTA & CTA \\
\hline Amino Acid & Ile & Phe & Leu & Leu & Leu \\
\hline Total codon occurrence & 193 & 173 & 163 & 152 & 143 \\
\hline
\end{tabular}

Table 4.7. Top five most used codons in the A. limnaeus, A. panchax, $N$. furzeri, and $K$. marmoratus mtgenomes. Codon useage was determined using CAIcal. Top codons that are shared by all four species are noted in bold. 


\begin{tabular}{|r|r|l|l|r|r|r|}
\hline \multicolumn{1}{|c|}{ Gene } & Position & $\begin{array}{l}\text { Polymorphism } \\
\text { Type }\end{array}$ & $\begin{array}{l}\text { Variant } \\
\text { Frequency }\end{array}$ & Length & Change & Coverage \\
\hline ND4L & 15,751 & $\begin{array}{l}\text { SNP } \\
\text { (transversion) }\end{array}$ & $25.00 \%$ & $1 \mathrm{bp}$ & $\mathrm{T} \rightarrow \mathrm{A}$ & $10,434 \mathrm{X}$ \\
\hline $16 \mathrm{~S}$ & 1,591 & SNP (transition) & $25.90 \%$ & $1 \mathrm{bp}$ & $\mathrm{T} \rightarrow \mathrm{C}$ & $8,571 \mathrm{X}$ \\
\hline $16 \mathrm{~S}$ & 1,588 & SNP (transition) & $26.00 \%$ & $1 \mathrm{bp}$ & $\mathrm{T} \rightarrow \mathrm{C}$ & $8,568 \mathrm{X}$ \\
\hline $16 \mathrm{~S}$ & 1,587 & SNP (transition) & $26.00 \%$ & $1 \mathrm{bp}$ & $\mathrm{G} \rightarrow \mathrm{A}$ & $8,569 \mathrm{X}$ \\
\hline $16 \mathrm{~S}$ & 1,584 & SNP (transition) & $25.30 \%$ & $1 \mathrm{bp}$ & $\mathrm{G} \rightarrow \mathrm{A}$ & $8,86 \mathrm{X}$ \\
\hline
\end{tabular}

Table 4.8. Single nucleotide polymorphisms (SNPs) detected in the $A$. limnaeus mtgenome using the Geneious variant caller. Variants were called with a minimum threshold of $25 \%$ occurance in the Illumina reads. 


\section{Chapter 5}

\section{Characterization of the Austrofundulus limnaeus genome}

Over the past two decades, studies in the annual killifish

Austrofundulus limnaeus have changed the understanding of the magnitude of environmental stress that is tolerable by vertebrates (Podrabsky and Hand, 2015). A. limnaeus embryos have been shown to tolerate loss of $50 \%$ water content, survive for months without oxygen, tolerate wide ranges in salinity or oxygen, and have exceptional tolerance to UV radiation exposure (Anderson and Podrabsky, 2014; Machado and Podrabsky, 2007; Podrabsky et al., 2001; Podrabsky et al., 2007; Wagner and Podrabsky, 2015a). Little is known about how a life history in a harsh environment can influence vertebrate genome sequence and gene expression. Even the basic genome biology of $A$. limnaeus, such as genome size and nucleotide composition, is a mystery.

In addition, recent advances in epigenetics have demonstrated the importance of reversible changes to DNA, such as DNA methylation of cytosine $(5 \mathrm{mC})$, in regulating gene expression responses to environmental cues (Bogdanovic and Gómez-Skarmeta, 2013; Flores et al., 2013; Varriale, 2014). These studies suggest that DNA methylation can cause heritable and reversible changes in gene expression that can shape the evolution of a 
species in response to environmental factors. How $5 \mathrm{mC}$ might have a role in expression of the annual killifish phenotype, however, is another mystery.

In Chapter 3, I explored how temporal changes in gene expression could shift developmental timing in A. limnaeus, possibly to prolong the undifferentiated state. However, the molecular mechanisms involved in this process are almost certainly more complicated than can be determined with PCR and gene fragments. With the recent advent of high-throughput sequencing, nearly complete whole genome assemblies from nonmodel organisms such as A. limnaeus are now economically feasible. The availability of these genomes is changing the landscape of biology and opens the possibility of obtaining complete or nearly complete gene models for whole gene networks in almost any species.

The first goal of this chapter was to sequence and assemble a draft genome of A. limnaeus, resulting in the first South American annual killifish yet sequenced. The assembled A. limnaeus genome is then used to find gene models for the genes described in Chapter 3 to demonstrate its practicality. The second goal was to determine a whole-genome total $5 \mathrm{mC}$ profile throughout A. limnaeus embryonic development to determine global changes in $5 \mathrm{mC}$ content to infer possible impacts for the annual killifish phenotype.

\section{Materials and Methods}

Genome size estimation by flow cytometry. 
Zebrafish and chicken blood were generously provided by Dr. Kim Brown (Portland State University) and Chrissie Zaerpoor (Kookoolan Farms, Yamhill, OR), respectively. Whole blood from zebrafish $(\mathrm{n}=2)$, chicken $(\mathrm{n}=$ 1), or A. limnaeus ( $\mathrm{n}=3$ ) was homogenized in $1 \mathrm{ml}$ of Galbraith buffer (30 mM sodium citrate, $45 \mathrm{mM} \mathrm{MgCl}$, 20 mM MOPS, 0.1\% Triton-X 100, $1 \mathrm{mg} \mathrm{ml}^{-}$ ${ }^{1}$ RNAse A, $\mathrm{pH}$ 7.2) on ice using a Sorvall Omni-mixer and loose-fitting Teflon pestle for about 20 strokes, speed setting 2 . Three technical replicates of the chicken blood were analyzed. Homogenates were filtered through a $35 \mu \mathrm{m}$ mesh screen by centrifugation at $100 \mathrm{xg}$ for 1 minute at $4^{\circ} \mathrm{C}$. Dissociated cells were stained in $1 \mathrm{mg} \mathrm{ml}^{-1}$ propidium iodide for 30 minutes at room temperature and fluorescence intensity were measured using the BD Accuri C6 flow cytometer at a flow rate of $14 \mu \mathrm{min}^{-1}$ for 100,000 counts (BD Biosciences, San Jose, CA). Counts were gated manually to remove noise from cellular debris. Fluorescence peaks were identified and analyzed with the included BD CSampler Software. The genome size of A. limnaeus was inferred from linear regression of zebrafish and chicken nuclei fluorescence relative to Golden Path Length genome size.

\section{DNA extraction of adult tissue}

DNA was extracted for Illumina library prep and sequencing using the same protocol described in Chapter 4. Except for two of the long-insert mate-pair libraries, which were derived from a mixture of four male brains, 
all DNA was extracted and sequenced from the same A. limnaeus male described in Chapter 4.

Assembly of Illumina reads.

Adapter-free reads were de novo assembled using two algorithm strategies. The library types and insert sizes used for genome assembly are shown in Table 5.2. First, the reads were assembled using the Allpaths-LG pipeline, which is based on a modified de Brujin graphing algorithm (Gnerre et al., 2011). In a separate assembly, the fragment reads were error corrected using Allpaths-LG and de novo assembled using JR-assembler, an assembler that is based on read overlap to extend contigs (Chu et al., 2013). Contigs were ordered into scaffolds within the individual assemblies by using SSPACE Basic 3.0 using the mate-pair libraries listed in Table $5.2(-\mathrm{k}=3$, $a=0.7$ ) (Boetzer et al., 2011). The resulting scaffolds were then merged between Allpaths-LG and JR-assembler to provide the best representation of unique scaffolds from both assemblies. L_RNA_Scaffolder software was used to improve the assembly by breaking apart and rejoining poorly supported scaffolds using a preliminary transcriptome derived from a $12 \mathrm{dpd}$ embryo RNAseq dataset (Riggs and Podrabsky, unpublished; (Xue et al., 2013)). The assembly was run through a final round of SSPACE Basic 3.0, and this version constitutes version 1.0 of the A. limnaeus genome. 
Analysis of genome assembly

Genome completeness was estimated with the Core Eukaryotic Genes Mapping Approach (CEGMA) (Parra et al., 2007). CEGMA scans genomic sequences for homologous sequences to 248 proteins thought to be present in all eukaryotes. For CEGMA comparative analysis to other fish, genomes of the Atlantic Cod (Gadus morhua, Order Gadiformes, assembly gadMor1) and stickleback (Gasterosteus aculeatus, Order Gasterosteiformes, assembly Broad S1) were retrieved from the Ensembl webserver (http://www.ensembl.org). Repetitive DNA elements in the A. limnaeus genome, such as transposons, were identified with RepeatModeler 1.0.8 (Smit and Hubley, 2011). Genome coverage by Illumina reads was determined by read mapping with BBMap version 35.10 (http://sourceforge.net/projects/bbmap/).

\section{Identification of genes of interest}

The A. limnaeus partial genes identified in Chapter 3 (oct4, sox3, sox2, chordin, noggin-1, noggin-2, and follistatin) were used to locate scaffolds that likely contained gene models within the assembled genome. These sequences were aligned to the A. limnaeus genome using the blast algorithm (McGinnis and Madden, 2004). Scaffolds that aligned with genes, along with the mRNAs identified in other species used in chapter 3, were extracted and used as input for the MAKER2 gene prediction software (Holt and Yandell, 
2011). Identities of the polypeptides generated by MAKER2 were inferred by blastp using the NCBI non-redundant protein database (Johnson et al., 2008; McGinnis and Madden, 2004). The A. limnaeus genome and annotated genes were visualized using JBrowse 1.11.6 (Skinner et al., 2009).

5mC Enzyme linked immunosorbant assay

Measurement of total $5 \mathrm{mC}$ content in embryonic tissues via enzyme linked immunosorbant assay (ELISA) was performed as described in chapter 2 with the following changes: primary antibody (Anti-5mC, clone 33D3, Mouse host, IgG, Active Motif \#39649) was diluted 1:2000 in blocking buffer prior to use and $125 \mathrm{ng}$ of DNA was used as input per well. The embryonic stages and number of embryos per replicate are described in Table 5.1.

Statistics

One-way ANOVAs, Bonferroni post hoc tests, and t-tests were performed with Graph Pad Prism 5 (GraphPad Software, Inc., 2009). Statistical significance was determined at a level of $\mathrm{p}<0.05$.

\section{Results}

PI fluorescence intensity of zebrafish and chicken free nuclei increased linearly with increasing genome size (Figure 5.1). Most of the nuclei were single $(2 \mathrm{~N})$ with a very small proportion of zebrafish nuclei 
showing as doublets $(4 \mathrm{~N})$. The $A$. limnaeus genome is smaller than both the zebrafish and chicken genomes and is estimated to be $1.03 \mathrm{~GB}$ after extrapolation of PI fluorescence.

The final assembly of the A. limnaeus genome, including gaps, is 867 $\mathrm{Mb}$ with an N50 of $0.983 \mathrm{Mb}$ and is represented in 29,785 scaffolds (Table 5.3). Although many contigs could be assembled into scaffolds, there are numerous small contigs that could not be placed (Figure 5.2). Based on frequency of unique sequences (also known as unique k-mers), Allpaths-LG estimated the size of the A. limnaeus genome to be $974 \mathrm{Mb}$, which is slightly less than the estimate by flow cytometry. The A. limnaeus genome contains slightly less percent $\mathrm{G}+\mathrm{C}$ composition than other species compared in this chapter (Table 5.4). Repeat content varied depending on the species, and ranged from $6.6 \%$ in the stickleback, to $52.2 \%$ in zebrafish (Danio rerio). (Table 5.4). The A. limnaeus genome was estimated to be $42 \%$ repetitive, which is similar to $N$. furzeri at $45 \%$. All fish species examined had lower estimated genome sizes and repeat content compared to humans (66-69\%). RepeatModeler was able to identify and characterize about $30 \%$ of the total 42\% estimated repeat content in A. limnaeus (Table 5.5).

CEGMA analysis of the A. limnaeus assembled genome identified 69\% of 248 conserved eukaryotic proteins to be represented in completion, with $96 \%$ of the proteins being identified in either a partial or complete state (Table 5.6). The CEGMA results for A. limnaeus indicates about a 5\% increase 
in complete CEGMA gene models compared to the Atlantic Cod (G. morhua) genome, although the stickleback (G. aculeatus) showed a higher rate of complete protein identification compared to both A. limnaeus and G. morhua.

Open reading frames for chordin, noggin-1, noggin-2, sox2, and sox3 were identified using MAKER2 on the A. limnaeus genome assembly (Table 5.7). Incomplete reading frames were identified for oct 4 and follistatin. Gene identities and putative conserved domains were inferred using blastp alignments to the NCBI nr database (Figures 5.3A-5.3G). Annotated genes and repetitive elements were visualized with JBrowse (Figure 5.4).

\section{Global 5mC ELISA}

Global $5 \mathrm{mC}$ content did not change significantly when all developmental stages were compared to each other (One-way ANOVA with Bonferroni post hoc, $\mathrm{p}>0.05$, Figure 5.5). There was a trend for higher $5 \mathrm{mC}$ in pre-DII stages. If stages are grouped into pre-DII and post-DII stages, the means are statistically different (unpaired two-tailed t-test, $\mathrm{p}<0.0001$ ).

\section{Discussion}

The first goal of this chapter was to sequence and assemble the genome of A. limnaeus as completely as possible to provide the best input for the genome annotation process. The highly repetitive sequence composition of the A. limnaeus genome likely contributed to the fragmented assembly 
described in this chapter. Although the current iteration of the A. limnaeus genome may not be as complete as a genome assembled using Sanger longread technology, such as the stickleback, it appears to be highly comparable to the genome assembly of the Atlantic Cod, whose genome was also de novo assembled exclusively with high-throughput short-read technology. Notably, the Atlantic Cod has an estimated $43 \%$ less repeat content than $A$. limnaeus and yet the assembly qualities are comparable. Several complete and nearly complete gene models could be identified even without the availability of $A$. limnaeus-specific transcriptome data. The current iteration of the $A$. limnaeus genome has been submitted for annotation using the automated NCBI Eukaryotic Genome Annotation Pipeline (http://www.ncbi.nlm.nih.gov/genome/annotation_euk/, GenBank submission accession LDAR01000000). Because of the added complexity of gene splicing in eukaryotic gene expression, it is likely that the identification of complete open frames will be greatly enhanced with the application of RNA-seq transcriptomics during the NCBI annotation process (Romney and Podrabsky, unpublished; Riggs and Podrabsky, unpublished).

With the upcoming release of the $N$. furzeri and K. marmoratus genomes (Brunet pers. comm.; Kelley et al., 2012) the A. limnaeus genome described in this chapter will be an invaluable tool for comparative genomics between killifish species. Identification of positive selection in specific genes and evidences of evolution, such as selective sweeps, within the Superfamily 
Aplocheiloidei will be possible by comparison to other teleost species. Additionally, the RepeatModeler data described in this chapter suggests that there may be unidentified repeat elements in A. limnaeus that are not currently shared by teleost species in the RepeatMasker database, which currently does not contain any Order Cyprinodontiformes teleost species (Tempel, 2012). It will be interesting to see which of these repeat elements are specific to the Superfamily Aplocheiloidei and to determine what role these elements may have had in shaping the genomes of annual killifish (Feschotte and Pritham, 2007). The end goal of these annotation processes will be to establish a searchable database containing all available gene models and gene elements in a graphical interface.

The second goal of this chapter was to establish the first profile of global changes in $5 \mathrm{mC}$ across $A$. limnaeus embryonic development. In zebrafish, embryonic development is associated with global DNA hypermethylation that increases significantly after the shield stage (Fang et al., 2013). Surprisingly, A. limnaeus embryos show a trend for hypomethylation following entry into diapause II. It is interesting to note that many cancers are characterized by global hypomethylation and it has been suggested that hypomethylation may have a role in preventing apoptosis in cancer cells (Hervouet et al., 2013). Previous work has suggested that $A$. limnaeus embryos avoid apoptosis when challenged with anoxia treatments that would normally cause apoptosis in mammals (Meller 
and Podrabsky, 2013). These methylation data suggest that global DNA hypomethylation may have a role in entry into developmental arrest and apoptosis suppression. Although it is difficult to draw conclusions on specific gene DNA methylation based on the data shown because gene expression changes associated with $5 \mathrm{mC}$ are site-specific (Varriale, 2014), these data suggest that $A$. limnaeus embryos have unique embryonic methylation profiles that appear to be associated with entrance into dormancy. Locating the site-specific positions of $5 \mathrm{mC}$ methylation changes in the A. limnaeus genome during embryonic development would be invaluable for determining the extent to which DNA methylation can facilitate the unique physiology of diapausing embryos. 

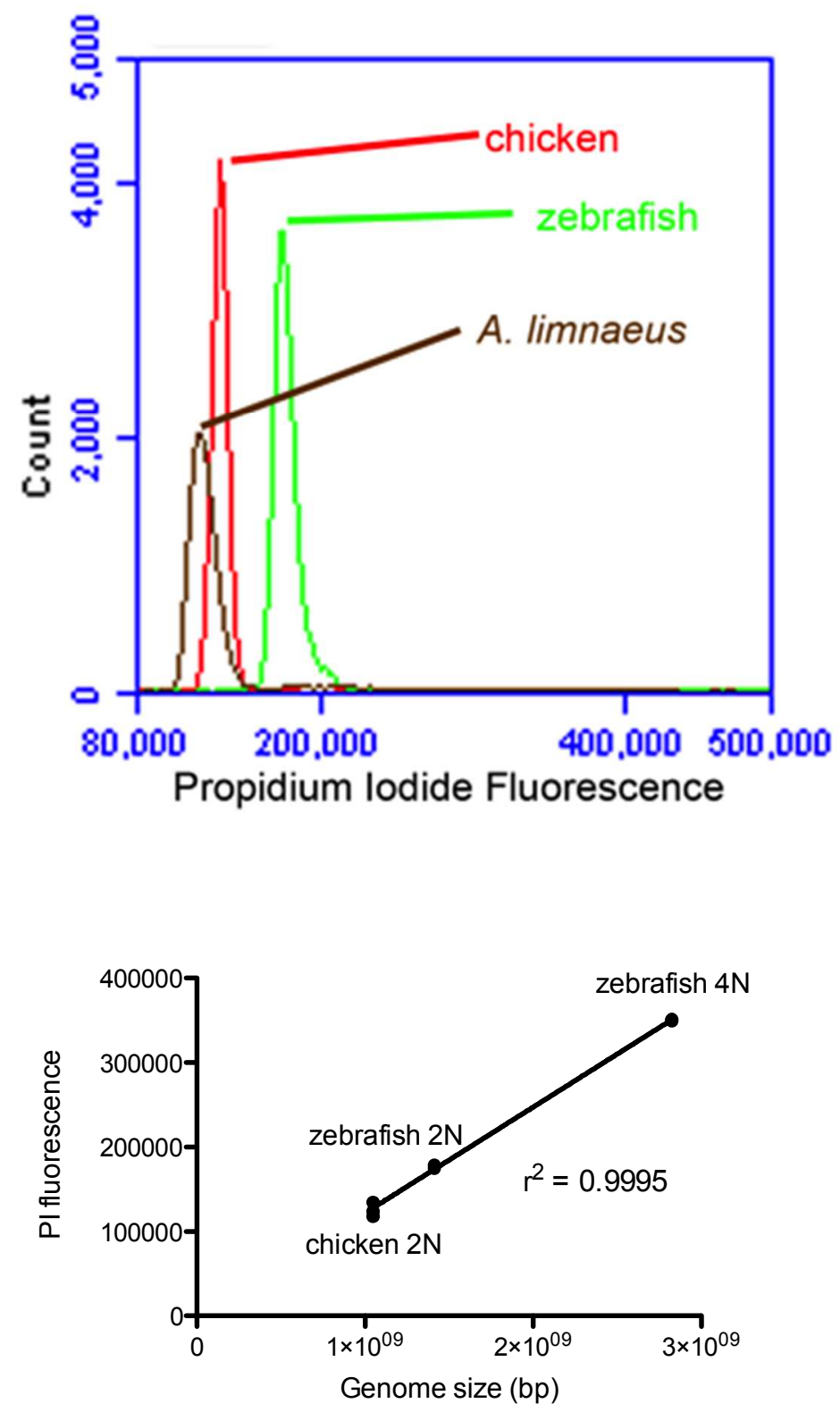

Figure 5.1. Size estimation of the A. limnaeus genome by flow cytometry. Top Panel: Representative graph comparing nuclei sizes of chicken and zebrafish to that of $A$. limnaeus using relative propidium iodide fluorescence. Bottom panel: Standard generated from chicken and zebrafish nuclei used to infer the genome size of $A$. limnaeus. Replicates are plotted as individual data points ( $\mathrm{n}=3$ for chicken, $\mathrm{n}=2$ for zebrafish $2 \mathrm{~N}$ and $4 \mathrm{~N}$ ). The zebrafish data points are overlapping. 


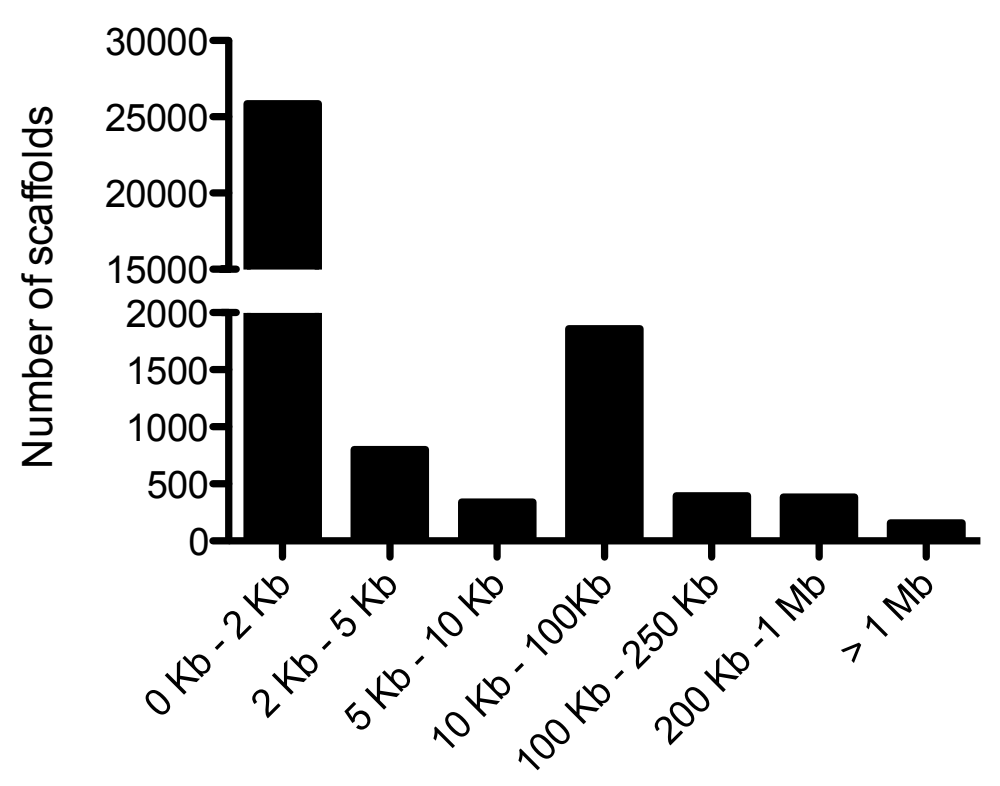

Scaffold size in nucleotide bases

Figure 5.2. Size distribution of scaffolds in the current iteration of the $A$. limnaeus genome assembly. The total number of scaffolds is 29,785 . 
Figure 5.3. Top blastp alignments of the putative A. limnaeus genes identified by MAKER gene prediction software. Scaffolds containing genes of interest were initially identified using blast alignment to the gene fragments identified in Chapter 3.

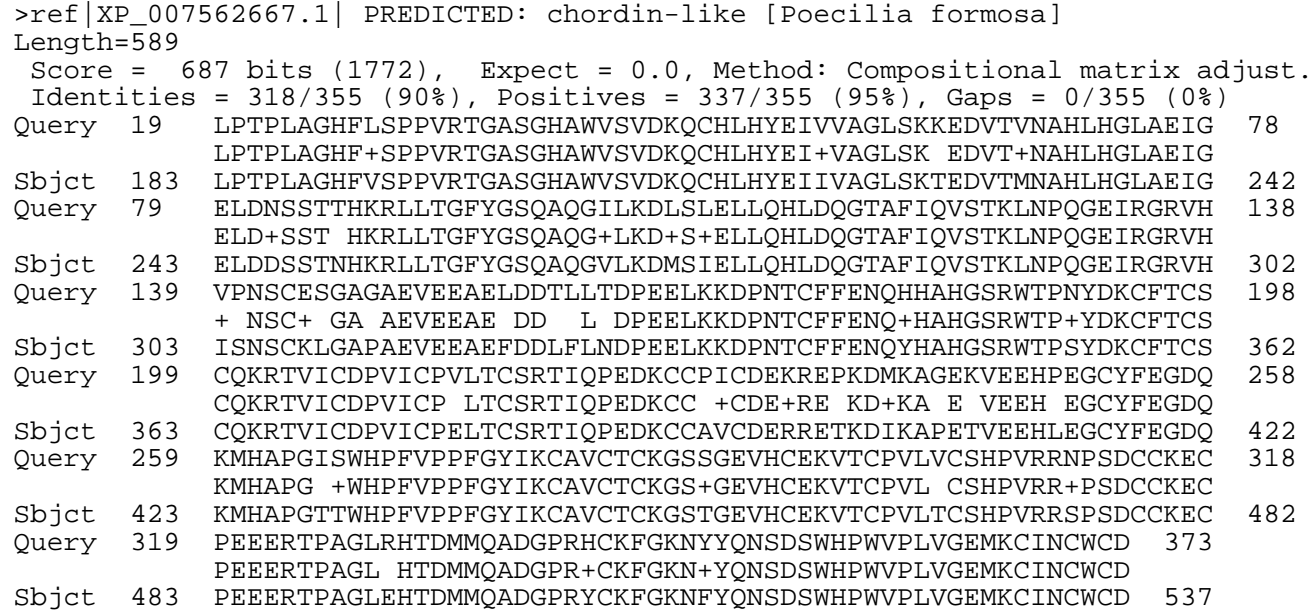

Figure 5.3A. Top match blastp alignment of the putative A. limnaeus chordin protein to the NCBI nr protein database. Predicted conserved domains included a chordin superfamily domain (residues 19-138), and two von Willebrand factor type C domains (residues 174-230 and 252-318).

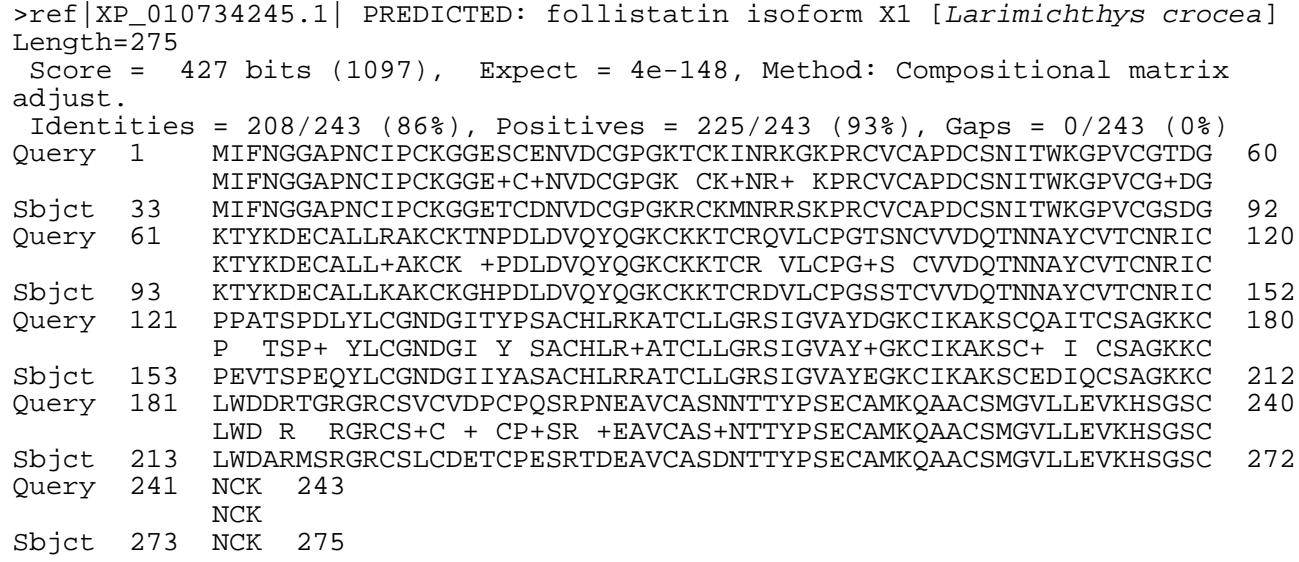

Figure 5.3B. Top match blastp alignment of the putative $A$. limnaeus follistatin protein to the nr protein database. Predicted conserved domains included a follistatin-like SPARC (secreted protein, acidic, and rich in cysteines) domain (residues 19-74), and two Kazal type serine protease inhibitors and follistatin-like domains (residues 120-163 and 207-240). 


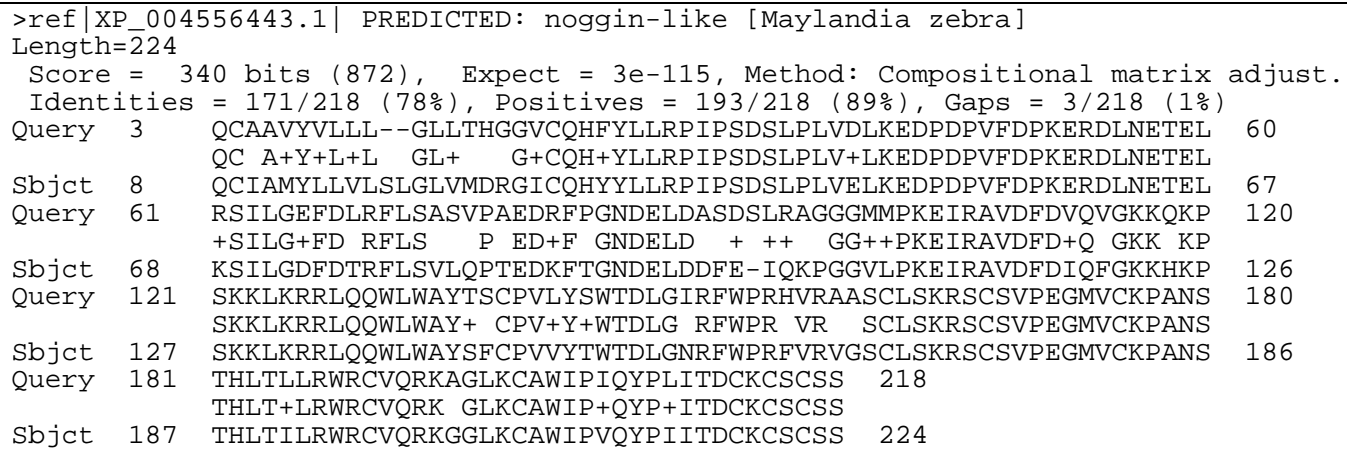

Figure 5.3C. Top match blastp alignment of the putative $A$. limnaeus noggin1 protein to the nr protein database. The predicted conserved domain was a Noggin superfamily domain (residues 21-216).

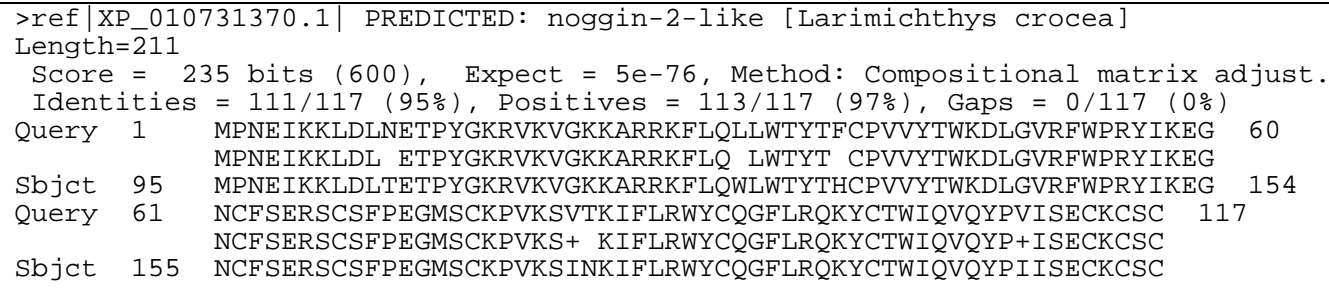

Figure 5.3D. Top match blastp alignment of the putative A. limnaeus noggin2 protein to the nr protein database. The predicted conserved domain was a Noggin superfamily domain (residues 1-117). 


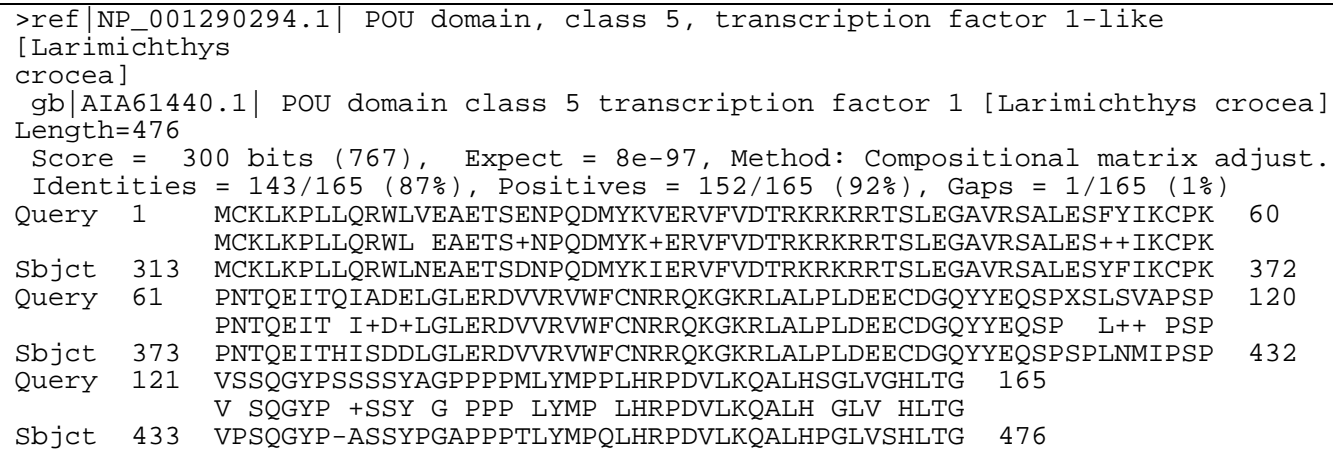

Figure 5.3E. Top match blastp alignment of the putative $A$. limnaeus oct 4 (pou5f1) protein to the nr protein database.

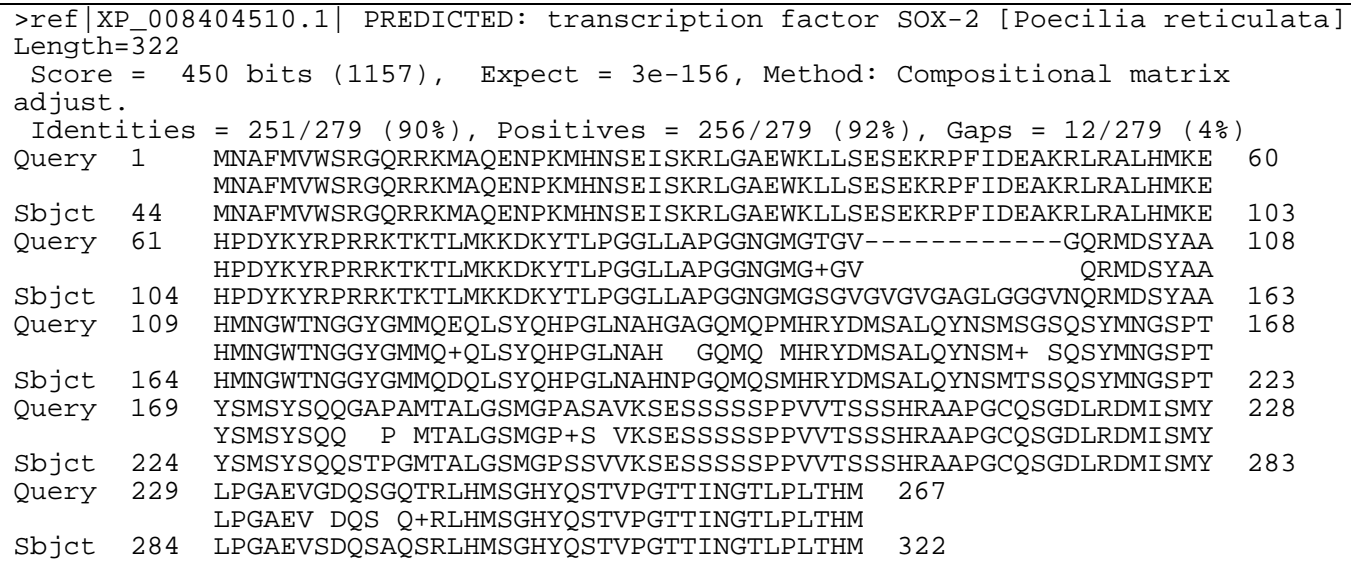

Figure 5.3F. Top match blastp alignment of the putative A. limnaeus sox2 protein to the nr protein database. Putative conserved domains included a high mobility group box (SOX-TCF_HMG-box, residues 1-65) and a SOX transcription factor domain (residues 66-146). 


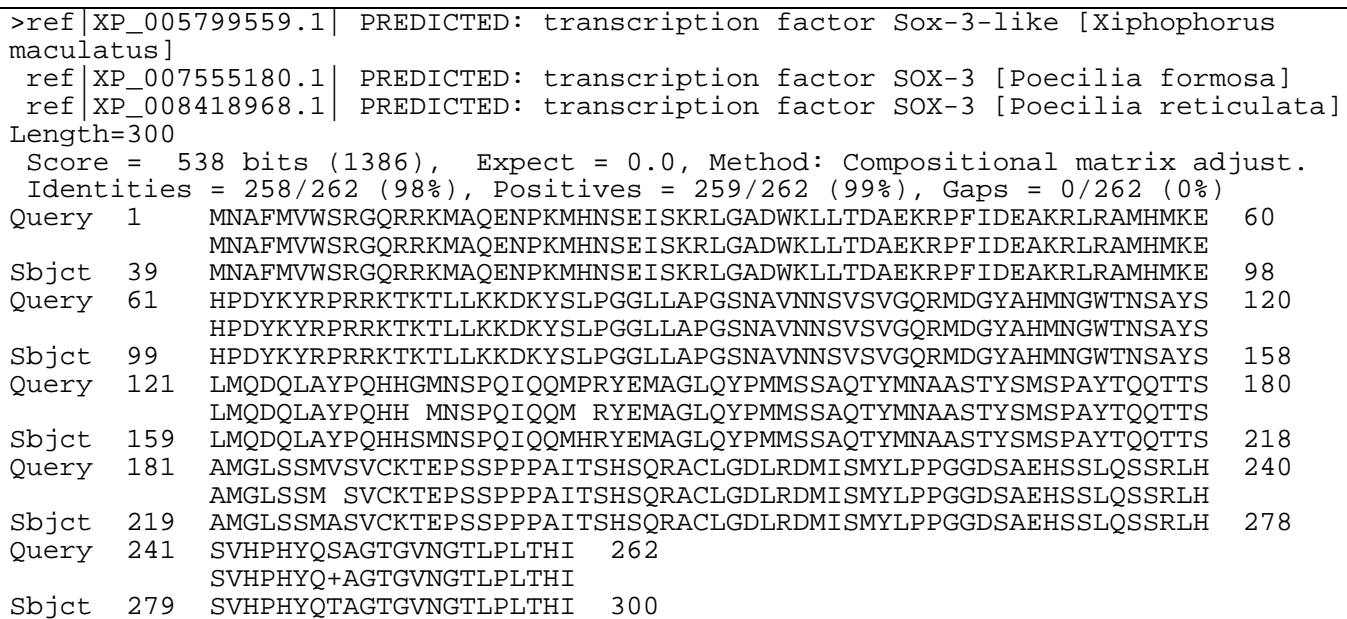

Figure 5.3G. Top match blastp alignment of the putative A. limnaeus sox3 protein to the nr protein database. Putative conserved domains included a high mobility group box (SOX-TCF_HMG-box, residues 1-65) and a SOX transcription factor domain (residues 66-146). 


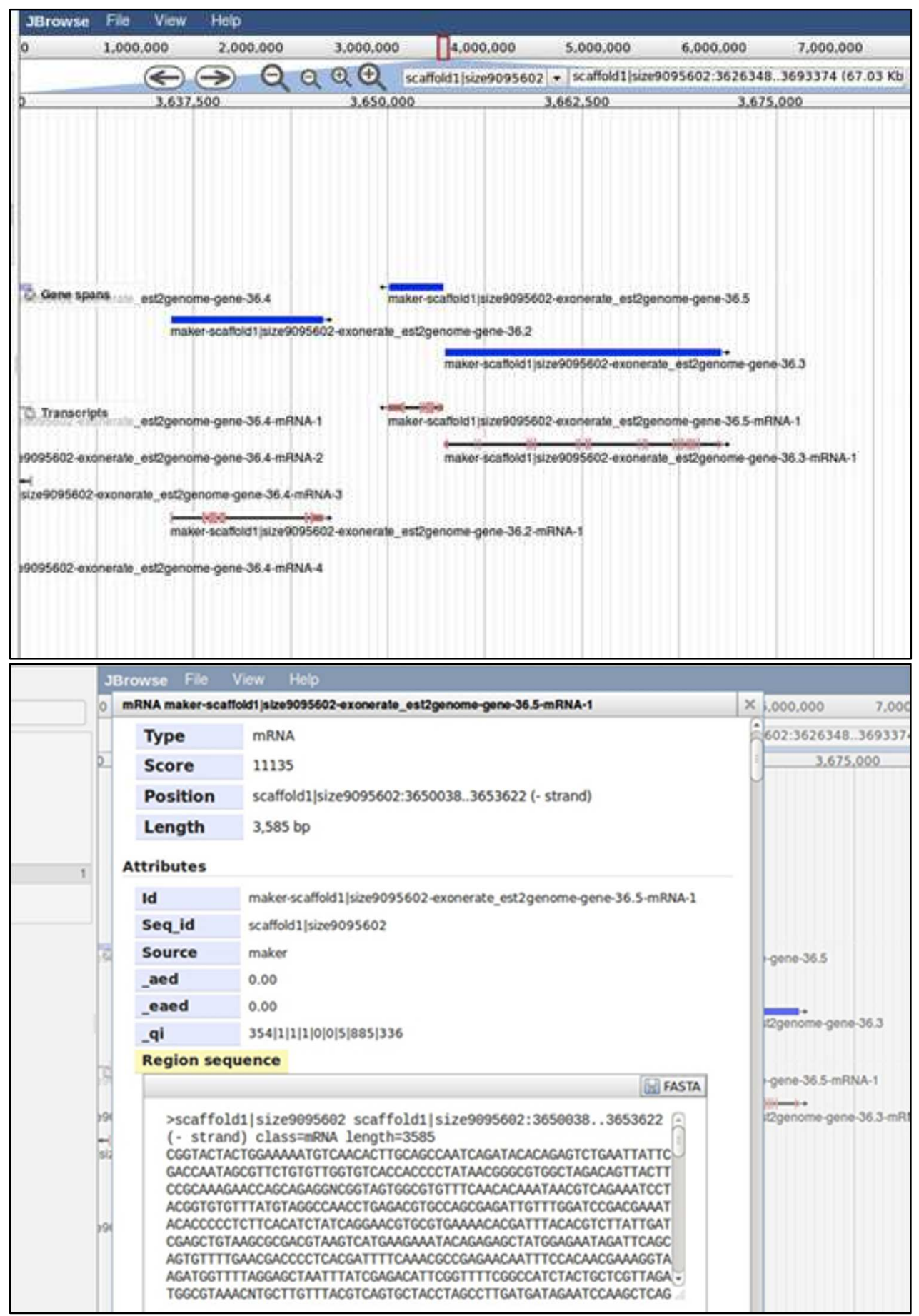

Figure 5.4. Representative screen images of the A. limnaeus genome and annotations visualized in a graphical interface (J-Browse).

Top panel. Users are able to select a scaffold in JBrowse and visualize all identified repeat elements and gene predictions in that sequence.

Bottom panel. Users can select gene predictions and view the sequence, length, and molecule type. 


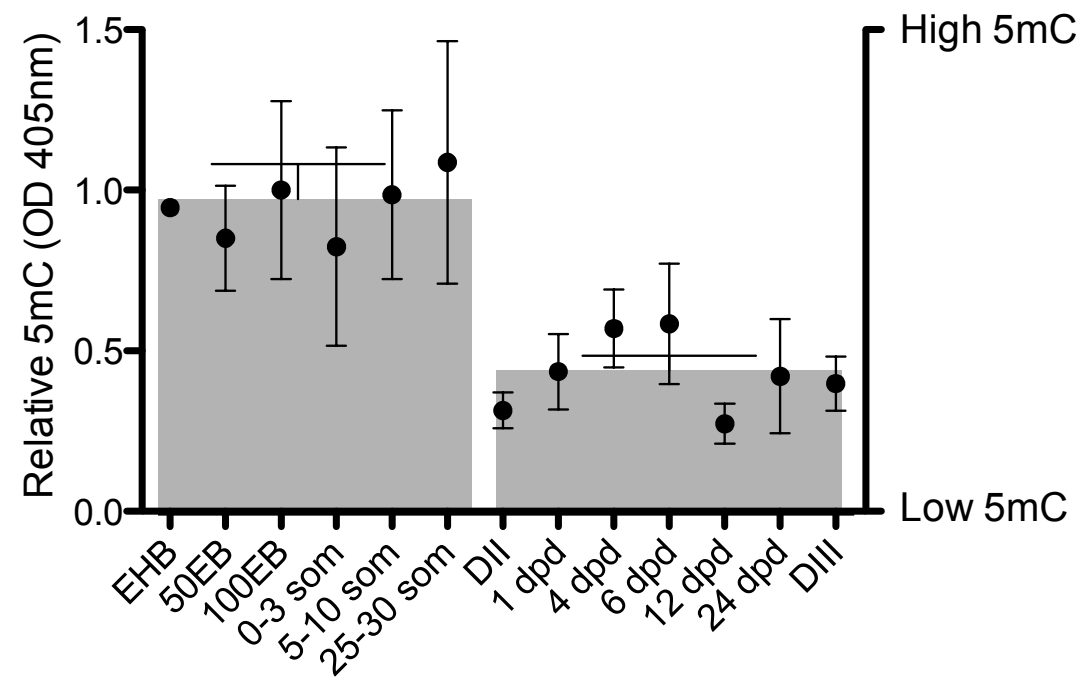

Figure 5.5. Comparison of global $5 \mathrm{mC}$ between embryonic stages as measured by relative optical density (OD) at $405 \mathrm{~nm}$ following ELISA (black dots). Error bars are means \pm SEM ( $n=4$ for all stages except for EHB, which is $\mathrm{n}=2$ ). The embryonic stages are not significantly different when compared to each other (One-way ANOVA with Bonferroni post hoc, $p>$ $0.05)$. However, if data are grouped into pre-DII or post-DII, the means are statistically significant (grey bar graphs, unpaired two-tailed t-test, $\mathrm{p}<$ 0.0001). 


\begin{tabular}{|c|c|c|c|c|c|}
\hline Stage & WS & Age & Description & $\begin{array}{l}\text { Pooled } \\
\text { individuals }\end{array}$ & $N$ \\
\hline $\begin{array}{l}\text { Early Hollow } \\
\text { Blastula }\end{array}$ & 12 & $1 \mathrm{dpf}$ & $\begin{array}{l}\text { Presence of a segmentation cavity } \\
\text { containing blastomeres and covered by } \\
\text { enveloping layer cells }\end{array}$ & 50 & 2 \\
\hline 50\% Epiboly & 17 & $2 \mathrm{dpf}$ & $\begin{array}{l}\text { Half of the yolk surface covered by } \\
\text { periblast and enveloping layer. In } \\
\text { between the two layers are embryonic } \\
\text { blastomeres that have become ameboid } \\
\text { and migrated away from the central } \\
\text { blastula. }\end{array}$ & 40 & 4 \\
\hline 100\% Epiboly & $\begin{array}{l}20- \\
21\end{array}$ & $4 \mathrm{dpf}$ & $\begin{array}{l}\text { Yolk surface completely covered by } \\
\text { periblast, enveloping layer, and } \\
\text { randomly distributed embryonic } \\
\text { blastomeres. }\end{array}$ & 30 & 4 \\
\hline $0-3$ somite & 28 & $10 \mathrm{dpf}$ & $\begin{array}{l}\text { Presence of a solid neural keel, head } \\
\text { fold, and Kupffer's vesicle. } 0-3 \text { somites } \\
\text { present. }\end{array}$ & 15 & 4 \\
\hline 5-10 somite & $\begin{array}{l}29- \\
30\end{array}$ & $\begin{array}{l}12-14 \\
\mathrm{dpf}\end{array}$ & $\begin{array}{l}\text { Heart visible 5-10 somites, cephalic } \\
\text { region present }\end{array}$ & 15 & 4 \\
\hline $25-30$ somite & 31 & $\begin{array}{l}18-20 \\
\mathrm{dpf}\end{array}$ & $\begin{array}{l}\text { Functional heart, major divisions of } \\
\text { brain visible, } 25-30 \text { somites }\end{array}$ & 15 & 4 \\
\hline Diapause II & 33 & $32 \mathrm{dpf}$ & $\begin{array}{l}\text { Presence of optic cups and associated } \\
\text { lenses, otic vesicles, functional heart, } \\
\text { and } 38-40 \text { pairs of somites. Heart rate } \\
\text { of } 0-10 \mathrm{bpm} \text {. }\end{array}$ & 20 & 4 \\
\hline $\begin{array}{l}\text { Very early } \\
\text { post-diapause } \\
\text { II }\end{array}$ & - & $1 \mathrm{dpd}$ & $\begin{array}{l}\text { No pigmentation, heartbeat is over } 0-10 \\
\text { bpm, evidence of enlarging head }\end{array}$ & 10 & 4 \\
\hline $\begin{array}{l}\text { Early post- } \\
\text { diapause II }\end{array}$ & 36 & $4 \mathrm{dpd}$ & $\begin{array}{l}\text { Slight retinal pigmentation, appearance } \\
\text { of melanocytes distrubuted as spots on } \\
\text { the embryo body }\end{array}$ & 10 & 4 \\
\hline $\begin{array}{l}\text { Early half- } \\
\text { overgrowth }\end{array}$ & 37 & $6 \mathrm{dpd}$ & $\begin{array}{l}\text { Retinal pigmentation, light body } \\
\text { pigmentation, red blood cells present }\end{array}$ & 10 & 4 \\
\hline $\begin{array}{l}\text { Full } \\
\text { overgrowth }\end{array}$ & 40 & $12 \mathrm{dpd}$ & $\begin{array}{l}\text { Heavy eye pigmentation, large gut, } \\
\text { appearance of air bladder }\end{array}$ & 10 & 4 \\
\hline $\begin{array}{l}\text { Early pre- } \\
\text { hatching }\end{array}$ & 43 & $24 \mathrm{dpd}$ & Fully formed embryo & 10 & 4 \\
\hline Diapause III & 43 & $32 \mathrm{dpd}$ & $\begin{array}{l}\text { Fully formed embryo that has not } \\
\text { hatched for several days }\end{array}$ & 7 & 4 \\
\hline
\end{tabular}

Table 5.1. Selected $A$. limnaeus embryonic stages used for $5 \mathrm{mC}$ ELISA. Embryos were staged according to Wourms (1972a) and sampled for total DNA extraction. 


\begin{tabular}{|l|l|l|l|l|}
\hline Library & $\begin{array}{l}\text { Raw bases } \\
\text { (GB) }\end{array}$ & Raw reads & $\begin{array}{l}\text { Selected } \\
\text { insert size }\end{array}$ & $\begin{array}{l}\text { Sequence } \\
\text { coverage } \\
\text { (post } \\
\text { assembly) }\end{array}$ \\
\hline Fragment & 71.51 & $707,993,530$ & $180 \mathrm{bp}$ & $68.2 \mathrm{X}$ \\
\hline MP1 & 57.96 & $573,889,020$ & $4 \mathrm{~kb}$ & $19.7 \mathrm{X}$ \\
\hline MP2 & 7.59 & $75,189,402$ & $7.5 \mathrm{~kb}$ & $3 \mathrm{X}$ \\
\hline MP3 & 7.47 & $73,950,464$ & $10-15 \mathrm{~kb}$ & $3 \mathrm{X}$ \\
\hline MixMP4 & 14.12 & $139,799,186$ & $5-8 \mathrm{~kb}$ & $6 \mathrm{X}$ \\
\hline MixMP5 & 13.77 & $136,307,424$ & $8-15 \mathrm{~kb}$ & $6 \mathrm{X}$ \\
\hline TOTAL & 172.42 & $1,707,129,026$ & - & $105.9 \mathrm{X}$ \\
\hline
\end{tabular}

Table 5.2. Input Illumina reads and bases for de novo assembly of the $A$. limnaeus genome. MP libraries refer to jumping libraries with large insert sizes. MixMP libraries were jumping libraries were derived from input DNA from a mixture of 4 adult male individuals. 


\begin{tabular}{|l|l|l|l|l|}
\hline $\begin{array}{l}\text { Assembled } \\
\text { bases } \\
\text { (including } \\
\text { gaps) }\end{array}$ & $\begin{array}{l}\text { Assembled } \\
\text { bases } \\
\text { (excluding } \\
\text { gaps) }\end{array}$ & $\begin{array}{l}\mathbf{N 5 0} \\
\text { scaffolds }\end{array}$ & $\begin{array}{l}\text { Total } \\
\text { number of } \\
\text { scaffolds } \\
\text { (>200 bp) }\end{array}$ & $\begin{array}{l}\text { Max } \\
\text { scaffold } \\
\text { length }\end{array}$ \\
\hline $867 \mathrm{Mb}$ & $695 \mathrm{Mb}$ & $0.983 \mathrm{Mb}$ & 29,785 & $10.1 \mathrm{Mb}$ \\
\hline
\end{tabular}

Table 5.3. Basic assembly statistics of the A. limnaeus genome. The N50 length is the contig length in bases in which all contigs of that length and longer contains half of the total assembled bases. This iteration contains the merged assembly of Allpaths-LG and JR-assembler with scaffolding by SSPACE. 


\begin{tabular}{|l|l|l|l|l|}
\hline Species & $\begin{array}{l}\text { Genome } \\
\text { size (GB) }\end{array}$ & \%GC & \% Repetitive & Ref \\
\hline A. limnaeus & 0.974 & 41.6 & 44 & This chapter \\
\hline D. rerio & 1.41 & 50.6 & 52.2 & (Howe et al., 2013) \\
\hline N. furzeri & $1.6-1.9$ & 44.9 & 45 & $\begin{array}{l}\text { (Reichwald et al., } \\
\text { 2009) }\end{array}$ \\
\hline G. aculeatus & 0.461 & 50.5 & 6.6 & (Jones et al., 2012) \\
\hline $\begin{array}{l}\text { G. morhua } \\
\text { Homo } \\
\text { sapiens }\end{array}$ & 0.83 & 50.0 & 25.4 & (Star et al., 2011) \\
\hline & 46.1 & $66-69$ & $\begin{array}{l}\text { NSDC Assembly } \\
\text { GCA_000001405.17, } \\
\text { (Romiguier et al., } \\
\text { 2010), (De Koning } \\
\text { et al., 2011) }\end{array}$ \\
\hline
\end{tabular}

Table 5.4. Species comparison of total estimated genomic GC and repeat content. The estimated genome size of $N$. furzeri is based on flow cytometry. For all others, the genome sizes are based on total assembly length. 


\begin{tabular}{|l|l|l|l|}
\hline & A. limnaeus & D. rerio & \\
\hline $\begin{array}{l}\text { Estimated repeat (at read level) } \\
\%\end{array}$ & 44 & - & \\
\hline Repeat Masker \% & 27.55 & - & \\
\hline tandem repeat finder \% & 3.13 & - & \\
\hline Total \% identified & 30.68 & 52.2 & \\
\hline & & & \\
\hline Repeat class/superfamily & & & Note \\
\hline SINE \% & 0.69 & 2.216 & type I \\
\hline & & & transposons \\
\hline LINE \% & 3.89 & 2.58 & transposons \\
\hline LTR elements \% & & & $\begin{array}{l}\text { type I } \\
\text { transposons }\end{array}$ \\
\hline & 0.77 & 3.314 & $\begin{array}{l}\text { type I } \\
\text { transposons }\end{array}$ \\
\hline non-LTR elements & & & $\begin{array}{l}\text { type II } \\
\text { transposons }\end{array}$ \\
\hline DNA elements \% & - & 2.495 & \\
\hline Unclassified & 6.36 & 38.51 & \\
\hline Simple repeats \% & 15.22 & 0.05 & \\
\hline Low complexity & 0.42 & 6.44 & \\
\hline
\end{tabular}

Table 5.5. Comparison of repetitive elements identified by RepeatModeler to ones identified in zebrafish (D. rerio) (Howe et al., 2013). Type I transposons are also referred to as retrotransposons and type II transposons are also referred to as DNA transposons (Feschotte and Pritham, 2007; Temin, 1985). 


\begin{tabular}{|l|l|l|l|}
\hline Species & Complete genes & $\begin{array}{l}\text { Partial and } \\
\text { complete genes }\end{array}$ & Reference \\
\hline A. limnaeus & $68.97 \%(171 / 248)$ & $\begin{array}{l}95.96 \% \\
(237 / 248)\end{array}$ & This chapter \\
\hline G. morhua & $63.71 \%(158 / 248)$ & $95.97(238 / 248)$ & $\begin{array}{l}\text { (Star et al., } \\
2011)\end{array}$ \\
\hline G. aculeatus & $86.29 \%(214 / 248)$ & $97.58(242 / 248)$ & $\begin{array}{l}\text { (Jones et al., } \\
2012)\end{array}$ \\
\hline
\end{tabular}

Table 5.6. CEGMA gene completion reports for the A. limnaeus, Atlantic Cod (G. morhua), and Stickleback (G. aculeatus) genome assemblies. CEGMA searches genomic sequences for 248 genes that have been proposed as having homologs present in all eukaryotes. 


\begin{tabular}{|l|l|l|l|l|}
\hline Gene & $\begin{array}{l}\text { \# amino } \\
\text { acids }\end{array}$ & Start codon & Stop codon & $\begin{array}{l}\text { Scaffold } \\
\text { location }\end{array}$ \\
\hline chordin & 395 & ATG & TAA & Scaffold491 \\
\hline follistatin & 243 & - & TAA & Scaffold84 \\
\hline noggin-1 & 218 & ATG & TAG & Scaffold333 \\
\hline noggin-2 & 117 & ATG & TGA & Scaffold48 \\
\hline oct4 & 165 & - & TAG & Scaffold20 \\
\hline sox 2 & 267 & ATG & TAG & Scaffold648 \\
\hline sox3 & 262 & ATG & TGA & Scaffold1 \\
\hline
\end{tabular}

Table 5.7. Identified reading frames of genes of interest in the A. limnaeus genome. The scaffold location identifies the scaffold number in which the gene occurs in the current iteration of the A. limnaeus genome. A complete open reading frame would include both a start and stop codon. 


\section{Chapter 6:}

\section{Summary and future directions}

Development in an unpredictable environment requires a delicate balance allowing room for the evolution of novel strategies while conserving basic cellular processes. Previous work in Austrofundulus limnaeus has clearly shown that annual killifish have a unique biology that has likely been driven by strong environmental pressures. However, this project has demonstrated that basic processes such as DNA repair and sequence evolution are unsurprisingly still a part of the annual killifish life history. Until this project, the mechanisms used by diapausing vertebrates to tolerate DNA damage during embryonic development were unknown. The ability of A. limnaeus diapausing embryos to tolerate cell stress at higher degrees than other vertebrates also extends to DNA damage induced by UV-C radiation. This project also demonstrated the first evidence of a unique developmental stage in annual killifish that may be able buffer against cytotoxic cell stress by gene expression mechanisms that maintain pluripotency for an extended period of time. The unique response of $A$. limnaeus also extends to its regulation of mtDNA copy number, and the data presented here suggests that A. limnaeus embryos are able to stabilize mitochondria even after treatments that would normally cause mitochondrial dysfunction. 
Perhaps the most exciting outcome of this project is the generation of

a mitochondrial and draft nuclear genome of A. limnaeus. The mtgenome and nuclear genome assemblies characterized during this project will be an invaluable tool for future research on the annual killifish phenotype. Future functional annotation of the A. limnaeus nuclear genome will be essential for understanding the genetic complexities of extreme stress tolerance.

Although this project has elucidated several aspects of DNA sequence, repair, and expression in A. limnaeus, there are many future directions that can be taken from the data presented here.

\section{Major findings from Chapter 2}

Embryos of A. limnaeus have an exceptional tolerance to DNA damage induced by UV-C radiation, although the developmental consequences of the damage appear to be stage dependent. Embryos appear to be strongly dependent on photolyase activity to reverse DNA lesions, although 4 and 32 dpf embryos may be able to tolerate lesions for several days or weeks. This apparent lack of dark repair mechanisms, and heavy reliance on PR during diapause could have profound influences on the maintenance of genome integrity during diapause. Apoptotic cells were rarely observed following UV radiation in embryos at 4 and $32 \mathrm{dpf}$, an atypical response among vertebrates that supports previous notions that apoptosis signaling may be suppressed during diapause. One of the most interesting results we found 
was the general lack of abnormal embryos after UV-C irradiation at $4 \mathrm{dpf}$. Although our population of A. limnaeus do not regularly arrest in diapause I at the dispersed blastomere stage under standard laboratory conditions, previous investigators have suggested that arrest at this stage may be common in other species of annual killifish (some of which are congeners of A. limnaeus) in response to stressful conditions (Genade et al., 2005;

Wourms, 1965). As previously proposed by Wourms (1972b), the dispersed blastomere stage in annual killifish may function to buffer environmental insult by delaying the sensitive embryonic organization and differentiation states that would occur after the onset of gastrulation. Damaged or dead embryonic cells could be replaced by mitotic proliferation of surrounding cells with an equal differentiation status and no positional affiliations, thus minimizing abnormal morphogenesis.

\section{Major findings from Chapter 3}

The mRNA expression of oct4, sox3, sox2, chordin, follistatin, noggin-1, and noggin-2 are dynamic across embryonic development in A. limnaeus. These data suggest that gastrulation and formation of the primary germ layers are delayed for several days after the completion of epiboly until the $\mathrm{D} / \mathrm{R}$ process is near complete. I propose that gastrulation does not commence during epiboly because of BMP inhibition by early chordin and noggin-1 expression. The dispersed blastomeres resulting from this process 
are very likely pluripotent and lack spatial orientation, and this may benefit the embryos by delaying the sensitive process of gastrulation and axis formation until environmental conditions are favorable. The implications for this work reach far beyond the peculiar developmental patterns of annual killifish, and suggest that even highly conserved developmental pathways that are required for the formation of the basic vertebrate body plan can be altered in response to intense selective pressure to generate unique life histories and alter the timing of early development. Data presented here represent the first support for the hypothesis that damaged embryonic cells could indeed be replaced by surrounding undifferentiated cells if the cytotoxic events occur during the dispersed blastomere phases.

\section{Major findings from Chapter 4}

In this chapter, I described the first complete mtgenome of a South American annual killifish. It is unclear if the increased rate of substitution observed in the mtgenomes of annual killifish is due to natural selection or drift. Within the Superfamily Aplocheiloidei, there appears to be a trend for unusual D-loop architecture that may have physiological implications for anoxia tolerance. One of the most surprising outcomes in this chapter is the observation that mtDNA copy number is inversely correlated with OXPHOS activity. Additionally, the observation that mtDNA content does not change 
following anoxia/reoxygenation suggests that quenching or prevention of ROS may be an essential component of anoxia tolerant mitochondria.

\section{Major findings for Chapter 5}

By available metrics, the current iteration of the A. limnaeus genome is comparable to other previously published genomes in completeness, especially those that were assembled exclusively with short reads. This chapter demonstrated how the A. limnaeus genome could be used to identify open reading frames or repetitive elements and visualized in a graphical interface. Following completion of the NCBI gene annotation pipeline, the $A$. limnaeus genome will be an invaluable tool for discovery of DNA elements that may have had a role in evolution of the annual killifish life history.

\section{Future research directions}

One of the most surprising results of Chapter 2 was the observation that most UV-C irradiated DII embryos did not exhibit substantial apoptosis as determined by TUNEL assay, even at the highest doses of UV-C. Similarly, DII embryos exposed to anoxia do not have increases in apoptotic cells, and exposure to anoxia is associated with increased expression of p53 tumor suppressor (Meller et al., 2012; Meller and Podrabsky, 2013). Because of its role in cell cycle regulation and induction of apoptosis, p53 gene expression has been implicated as an important factor in recognition and repair of DNA 
damage from UV radiation exposure (Smith and Fornace, 1997). It is possible that the stress response pathway involving p53 is shared between anoxia and UV radiation exposure, and characterization of p53 following UV radiation exposure may help clarify how A. limnaeus are able to tolerate more UV radiation exposure than other species. Additionally, the observation that DII embryos accumulate DNA damage induced by UV-C radiation when not exposed to reactivating light, instead of repairing it, suggests that A. limnaeus diapausing embryos may be similar to Artemia franciscana in that repair is not initiated until diapause is terminated (McLennan, 2009). The ability of many DII embryos to repair substantial amounts of CPDs and still develop normally is impressive. Determining if A. limnaeus can rapidly repair other forms of accumulated DNA damage prior to resumption of development (such as depurination, depyrimidation, and bases damaged by oxidative stress) may have implications for preventing mutation accumulation in humans, a driving factor in aging and cancer.

Until this project, the possible benefits of delaying formation of the embryonic axis by dispersion and reaggregation of embryonic blastomeres was speculative. The results of Chapter 2 and 3 suggest that the dispersed deep cells are very likely undifferentiated, as germ layer formation does not appear to be established until the embryonic axis is visible, and this dispersed state may act as a developmental buffer to allow loss of damaged cells. However, the mechanism by which embryonic cells reaggregate and 
initiate gastrulation independent of epiboly is unclear. Localization of the genes described in Chapter 3 during reaggregation phases would be invaluable for determining the extent to which axis formation mechanisms are still conserved between annual killifish and typical teleosts. Additionally, elucidating the role of cadherins, transmembrane proteins thought to regulate cell-cell adhesion during gastrulation (Shimizu et al., 2005), in $A$. limnaeus gastrulation would be helpful for building a model of axis formation in annual killifish. Because of recent interest in generating tissues and organs from pluripotent stem cells, determining how migration and differentiation of cells is accomplished in annual killifish would be a worthwhile endeavor.

It is clear from the results in Chapter 4 that A. limnaeus have mtDNA that is unique in sequence and in its response to anoxia. Determination of the extent to which mtDNA sequence is conserved between multiple populations of anoxia tolerant $A$. limnaeus would help clarify which regions of interest in the mtDNA, if any, may have a role in metabolic depression and anoxia tolerance. Previous work has suggested that the respiratory complexes of A. limnaeus mitochondria during diapause are able to undergo reversible rates of depressed activity through regulation of protein complex mRNA levels, translation rates, or biochemical modifications (Duerr and Podrabsky, 2010). The results in Chapter 4 demonstrate that mtDNA content does not change following anoxia/reoxygenation, suggesting that 
mitochondria are somehow stabilized instead of being subject to mitophagy or ROS-induced biogenesis. This would suggest that mitochondrial complexes are stabilized instead of degraded, and that ROS signaling may be quenched or prevented following reoxygenation. However, mitochondrial size, OXPHOS activity, and ROS generation following anoxia/reoxygenation were not directly measured in this project. Characterization of mitochondrial function during anoxia/reoxygenation through measurement of citrate synthase activity, mitochondrial volume, and ROS production will be important for testing the hypothesis that mitochondria and ROS signaling are stabilized in anoxia tolerant species. It is worth nothing that mitochondria appear to lack the NER and photolyase pathways that are usually involved with reversal of CPDs (Alexeyev et al., 2013). Suppressing mitophagy may prevent removal of mitochondria with DNA lesions induced by UV-C radiation, causing mitochondrial dysfunction and leading to mutation, although whether or not this is the case remains to be seen.

The genome assembly presented in Chapter 5 provides the foundation for some of the greatest possible advances in the understanding of annual killifish biology. Future annotation of coding genes, regulatory regions, and repeat elements will allow for cross-species comparisons and identification of elements that may have been important for the evolution of the annual killifish phenotype. Finally, sequence-specific determination of DNA methylation sites during $A$. limnaeus embryonic development will be key to 
establishing the role of reversible DNA modifications for entry into

embryonic diapause. 


\section{References}

Akimoto, Y. and Shiroya, T. (1987). Photoreversibility of UV-induced thymine dimers and abnormal morphogenesis in sea urchin embryos.

Photochemistry and Photobiology 45, 403-406.

Alcolea, M. P., Colom, B., Llado, I., Gianotti, M. and Garcia-Palmer, F. J. (2006). Mitochondrial Transcription Factor A (TFAM) is Increased in Rat Embryo During Placentation and Associated with Mitochondrial Differentiation. Cellular Physiology and Biochemistry 17, 79-88.

Alexeyev, M., Shokolenko, I., Wilson, G. and LeDoux, S. (2013). The maintenance of mitochondrial DNA integrity: critical analysis and update. Cold Spring Harbor perspectives in biology 5, a012641.

Anderson, S. N. and Podrabsky, J. E. (2014). The effects of hypoxia and temperature on metabolic aspects of embryonic development in the annual killifish Austrofundulus limnaeus. Journal of Comparative Physiology $B$ 184, 355-370.

Anzalone, C. R., Kats, L. B. and Gordon, M. S. (1998). Effects of solar UV-B radiation on embryonic development in Hyla cadaverina, Hyla regilla, and Taricha torosa. Conservation Biology 12, 646-653.

Applegate, L. and Ley, R. (1988). Ultraviolet radiation-induced lethality and repair of pyrimidine dimers in fish embryos. Mutation Research 198, 85-92.

Archer, T. C., Jin, J. and Casey, E. S. (2011). Interaction of Sox1, Sox2, Sox3 and Oct4 during primary neurogenesis. Developmental Biology 350, 429-440.

Armstrong, P. B. and Child, J. S. (1965). Stages in the normal development of Fundulus heteroclitus. Biological Bulletin 128, 143-168.

Artuso, L., Romano, A., Verri, T., Domenichini, A., Argenton, F., Santorelli, F. M. and Petruzzella, V. (2012). Mitochondrial DNA metabolism in early development of zebrafish (Danio rerio). Biochimica et Biophysica Acta (BBA)-Bioenergetics 1817, 1002-1011.

Bai, Y., Shakeley, R. M. and Attardi, G. (2000). Tight control of respiration by NADH dehydrogenase ND5 subunit gene expression in mouse mitochondria. Molecular and Cellular Biology 20, 805-815.

Ballard, J. W. O. and Whitlock, M. C. (2004). The incomplete natural history of mitochondria. Molecular Ecology 13, 729-744.

Bauer, H., Meier, A., Hild, M., Stachel, S., Economides, A., Hazelett, D., Harland, R. M. and Hammerschmidt, M. (1998). Follistatin and noggin are excluded from the zebrafish organizer. Developmental Biology 204, 488507.

Behjati, S., Huch, M., van Boxtel, R., Karthaus, W., Wedge, D. C., Tamuri, A. U., Martincorena, I. i., Petljak, M., Alexandrov, L. B. and Gundem, G. (2014). Genome sequencing of normal cells reveals developmental lineages and mutational processes. Nature 513, 422-425. 
Bernt, M., Donath, A., Jühling, F., Externbrink, F., Florentz, C., Fritzsch, G., Pütz, J., Middendorf, M. and Stadler, P. F. (2013). MITOS: Improved de novo metazoan mitochondrial genome annotation. Molecular phylogenetics and evolution 69, 313-319.

Berois, N., Arezo, M. J., Papa, N. G. and Clivio, G. A. (2012). Annual fish: developmental adaptations for an extreme environment. Wiley Interdisciplinary Reviews: Developmental Biology 1, 595-602.

Betley, J. N., Frith, M. C., Graber, J. H., Choo, S. and Deshler, J. 0. (2002). A ubiquitous and conserved signal for RNA localization in chordates. Current Biology 12, 1756-1761.

Blaustein, A., Kiesecker, J., Chivers, D. and Anthony, R. (1997). Ambient UV-B radiation causes deformities in amphibian embryos. Proceedings of the National Academy of Sciences of the United States of America 94, 13735-7.

Boetzer, M., Henkel, C. V., Jansen, H. J., Butler, D. and Pirovano, W. (2011). Scaffolding pre-assembled contigs using SSPACE. Bioinformatics 27, 578-9.

Bogdanovic, O. and Gómez-Skarmeta, J. L. (2013). Embryonic DNA methylation: insights from the genomics era. Briefings in Functional Genomics.

Bolger, A. M., Lohse, M. and Usadel, B. (2014). Trimmomatic: a flexible trimmer for Illumina sequence data. Bioinformatics, btu170.

Brash, D. (1997). Sunlight and the onset of skin cancer. Trends in Genetics 13, 410-4.

Bratic, A. and Larsson, N.-G. r. (2013). The role of mitochondria in aging. The Journal of Clinical Investigation 123, 951-957.

Broughton, R. E., Milam, J. E. and Roe, B. A. (2001). The complete sequence of the zebrafish (Danio rerio) mitochondrial genome and evolutionary patterns in vertebrate mitochondrial DNA. Genome Research 11, 1958-1967.

Burgess, S., Reim, G., Chen, W., Hopkins, N. and Brand, M. (2002). The zebrafish spiel-ohne-grenzen (spg) gene encodes the POU domain protein Pou2 related to mammalian Oct4 and is essential for formation of the midbrain and hindbrain, and for pre-gastrula morphogenesis. Development 129, 905-916.

Carling, P. J., Cree, L. M. and Chinnery, P. F. (2011). The implications of mitochondrial DNA copy number regulation during embryogenesis. Mitochondrion 11, 686-692.

Chapman S.C., Schubert F.R., Schoenwolf G.C., and Lumsden A. (2002). Analysis of spatial and temporal gene expression patterns in blastula and gastrula stage chick embryos. Developmental Biology 245, 187-199.

Chen, S.-D., Yang, D.-I., Lin, T.-K., Shaw, F.-Z., Liou, C.-W. and Chuang, Y.-C. (2011). Roles of oxidative stress, apoptosis, PGC-1CE \pm and 
mitochondrial biogenesis in cerebral ischemia. International Journal of Molecular Sciences 12, 7199-7215.

Chu, T.-C., Lu, C.-H., Liu, T., Lee, G. C., Li, W.-H. and Shih, A. C.-C. (2013). Assembler for de novo assembly of large genomes. Proceedings of the National Academy of Sciences 110, E3417-E3424.

Clark, K. A., Howe, D. K., Gafner, K., Kusuma, D., Ping, S., Estes, S. and Denver, D. R. (2012). Selfish little circles: transmission bias and evolution of large deletion-bearing mitochondrial DNA in Caenorhabditis briggsae nematodes. PLOS ONE 7, e41433-e41433.

Clegg, J. S. (1997). Embryos of Artemia franciscana survive four years of continuous anoxia: the case for complete metabolic rate depression. Journal of Experimental Biology 200, 467-475.

Clegg, J. S., Drinkwater, L. E. and Sorgeloos, P. (1996). The metabolic status of diapause embryos of Artemia franciscana (SFB). Physiological Zoology 69, 49-66.

Cui, J., Shen, X., Zhao, H. and Nagahama, Y. (2011). Genome-wide analysis of Sox genes in Medaka (Oryzias latipes) and their expression pattern in embryonic development. Cytogenetic and genome research 134, 283-294.

Dal-Pra, S., Fürthauer, M., Van-Celst, J., Thisse, B. and Thisse, C. (2006). Noggin1 and Follistatin-like2 function redundantly to Chordin to antagonize BMP activity. Developmental Biology 298, 514-526.

De Koning, A., Gu, W., Castoe, T. A., Batzer, M. A. and Pollock, D. D. (2011). Repetitive elements may comprise over two-thirds of the human genome. PLoS Genet 7, e1002384.

De Robertis, E., Larrain, J., Oelgeschläger, M. and Wessely, 0. (2000). The establishment of Spemann's organizer and patterning of the vertebrate embryo. Nature Reviews Genetics 1, 171-181.

Dee, C. T., Hirst, C. S., Shih, Y.-H., Tripathi, V. B., Patient, R. K. and Scotting, P. J. (2008). Sox3 regulates both neural fate and differentiation in the zebrafish ectoderm. Developmental Biology 320, 289-301.

Denver, D. R., Morris, K., Lynch, M., Vassilieva, L. L., and Thomas, W. K. (2000). High direct estimate of the mutation rate in the mitochondrial genome of Caenorhabditis elegans. Science 289, 2342-2344.

Devlin, E., Brammer, J., Puyear, R. and McKim, J. (1996). Prehatching development of the fathead minnow Pimephales promelas Rafinesque. USEPA Publication EPA.

Dong, Q., Svoboda, K., Tiersch, T. and Monroe, W. (2007). Photobiological effects of UVA and UVB light in zebrafish embryos: evidence for a competent photorepair system. Journal of Photochemistry and Photobiology B: Biology 88, 137-146.

Drinkwater, L. E. and Clegg, J. S. (1991). Experimental biology of cyst diapause. In Artemia Biology, eds. R. A. Brown P. Sorgeloos and C. N. A. Trotman), pp. 93-117. Boca Raton: CRC Press, Inc. 
Duerr, J. M. and Podrabsky, J. E. (2010). Mitochondrial physiology of diapausing and developing embryos of the annual killifish Austrofundulus limnaeus: implications for extreme anoxia tolerance. Journal of Comparative Physiology B: Biochemical, Systemic, and Environmental Physiology 180, 9911003.

Edgar, R. C. (2004). MUSCLE: multiple sequence alignment with high accuracy and high throughput. Nucleic Acids Research 32, 1792-1797.

Eisen, J. A. and Hanawalt, P. C. (1999). A phylogenomic study of DNA repair genes, proteins, and processes. Mutation Research/DNA Repair 435, 171-213.

Ekblom, R., Smeds, L. a. and Ellegren, H. (2014). Patterns of sequencing coverage bias revealed by ultra-deep sequencing of vertebrate mitochondria. BMC Genomics 15, 467.

Epel, D., Hemela, K., Shick, M. and Patton, C. (1999). Development in the Floating World: Defenses of Eggs and Embryos Against Damage from UV Radiation. American Zoologist 39, 271-278.

Eroshkin, F. M., Ermakova, G. V., Bayramov, A. V. and Zaraisky, A. G. (2006). Multiple noggins in vertebrate genome: cloning and expression of noggin2 and noggin4 in Xenopus laevis. Gene Expression Patterns 6, 180-186.

Essen, L. O. and Klar, T. (2006). Light-driven DNA repair by photolyases. Cell and Molecular Life Sciences 63, 1266-77.

Estes, S., Coleman-Hulbert, A. L., Hicks, K. A., de Haan, G., Martha, S. R., Knapp, J. B., Smith, S. W., Stein, K. C. and Denver, D. R. (2011). Natural variation in life history and aging phenotypes is associated with mitochondrial DNA deletion frequency in Caenorhabditis briggsae. $B M C$ Evolutionary Biology 11, 11.

Fang, X., Corrales, J., Thornton, C., Scheffler, B. E. and Willett, K. L. (2013). Global and gene specific DNA methylation changes during zebrafish development. Comparative Biochemistry and Physiology Part B: Biochemistry and Molecular Biology 166, 99-108.

Fernández-Silva, P., Enriquez, J. A. and Montoya, J. (2003). Replication and transcription of mammalian mitochondrial DNA. Experimental physiology 88, 41-56.

Feschotte, C. d. and Pritham, E. J. (2007). DNA transposons and the evolution of eukaryotic genomes. Annual Review of Genetics 41, 331.

Flores, K. B., Wolschin, F. and Amdam, G. V. (2013). The role of methylation of DNA in environmental adaptation. Integrative and Comparative Biology 53, 359-72.

Friedberg, E. C., Walker, G. C., Siede, W. and Wood, R. D. (2005). DNA repair and mutagenesis: American Society for Microbiology Press.

Fürthauer, M., Thisse, B. and Thisse, C. (1999). Three Different noggin Genes Antagonize the Activity of Bone Morphogenetic Proteins in the Zebrafish Embryo. Developmental Biology 214, 181-196. 
Gadberry, M. D., Malcomber, S. T., Doust, A. N. and Kellogg, E. A. (2005). Primaclade - a flexible tool to find conserved PCR primers across multiple species. Bioinformatics 21, 1263-1264.

Gao, J., Wang, Z., Shao, K., Fan, L., Yang, L., Song, H., Liu, M., Wang, Z., Wang, X. and Zhang, Q. (2014). Identification and characterization of a Sox2 homolog in the Japanese flounder Paralichthys olivaceus. Gene 544, 165176.

Gelfand, R. and Attardi, G. (1981). Synthesis and turnover of mitochondrial ribonucleic acid in HeLa cells: the mature ribosomal and messenger ribonucleic acid species are metabolically unstable. Molecular and Cellular Biology 1, 497-511.

Genade, T., Benedetti, M., Terzibasi, E., Roncaglia, P., Valenzano, D. R., Cattaneo, A. and Cellerino, A. (2005). Annual fishes of the genus Nothobranchius as a model system for aging research. Aging Cell 4, 223-233.

Gnerre, S., MacCallum, I., Przybylski, D., Ribeiro, F. J., Burton, J. N., Walker, B. J., Sharpe, T., Hall, G., Shea, T. P. and Sykes, S. (2011). Highquality draft assemblies of mammalian genomes from massively parallel sequence data. Proceedings of the National Academy of Sciences 108, 15131518.

Hahn, C., Bachmann, L. and Chevreux, B. (2013). Reconstructing mitochondrial genomes directly from genomic next-generation sequencing reads,Äîa baiting and iterative mapping approach. Nucleic Acids Research, gkt371.

Hahn, D. A. and Denlinger, D. L. (2011). Energetics of insect diapause. Annual Review of Entomology 56, 103-121.

Hamburger, V. (1988). The heritage of experimental embryology: Hans Spemann and the organizer: Oxford University Press New York:

Han, W., Ming, M. and He, Y.-Y. (2011). Caffeine promotes ultraviolet B-induced apoptosis in human keratinocytes without complete DNA repair. Journal of Biological Chemistry 286, 22825-22832.

Hanawalt, P. C. and Spivak, G. (2008). Transcription-coupled DNA repair: two decades of progress and surprises. Nature Reviews Molecular Cell Biology 9, 958-970.

Hand, S. C. and Menze, M. A. (2008). Mitochondria in energy-limited states: mechanisms that blunt the signaling of cell death. Journal of Experimental Biology 211, 1829-1840.

Hand, S. C. and Podrabsky, J. E. (2000). Bioenergetics of diapause and quiescence in aquatic animals. Thermochimica Acta 349, 31-42.

Hanski, I. and Gilpin, M. E. (1997). Metapopulation biology: Academic Press.

Harismendy, O., Ng, P. C., Strausberg, R. L., Wang, X., Stockwell, T. B., Beeson, K. Y., Schork, N. J., Murray, S. S., Topol, E. J. and Levy, S. (2009). Evaluation of next generation sequencing platforms for population targeted sequencing studies. Genome biol 10, R32. 
Hartmann, N., Reichwald, K., Wittig, I., Dröse, S., Schmeisser, S., Lück, C., Hahn, C., Graf, M., Gausmann, U. and Terzibasi, E. (2011). Mitochondrial DNA copy number and function decrease with age in the short-lived fish Nothobranchius furzeri. Aging cell 10, 824-831.

Hays, J., Blaustein, A., Kiesecker, J., Hoffman, P., Pandelova, I., Coyle, D. and Richardson, T. (1996). Developmental responses of amphibians to solar and artificial UVB sources: a comparative study. Photochemistry and Photobiology 64, 449-56.

Hemmati-Brivanlou, A., Kelly, O. G. and Melton, D. A. (1994).

Follistatin, an antagonist of activin, is expressed in the Spemann organizer and displays direct neuralizing activity. Cell 77, 283-95.

Hers, I., Vincent, E. E. and Tavare, J. M. (2011). Akt signalling in health and disease. Cellular Signalling 23, 1515-1527.

Hervouet, E., Cheray, M., Vallette, F. M. and Cartron, P.-F. (2013). DNA methylation and apoptosis resistance in cancer cells. Cells 2, 545-573.

Hirst, J. (2013). Mitochondrial complex I. Annual review of biochemistry 82, 551-575.

Hoarau, G., Holla, S., Lescasse, R., Stam, W. T. and Olsen, J. L. (2002). Heteroplasmy and evidence for recombination in the mitochondrial control region of the flatfish Platichthys flesus. Molecular biology and evolution 19, 2261-2264.

Holt, C. and Yandell, M. (2011). MAKER2: an annotation pipeline and genome-database management tool for second-generation genome projects. BMC Bioinformatics 12, 491.

Howe, K., Clark, M. D., Torroja, C. F., Torrance, J., Berthelot, C., Muffato, M., Collins, J. E., Humphray, S., McLaren, K. and Matthews, L. (2013). The zebrafish reference genome sequence and its relationship to the human genome. Nature 496, 498-503.

Hrbek, T. and Larson, A. (1999). The evolution of diapause in the killifish family Rivulidae (Atherinomorpha, Cyprinodontiformes): a molecular phylogenetic and biogeographic perspective. Evolution 53, 12001216.

Hrbek, T., Taphorn, D. C. and Thomerson, J. E. (2005). Molecular phylogeny of Austrofundulus Myers (Cyprinodontiformes: Rivulidae), with revision of the genus and the description of four new species. Zootaxa 825, 139.

Hurtubise, R. D., Havel, J. E. and Little, E. E. (1998). The effects of ultraviolet-B radiation on freshwater invertebrates: Experiments with a solar simulator. Limnology and Oceanography 43, 1082-1088.

Hyodo-Taguchi, Y. (1983). Effects of UV irradiation on embryonic development of different inbred strains of the fish Oryzias latipes. Journal of Radiation Research 24, 221-228.

Häkkinen, J., Pasanen, S. and Kukkonen, J. (2001). The effects of solar UV-B radiation on embryonic mortality and development in three 
boreal anurans (Rana temporaria, Rana arvalis and Bufo bufo). Chemosphere 44, 441-6.

IDT. Primerquest: http://www.idtdna.com/Primerquest/.

IDT. PrimeTime ZEN Double-Quenched Probes:

http://cdn.idtdna.com//catalog/primetime/zenoverview.pdf.

Iemura, S.-i., Yamamoto, T. S., Takagi, C., Uchiyama, H., Natsume, T., Shimasaki, S., Sugino, H. and Ueno, N. (1998). Direct binding of follistatin to a complex of bone-morphogenetic protein and its receptor inhibits ventral and epidermal cell fates in early Xenopus embryo.

Proceedings of the National Academy of Sciences 95, 9337-9342.

Ishibashi H., Matsumura N., Hanafusa H., Matsumoto K., De Robertis E., and Kuroda H. (2008). Expression of siamois and twin in the blastula chordin/noggin signaling center is required for brain formation in xenopus laevis embryos. Mechanisms of Development 125, 58-66

Iwamatsu, T. (2004). Stages of normal development in the medaka Oryzias latipes. Mechanisms of Development 121, 605-618.

Iwasaki, W., Fukunaga, T., Isagozawa, R., Yamada, K., Maeda, Y., Satoh, T. P., Sado, T., Mabuchi, K., Takeshima, H. and Miya, M. (2013). MitoFish and MitoAnnotator: A mitochondrial genome database of fish with an accurate and automatic annotation pipeline. Molecular biology and evolution 30, 2531-2540.

Jacobs, H. T., Lehtinen, S. K. and Spelbrink, J. N. (2000). No sex please, we're mitochondria: a hypothesis on the somatic unit of inheritance of mammalian mtDNA. BioEssays 22, 564-572.

Jiang, Z. J., Castoe, T. A., Austin, C. C., Burbrink, F. T., Herron, M. D., McGuire, J. A., Parkinson, C. L. and Pollock, D. D. (2007). Comparative mitochondrial genomics of snakes: extraordinary substitution rate dynamics and functionality of the duplicate control region. BMC Evolutionary Biology $\mathbf{7}$, 123.

Johnson, M., Zaretskaya, I., Raytselis, Y., Merezhuk, Y., McGinnis, S. and Madden, T. L. (2008). NCBI BLAST: a better web interface. Nucleic acids research 36, W5-W9.

Jones, F. C., Grabherr, M. G., Chan, Y. F., Russell, P., Mauceli, E., Johnson, J., Swofford, R., Pirun, M., Zody, M. C. and White, S. (2012). The genomic basis of adaptive evolution in threespine sticklebacks. Nature 484, 55-61.

Joyner-Matos, J., Bean, L. C., Richardson, H. L., Sammeli, T. and Baer, C. F. (2011). No evidence of elevated germline mutation accumulation under oxidative stress in Caenorhabditis elegans. Genetics 189, 1439-1447.

Jühling, F., Mario, M., Hartmann, R. K., Sprinzl, M., Stadler, P. F. and Pütz, J. (2009). tRNAdb 2009: compilation of tRNA sequences and tRNA genes. Nucleic Acids Research 37, D159-D162. 
Kamachi, Y., Uchikawa, M., Collignon, J. R. M., Lovell-Badge, R. and Kondoh, H. (1998). Involvement of Sox 1,2 and 3 in the early and subsequent molecular events of lens induction. Development 125, 2521-2532.

Kearse, M., Moir, R., Wilson, A., Stones-Havas, S., Cheung, M., Sturrock, S., Buxton, S., Cooper, A., Markowitz, S. and Duran, C. (2012). Geneious Basic: an integrated and extendable desktop software platform for the organization and analysis of sequence data. Bioinformatics 28, 16471649.

Kelley, J. L., Yee, M.-C., Lee, C., Levandowsky, E., Shah, M., Harkins, T., Earley, R. L. and Bustamante, C. D. (2012). The possibility of de novo assembly of the genome and population genomics of the mangrove rivulus, Kryptolebias marmoratus. Integrative and Comparative Biology 52, 737-742.

Kimmel, C. B., Ballard, W. W., Kimmel, S. R., Ullmann, B. and Schilling, T. F. (1995). Stages of embryonic development of the zebrafish. Developmental Dynamics 203, 253-310.

Kirschner, M. and Gerhart, J. (1998). Evolvability. Proceedings of the National Academy of Sciences of the United States of America 95, 8420-8427.

Kowald, A. and Kirkwood, T. B. (2014). Transcription could be the key to the selection advantage of mitochondrial deletion mutants in aging. Proceedings of the National Academy of Sciences 111, 2972-2977.

Kumazawa, Y. and Nishida, M. (1993). Sequence evolution of mitochondrial tRNA genes and deep-branch animal phylogenetics. Journal of Molecular Evolution 37, 380-398.

Lamb, T. M., Knecht, A. K., Smith, W. C., Stachel, S. E., Economides, A. N., Stahl, N., Yancopolous, G. D. and Harland, R. M. (1993). Neural induction by the secreted polypeptide noggin. Science 262, 713-718.

Lang, B. F., Gray, M. W. and Burger, G. (1999). Mitochondrial genome evolution and the origin of eukaryotes. Annual Review of Genetics 33, 351-397.

Langhelle, A., Lindell, M. J. and Nyström, P. (1999). Effects of ultraviolet radiation on amphibian embryonic and larval development. Journal of Herpetology, 449-456.

Larraín, J., Bachiller, D., Lu, B., Agius, E., Piccolo, S., and De Robertis, E. 2000. Bmp-binding modules in chordin: A model for signalling regulation in the extracellular space. Development 127:821-830.

Lee, H.-C. and Wei, Y.-H. (2005). Mitochondrial biogenesis and mitochondrial DNA maintenance of mammalian cells under oxidative stress. The International Journal of Biochemistry \& Cell Biology 37, 822-834.

Lee, J.-S., Miya, M., Lee, Y.-S., Kim, C. G., Park, E.-H., Aoki, Y. and Nishida, M. (2001). The complete DNA sequence of the mitochondrial genome of the self-fertilizing fish Rivulus marmoratus (Cyprinodontiformes, Rivulidae) and the first description of duplication of a control region in fish. Gene 280, 1-7. 
Lee, W.-J., Conroy, J., Howell, W. H. and Kocher, T. D. (1995). Structure and evolution of teleost mitochondrial control regions. Journal of Molecular Evolution 41, 54-66.

Lesseps, R., Hall, M. and Murnane, M. B. (1979a). Contact inhibition of cell movement in living embryos of an annual fish, Nothobranchius korthausae: its role in the switch from persistent to random cell movement. Journal of Experimental Zoology 207, 459-470.

Lesseps, R. J., Lapeyre, M. V. and Hall, M. V. (1979b). Tissue culture evidence on the control of the switch from contact inhibition of cell movement to overlapping behavior in annual fish embryos of Nothobranchius korthausae. Journal of Experimental Zoology 210, 521-528.

Lesser, M., Kruse, V. and Barry, T. (2003). Exposure to ultraviolet radiation causes apoptosis in developing sea urchin embryos. The Journal of Experimental Biology 206, 4097-4103.

Levinson, G. and Gutman, G. A. (1987). High frequencies of short frameshifts in poly-CA/TG tandem repeats borne by bacteriophage M13 in Escherichia coli K-12. Nucleic Acids Research 15, 5323-5338.

Li, J., Ma, X., Yu, W., Lou, Z., Mu, D., Wang, Y., Shen, B. and Qi, S. (2012). Reperfusion promotes mitochondrial dysfunction following focal cerebral ischemia in rats.

Lutz, P. L. and Milton, S. L. (2004). Negotiating brain anoxia survival in the turtle. J Exp Biol 207, 3141-3147.

Lutz, P. L., Prentice, H. M. and Milton, S. L. (2003). Is turtle longevity linked to enhanced mechanisms for surviving brain anoxia and reoxygenation? Experimental Gerontology 38, 797-800.

Machado, B. E. and Podrabsky, J. E. (2007). Salinity tolerance in diapausing embryos of the annual killifish Austrofundulus limnaeus is supported by exceptionally low water and ion permeability. Journal of Comparative Physiology B: Biochemical, Systemic, and Environmental Physiology 177, 809-820.

Macrae, T. H. (2005). Diapause: diverse states of developmental and metabolic arrest. Journal of Biological Research 3, 3-14.

Madronich, S., McKenzie, R., Björn, L. and Caldwell, M. (1998). Changes in biologically active ultraviolet radiation reaching the Earth's surface. Journal of Photochemistry and Photobiology B: Biology 46, 5-19.

Marandel, L., Labbe, C., Bobe, J., Jammes, H. l. n., Lareyre, J.-J. and Le Bail, P.-Y. (2013). Do not put all teleosts in one net: Focus on the sox2 and pou2 genes. Comparative Biochemistry and Physiology Part B: Biochemistry and Molecular Biology 164, 69-79.

Martinez, G. M. and Bolker, J. A. (2003). Embryonic and larval staging of summer flounder (Paralichthys dentatus). Journal of Morphology 255, 162-176.

Masui, S., Nakatake, Y., Toyooka, Y., Shimosato, D., Yagi, R., Takahashi, K., Okochi, H., Okuda, A., Matoba, R. and Sharov, A. A. (2007). 
Pluripotency governed by Sox 2 via regulation of Oct3/4 expression in mouse embryonic stem cells. Nature Cell Biology 9, 625-635.

Matsunaga, T., Hieda, K., \& Nikaido, O. (1991). WAVELENGTH DEPENDENT FORMATION OF THYMINE DIMERS AND (6-4) PHOTOPRODUCTS IN DNA BY MONOCHROMATIC ULTRAVIOLET LIGHT RANGING FROM 150 TO 365 nm. Photochemistry and photobiology 54, 403410.

McGinnis, S. and Madden, T. L. (2004). BLAST: at the core of a powerful and diverse set of sequence analysis tools. Nucleic Acids Research 32, W20-5.

McLennan, A. G. (2009). Ametabolic embryos of Artemia franciscana accumulate DNA damage during prolonged anoxia. Journal of Experimental Biology 212, 785-789.

Meller, C. L., Meller, R., Simon, R. P., Culpepper, K. M. and Podrabsky, J. E. (2012). Cell cycle arrest associated with anoxia-induced quiescence, anoxic preconditioning, and embryonic diapause in embryos of the annual killifish Austrofundulus limnaeus. Journal of Comparative Physiology B 182, 909-920.

Meller, C. L. and Podrabsky, J. E. (2013). Avoidance of apoptosis in embryonic cells of the annual killifish Austrofundulus limnaeus exposed to anoxia. PLOS ONE 8, e75837.

Metzgar, D. and Wills, C. (2000). Evidence for the adaptive evolution of mutation rates. Cell 101, 581-584.

Miller, M. A., Pfeiffer, W. and Schwartz, T. (2010). Creating the CIPRES Science Gateway for inference of large phylogenetic trees. In Gateway Computing Environments Workshop (GCE), 2010, pp. 1-8: IEEE.

Miller-Bertoglio, V. E., Fisher, S., Sánchez, A., Mullins, M. C. and Halpern, M. E. (1997). Differential Regulation of chordin Expression Domains in Mutant Zebrafish. Developmental Biology 192, 537-550.

Mitchell, D., Meador, J., Byrom, M. and Walter, R. (2001). Resolution of UV-induced DNA damage in Xiphophorus fishes. Marine Biotechnology 3, S61-S71.

Mitchell, D. L. (1988). THE RELATIVE CYTOTOXICITY OF (6,Äì4) PHOTOPRODUCTS AND CYCLOBUTANE DIMERS IN MAMMALIAN CELLS*. Photochemistry and Photobiology 48, 51-57.

Mitchell, D. L. and Hartman, P. S. (1990). The regulation of DNA repair during development. BioEssays 12, 74-79.

Miya, M., \& Nishida, M. (2000). Use of mitogenomic information in teleostean molecular phylogenetics: a tree-based exploration under the maximum-parsimony optimality criterion. Molecular phylogenetics and evolution 17, 437-455.

Miya, M., Takeshima, H., Endo, H., Ishiguro, N. B., Inoue, J. G., Mukai, T., Satoh, T. P., Yamaguchi, M., Kawaguchi, A. and Mabuchi, K. (2003). Major patterns of higher teleostean phylogenies: a new perspective 
based on 100 complete mitochondrial DNA sequences. Molecular phylogenetics and evolution 26, 121-138.

Mjelle, K. A., Karlsen, B. r. O., Jorgensen, T. E., Moum, T. and Johansen, S. D. (2008). Halibut mitochondrial genomes contain extensive heteroplasmic tandem repeat arrays involved in DNA recombination. $B M C$ Genomics 9, 10.

Montier, L. L. C., Deng, J. J. and Bai, Y. (2009). Number matters: control of mammalian mitochondrial DNA copy number. Journal of genetics and genomics 36, 125-131.

Mori, T., Nakane, M., Hattori, T., Matsunaga, T., Ihara, M. and Nikaido, 0. (1991). Simultaneous establishment of monoclonal antibodies specific for either cyclobutane pyrimidine dimer or (6-4) photoproduct from the same mouse immunized with ultraviolet-irradiated DNA. Photochemistry and Photobiology 54, 225-232.

Morrison, G. M. and Brickman, J. M. (2006). Conserved roles for Oct4 homologues in maintaining multipotency during early vertebrate development. Development 133, 2011-2022.

Mourabit, S., Edenbrow, M., Croft, D. P. and Kudoh, T. (2011). Embryonic development of the self-fertilizing Mangrove Killifish Kryptolebias marmoratus. Developmental Dynamics 240, 1694-1704.

Mouret, S., Baudouin, C., Charveron, M., Favier, A., Cadet, J. and Douki, T. (2006). Cyclobutane pyrimidine dimers are predominant DNA lesions in whole human skin exposed to UVA radiation. Proceedings of the National Academy of Sciences 103, 13765-13770.

Murphy, T. M. (1983). Membranes as targets of ultraviolet radiation. Physiologia Plantarum 58, 381-388.

Murphy, W. J., Thomerson, J. E., and Collier, G. E. (1999). Phylogeny of the neotropical killifish family Rivulidae (Cyprinodontiformes, Aplocheiloidei) inferred from mitochondrial DNA sequences. Molecular Phylogenetics and Evolution 13, 289-301.

Myers, G. S. (1952). Annual fishes. Aquarium Journal 23, 125-141.

Müller, W.-Ü., Bauch, T., Wojcik, A., Böcker, W. and Streffer, C. (1996). Comet assay studies indicate that caffeine-mediated increase in radiation risk of embryos is due to inhibition of DNA repair. Mutagenesis 11, 57-60.

Nahon, S., Castro Porras, V., Pruski, A. and Charles, F. (2009). Sensitivity to UV radiation in early life stages of the Mediterranean sea urchin Sphaerechinus granularis (Lamarck). Science of the Total Environment 407, 1892-900.

Neiman, M. and Taylor, D. R. (2009). The causes of mutation accumulation in mitochondrial genomes. Proceedings of the Royal Society of London B: Biological Sciences, rspb. 2008.1758. 
Nikaido, M., Tada, M., Saji, T., Ueno, N. (1997). Conservation of bmp signaling in zebrafish mesoderm patterning. Mechanisms of Development 61, 75-88.

Nilsson, G. E. and Lutz, P. L. (2004). Anoxia Tolerant Brains. J Cereb Blood Flow Metab 24, 475-486.

Norbury, C. J. and Zhivotovsky, B. (2004). DNA damage-induced apoptosis. Oncogene 23, 2797-2808.

Okuda, Y., Ogura, E., Kondoh, H. and Kamachi, Y. (2010). B1 SOX coordinate cell specification with patterning and morphogenesis in the early zebrafish embryo. PLoS Genetics 6, e1000936.

Okuda, Y., Yoda, H., Uchikawa, M., Furutani-Seiki, M., Takeda, H., Kondoh, H. and Kamachi, Y. (2006). Comparative genomic and expression analysis of group B1 sox genes in zebrafish indicates their diversification during vertebrate evolution. Developmental Dynamics 235, 811-825.

Onichtchouk, D., Geier, F., Polok, B., Messerschmidt, D. M., Mössner, R., Wendik, B., Song, S., Taylor, V., Timmer, J. and Driever, W. (2010). Zebrafish Pou5f1-dependent transcriptional networks in temporal control of early development. Molecular Systems Biology 6.

Padilla, P. A. and Roth, M. B. (2001). Oxygen deprivation causes suspended animation in the zebrafish embryo. Proceedings of the National Academy of Sciences of the United States of America 98, 7331-7335.

Park, E. H. and Yi, A. K. (1989). Photoreactivation rescue and dark repair demonstrated in UV-irradiated embryos of the self-fertilizing fish Rivulus ocellatus marmoratus (Teleostei; Aplocheilidae). Mutation Research/DNA Repair 217, 19-24.

Parra, G., Bradnam, K. and Korf, I. (2007). CEGMA: a pipeline to accurately annotate core genes in eukaryotic genomes. Bioinformatics 23, 1061-1067.

Pavey, S., Russell, T. and Gabrielli, B. (2001). G2 phase cell cycle arrest in human skin following UV irradiation. Oncogene 20, 6103.

Pfaffl, M. W. (2001). A new mathematical model for relative quantification in real-time RT-PCR. Nucleic Acids Research 29, e45-e45.

Pham, X. H., Farge, G. r., Shi, Y., Gaspari, M., Gustafsson, C. M. and Falkenberg, M. (2006). Conserved sequence box II directs transcription termination and primer formation in mitochondria. Journal of Biological Chemistry 281, 24647-24652.

Piccolo, S., Sasai, Y., Lu, B. and De Robertis, E. M. (1996). Dorsoventral patterning in Xenopus: inhibition of ventral signals by direct binding of chordin to BMP-4. Cell 86, 589-598.

Piechota, J., Tomecki, R., Gewartowski, K., Szczesny, R., Dmochowska, A., Kudla, M., Dybczynska, L., Stepien, P. P. and Bartnik, E. (2006). Differential stability of mitochondrial mRNA in HeLa cells. ACTA BIOCHIMICA POLONICA-ENGLISH EDITION- 53, 157. 
Podrabsky, J. E. (1999). Husbandry of the annual killifish Austrofundulus limnaeus with special emphasis on the collection and rearing of embryos. Env. Biol. Fish. 54, 421-431.

Podrabsky, J. E., Carpenter, J. F. and Hand, S. C. (2001). Survival of water stress in annual fish embryos: dehydration avoidance and egg envelope amyloid fibers. American Journal of Physiology 280, R123-R131.

Podrabsky, J. E., Garrett, I. D. F. and Kohl, Z. F. (2010). Alternative developmental pathways associated with diapause regulated by temperature and maternal influences in embryos of the annual killifish Austrofundulus limnaeus. Journal of Experimental Biology 213, 3280-3288.

Podrabsky, J. E. and Hand, S. C. (1999). The bioenergetics of embryonic diapause in an annual killifish, Austrofundulus limnaeus. Journal of Experimental Biology 202, 2567-2580.

Podrabsky, J. E. and Hand, S. C. (2000). Depression of protein synthesis during diapause in embryos of the annual killifish Austrofundulus limnaeus. Physiological and Biochemical Zoology 73, 799-808.

Podrabsky, J. E. and Hand, S. C. (2015). Physiological strategies during animal diapause: Lessons from brine shrimp and annual killifish. Journal of Experimental Biology in press.

Podrabsky, J. E., Hrbek, T. and Hand, S. C. (1998). Physical and chemical characteristics of ephemeral pond habitats in the Maracaibo basin and Llanos region of Venezuela. Hydrobiologia 362, 67-78.

Podrabsky, J. E., Lopez, J. P., Fan, T. W. M., Higashi, R. and Somero, G. N. (2007). Extreme anoxia tolerance in embryos of the annual killifish Austrofundulus limnaeus: Insights from a metabolomics analysis. Journal of Experimental Biology 210, 2253-2266.

Podrabsky, J. E., Menze, M. A. and Hand, S. C. (2012a). Rapid Communication: Long-term survival of anoxia despite rapid ATP decline in embryos of the annual killifish Austrofundulus limnaeus. Journal of Experimental Zoology A: Ecological Genetics and Physiology 317, 524-532.

Podrabsky, J. E., Riggs, C. L. and Duerr, J. M. (2012b). Anoxia Tolerance During Vertebrate Development - Insights from Studies on the Annual Killifish Austrofundulus limnaeus. In Anoxia, (ed. P. Padilla), pp. 3-24: InTech.

Puigbò, P., Bravo, I. G. and Garcia-Vallve, S. (2008). CAIcal: a combined set of tools to assess codon usage adaptation. Biology Direct 3, 38.

Raboin, M. J., Timko, A. F., Howe, D. K., Félix, M.-A. and Denver, D. R. (2010). Evolution of Caenorhabditis mitochondrial genome pseudogenes and Caenorhabditis briggsae natural isolates. Molecular biology and evolution 27, 1087-1096.

Rasbach, K. A. and Schnellmann, R. G. (2007). Signaling of mitochondrial biogenesis following oxidant injury. Journal of Biological Chemistry 282, 2355-2362. 
Regan, J. D., Carrier, W., Samet, C. and Olla, B. L. (1982). Photoreactivation in two closely related marine fishes having different longevities. Mechanisms of ageing and development 18, 59-66.

Rehemtulla, A., Hamilton, C. A., Chinnaiyan, A. M. and Dixit, V. M. (1997). Ultraviolet radiation-induced apoptosis is mediated by activation of CD-95 (Fas/APO-1). Journal of Biological Chemistry 272, 25783-25786.

Reichwald, K., Lauber, C., Nanda, I., Kirschner, J., Hartmann, N., Schories, S., Gausmann, U., Taudien, S., Schilhabel, M. B., Szafranski, K. et al. (2009). High tandem repeat content in the genome of the short-lived annual fish Nothobranchius furzeri: a new vertebrate model for aging research. Genome Biology 10, R16.1-R16.17.

Reim, G. and Brand, M. (2006). Maternal control of vertebrate dorsoventral axis formation and epiboly by the POU domain protein Spg/Pou2/Oct4. Development 133, 2757-2770.

Reuter, J. S. and Mathews, D. H. (2010). RNAstructure: software for RNA secondary structure prediction and analysis. BMC Bioinformatics 11, 129.

Riedl, T., Hanaoka, F. and Egly, J. Ä. (2003). The comings and goings of nucleotide excision repair factors on damaged DNA. The EMBO journal 22, 5293-5303.

Rogers, C. D., Harafuji, N., Archer, T., Cunningham, D. D. and Casey, E. S. (2009). Xenopus Sox 3 activates sox 2 and geminin and indirectly represses Xvent2 expression to induce neural progenitor formation at the expense of non-neural ectodermal derivatives. Mechanisms of Development 126, 42-55.

Rokas, A., Ladoukakis, E. and Zouros, E. (2003). Animal mitochondrial DNA recombination revisited. Trends in Ecology \& Evolution 18, 411-417.

Romiguier, J., Ranwez, V., Douzery, E. J. and Galtier, N. (2010). Contrasting GC-content dynamics across 33 mammalian genomes: relationship with life-history traits and chromosome sizes. Genome Research 20, 1001-1009.

Ronquist, F. and Huelsenbeck, J. P. (2003). MrBayes 3: Bayesian phylogenetic inference under mixed models. Bioinformatics 19, 1572-1574.

Rosenstein, B. S. and Mitchell, D. L. (1987). Action spectra for the induction of pyrimidine (6-4) pyrimidone photoproducts and cyclobutane pyrimidine dimers in normal human skin fibroblasts. Photochemistry and Photobiology 45, 775-780.

Sale, J. E., Lehmann, A. R. and Woodgate, R. (2012). Y-family DNA polymerases and their role in tolerance of cellular DNA damage. Nature Reviews Molecular Cell Biology 13, 141-152.

Sambrook, J., Fritsch, E. F. and Maniatis, T. (1989). Molecular Cloning. A laboratory manual. New York: Cold Spring Harbor Press. 
Sancar, A. (1994). Structure and function of DNA photolyase. Biochemistry 33, 2-9.

Sancar, A., Lindsay-Boltz, L., Unsal-Kacmaz, K. and Linn, S. (2004). Molecular mechanisms of mammalian DNA repair and the DNA damage checkpoints. Annual Review of Biochemistry 73, 39-85.

Sancar, G. B. (2000). Enzymatic photoreactivation: 50 years and counting. Mutation Research/Fundamental and Molecular Mechanisms of Mutagenesis 451, 25-37.

Sasai, Y., Lu, B., Steinbeisser, H., Geissert, D., Gont, L. K. and De Robertis, E. M. (1994). Xenopus chordin: A novel dorsalizing factor activated by organizer-specific homeobox genes. Cell 79, 779-790.

Scheffler, I. E. (2011). Mitochondria: John Wiley \& Sons.

Schier A.F. and Talbot W.S. (2005). Molecular genetics of axis formation in zebrafish. Annual Reviews Genetics 39, 561-613.

Schlueter, P. J., Peng, G., Westerfield, M. and Duan, C. (2007). Insulin-like growth factor signaling regulates zebrafish embryonic growth and development by promoting cell survival and cell cycle progression. Cell Death and Differentiation 14, 1095-1105.

Schmittgen, T. D. and Livak, K. J. (2008). Analyzing real-time PCR data by the comparative CT method. Nature Protocols 3, 1101-1108.

Schulte-Merker, S., Lee, K. J., McMahon, A. P. and Hammerschmidt, M. (1997). The zebrafish organizer requires chordino. Nature 387, 862-863.

Setiamarga, D. H., Miya, M., Yamanoue, Y., Mabuchi, K., Satoh, T. P., Inoue, J. G. and Nishida, M. (2008). Interrelationships of Atherinomorpha (medakas, flyingfishes, killifishes, silversides, and their relatives): the first evidence based on whole mitogenome sequences. Molecular phylogenetics and evolution 49, 598-605.

Setlow, R. B., Swenson, P. A. and Carrier, W. L. (1963). Thymine dimers and inhibition of DNA synthesis by ultraviolet irradiation of cells. Science 142, 1464-1466.

Seutin, G., Lang, B. F., Mindell, D. P. and Morais, R. (1994). Evolution of the WANCY region in amniote mitochondrial DNA. Molecular biology and evolution 11, 329-340.

Shimizu, T., Yabe, T., Muraoka, O., Yonemura, S., Aramaki, S., Hatta, K., Bae, Y.-K., Nojima, H. and Hibi, M. (2005). E-cadherin is required for gastrulation cell movements in zebrafish. Mechanisms of Development 122, 747-763.

Sinha, R. and Häder, D. (2002). UV-induced DNA damage and repair: a review. Photochemical and Photobiological Sciences 1, 225-36.

Skinner, M. E., Uzilov, A. V., Stein, L. D., Mungall, C. J. and Holmes, I. H. (2009). JBrowse: a next-generation genome browser. Genome Research 19, 1630-1638. 
Smit, A. and Hubley, R. (2011). RepeatModeler. Institute of Systems Biology 1.

Smith, C., Heyne, S., Richter, A. S., Will, S. and Backofen, R. (2010). Freiburg RNA Tools: a web server integrating INTARNA, EXPARNA and LOCARNA. Nucleic Acids Research 38, W373-W377.

Smith, M. A., Berrill, M. and Kapron, C. M. (2002). Photolyase activity of the embryo and the ultraviolet absorbance of embryo jelly for several Ontario amphibian species. Canadian journal of zoology 80, 11091116.

Smith, M. L. and Fornace, A. J. (1997). p53-mediated protective responses to UV irradiation. Proceedings of the National Academy of Sciences 94, 12255-12257.

Smith, W. C. and Harland, R. M. (1992). Expression cloning of noggin, a new dorsalizing factor localized to the Spemann organizer in Xenopus embryos. Cell 70, 829-840.

Solnica-Krezel, L. (2005). Conserved patterns of cell movements during vertebrate gastrulation. Current Biology 15, R213-R228.

Stackley, K. D., Beeson, C. C., Rahn, J. J. and Chan, S. S. (2011). Bioenergetic profiling of zebrafish embryonic development. PLOS ONE 6, e25652-e25652.

Star, B., Nederbragt, A. J., Jentoft, S., Grimholt, U., Malmstr $\sqrt{\Pi m}$ M., Gregers, T. F., Rounge, T. B., Paulsen, J., Solbakken, M. H. and Sharma, A. (2011). The genome sequence of Atlantic cod reveals a unique immune system. Nature 477, 207-210.

Stergiou, L., Doukoumetzidis, K., Sendoel, A. and Hengartner, M. 0. (2007). The nucleotide excision repair pathway is required for UV-Cinduced apoptosis in Caenorhabditis elegans. Cell Death and Differentiation 14, 1129-1138.

Stergiou, L., Eberhard, R., Doukoumetzidis, K. and Hengartner, M. (2011). NER and HR pathways act sequentially to promote UV-C-induced germ cell apoptosis in Caenorhabditis elegans. Cell Death \& Differentiation 18, 897-906.

Sánchez-Sánchez, A. V., Camp, E., García-España, A., Leal-Tassias, A. and Mullor, J. L. (2010). Medaka Oct4 is expressed during early embryo development, and in primordial germ cells and adult gonads. Developmental Dynamics 239, 672-679.

Takashima, S., Shimada, A., Kobayashi, D., Yokoi, H., Narita, T., Jindo, T., Kage, T., Kitagawa, T., Kimura, T., Sekimizu, K. et al. (2007). Phenotypic analysis of a novel chordin mutant in medaka. Developmental Dynamics 236, 2298-2310.

Takeda, H., Matsuzaki, T., Oki, T., Miyagawa, T. and Amanuma, H. (1994). A novel POU domain gene, zebrafish pou2: expression and roles of two alternatively spliced twin products in early development. Genes \& development 8, 45-59. 
Tam, P. P. and Loebel, D. A. (2007). Gene function in mouse embryogenesis: get set for gastrulation. Nature Reviews Genetics 8, 368-381.

Temin, H. (1985). Reverse transcription in the eukaryotic genome: retroviruses, pararetroviruses, retrotransposons, and retrotranscripts. Molecular biology and evolution 2, 455-468.

Tempel, S. b. (2012). Using and understanding RepeatMasker. In Mobile Genetic Elements, pp. 29-51: Springer.

Thoma, F. (1999). Light and dark in chromatin repair: repair of UV,Äêinduced DNA lesions by photolyase and nucleotide excision repair. The EMBO journal 18, 6585-6598.

Tsai, H.-Y., Chang, M., Liu, S.-C., Abe, G. and Ota, K. G. (2013). Embryonic development of goldfish (Carassius auratus): a model for the study of evolutionary change in developmental mechanisms by artificial selection. Developmental Dynamics 242, 1262-1283.

Tsuboi K. (1950). Mouse liver nucleic acids II. Ultra-violet absorption studies. Biochimica et Biophysica Acta 6, 202-209.

Ura, K., Araki, M., Saeki, H., Masutani, C., Ito, T., Iwai, S., Mizukoshi, T., Kaneda, Y. and Hanaoka, F. (2001). ATP-dependent chromatin remodeling facilitates nucleotide excision repair of UV-induced DNA lesions in synthetic dinucleosomes. The EMBO journal 20, 2004-2014.

Vancampenhout, K., Caljon, B., Spits, C., Stouffs, K., Jonckheere, A., De Meirleir, L., Lissens, W., Vanlander, A., Smet, J. l. and De Paepe, B. (2014). A bumpy ride on the diagnostic bench of massive parallel sequencing, the case of the mitochondrial genome. PloS One, e112950.

Varriale, A. (2014). DNA Methylation, Epigenetics, and Evolution in Vertebrates: Facts and Challenges. International Journal of Evolutionary Biology 2014, 1-7.

von der Hardt S., Bakkers J., Inbal A., Carvalho L., Solnica-Krezel L., Heisenberg C.-P., amd Hammerschmidt M. (2007). The bmp gradient of the zebrafish gastrula guides migrating lateral cells by regulating cell-cell adhesion. Current Biology 17, 475-487.

Wagner, J. T. and Podrabsky, J. E. (2015a). Extreme tolerance and developmental buffering of UV-C induced DNA damage in embryos of the annual killifish Austrofundulus limnaeus. Journal of Experimental Zoology 323A, 10-30.

Wagner, J. T. and Podrabsky, J. E. (2015b). Gene expression patterns that support novel developmental stress buffering in embryos of the annual killifish Austrofundulus limnaeus. EvoDevo 6.

Wang, D., Manali, D., Wang, T., Bhat, N., Hong, N., Li, Z., Wang, L., Yan, Y., Liu, R. and Hong, Y. (2011). Identification of pluripotency genes in the fish medaka. Int J Biol Sci. 7, 440-451.

Watanabe, Y.-i., Suematsu, T. and Ohtsuki, T. (2014). Losing the stem-loop structure from metazoan mitochondrial tRNAs and co-evolution of interacting factors. Frontiers in Genetics 5. 
Westerfield, M. (1995). The zebrafish book: a guide for the laboratory use of zebrafish (Brachydanio rerio): M. Westerfield (Eugene, OR).

Whitehead, A. (2009). Comparative mitochondrial genomics within and among species of killifish. BMC Evolutionary Biology 9, 11.

Wiegand, M. D., Young, D. L. W., Gajda, B. M., Thuen, D. J. M., Rittberg, D. A. H., Huebner, J. D. and Loadman, N. L. (2004). Ultraviolet light-induced impairment of goldfish embryo development and evidence for photorepair mechanisms. Journal of Fish Biology 64, 1242-1256.

Will, S., Joshi, T., Hofacker, I. L., Stadler, P. F. and Backofen, R. (2012). LocARNA-P: Accurate boundary prediction and improved detection of structural RNAs. RNA 18, 900-914.

Willett, K., Lienesch, L. and Di Giulio, R. (2001). No detectable DNA excision repair in UV-exposed hepatocytes from two catfish species. Comparative Biochemistry and Physiology Part C: Toxicology \& Pharmacology 128, 349-358.

Willmore, W. and Storey, K. (1997). Antioxidant systems and anoxia tolerance in a freshwater turtle Trachemys scripta elegans. Molecular and Cellular Biochemistry 170, 177-185.

Winnier, G., Blessing, M., Labosky, P.A., Hogan, B. (1995). Bone morphogenetic protein 4 is required for mesoderm formation and patterning in the mouse. Genes and development 9, 2105-2116.

Wood, H. B. and Episkopou, V. (1999). Comparative expression of the mouse Sox1, Sox2 and Sox 3 genes from pre-gastrulation to early somite stages. Mechanisms of Development 86, 197-201.

Wourms, J. (1965). Naturally occurring phases of cellular dispersion and reaggregation during early vertebrate development. American Zoologist 662.

Wourms, J. P. (1972a). Developmental biology of annual fishes I. Stages in the normal development of Austrofundulus myersi Dahl. Journal of Experimental Zoology 182, 143-168.

Wourms, J. P. (1972b). The developmental biology of annual fish II. Naturally occuring dispersion and reaggregation of blastomeres during the development of annual fish eggs. Journal of Experimental Zoology 182, 169200.

Wourms, J. P. (1972c). The developmental biology of annual fishes III. Pre-embryonic and embryonic diapause of variable duration in the eggs of annual fishes. Journal of Experimental Zoology 182, 389-414.

Xu, B. and Clayton, D. A. (1995). A persistent RNA-DNA hybrid is formed during transcription at a phylogenetically conserved mitochondrial DNA sequence. Molecular and Cellular Biology 15, 580-589.

Xue, W., Li, J.-T., Zhu, Y.-P., Hou, G.-Y., Kong, X.-F., Kuang, Y.-Y. and Sun, X.-W. (2013). L_RNA_scaffolder: scaffolding genomes with transcripts. BMC Genomics 14, 604 . 
Yabu, T., Todoriki, S. and Yamashita, M. (2001). Stress-induced apoptosis by heat shock, UV and $\gamma$-ray irradiation in zebrafish embryos detected by increased caspase activity and whole-mount TUNEL staining. Fisheries Science 67, 333-340.

Yasuda, S. and Sekiguchi, M. (1970). T4 endonuclease involved in repair of DNA. Proceedings of the National Academy of Sciences 67, 18391845.

Yasuhira, S. and Yasui, A. (1992). Visible light-inducible photolyase gene from the goldfish Carassius auratus. Journal of Biological Chemistry 267, 25644-25647.

Yasui, A., Eker, A., Yasuhira, S., Yajima, H., Kobayashi, T., Takao, M. and Oikawa, A. (1994). A new class of DNA photolyases present in various organisms including aplacental mammals. The EMBO journal 13, 6143.

Yin, W., Signore, A. P., Iwai, M., Cao, G., Gao, Y. and Chen, J. (2008). Rapidly increased neuronal mitochondrial biogenesis after hypoxic-ischemic brain injury. Stroke 39, 3057-3063.

Youle, R. J. and Van Der Bliek, A. M. (2012). Mitochondrial fission, fusion, and stress. Science 337, 1062-1065.

Yu, J., Vodyanik, M. A., Smuga-Otto, K., Antosiewicz-Bourget, J., Frane, J. L., Tian, S., Nie, J., Jonsdottir, G. A., Ruotti, V., Stewart, R. et al. (2007). Induced Pluripotent Stem Cell Lines Derived from Human Somatic Cells. Science 318, 1917-1920.

Zar, J. H. (1996). Biostatistical Analysis. Upper Saddle River, N.J.: Prentice Hall.

Zhang, C., Basta, T., Hernandez-Lagunas, L., Simpson, P., Stemple, D. L., Artinger, K. B. and Klymkowsky, M. W. (2004). Repression of nodal expression by maternal B1-type SOXs regulates germ layer formation in Xenopus and zebrafish. Developmental Biology 273, 23-37.

Zhang, H., Bosch-Marce, M., Shimoda, L. A., Tan, Y. S., Baek, J. H., Wesley, J. B., Gonzalez, F. J. and Semenza, G. L. (2008). Mitochondrial autophagy is an HIF-1-dependent adaptive metabolic response to hypoxia. Journal of Biological Chemistry 283, 10892-10903.

Zimmerman, L. B., de Jesús-Escobar, J. M. and Harland, R. M. (1996). The Spemann organizer signal noggin binds and inactivates bone morphogenetic protein 4. Cell 86, 599-606. 